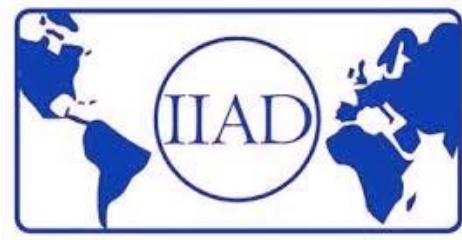

\title{
AVANCES EN EL ESCLARECIMIENTO DE LA AUTENTICIDAD DE LA MIEL
}

TESIS DOCTORAL

Presentada por:

Lara Sobrino Gregorio

Dirigida por:

Dra. Isabel Escriche Roberto

Dra. Marisol Juan Borrás 


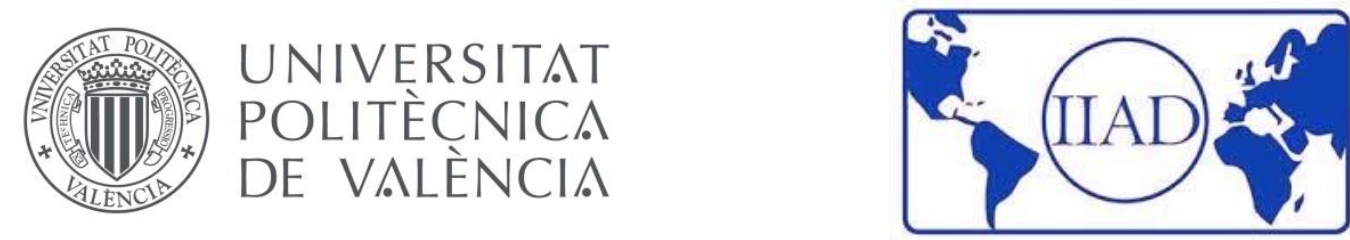

La Dra. Isabel Escriche Roberto, Catedrática de Universidad y la Dra. Marisol Juan Borrás, Técnico Superior de Investigación, pertenecientes al Departamento de Tecnología de Alimentos de la Universitat Politècnica de València e Investigadoras del Instituto de Ingeniería de Alimentos para el Desarrollo de la misma Universidad,

\section{Hacen constar que:}

La memoria titulada "Avances en el esclarecimiento de la autenticidad de la miel" que presenta Dá Lara Sobrino Gregorio para optar al grado de Doctor por la Universitat Politècnica de València, ha sido realizada en el Instituto de Ingeniería de Alimentos para el Desarrollo (IIAD-UPV) bajo nuestra dirección y que reúne las condiciones para ser defendida por su autora.

Valencia, 24 de Abril de 2020

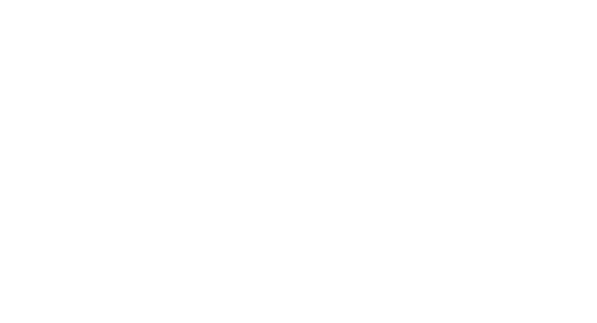

Fdo. Isabel Escriche Roberto

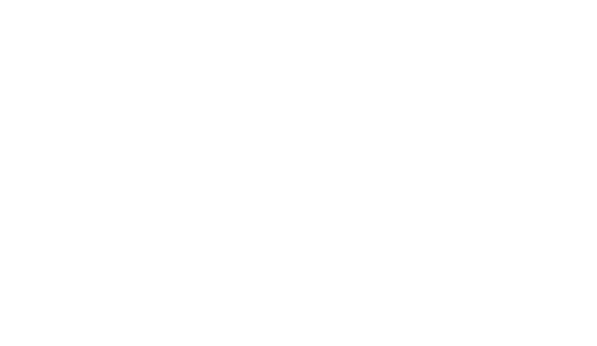

Fdo. Marisol Juan Borrás 

A mis padres 



\section{AGRADECIMIENTOS}

En primer lugar agradecer a mis directoras de tesis la gran confianza depositada en mí desde el principio. Cruzarme en vuestro camino me abrió las puertas a la investigación, a un mundo al que ni siquiera pensé que podía pertenecer y en el que ahora estoy inmersa por completo. No sé qué me deparará el mundo profesional a partir de ahora, pero estos años de experiencia junto a vosotras me han enriquecido como profesional y como persona.

Isabel, gracias por tu apoyo durante todos estos años, eres el motor que me ha hecho continuar en esta aventura con la cabeza bien alta. No siempre las cosas salen bien, pero tu fuerza para avanzar pese a las adversidades es contagiosa y la trasmites donde quiera que vayas. Sin duda, una gran directora con la que he podido compartir, no solo laboratorios y despachos, sino parte de mi vida y experiencias. Gracias por todo.

Marisol, gracias por enseñarme tanto y tener una paciencia infinita. Tu energía da vida al laboratorio, generas un ambiente familiar en el que entra cada persona que pasa por aquí. Tu trabajo es indispensable, pero tu presencia lo es más. No hay laboratorio de la miel sin Marisol. Gracias.

Gracias también a ti, Yolanda, por darme la estabilidad profesional que necesitaba para lanzarme por completo en esta nueva etapa. La investigación no es fácil y esta experiencia me ha hecho más fuerte. Saber gestionar los malos momentos es un aprendizaje duro, pero muy valioso, y tú has sabido dar ejemplo y seguir hacia delante. No hay que rendirse.

Gracias a todas aquellas personas que me han acompañado en diferentes etapas de mi tesis doctoral. He pasado por tantos laboratorios y despachos que es imposible que el cambio me de miedo, porque cada vez que he empezado en un nuevo sitio, lo único que ha hecho es enriquecerme profesionalmente y darme gente maravillosa. Gracias a todos por apoyarme y darme momentos tan bonitos para el recuerdo.

Gracias a mis amigas por saber incluso antes que yo que lo iba a conseguir, que valía para esto. Gracias por alegraros tanto como yo por cada uno de mis logros. Cada artículo publicado era un motivo de celebración, los "ienhorabuena!" que mejor sientan. Gracias por seguir aquí, conmigo, aunque a veces sea a kilómetros de distancia. Os quiero.

Y por último ellos, mi familia, mi pequeña pero gran familia. Gracias por apoyarme en todo, por saber entenderme, por estar ahí siempre, incondicionalmente. Gracias por animarme cuando hacía falta, gracias por darme los empujoncitos necesarios para seguir, gracias por vuestra paciencia. Sin vosotros nada hubiera sido posible, parte de este trabajo es vuestro, disfrutadlo. Os quiero muchísimo. 

Gracias a la Universitat Politècnica de València por el apoyo económico a través del programa ADSIDEO-Cooperación 2016 (Asesoramiento en la gestión de calidad y seguridad de los productos apícolas de las comunidades lencas de Honduras. Modelo de promoción social, ambiental y económico de las poblaciones rurales de Centroamérica) y por el apoyo al contrato de Marisol Juan Borrás en el marco de PAID10-17 (Ayuda para la contratación de acceso al Sistema Español de Ciencia, Tecnología e Innovación en Estructuras de Investigación). También agradecer a la Generalitat Valenciana por el proyecto AICO/2015/104 (Desarrollo de una metodología basada en el análisis de $A D N$, para la detección de adulteraciones en miel; Prueba de concepto aplicada a la adición de jarabes de maíz) y a la Agencia estatal de Investigación por el proyecto AGL2016-77702-R (Diseño de un biosensor de ADN basado en tecnología HFFQCM para la detección de sustancias adulterantes en miel).

Es importante también destacar que parte de esta tesis doctoral se ha realizado en el marco del proyecto de colaboración entre el Ministerio de Agricultura y Pesca, Alimentación y Medio Ambiente y el Instituto Universitario de Ingeniería de Alimentos para el Desarrollo de la Universitat Politècnica de València (Laboratorio de Control de Calidad de la Miel y los Productos Apícolas), para la caracterización de las principales mieles monoflorales españolas (B.O.E. núm. 150, pp. 63347-63353 de 2018). 



\section{RESUMEN}

La miel, en la actualidad, es uno de los alimentos con mayor riesgo de sufrir fraude alimentario, favorecido especialmente por la internacionalización de los mercados. La adulteración de la miel ocasiona competencia desleal e importantes pérdidas económicas para el sector apícola que necesita aumentar su nivel de competitividad en un mercado cada vez más amenazado por importaciones masivas procedentes de países de fuera de la UE, en ocasiones de dudosa calidad. En este contexto, garantizar su autenticidad, tanto en lo referente al origen botánico y geográfico como a la adulteración por adición de jarabes, es un tema de gran inquietud en la Unión Europea y especialmente en España, principal país productor. Esta situación ha suscitado el interés por caracterizar la miel monofloral española dando lugar en 2018 a un acuerdo de colaboración entre el Ministerio de Agricultura Pesca y Alimentación (MAPA) y LABMIEL (Laboratorio de control de calidad de la miel y los productos apícolas de la Universitat Politècnica de València), dónde se ha desarrollado la presente tesis doctoral.

El origen botánico de las plantas en las que pecorean las abejas, además de atribuir diferentes propiedades y características organolépticas a la miel, puede informar sobre el origen geográfico en la que ha sido cosechada. Esto es debido a que ciertas plantas están vinculadas a países o incluso a zonas geográficas específicas, por lo que el rastreo de los pólenes de dichas plantas se utiliza para la caracterización geográfica de las mieles. Las mieles con mayor valor comercial son las monoflorales y, por tanto, son las que mayor fraude sufren por un etiquetado incorrecto en base a su origen botánico. La producción de una miel monofloral necesita de mayor dedicación por parte del apicultor, ya que requiere seleccionar la flora en la que ubicar las colmenas y de un adecuado corte y acopio de la miel cosechada sin mezclar floraciones. Aunque existen criterios comerciales para denominar una miel como monofloral o de mielada (especialmente relacionados con el contenido polínico o elementos de mielada, respectivamente), todavía no hay establecidos criterios legales.

Por otra parte, las mieles de milflores son las que sufren mayor adulteración por adición de jarabes de origen vegetal. Aunque este tipo de adulteración apareció hace más de medio siglo, en la actualidad es cada vez más patente debido al desarrollo industrial en la obtención de jarabes con características composicionales cada vez más semejantes a la miel. Entre los diferentes jarabes que se utilizan para este fin, el de arroz es uno de los más presentes, especialmente por el mercado asiático del que proceden muchas importaciones. Los métodos analíticos para la detección de este tipo de fraude han evolucionado en paralelo al desarrollo de las técnicas de adulteración y al incremento de jarabes "similares a la miel". Hoy en día, son numerosas las técnicas disponibles para este fin, pero además de su elevado coste, ninguna de ellas es concluyente por si misma. Por ello, se está impulsando el desarrollo de nuevos 
métodos analíticos para detectar y cuantificar la adulteración de la miel dirigidos hacia técnicas fáciles, baratas y rápidas, que permitan a la industria garantizar su autenticidad sin tener que realizar grandes inversiones económicas. Para ello, es necesario avanzar en el desarrollo de nuevas metodologías innovadoras y con la mayor automatización posible. Estas técnicas no necesariamente deben basarse en la identificación de un compuesto determinado, sino más bien en la recogida de un conjunto elevado de datos que se relacionen con ciertas características de las mieles.

Por todo ello, el objetivo de esta tesis doctoral ha sido avanzar en el esclarecimiento de la autenticidad de la miel aplicando técnicas analíticas emergentes en este campo. Todo ello con la finalidad de facilitar la identificación de fraudes, durante la comercialización de la miel, relacionados con su clasificación botánica y geográfica, así como con su adulteración por adición de jarabes.

La caracterización de los compuestos integrantes de la fracción volátil de las mieles, mediante cromatografía de gases-espectrometría de masas (GC-MS), se puede considerar un método complementario al polínico para garantizar el correcto etiquetado de las mieles monoflorales que se comercializan. La información de los compuestos constituyentes de dicha fracción se correlaciona bien con la percepción sensorial de las mieles, por ello, esta metodología resulta especialmente útil en aquellas variedades cuyo polen está infra-representado, como es el caso de la miel de lavanda; y se aconseja especialmente cuando una miel presenta específicas características organolépticas diferenciadoras. En este sentido, se ha puesto en evidencia que la información que se muestra en la etiqueta de mieles que se comercializan como monoflorales de esta variedad, no se corresponde con el requisito comercial habitual (mínimo $10 \%$ de polen Lavandula spp.); a pesar de poseer compuestos volátiles y percepción sensorial característicos de la misma. Sin embargo, la información de la etiqueta de mieles comercializadas como tomillo (cuyo polen no está infra-representado) era correcta considerando el contenido de polen, así como sus características olfato-gustativas y perfil volátil típicas de esta variedad de miel.

Una lengua electrónica voltamétrica de pulsos (compuesta de electrodos metálicos de Ir, Rh, Pt, Au), con limpieza y pulido electroquímico, en combinación con análisis estadísticos de componentes principales (PCA), permite discriminar mieles procedentes de diferentes orígenes geográficos (Mozambique, Honduras y España), así como mieles de diferentes orígenes botánicos (monoflorales de girasol, azahar y brezo). Además, la lengua electrónica es capaz de diferenciar la adición de jarabes (cebada, maíz o arroz integral) a dichas mieles cuando ésta tiene lugar por encima de un 2.5\%. Aplicando regresiones de mínimos cuadrados parciales (PLS) se ha demostrado que los datos proporcionados por dicha lengua electrónica predicen adecuadamente ciertos parámetros fisicoquímicos como la conductividad $\left(r^{2}=0.948\right)$. Con relación a las adulteraciones, las mejores predicciones se han obtenido para la 
miel de girasol y de brezo con incorporación de jarabe de maíz $\left(r^{2}=0.997\right.$ y $\left.r^{2}=0.994\right)$ y para la miel de brezo con jarabe de cebada $\left(r^{2}=0.997\right)$.

Las propiedades térmicas evaluadas mediante calorimetría diferencial de barrido (DSC) en combinación con análisis estadístico de componentes principales (PCA) ha permitido diferenciar niveles de adulteración en la miel $(5,10$ y $20 \%)$ por adición de jarabes (agave, arce, caña, cebada, maíz y diferentes tipos de arroz). La adición de jarabes a la miel pura promovió cambios significativos en las propiedades térmicas de las mieles adulteradas, en proporción al nivel de adulteración y al tipo de jarabe, especialmente debido a las diferencias en su composición de azúcares.

La técnica de PCR ha permitido por primera vez identificar la adulteración por adición de melaza de arroz en miel de azahar, logrando identificar porcentajes de adulteración menores a los de otras metodologías más costosas y laboriosas. El mayor obstáculo en la aplicación de esta técnica se encontró en la etapa previa de extracción de ADN, debido a la dificultad en la obtención de cantidad y calidad suficiente del mismo para su posterior amplificación por PCR. La PCR en tiempo real, mediante la construcción de una curva estándar de diluciones seriadas de distintas concentraciones de ADN de arroz, permitió detectar diferentes porcentajes de adición de melaza de arroz con una exactitud de hasta $2-5 \%$.

En definitiva, la GC-MS y la lengua electrónica voltamétrica son técnicas prometedoras para la clasificación de las mieles monoflorales. La primera presenta la ventaja de poder determinar compuestos volátiles característicos específicos de determinadas variedades de miel, relacionados con el origen botánico de las plantas en las que pecorean las abejas; por lo que su presencia y abundancia específica puede inequívocamente relacionarse con una determinada miel monofloral. Sin embargo, tiene la desventaja de ser una técnica cara y que requiere de personal altamente cualificado. Por el contrario, la lengua electrónica voltamétrica (construida con sensores metálicos, en combinación con un apropiado análisis estadístico), de forma rápida y sencilla, está dando resultados fiables en la discriminación de mieles por monofloralidad, procedencia geográfica y adulteración. Las técnicas de DSC y PCR están siendo efectivas para identificar adulteración de la miel por adición de jarabes, aunque para ser concluyentes con ellas se debería considerar un mayor número de tipos de mieles y jarabes a los analizados en la presente tesis doctoral. Una vez que se haya resuelto el factor limitante de la etapa de extracción de ADN, la PCR será una técnica idónea para identificar otras melazas y jarabes. 



\section{RESUM}

La mel en l'actualitat és un dels aliments amb major risc de patir frau alimentari, fet afavorit especialment per la internacionalització dels mercats. L'adulteració de la mel ocasiona competència deslleial i importants pèrdues econòmiques per al sector apícola que necessita augmentar el seu nivell de competitivitat a un mercat cada vegada més amenaçat degut a importacions massives procedents de països de fora de la UE, a vegades de dubtosa qualitat. En aquest context, garantir l'autenticitat de la mel, tan referent a l'origen botànic i geogràfic com a l'adulteració per addició de xarops, és un tema de gran inquietud a la Unió Europea i especialment a Espanya, principal país productor. Aquesta situació ha promogut un acord de col-laboració entre el Ministeri d'Agricultura Pesca i Alimentació (MAPA) i LABMIEL (Laboratori de control de qualitat de la mel i els productes apícoles de la Universitat Politècnica de València, a partir del qual s'ha desenvolupat la present tesi doctoral) amb la finalitat de caracteritzar la mel espanyola.

L'origen botànic de les plantes on picoregen les abelles, a més d'atribuir diferents propietats i característiques organolèptiques a la mel, pot donar informació de l'origen geogràfic on ha estat collida. Això, és pel fet que hi han plantes vinculades a països o fins i tot a zones geogràfiques específiques, per això, el rastreig dels pòl-lens d'aquestes plantes s'utilitza per a conèixer la caracterització geogràfica de les mels. Les mels amb major valor comercial són les monoflorals, i per tant, són les que major frau pel seu origen botànic sofreixen. La producció d'aquestes necessita més dedicació per part de l'apicultor, ja que requereixen d'una selecció de la flora on situar els ruscos i realitzar l'adequat tall i apilament de la mel collida sense barrejar floracions. Encara que existeixen criteris comercials per a denominar una mel com monofloral o de mielada (especialment relacionats amb el contingut pol-línic o elements de mielada, respectivament), encara no hi ha establert cap criteri legal.

D'altra banda, les mels de milflors són les que pateixen una major adulteració per addició de xarops d'origen vegetal. Encara que aquest tipus d'adulteració va aparèixer fa més de mig segle, a hores d'ara és cada vegada més recurrent a causa del desenvolupament industrial en l'obtenció de xarops amb característiques composicionals cada vegada més semblants a la mel. D'entre els diferents xarops que s'utilitzen per a aquesta fi, el d'arròs és un dels més presents, especialment pel mercat asiàtic d'on procedeixen moltes importacions.

Els mètodes analítics utilitzats per detectar aquesta mena de frau han evolucionat en paral-lel al desenvolupament de les tècniques d'adulteració amb xarops cada vegada més "avançats". Encara que avui dia les tècniques són múltiples, i moltes són econòmicament elevades, la tendència en els mètodes analítics per a detectar $\mathrm{i}$ quantificar l'adulteració de la mel s'està dirigint cap a la cerca de tècniques fàcils, barates i ràpides, que permeten a la indústria demostrar autenticitat sense haver de 
realitzar aquestes grans inversions econòmiques. Per aquest motiu és necessari avançar en la recerca de noves metodologies amb la major automatització possible. Aquestes tècniques, no necessàriament cal que es basen en la identificació d'un compost determinat, sinó més aviat en la recollida d'un conjunt elevat de dades que es relacionen amb certes característiques de les mels.

L' objectiu d'aquesta tesi doctoral ha estat avançar en l'aclariment de l'autenticitat de la mel aplicant tècniques analítiques emergents en aquest camp. Tot això amb la finalitat de facilitar la identificació de fraus, durant la comercialització de la mel, relacionats amb la seva classificació botànica i geogràfica, així com amb la seva adulteració per addició de xarops.

La caracterització dels compostos integrants de la fracció volàtil de les mels, mitjançant cromatografia de gasos-espectrometria de masses (GC-MS), es pot considerar un mètode complementari al pol-línic per a garantir el correcte etiquetatge de les mels monoflorals que es comercialitzen. La informació dels compostos constituents d'aquesta fracció es correlaciona bé amb la percepció sensorial de les mels, per això, aquesta metodologia resulta especialment útil en aquelles varietats on el pol-len està infra-representat, com és el cas de la mel de lavanda; i s'aconsella especialment quan una mel presenta característiques organolèptiques específiques diferenciadores. En aquest sentit, s'ha posat en evidència que la informació que es mostra en l'etiqueta de mels que es comercialitzen com monoflorals d'aquesta varietat, no es correspon amb el requisit comercial habitual (mínim 10\% de pol-len Lavandula spp.); malgrat posseir compostos volàtils i percepció sensorial característics d'aquesta. No obstant això, la informació de l'etiqueta de mels comercialitzades com a farigola (el pol.len de la qual no està infra-representat) era correcta considerant el contingut de pol·len, així com les seues característiques olfacte-gustatives i perfil volàtil típics d'aquesta varietat de mel.

Una llengua electrònica voltamètrica de polsos (composta d'elèctrodes metàl-lics de Ir, $\mathrm{Rh}, \mathrm{Pt}, \mathrm{Au}$ ), amb neteja i poliment electroquímic, en combinació amb anàlisis estadístiques de components principals (PCA), permet discriminar mels procedents de diferents orígens geogràfics (Moçambic, Hondures i Espanya), així com mels de diferents orígens botànics (monoflorals de gira-sol, flor del taronger i bruc). A més, la llengua electrònica és capaç de diferenciar l'addició de xarops (ordi, blat de moro o arròs integral) a aquestes mels quan aquesta té lloc per sobre d'un 2.5\%. Aplicant regressions de mínims quadrats parcials (PLS) s'ha demostrat que les dades proporcionades per aquesta llengua electrònica prediuen adequadament certs paràmetres fisicoquímics com la conductivitat $\left(r^{2}=0.948\right)$. En relació amb les adulteracions, les millors prediccions s'han obtingut per la mel de gira-sol i de bruc amb incorporació de xarop de blat de moro $\left(r^{2}=0.997\right.$ i $\left.r^{2}=0.994\right)$ i per a la mel de bruc amb xarop d'ordi $\left(r^{2}=0.997\right)$.

Les propietats tèrmiques avaluades mitjançant calorimetria diferencial de Flux (DSC) en combinació amb anàlisi estadística de components principals (PCA) ha permés 
diferenciar nivells d'adulteració en la mel (5, 10 i 20\%) per addició de xarops (àgave, auró, canya, ordi, blat de moro i diferents tipus d'arròs). L'addició de xarops a la mel pura va promoure canvis significatius en les propietats tèrmiques de les mels adulterades, en proporció al nivell d'adulteració i a la mena de xarop, especialment a causa de les diferències en la seva composició de sucres.

La tècnica de PCR ha permés per primera vegada identificar l'adulteració per addició de melassa d'arròs en mel de flor del taronger, aconseguint identificar percentatges d'adulteració menors als d'altres metodologies més costoses i laborioses. El major obstacle en l'aplicació d'aquesta tècnica es va trobar en l'etapa prèvia d'extracció d'ADN, a causa de la dificultat en l'obtenció de quantitat i qualitat suficient del mateix per a la seva posterior amplificació per PCR. La PCR en temps real, mitjançant la construcció d'una corba estàndard de dilucions seriades de diferents concentracions d'ADN d'arròs, va permetre detectar diferents percentatges d'addició de melassa d'arròs amb una exactitud de fins a 2-5\%.

En definitiva, la GC-MS i la llengua electrònica voltamètrica són tècniques prometedores per a la classificació de les mels monoflorals. La primera presenta l'avantatge de poder determinar compostos volàtils característics específics de determinades varietats de mel, relacionats amb l'origen botànic de les plantes en les quals picoregen les abelles; pel que la seva presència i abundància específica pot inequívocament relacionar-se amb una determinada mel monofloral. No obstant això, té el desavantatge de ser una tècnica cara i que requereix de personal altament qualificat. Per contra, la llengua electrònica, encara que inespecíficament, està donant resultats convincents de manera ràpida i senzilla en la discriminació de mels per procedència geogràfica i per adulteració. Les tècniques de DSC i PCR estan oferint evidències convincents de la seva utilitat per a identificar adulteració en la mel per addició de xarops, encara que per a ser concloents amb elles s'hauria de considerar un major nombre de tipus de mels i xarops als analitzats en la present tesi doctoral. Una vegada que s'hagi resolt el factor limitant de l'etapa d'extracció d'ADN, la PCR serà una tècnica idònia per a identificar altres melasses i xarops. 



\section{ABSTRACT}

Honey is currently one of the foodstuffs with the highest risk of fraud, especially favoured by the globalisation. The adulteration of honey causes unfair competition and significant economic losses for the beekeeping sector. It needs to be more competitive in a market increasingly threatened by massive imports from countries outside de European Union (EU) sometimes of dubious quality. In this context, guaranteeing the authenticity of honey, both in terms of botanical and geographical origin and adulteration by the addition of syrups, is a matter of great concern in the EU and, more specifically in Spain as its biggest producer. In this sense, Spanish authorities are feeling the need of putting in value honey harvested in this country. This situation promoted a collaboration agreement between the Ministerio de Agricultura Pesca y Alimentación (MAPA) and LABMIEL (Laboratorio de control de calidad de la miel y los productos apícolas de la Universitat Politècnica de València, where the present doctoral thesis was developed) with the aim of characterising Spanish honey.

The botanical origin of the plants visited by bees, in addition to attributing different properties and organoleptic characteristics to honey, can give information of the geographical origin where honey was harvested. This is because certain plants are linked to countries or even to specific geographical areas; therefore the tracking of pollens of these plants is used for the geographical characterisation of honey. Monofloral honey has the highest commercial value, therefore, they suffer the most fraud due to incorrect labelling of its botanical origin. Its production needs more dedication by the beekeeper, since it requires a selection of the flora in which the hives should be placed and carry out proper harvesting procedures without mixing what has been collected. Although there are commercial criteria to label a honey as monofloral or honeydew (especially related to pollen content or honeydew elements, respectively), there is currently no established legal criteria.

Polyfloral honey suffers the most adulteration by adding syrups of vegetable origin. Although this type of adulteration appeared more than half a century ago, it is now much more visible due to industrial development in obtaining syrups with compositional characteristics increasingly "similar" to honey. Among the different syrups that are used for this purpose, rice is one of the most present, especially for the Asian market from which many imports come.

Analytical methods for the detection of this type of fraud have evolved in parallel to the development of adulteration techniques with increasingly "similar" honey syrups. Currently, multiple techniques are available and in many cases are not cost effective. The tendency to detect adulteration is driving the search for easy, cheap and fast techniques that allow the Industry guarantee authenticity without having to make these large economic investments. For this, it is necessary to advance in the development of new innovative methodologies and with the greatest possible 
automation. These techniques should not necessarily be based on the identification of a particular compound, but rather on the collection of a high set of data that are related to certain honey characteristics.

Therefore, the objective of this doctoral thesis has been to advance in clarifying the authenticity of honey by applying emerging analytical techniques specifically in this field. All this with the finality of facilitating the identification of fraud, during the marketing of honey, related to its botanical and geographical classification, as well as its adulteration by the addition of syrups.

The characterization of the compounds that make up the volatile fraction of honey, by gas chromatography-mass spectrometry (GC-MS), can be considered a complementary method to the pollen analysis to ensure the correct labelling of the monofloral honeys that are marketed. The information of the constituent compounds of this fraction correlates well with the sensory perception of honey, therefore, this methodology is especially useful in those varieties whose pollen is under-represented (as is the case with lavender honey); and it is especially recommended when a honey has specific organoleptic differentiating characteristics. In this work it has been shown that the information on the label of honey marketed as monofloral of this variety does not correspond to the usual commercial requirement (minimum $10 \%$ of pollen Lavandula spp.); despite having the expected volatile compounds and sensory perception characteristics. However, the information on the label of honeys marketed as thyme (whose pollen is not under-represented) was correct considering the pollen content, as well as its olfactory-gustatory characteristics and volatile profile typical of this honey variety.

A pulse voltammetric electronic tongue (composed of metallic electrodes of Ir, Rh, Pt, $\mathrm{Au})$, with electrochemical cleaning and polishing, in combination with statistical analysis of main components (PCA), allows discriminating honey from different geographical origins (Mozambique, Honduras and Spain), as well as honey from different botanical origins (sunflower, orange blossom and heather monofloral). In addition, the electronic tongue is able to differentiate the addition of syrups (barley, corn or brown rice) to these honeys when this addition is over $2.5 \%$. Applying partial least squares regressions (PLS) it has been shown that the data provided by this electronic tongue adequately predicts certain physicochemical parameters such as conductivity $\left(r^{2}=0.948\right)$. With regard to adulterations, the best predictions have been obtained for sunflower and heather honey with the incorporation of corn syrup $\left(r^{2}=\right.$ 0.997 and $\left.r^{2}=0.994\right)$ and for heather honey with barley syrup $\left(r^{2}=0.997\right)$.

The thermal properties evaluated by differential scanning calorimetry (DSC) in combination with statistical analysis of main components (PCA) has allowed differentiating levels of adulteration in honey $(5,10$ and $20 \%)$ by adding syrups (agave, maple, cane), barley, corn and different types of rice). The addition of syrups to pure honey provoked significant changes in the thermal properties of adulterated honey, in 
proportion to the level of adulteration, and the type of syrup, especially due to differences in their sugar composition.

The PCR technique has allowed detecting for the first time the adulteration by adding rice molasses in orange blossom honey, managing to identify adulteration percentages lower than those of other more expensive and laborious methodologies. The greatest obstacle in the application of this technique was found in the previous stage of DNA extraction, due to the difficulty in obtaining sufficient quantity and quality of the DNA for subsequent PCR amplification. Real-time PCR, by constructing a standard curve of serial dilutions of different rice DNA concentrations, allowed detecting different percentages of rice molasses addition with an accuracy of between 2 to $5 \%$.

In short, the characterisation of the volatile fraction of honeys by GC-MS and the electronic voltammetric tongue are promising techniques for the classification of monofloral honeys. The first has the advantage of being able to detect specific and characteristic volatile compounds of certain varieties of honey, related to the botanical origin of the plants visited by bees. Therefore, their presence and specific abundance can unequivocally relate to a particular monofloral honey. However, it has the disadvantage of being an expensive technique that requires highly qualified personnel. On the contrary, the electronic tongue, although does not detect specific compounds of honey, it is quick and easy, and give convincing results in the discrimination of honey by geographical origin and adulteration. The techniques of DSC and PCR are offering promising evidence of its usefulness to identify adulteration in honey by adding syrups. In order to be conclusive with them, a greater number of types of honey and syrups should be considered to those analysed in this doctoral thesis. Once the limiting factor of the DNA extraction stage has been resolved, the PCR will be an encouraging technique in the identification of other molasses and syrups. 



\section{ÍNDICE GENERAL}

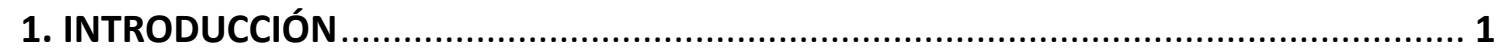

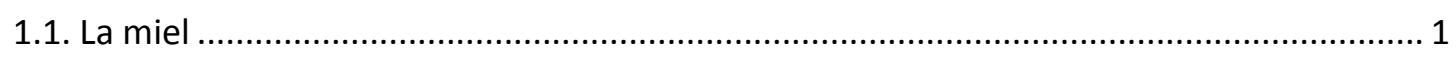

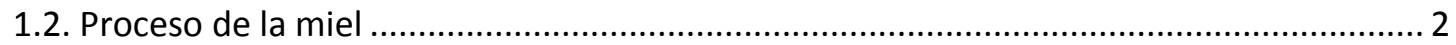

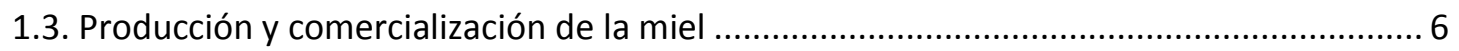

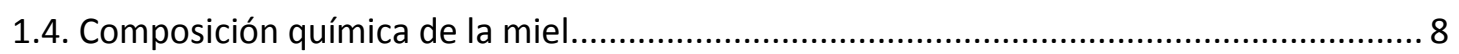

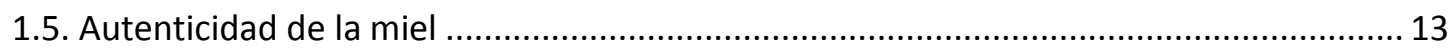

1.5.1. Autentificación del origen botánico y geográfico de la miel..................................... 14

1.5.2. La adulteración de la miel por adición de jarabes .................................................... 14

1.6. Métodos para verificar la autenticidad de la miel ........................................................ 17

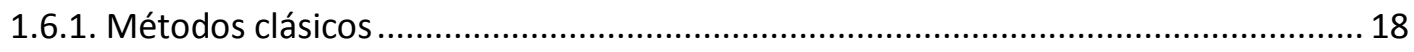

1.6.1.1. Métodos clásicos en uso ……….................................................................... 18

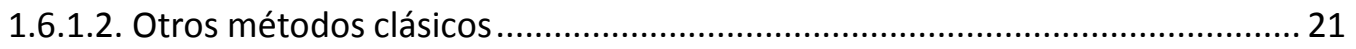

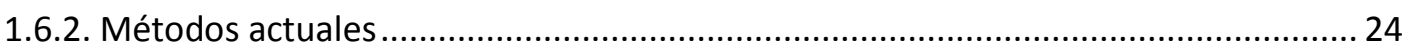

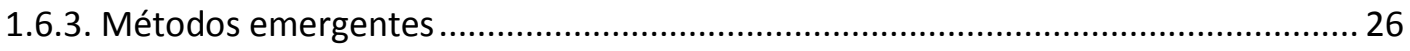

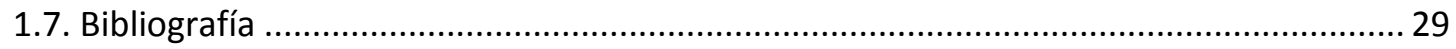

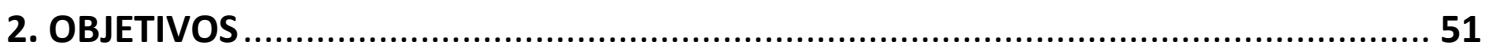

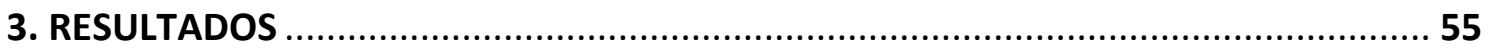

3.1. Volatile profile in the accurate labelling of monofloral honey. The case of lavender and

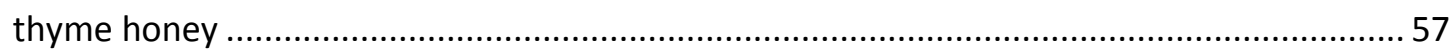

3.2. Using an automatic pulse voltammetric electronic tongue to verify the origin of honey from Spain, Honduras and Mozambique ................................................................................ 79

3.3. Thermal properties of honey as affected by the addition of sugar syrup ...................... 97

3.4. Detection of honey adulteration by conventional and real-time PCR .......................... 117

3.5. Monitoring honey adulteration with sugar syrups using an automatic pulse

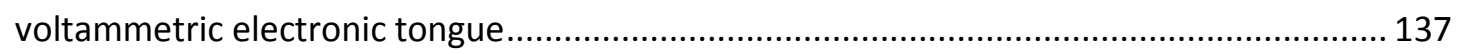

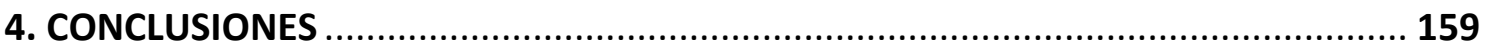





\section{ÍNDICE DE FIGURAS}

\section{INTRODUCCIÓN}

Figura 1.1. Abeja recolectora llena de polen (mieldeabejas.net, 2019)........................ 1

Figura 1.2. Cuadro de cera repleto de abejas (autor) ..................................................... 3

Figura 1.3. Centrífuga preparada para la extracción de miel de los cuadros (Blog de apicultura, 2020).....

Figura 1.4. Bidones de miel almacenados en la industria (autor).

Figura 1.5. Rueda de olor y aroma de la miel (International Honey Commision, 2001).

Figura 1.6. Escala Pfund de color de la miel (León, 2013)..... 21

\section{RESULTADOS}

Figure 3.1.1. Pictures at $400 \times$ magnification of pollen of Lavandula spp. (A) and Thymus spp. (B). A1 and B1- Light micrographs. A2 and B2 - DIC (differential interference contrast optics) micrographs.

Figure 3.1.2. (2.a) Scores (brand samples) and (2.b) loading (volatile compounds) plots of the first two components. $(L)$ and $(T)=$ percentage of Lavender spp. and Thyme spp. pollen.

Figure 3.1.3. Score plots of the first two components of the PCA-DA model. (L) and (T) $=$ percentage of Lavender spp. and Thyme spp. pollen, (0-3)=intensity of organoleptic perception of the first named honey.

Figure 3.2.1. Typical voltammetric pulse pattern.

Figure 3.2.2. Electrochemical trace of the layered sequence of the potential for honey samples from three different countries: Mozambique, Honduras and Spain.

Figure 3.2.3. Score plot of the PCA performed on multifloral honey samples from three different countries: Mozambique, Honduras and Spain.

Figure 3.3.1. Typical $1^{\text {st }}$ and $2^{\text {nd }}$ heating scan of honey and syrup samples. 106

Figure 3.3.2. Typical DSC curves $\left(2^{\text {nd }}\right.$ heating scan) of adulterated samples with two glass transition temperatures. 107

Figure 3.3.3. PCA biplot (scores and loadings) of the variables (Tg onset, Tg midpoint, fructose, glucose, sucrose, maltose and proteins) and samples: 10 types of pure syrups (agave, maple, sugar cane, barley, corn, brown rice and rice I-IV), 6 types of pure honey (sunflower; orange blossom, rosemary, heather, forest and polyfloral honey), and mixtures of sunflower honey with all the syrups at different proportions simulating the adulteration of honey (honey/syrup: 80/20; 90/10; 95/05). 110 
Figure 3.3.4. PCA biplot (scores and loadings) of the variables (Tg onset, Tg midpoint, fructose, glucose, sucrose, maltose and proteins) and mixtures of sunflower honey with all the syrups at different proportions simulating the adulteration of honey (honey/syrup: 80/20; 90/10; 95/05).

Figure 3.4.1. Agarose gel electrophoresis of PCR products for pure molasses (I and II) using rice primers (SPS2, PLD1 and PLD2). Figure 3.4.1.A: $M$ : marker; 1-3: pure molasses I, negative and positive control with SPS2 primers; 4-6: pure molasses I, negative and positive control with PLD1 primers; 7-9: pure molasses I, negative and positive control with PLD2 primers. Figure 3.4.1.B: M: marker; 10-12: pure molasses II, negative and positive control with SPS2 primers; 13-15: pure molasses II, negative and positive control with PLD1 primers; 16-18: pure molasses II, negative and positive control with PLD2 primers.

Figure 3.4.2. Agarose gel electrophoresis of PCR products for honey mixtures containing rice molasses I using rice primers (SPS2 and PLD1). Figure 3.4.2.A: M: marker; 1: pure honey with SPS2 primers; 2-7: honey mixed with 1, 2, 5 10, 20, 50\% rice molasses I with SPS2 primers; 8: pure molasses I with SPS2 primers; C-: negative control with SPS2 primers; C+: positive control with SPS2 primers. Figure 3.4.2.B: M: marker; 9: pure honey with PLD1 primers; 10-15: honey mixed with 1, 2, 5 10, 20, 50\% rice molasses I with PLD1 primers; 16: pure molasses I with PLD1 primers; C-: negative control with PLD1 primers; C+: positive control with PLD1 primers. 125

Figure 3.4.3. Agarose gel electrophoresis of PCR products for honey mixtures containing rice molasses II using rice primers (SPS2 and PLD1). Figure 3.4.3.A: $\mathrm{M}$ : marker; 1: pure honey with SPS2 primers; 2-7: honey mixed with 1, 2, 5 10, 20, 50\% rice molasses II with SPS2 primers; 8: pure molasses II with SPS2 primers; C-: negative control with SPS2 primers; C+: positive control with SPS2 primers. Figure 3.4.3.B: M: marker; 9: pure honey with PLD1 primers; 10-15: honey mixed with 1, 2, 5 10, 20, 50\% rice molasses II with PLD1 primers; 16: pure molasses I with PLD1 primers; C-: negative control with PLD1 primers; C+: positive control with PLD1 primers.

Figure 3.4.4. Example of a PCR amplification plot for honey containing different percentages of rice molasses simulating the adulteration (1, 2, 5, 10, 20 and 50\%). A: molasses I using SPS2; B: molasses I using PLD1; C: molasses II using SPS2; D: molasses II using PLD1. Abbreviations: I (molasses I), II (molasses II), H (honey), C+ (positive control) and C- (negative control).

Figure 3.4.5. Rice genomic DNA standard curve where $C p$ value was plotted against Log DNA concentration $(\mathrm{ng} / \mu \mathrm{L})$ of DNA standard solution. 131

Figure 3.5.1. Voltammetric pulse pattern 143

Figure 3.5.2. Score plot of the PCA performed on pure honeys (sunflower, orange blossom, heather) and pure syrups (barley, corn, brown rice) samples. 145 
Figure 3.5.3. Electrochemical trace of the layered sequence of the potential for sunflower honey adulterated with barley syrup at different levels $(40,20,10,5$ and $2.5 \%)$

146

Figure 3.5.4. Scores plot of the PCA performed on barley syrup and pure honey (A: sunflower; $\mathrm{B}$ : orange blossom; $\mathrm{C}$ : heather hone), and mixtures of both in different percentages $(40,20,10,5$ and $2.5 \%)$ simulating the adulteration of honey. 147

Figure 3.5.5. Predicted versus measured values of heather honey adulterated with barley syrup given by PLS model. 



\section{ÍNDICE DE TABLAS}

\section{INTRODUCCIÓN}

Tabla 1.1. Alertas relativas a mieles adulteradas en diferentes países (FDA, 2019). .... 17

Tabla 1.2. Contenido diastásico en diferentes mieles. Unidades expresadas como valores de la escala Schade (Juan-Borrás, 2016).

\section{RESULTADOS}

Table 3.1.1. Olfato-gustatory profile and average values of the physicochemical parameters and colour of each of the brands commercially labelled as lavender or thyme honey. $\mathrm{L}=$ lavender; $\mathrm{T}=$ thyme. Brand codes refer to the average percentage of pollen of Lavandula spp. (L) and (Thymus spp.). The organoleptic score of the brands was based on their monofloral (lavender or thyme) olfato-gustatory profile, perception intensity from 0 (absence) to 3 (very intense).

Table 3.1.2. Volatile compounds (average values and standard deviation) in samples labelled as lavender or thyme honey. The data were calculated (ug/ $\mathrm{kg}$ of honey) assuming a response factor equal to one.

Table 3.1.3. Comparison of commercial labelling and possible classifications of samples according to presence of pollen, organoleptic profile and volatile compounds.

Table 3.2.1. Melissopalynological results of the analyzed honey from Spain, Honduras and Mozambique.

Table 3.2.2. Mean and standard deviation values of moisture, electrical conductivity, colour, fructose and glucose found in honey from different countries (Mozambique, Honduras and Spain) and ANOVA results (F-ratio and significant differences). 88

Table 3.2.3. PLS prediction results obtained from the validation data for the multifloral honeys with analytical parameters.

Table 3.3.1. Major sugars, total proteins and glass transition temperature ( $\mathrm{Tg}$ onset and Tg midpoint) of pure honey and syrup samples. Mean values and standard deviation (in brackets). 104

Table 3.3.2. Glass transition temperature $(\mathrm{Tg})$ and estimated composition of adulterated samples. Mean values and standard deviation, in brackets.

Table 3.4.1. Oligonucleotide primers used in the PCR amplifications.

Table 3.4.2. Cp values (mean values and standard deviation), Log of concentrations and rice DNA concentrations in pure rice molasses I and II, pure orange blossom honey, and mixture of both in different percentages $(1,2,5,10,20$ and 50\%, respectively) simulating the adulteration of honey..... 131 
Table 3.5.1. Electrochemical polishing of the working electrodes: configuration of basic or acidic solution in the sequence of cathodic and anodic pulse applied to the different metals.

144

Table 3.5.2. PLS prediction results obtained from the validation data for the adulteration of pure honeys (sunflower, orange blossom, heather) with syrup (barley, corn, brown rice) at different percentages $(40,20,10,5$ and $2.5 \%)$. 149 


1. INTRODUCCIÓN 



\section{Introducción}

\subsection{La miel}

La miel es un edulcorante natural, consumido desde hace miles de años, con importantes cualidades nutricionales. Puede ser fluida, espesa o cristalina y su color variar desde casi incoloro hasta muy oscuro. Posee acción bactericida y puede actuar como agente terapéutico frente a determinadas infecciones y desequilibrios nutricionales. Se trata de un alimento prácticamente seguro desde el punto de vista microbiológico y biológicamente estable debido principalmente a su bajo $\mathrm{pH}$, baja actividad de agua y a la presencia de sustancias antimicrobianas (Fattori, 2004). Por todo ello, está considerada uno de los alimentos más completos que la naturaleza proporciona (Fernández-Uriel, 2011).

La norma de calidad relativa a la miel la define como "una sustancia natural dulce producida por la abeja Apis mellifera a partir del néctar de las plantas, de secreciones de partes vivas de las mismas o de excreciones de insectos, que las abejas recolectan, transforman, depositan, deshidratan, almacenan y finalmente dejan en colmenas para que madure" (Directiva Europea 2014/63/UE, trasposición a España en Real Decreto 1049/2003, modificado por el Real Decreto 473/2015). Las abejas recolectoras son las encargadas de succionar, mediante una larga lengua retráctil, y almacenar, en el buche melario, el néctar o el mielato hasta llegar a la colmena (figura 1.1) (Ruíz, 2011; Belitz et al., 2014). El néctar es una disolución acuosa, compuesta principalmente de azúcares, que es segregado por las plantas en los nectarios, situados habitualmente en la corola de las flores. Estos nectarios están colocados de manera que los insectos se impregnan de polen cuando recolectan el néctar, contribuyendo a la polinización. Por ello, en la miel se encuentran, en mayor o menor medida, granos de polen (JuanBorrás, 2016). En cambio, los mielatos son secreciones azucaradas de ciertas plantas o insectos hemípteros (Suárez, 2009).

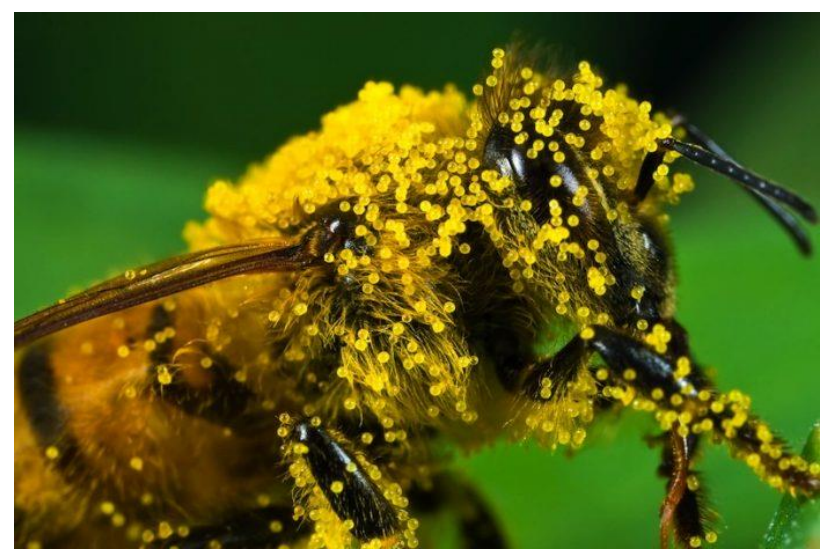

Figura 1.1. Abeja recolectora llena de polen (mieldeabejas.net, 2019). 
Atendiendo al origen botánico de las plantas en las que la abeja pecorea, las mieles se clasifican en (Real Decreto 1049/2003):

- Mieles monoflorales o uniflorales: las que provienen mayoritariamente de una especie vegetal determinada y poseen características organolépticas, físicoquímicas y palinológicas específicas. Ejemplos: miel de romero, miel de azahar, miel de girasol, miel de castaño, etc.

- Mieles multiflorales, poliflorales o milflores: las que proceden de una flora variada, no siendo ninguna de ellas predominante, y por lo tanto no se les puede atribuir ninguna variedad botánica específica.

- Mieles de mielada o mielatos: las que proceden en su mayor parte de secreciones de las partes vivas de las plantas o de excreciones de insectos chupadores de plantas (hemípteros). Ejemplos: miel de encina, miel de roble, miel de carrasca, etc.

Todas las mieles tienen un sabor y aroma característico de este alimento, pero con ciertos matices en función de su origen botánico. La flora representativa de un lugar geográfico determinado le conferirle ciertas características y propiedades organolépticas específicas (Juan-Borrás, 2016).

\subsection{Proceso de la miel}

\section{Del campo a la industria}

En la colmena, las abejas regurgitan la mezcla de néctar y/o mielato, saliva y enzimas, y la depositan en celdas (Ruíz, 2011). Las abejas obreras, agitando las alas disminuyen la humedad de esta mezcla hasta un $16-19 \% \mathrm{y}$, posteriormente para que madure, operculan las celdas cubriéndolas con una fina capa de cera. En esta etapa ocurre principalmente la hidrólisis de la sacarosa (azúcar mayoritario en el néctar) en glucosa y fructosa (azúcares mayoritarios de la miel) (Belitz et al., 2014). Una vez operculada se puede considerar que el producto obtenido es miel y estaría lista para ser recogida del panal por el apicultor (Del Baño Breis, 2000; Ruíz, 2011).

El apicultor, previamente habrá tenido que decidir la época del año y el lugar de localización de las colmenas, teniendo en cuenta la meteorología y la flora de la zona, ya que de ello dependerá el tipo de miel que se obtenga (Ruíz, 2011; Juan-Borrás, 2016). Posteriormente, con las colmenas ya preparadas (formadas por cuadros de cera), las abejas producirán la miel (figura 1.2). Cuando la miel está suficientemente madura es retirada del panal por los apicultores, realizando previamente el "desabejado" (con ahumador) para expulsar a las abejas y evitar de esta manera su ataque (Buleo, 2012). 


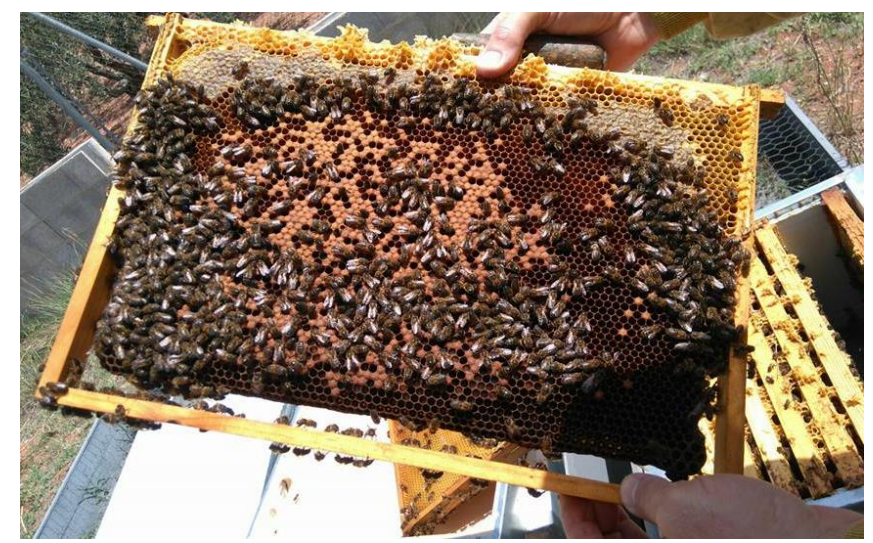

Figura 1.2. Cuadro de cera repleto de abejas (autor).

En climas mediterráneos se aconseja retirar únicamente los cuadros que tengan más de 2/3 partes de su superficie perfectamente operculada. En el caso de regiones húmedas es mejor que estén casi totalmente operculados (Díaz-Moreno, 2009; Suárez, 2009).

Es esencial que el apicultor no coseche toda la miel y deje una cantidad adecuada en el panal para que las abejas puedan alimentarse y continuar sus funciones con normalidad (Suárez, 2009). Cuando en invierno el alimento dentro de la colmena es insuficiente, habitualmente se les ayuda proporcionándoles alimento externo, normalmente jarabes de azúcares. En este caso el apicultor no debe cosechar esta "pseudomiel", ya que sería un fraude comercializar el producto obtenido como miel (Wei et al., 2019).

Las etapas posteriores de desoperculado (eliminación los opérculos de cera) y de extracción de la miel se pueden realizar bien en el campo junto a las colmenas o, preferiblemente, en salas de extracción habilitadas para ello. Éstas deben estar bien iluminadas, aireadas y cumplir con adecuados requisitos de higiene, humedad (aproximadamente 60\%) y temperatura (no superior a $30{ }^{\circ} \mathrm{C}$ ). La extracción de la miel se puede realizar por decantación, prensado o centrifugación (figura 1.3). Este último procedimiento es el más habitual, ya que además de obtener un mayor rendimiento, es rápido y los panales no sufren daño (Suárez, 2009; Ruíz, 2011; Visquert, 2015). En el centrifugado, la fuerza centrífuga hace que la miel salga de las celdas, atraviese una tela metálica y vaya a un recipiente donde se recoge por gravedad. Posteriormente se filtra y se decanta para eliminar burbujas de aire ocluidas, impurezas, restos de cera, abejas, etc. (Díaz-Moreno, 2009; Ruíz, 2011). Esta etapa puede durar desde unos pocos días hasta alrededor de 1 mes, dependiendo del peso y viscosidad de la miel, de la temperatura o de la forma y altura de los recipientes en los que se almacena (Piana et al., 1989). La miel ya limpia y decantada se suele recoger en bidones metálicos de aproximadamente $300 \mathrm{~kg}$ y se lleva a las industrias de procesado y envasado de miel (Juan-Borrás, 2016). 


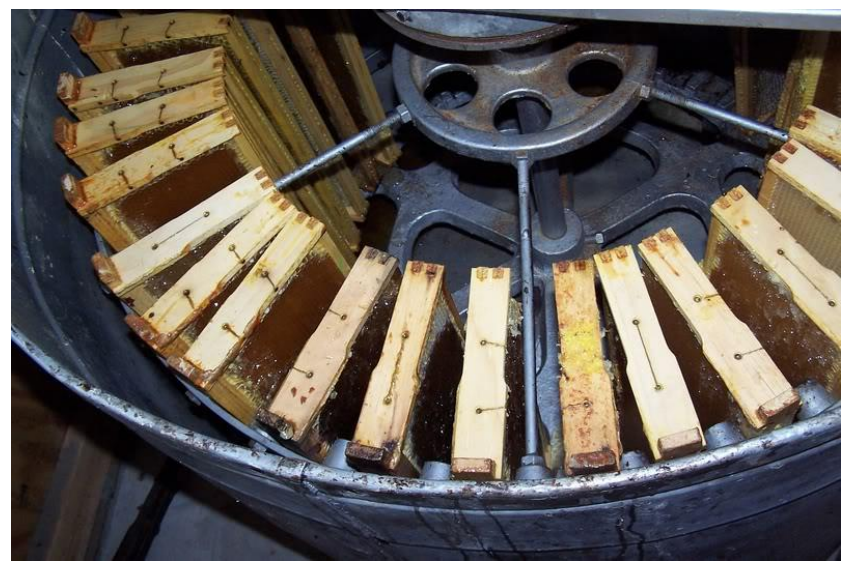

Figura 1.3. Centrífuga preparada para la extracción de miel de los cuadros (Blog de apicultura, 2020).

\section{Etapa industrial}

Los bidones de miel, una vez llevados a la industria, son clasificados para conformar diferentes lotes de producción (entre 3,000 y $40,000 \mathrm{~kg}$ ) (figura 1.4). A continuación, la miel se somete a una etapa de licuación ( $40-55{ }^{\circ} \mathrm{C}$ durante $2-4$ días) para conseguir la fusión de cristales presentes en ella y así obtener una miel más manejable y poder trasvasarla, fraccionarla y mezclarla (Visquert, 2015). Después de la licuación se realiza la pasteurización, sometiendo la miel a un choque térmico para ralentizar su cristalización y destruir microorganismos, fundamentalmente levaduras (Biluca et al., 2014). La temperatura de pasteurización recomendada es aproximadamente de $80{ }^{\circ} \mathrm{C}$ durante 6-7 minutos. Este calentamiento y el posterior enfriamiento deben realizarse lo más rápidamente posible para minimizar la pérdida de calidad y garantizar su frescura, en la medida de lo posible (White \& Rudyj, 1980; Díaz-Moreno, 2009).

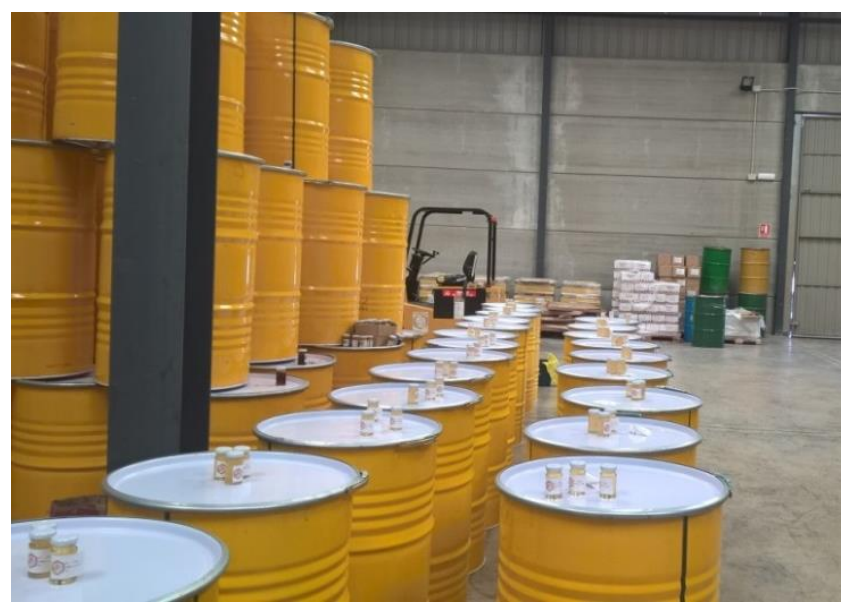

Figura 1.4. Bidones de miel almacenados en la industria (autor).

Otro tipo de procesado más artesanal es el destinado a obtener un producto "denominado miel cruda" sometiéndola únicamente a un ligero tratamiento de licuación para facilitar su manejo. De esta manera se mantienen mejor las características de la miel cruda. 
Finalmente se procede al envasado y etiquetado de la miel en recipientes que permitan su conservación. El envase más apropiado es el vidrio, aunque también es habitual utilizar plástico, especialmente en el formato de dosificador antigoteo. Las industrias de envasado también comercializan la miel pasterizada a granel en bidones, cuyo destino fundamental es otras industrias alimentarias o cosméticas (Suárez, 2009).

La miel no tiene fecha de caducidad, pero debe indicarse una fecha de consumo preferente, que suele oscilar entre de 18 y 24 meses. Durante este periodo el envasador es el responsable de que ésta se encuentre en buen estado, por ello, es necesario que la industria vigile todo el proceso, desde su recepción como materia prima hasta que llega al consumidor envasada (Visquert, 2015). Para ello, las empresas deben controlar el cumplimiento de la normativa, antes mencionada, relativa a la calidad de la miel en lo que respecta a los parámetros que contempla (azúcares, agua, conductividad eléctrica, ácidos libres, índice diastásico e hidroximetilfurfural). Además, las empresas deben tener en cuenta otros parámetros que, no siendo obligatorios por ley, son exigidos por las transacciones comerciales, ya que influyen en la aceptación de la miel por parte del consumidor (color, aroma, textura, denominación botánica y geográfica, etc.) (Juan-Borrás, 2016).

\section{De la industria al consumidor}

La miel envasada se debe conservar en un ambiente fresco y seco, tanto por parte de la industria como del consumidor, para que mantenga en la medida de lo posible sus características originales y se ralenticen los procesos de deterioro (Visquert, 2015).

A través de la etiqueta, las industrias envasadoras de miel informan al consumidor tanto de los aspectos que la ley exige, como de aquellos que tienen por finalidad captar su interés. La miel envasada, además de cumplir la norma de etiquetado relativa a todos los productos alimentarios (Reglamento UE 1169/2011), debe atenerse a lo especificado a tal efecto en su normativa (Real Decreto 1049/2003). Es necesario indicar "el origen floral o vegetal, si la miel procede totalmente o en su mayor parte del origen indicado y si posee las características organolépticas, fisicoquímicas y microscópicas de dicho origen". Además, la norma establece que se deberá indicar "el origen regional, territorial o topográfico, si la miel procede enteramente del origen indicado". También se puntualiza que "en el caso de mezclas, si las mieles son originarias de más de un estado miembro o tercer país, dicha mención podrá sustituirse por una de las siguientes leyendas":

-"Mezcla de mieles originarias de la CE"

- "Mezcla de mieles no originarias de la CE"

- "Mezcla de mieles originarias y no originarias de la CE" 
Esta situación permite etiquetar a las mieles sin concretar el país de procedencia, generando confusión y por lo tanto la desconfianza del comprador. Éste valora cada vez más el origen (geográfico y/o botánico) de la miel, influyendo en gran medida en su decisión de compra. Mediante esta forma de "informar en la etiqueta" es imposible obtener una valoración de genuinidad del producto, ya que las industrias envasadoras de miel pueden etiquetar una miel como "mezcla de mieles originarias y no originarias de la CE", incluso teniendo tan solo un $1 \%$ de miel procedente de la CE.

Actualmente, el Ministerio de Agricultura, Pesca y Alimentación (MAPA) trabaja en un nuevo Real Decreto para implantar un etiquetado obligatorio más detallado sobre el país de origen de la miel para una mayor protección del consumidor, tomando como referencia el caso de Italia, donde en el año 2006 el Ministero delle Politiche Agricole, Alimentari e Forestali italiano impuso la obligación de indicar en la etiqueta el país o países de origen de la miel (nota de prensa, 2019a,b).

\subsection{Producción y comercialización de la miel}

\section{En la Unión Europea (UE)}

El sector de la apicultura en la Unión Europea (UE), a pesar de no ser muy extenso en comparación con otros sectores, tiene un importante papel en el asentamiento de las poblaciones rurales y en la polinización de la agricultura. Por ello, la política agrícola común apoya a este sector con la finalidad de mitigar el impacto negativo de ciertas actividades agrícolas sobre los polinizadores.

La UE viene respaldando desde 1997 al sector apícola mediante sucesivos Reglamentos, posibilitando la elaboración de programas nacionales que ayuden a este sector. El objetivo es mejorar las condiciones de producción y comercialización de los productos apícolas (miel, jalea real, polen, propóleo y cera de abejas), para minimizar los obstáculos que tienen los apicultores para mantener sus colmenas y su producción de miel. Entre ellos cabría mencionar: aumento de costes, fuerte competencia debida a la importación de mieles más baratas, pérdida de colonias de abejas, enfermedades, etc.

En la UE existen en torno a 600,000 apicultores (datos de 2017-2019) y 16 millones de colmenas (datos de 2014-2016), ubicados en su mayoría en el sur de la UE: España, Francia, Grecia, Rumanía e Italia. El número de apicultores de la UE ha descendido en los últimos años y además, el $96 \%$ de ellos gestionan menos de 150 colmenas, por lo que el colmenar no se considera "profesional". Tan solo el $4 \%$ de los apicultores de la UE tienen más de 150 colmenas y pueden ser clasificados como apicultores "profesionales" (datos de 2015) (Comisión Europea, 2016).

La UE produce aproximadamente $250,000 \mathrm{Tm}$ de miel al año, posicionándose como el segundo productor mundial de miel después de China. Aun así, el porcentaje de 
autosuficiencia de la UE se encuentra alrededor del $60 \%$, por lo que no se produce suficiente miel para cubrir su propio consumo. En general, ha habido un aumento de la producción de la miel en los diferentes estados miembros, encabezada por: Rumanía, España, Hungría, Alemania e Italia. No obstante, este aumento es lento debido a los obstáculos nombrados con anterioridad, consecuencia, en muchos casos, de la intensificación agrícola. Por este motivo, la UE ha aumentado progresivamente las importaciones de países terceros llegando a convertirse en el primer importador mundial de miel. Tan solo en el 2015 se importó 200,000 Tm, la mayoría procedente de China (100,000 Tm, aproximadamente), seguida por México y Ucrania. La miel importada, en general, tiene un precio muy inferior a la de la UE; como ejemplo decir que, en ese mismo año, el precio unitario medio de las importaciones de miel de origen chino fue de $1.64 € / \mathrm{kg}$, mientras que el de la de milflores de la UE vendida a granel al por mayor fue de $3.78 € / \mathrm{kg}$. En cambio, las exportaciones de la UE son insignificantes. Solamente 20,000 toneladas de miel fueron exportadas en el 2015, por la demanda de miel de alta calidad, a países como Suiza, Arabia Saudí, Japón, Estados Unidos y Canadá. En este caso, el precio unitario medio de las exportaciones de miel fue de $5.77 € / \mathrm{kg}$ (Comisión Europea, 2016).

En general, el precio suele variar mucho según el tipo de miel, el origen geográfico, las denominaciones de calidad y el punto de venta. Una miel de milflores puede costar entre $2.54 € / \mathrm{kg}$ de miel vendida a granel al por mayor en Polonia y $15.18 € / \mathrm{kg}$ de miel vendida en el lugar de producción en el Reino Unido (Comisión Europea, 2016).

\section{En España}

El número de apicultores en España en el 2018 era aproximadamente de 31,500, con el nivel más alto de profesionalización de la UE. En nuestro país más del $18 \%$ de apicultores son "profesionales" (tienen explotaciones con más de 150 colmenas). El número de explotaciones profesionales se han mantenido estables durante estos últimos años, en cambio, las explotaciones apícolas en España han aumentado en torno al $40 \%$ en el periodo comprendido entre el 2010 y el 2018 . España es el país de la UE más importante en cuanto a producción apícola, con un $16 \%$ del censo total comunitario, seguido de Francia (10\%), Grecia (10\%) y Rumania (10\%). El número registrado de colmenas en nuestro país, en diciembre de 2017 , fue de $2,869,444$, de las cuales el $80 \%$ pertenecían a apicultores "profesionales". En el periodo comprendido entre 2008 y 2017, este censo ha ido aumentando progresivamente en más de un $20 \%$, obteniendo los mayores censos de colmenas en Extremadura $(622,894)$, Andalucía $(562,680)$, Castilla y León $(448,233)$ y Comunidad Valenciana $(360,245)$ (Ministerio de Agricultura, Pesca y Alimentación, 2018a).

La producción de miel en España se sitúa en torno a las 31,000 Tm (año 2016), producción que ha ido descendiendo respecto a pasados años (35,000 Tm en 2003, 34,000 Tm en 2011 ó 33.000 en 2015), debido a unas condiciones climáticas 
desfavorables que han dado lugar a unos bajos rendimientos de la miel. La mayor producción de miel, que concentra más del 70\% del total de la producción en España, se sitúa en 4 Comunidades Autónomas: Andalucía (21.1\%), Comunidad Valenciana (19.6\%), Castilla y León (15.8\%) y Extremadura (10.7\%), coincidiendo con las CCAA con mayor censo de colmenas. En España había ido en aumento el nivel de autoabastecimiento en los últimos años para situarse en valores próximos al $100 \%$, pero ese porcentaje comenzó a reducirse en 2017, situándose en valores próximos al $80 \%$. Como anteriormente se ha comentado, el porcentaje de autosuficiencia de la UE se encuentra mucho más bajo (alrededor del 60\%) y en consecuencia España importa miel, principalmente de China, seguida de Portugal, Argentina, Ucrania y Países Bajos. En el caso de Argentina se ha producido un descenso de las importaciones, dando paso a Uruguay como proveedor complementario. Por otro lado, las exportaciones de miel han ido creciendo hasta consolidarse en el mercado exterior como una línea de comercialización con entidad propia. En 2017, los principales países de exportación de España fueron Francia (6,835 Tm), Alemania (3,973 Tm) e Italia (1,827 Tm), seguido de países como Portugal, Arabia Saudí y Reino unido (Ministerio de Agricultura, Pesca y Alimentación, 2018a).

Con relación al precio de la miel, en la campaña 2017/2018, se registraron subidas generalizadas de cotizaciones en los diferentes tipos de mieles: $14.47 \%$ para la miel multifloral a granel, $13.32 \%$ para la miel de mielada a granel, $1.40 \%$ para la miel multifloral envasada y $20.44 \%$ para la miel de mielada envasada. Sus precios al finalizar la campaña fueron de $3.28 € / \mathrm{kg}, 4.75 € / \mathrm{kg}, 5.08 € / \mathrm{kg}$ y $6.88 € / \mathrm{kg}$, respectivamente. También se registraron subidas generalizadas para las mieles monoflorales, obteniendo unos precios al finalizar la campaña de $4.23,4.12$ y $4.81 € / \mathrm{kg}$ para la miel de azahar, de eucalipto y de romero a granel y de 6.36, 5.97 y $6.15 € / \mathrm{kg}$ para esas mismas mieles envasadas (Ministerio de Agricultura, Pesca y Alimentación, 2018b).

\subsection{Composición química de la miel}

La miel está formada por más de 181 componentes diferentes (Viuda-Martos et al., 2008) que le confieren unas características de color, sabor y aroma típico, así como ciertas propiedades fisicoquímicas (Sáenz \& Gómez, 2000). Se trata de una disolución acuosa concentrada de azúcares, principalmente de glucosa y fructosa, que contiene además una compleja mezcla de otros hidratos de carbono, enzimas, ácidos orgánicos, proteínas, minerales, aminoácidos, sustancias aromáticas, pigmentos, ceras, granos de polen, etc. (Belitz et al., 2014). Esta composición puede variar según su origen botánico, origen geográfico, condiciones climáticas, paso del tiempo, estado de la colmena, así como por las prácticas apícolas (Sáenz \& Gómez, 2000; Bertoncelj et al., 2007; Guler et al., 2007; Al et al., 2009; Álvarez-Suárez et al., 2014; Escuredo et al., 2014; Nayik et al., 2014; Juan-Borrás, 2016; Escriche et al., 2016; Escriche et al., 2017). 


\section{Carbohidratos}

Los carbohidratos son los componentes más importantes de la miel constituyendo aproximadamente el $80 \%$ de la materia total y el $95-99 \%$ de la materia seca (Visquert, 2015). Son responsables de su elevado poder calórico y sabor dulce (León, 2013). Las principales características sensoriales y fisicoquímicas de la miel, como pueden ser el sabor, la viscosidad, la granulación y la higroscopicidad, son atribuidas a los carbohidratos (Cavia et al., 2002; Juan-Borrás et al., 2014). Desempeñan un papel muy importante en la conservación de la miel, gracias a la presión osmótica que ejercen, ralentizando el desarrollo de levaduras (De Lorenzo et al., 2002) e impidiendo el crecimiento de la casi totalidad de mayoría de microorganismos (Fernández-Uriel, 2011).

Los monosacáridos fructosa y glucosa son los carbohidratos mayoritarios presentes en la miel (21.7-53.9\% y 20.4-44.4\%, respectivamente) (Codex Alimentarius, 2001; JuanBorrás, 2016). Según la legislación vigente, la suma de estos azúcares no debe ser inferior a $60 \%$ para mieles de flores y no inferior a $45 \%$ en mieles de mielada o mezclas de esta miel con miel de flores (Real Decreto 1049/2003). El sabor dulce es proporcionado principalmente por la fructosa, por lo que mieles con un alto contenido en fructosa, como la de acacia, serán más dulces (Bogdanov et al., 2008). En menor cantidad se encuentran los disacáridos maltosa (7\%) y sacarosa ( $<3 \%$ ) (Piana et al., 1989), y por último, en más baja proporción otros disacáridos y oligosacáridos como isomaltosa, maltulosa, erlosa, turanosa y melecitosa (Fattori, 2004; Juan-Borrás, 2016). Algunos de estos azúcares tienen origen en el néctar o en los mielatos, aunque otros también proceden de la acción de los enzimas segregados por las abejas (Díaz-Moreno, 2009).

Los carbohidratos, además de aportar las principales características sensoriales y fisicoquímicas y ser los compuestos mayoritarios de la miel, pueden aportan información acerca de su estado de maduración (Serra-Bonvehí \& Ventura, 1995). Un contenido en sacarosa más alto de lo esperado puede ser debido a una recogida precoz de la miel, antes de que esté madura. Por ello, la legislación regula este parámetro y establece que el contenido máximo de sacarosa debe ser del $5 \%$, a excepción de las mieles de: falsa acacia "Robinia pseudoacacia", alfalfa "Medicago sativa", Banksia de Menzies "Banksia menziesii", sulla "Hedysarum", eucalipto rojo "Eucalyptus camaldulensis", "Eucryphia lucida", "Eucryphia milliganii" y la de "Citrus spp.", para las que el contenido máximo debe ser del $10 \%$. Con respecto a otras mieles como la de espliego "Lavandula spp." y la de borraja "Borago officinalis" se admite hasta 15\% (Real Decreto 1049/2003).

Es importante destacar el papel de los carbohidratos en la generación de un compuesto fundamental en la calidad de la miel como es el 5-(hidroximetil)-2furancarboxilaldehído ó hidroximetilfurfural (HMF). Éste se forma como consecuencia 
de la deshidratación de la fructosa en medio ácido (pH 3.9 aproximadamente) (De Lorenzo et al., 2002). En la miel este fenómeno se ve acelerado cuando se somete a altas temperaturas (tanto en el procesado como en el almacenamiento) y se acentúa con el tiempo transcurrido desde su recolección (White \& Siciliano, 1980; León, 2013). EI HMF no es un componente habitual en la miel fresca; su elevada presencia indica mal tratamiento y almacenamiento, sí como su envejecimiento. Por ello, la cuantificación de este parámetro es de vital importancia para garantizar la frescura de la miel (Rodríguez, 2015; Visquert, 2015). Según la legislación vigente, el HMF no puede superar los $40 \mathrm{mg} / \mathrm{kg}$ para mieles en general, a excepción de la destinada a uso industrial. Para las mieles procedentes de regiones de clima tropical y las mezclas de estas mieles, se admite hasta $80 \mathrm{mg} / \mathrm{kg}$ (Real Decreto 1049/2003). Sin embargo, las empresas de envasado no aceptan como materia prima mieles con un HMF superior a $20 \mathrm{mg} / \mathrm{kg}$, ya que saben que durante su almacenamiento, procesado y comercialización, la concentración de este compuesto se incrementa.

\section{Agua}

El contenido en agua de la miel oscila entre 14 y $21 \%$, con un promedio de $17 \%$. Este valor depende fundamentalmente del origen botánico, condiciones climáticas, estación del año, grado de maduración alcanzado en la colmena y condiciones de almacenamiento. El contenido de agua influirá en su calidad final (Gallina et al., 2010) afectando directamente a su valor comercial, ya que contribuye a su peso específico, viscosidad, sabor, palatabilidad, solubilidad y estabilidad (Sáenz \& Gómez, 2000; Escriche et al., 2016; Escriche et al., 2017). La cantidad de agua que contiene la miel condiciona su manejo y conservación; un bajo porcentaje dificulta su manejabilidad, mientras que un porcentaje alto determina su conservación. Esto es así ya que el agua facilitada las reacciones de transformación y alteración, especialmente la fermentación por levadura (por encima del 20\%). Sin embargo, en la fermentación de la miel también influyen otros factores, como el contenido microbiano inicial, el tiempo y la temperatura de almacenamiento. La fermentación no implica ningún peligro para la salud del consumidor, pero provoca su rechazo, con la consecuente pérdida económica para la industria (Belitz \& Grosch, 1997; Juan-Borrás, 2016). Por este motivo, la ley establece que las mieles comerciales no deben tener un porcentaje de humedad mayor del 20\%, exceptuando a las mieles de brezo "Calluna" y las de uso industrial, que pueden llegar al 23\% (Real Decreto 1049/2003).

\section{Ácidos}

Los ácidos presentes en la miel influyen en sus propiedades organolépticas (Cavia et al., 2007). Éstos hacen de la miel un producto ácido, con un pH que oscila entre 3.4 y 6.1 , hecho que dificulta la presencia y el crecimiento microbiano. El ácido mayoritario y más importante en la miel es el glucónico, formado a partir de la glucosa por acción 
enzimática, sin embargo cabe destacar la presencia de otros ácidos como: acético, butírico, cítrico, fórmico, láctico, málico, oxálixo, artárico, pirúvico y succínico. Los ácidos proceden del néctar o de las secreciones azucaradas recolectadas, aunque también son el resultado de procesos enzimáticos y fermentativos (Piana et al., 1989; Belitz \& Grosch, 1997; Visquert, 2015). Se encuentran como ácidos libres o como lactonas, funcionando éstas últimas como reserva ácida (Sáinz et al., 2000). La norma relativa a la calidad de la miel establece que el contenido de ácidos libres no debe ser mayor a 50 miliequivalentes por $1000 \mathrm{~g}$, a excepción de la miel para uso industrial que no debe exceder de 80 miliequivalentes de ácidos por $1000 \mathrm{~g}$ (Real Decreto 1049/2003). La miel también contiene ácidos fenólicos como cafeico, cinámico y ferúlico, que contribuyen a sus propiedades antioxidantes (Fattori, 2004).

\section{Proteínas}

El contenido de proteínas de la miel es muy bajo, aproximadamente $0.5 \%$, debido a su contenido en enzimas y aminoácidos libres, pero sobre todo por la presencia de polen. Por ello, las mieles que tienen un contenido de polen alto, tienen mayor porcentaje de proteínas (Bogdanov et al., 2008; León, 2013). Entre las proteínas destacan las albúminas, globulinas, proteasas y los nucleoproteídos (Cavia, 2002).

Los aminoácidos libres están presentes en torno a $100 \mathrm{mg} / 100 \mathrm{~g}$ materia seca, siendo la prolina (procedente de las abejas) el 50-85\% de esta fracción aminoacídica (Belitz \& Grosch, 1997). Otros aminoácidos presentes en la miel son lisina, metionina, histidina, arginina, ácido aspártico, triptófano, serina, ácido glutámico, fenilalanina, valina, isoleucina, tirosina, tripsina y treonina (Crane, 1975; Fattori, 2004).

Las enzimas tienen origen vegetal (del néctar) y animal (del tracto intestinal de las abejas). Aunque son componentes minoritarios en la miel, juegan un papel importante al ser las encargadas de transformar los azúcares del néctar o del mielato. Entre las enzimas más importantes se encuentran las diastasas o amilasas (procedentes tanto de la abeja como del néctar), que hidrolizan el almidón en glucosa. Sin embargo, no se sabe con certeza la función de estas enzimas en el proceso de formación de la miel, ya que el néctar no contiene almidón (White, 1978; Ropa, 2010; Visquert, 2015). Otras de las enzimas más importantes son las invertasas o sacarasas, las cuales hidrolizan la sacarosa del néctar en fructosa y glucosa. Estas enzimas son fundamentales en la formación de la miel, pero al ser inestables al calor, se deterioran con el tiempo. En menor medida ocurre lo mismo con las diastasas (Visquert, 2015). Ambas enzimas son indicadoras de la calidad de la miel, reflejando el envejecimiento o un excesivo calentamiento de la misma (Bogdanov, 2011). En la miel también están presentes las catalasas, las fosfatasas y las glucosidasas (Sáenz \& Gómez, 2000; Visquert, 2015). Estas últimas, provenientes de la glándula hipofaríngea de las abejas recolectoras, transforman la glucosa en ácido glucónico (antibacteriano y principal responsable de la acidez de la miel) (Ohashi et al., 1999). 


\section{Minerales}

El contenido en minerales de la miel es muy bajo, oscila entre 0.1 y $0.2 \%$, siendo el potasio el elemento mayoritario (80\%) (De Lorenzo, 2002), seguido por el cloro, azufre, sodio, calcio, fósforo, magnesio, manganeso, silicio, hierro y cobre (Belitz \& Grosch, 1997; Piana et al., 1988). Estos minerales proceden principalmente del suelo donde ha crecido la planta de la que proviene la miel, por lo que se presentan en forma de sales disueltas en el agua: pasan a la planta a través de las raíces y la savia hasta los nectarios, donde acaban siendo parte del néctar (Crane, 1990; Gómez, 2004). A pesar del bajo contenido de minerales de la miel, son importantes a nivel alimenticio, contribuyendo a su valor nutritivo (Cervera \& Cervera, 1994; Conti, 2000; Bogdanov et al., 2008; Vanhanen et al., 2011; Alqarni et al., 2014), ya que estos elementos traza tienen importantes funciones biológicas (Álvarez-Suárez et al., 2010). A su vez, la presencia de metales pesados tales como el plomo, el cadmio, el mercurio y el aluminio indican un mal procesamiento o contaminación de la miel (Bogdanov et al., 2007; Tuzen et al., 2007; Silici et al., 2008; Alqarni et al., 2014).

\section{Lípidos}

Los lípidos constituyen tan solo el $0.04 \%$ de la miel y provienen, principalmente, de las plantas y de los restos de cera. Entre los lípidos presentes en la miel se encuentran glicéridos, esteroles, fosfolípidos y ácidos grasos como el ácido láurico, el pentadecanoico, el palmítico y el oleico (Instituto Nacional de Farmacología y Bromatología, 1978; Sáenz \& Gómez, 2000).

\section{Vitaminas}

En la miel, las vitaminas, procedentes del polen y del néctar de las plantas, están presentes en cantidades muy pequeñas, no contribuyendo en gran medida al valor nutricional de la misma. Las vitaminas más abundantes son las hidrosolubles, siendo el ácido ascórbico (vitamina C) una de las vitaminas mayoritarias (Sáenz \& Gómez, 2000). En menor medida se encuentran las vitaminas del grupo B como la tiamina (B1), la riboflavina (B2), el ácido nicotínico, la piridoxina (B6), la cianocobalamina (B12) y el ácido pantoténico (Crane, 1975; Horn, 1996; Piana et al., 1989). Por último, también están presentes, en menor proporción, las vitaminas A, K y D (De Lorenzo et al., 2002; Fernández-Uriel, 2011).

\section{Compuestos volátiles}

Los compuestos volátiles, además de los azúcares y los ácidos, contribuyen al aroma y sabor de la miel (De la fuente et al., 2007; Kadar et al., 2011; Juan-Borrás et al., 2014; Juan-Borrás, 2016; Tanleque-Alberto et al., 2019). Aproximadamente 500 compuestos volátiles han sido identificados en diferentes tipos de miel, siendo mayoritariamente 
compuestos carbonílicos, alcoholes y ésteres. Entre los carbonílicos destacan: formaldehído, acetaldehído, propionaldehído, isobutiraldehído, isovalerialdehído, metacroleína y acetona; y entre los alcoholes: isopropanol, etanol, 2-butanol, npropanol, 3-pentanol, isobutanol, alcohol bencílico y 2-metil 1-butanol. Los ésteres más destacados son el metilformiato y el etilformiato. En general, estos compuestos son muy lábiles y su concentración se puede alterar por un excesivo recalentamiento o a una inadecuada conservación de las mieles (Sáenz \& Gómez, 2000; Visquert, 2015).

\section{Polifenoles}

Los polifenoles son compuestos orgánicos que poseen uno o más anillos aromáticos y grupos hidroxilos unidos a él (Bogdanov et al., 2004). Provienen del néctar o de secreciones de las plantas, por ello su estudio puede ser útil para la clasificación botánica de las mieles (Escriche et al., 2014; Tanleque-Alberto \& Escriche, 2020). Principalmente se trata de flavonoides como flavonas, flavonoles, flavanonas, antocianidinas, isoflavonas y chalconas, y ácidos fenólicos, como el ácido benzoico y el ácido cinámico (Juan, 2001). Aunque su presencia en la miel es muy baja, encontrándose de forma más abundante en las mieles oscuras (Estevinho et al., 2008; Ferreira et al., 2009; Juszczak et al., 2009), son compuestos importantes ya que contribuyen en sus propiedades antioxidantes (Gheldof \& Engeseth, 2002; Bogdanov et al., 2008; Oroian \& Escriche, 2015; Juan-Borrás et al., 2017; Tanleque-Alberto \& Escriche, 2020),

\section{Pigmentos}

Los pigmentos son escasos en la miel pero importantes, ya que influyen decisivamente en su color, una de las características comerciales más importante por la relación que tiene con el origen botánico (Visquert et al., 2014; Visquert, 2015). Hay dos tipos de pigmentos: liposolubles, como los carotenoides, e hidrosolubles, como ciertos compuestos polifenólicos cuya oxidación genera colores oscuros. Es por ello que las mieles claras contienen mayoritariamente pigmentos liposolubles y viceversa (DíazMoreno, 2009).

\subsection{Autenticidad de la miel}

Las actividades fraudulentas que se producen en el sector apícola son favorecidas especialmente por la internacionalización de los mercados. En este contexto, la autenticidad de la miel, tanto en lo referente al origen botánico y geográfico como a su adulteración por adición de jarabes, es un tema de vital importancia en la Unión Europea. Esta inquietud se enmarca en el área de la "Seguridad y Calidad alimentaria» y, hoy en día, se considera uno de los retos prioritarios de la Unión Europea y del Plan Estatal de investigación científica. 


\subsubsection{Autentificación del origen botánico y geográfico de la miel}

Las mieles con mayor valor en el mercado son las monoflorales debido a que su producción requiere más dedicación por parte del apicultor. Conseguir que la miel proceda mayoritariamente de una especie vegetal determinada es complicado, ya que las abejas pecorean en diferentes especies botánicas (Juan-Borrás, 2016). Como anteriormente se ha comentado, el apicultor debe seleccionar la flora en la que ubica las colmenas. Además, debe realizar adecuadamente el corte y acopio de la miel cosechada sin mezclar floraciones.

En países como Italia, Francia y España, gracias a que el consumidor especialmente aprecia las mieles monoflorales, casi la mitad de la miel que se comercializa tiene una denominación botánica (Juan-Borrás, 2016). Según las normas establecidas por el Codex Alimentarius (2001), se pueden utilizar denominaciones botánicas específicas para las mieles (miel de girasol, miel de romero, miel de eucalipto, etc.), siempre y cuando éstas procedan del origen indicado, a partir de fuentes botánicas concretas y tengan las correspondientes características fisicoquímicas, organolépticas y microscópicas (Persano-Oddo \& Bogdanov, 2004). Sin embargo, aunque hay algunos límites comerciales (especialmente relacionados con el contenido polínico) para la denominación de miel de flores y mieles de mielada, todavía no hay establecidos criterios legales. Esto está ocasionando que ciertos laboratorios europeos y algunos autores hayan establecido unos límites propios para clasificar la mieles atendiendo a su monofloralidad (Sáenz \& Gómez, 2000; Gómez-Pajuelo, 2004). Esta situación dificulta el comercio internacional, ya que los criterios pueden variar entre países y entre transacciones comerciales.

El origen botánico de las mieles, además de atribuir diferentes propiedades y características organolépticas a la miel, puede dar información sobre su origen geográfico. Ciertas plantas están vinculadas a lugares concretos, o lo que es lo mismo, ciertos tipos de mieles pueden ser producidas en determinados países o incluso en específicas zonas geográficas. Cabe la posibilidad de que un tipo de miel pueda ser cosechada en varios países, pero con variaciones en sus pólenes acompañantes (flora autóctona); es entonces cuando la presencia de polen de una determinada planta en la miel indicará si ésta es de un país u otro (Juan-Borrás, 2016, Tanleque-Alberto et al., 2019).

\subsubsection{La adulteración de la miel por adición de jarabes}

La Directiva Europea 2001/110/CE define la miel como una "sustancia natural" en la que "no deberá añadirse ningún ingrediente alimentario, incluidos los aditivos alimentarios, ni ninguna otra sustancia aparte de miel". También indica que "no se podrá retirar de la miel el polen ni ninguno de sus componentes específicos, excepto cuando resulte inevitable en el proceso de eliminación de materia orgánica o 
inorgánica ajena a la miel". Por ello, realizar cualquiera de estas actividades se considera como fraude. Además, según el Código Alimentario Español, se define como adulterado "todo alimento al que se haya adicionado o sustraído cualquier sustancia para variar su composición, peso o volumen, con fines fraudulentos o para encubrir o corregir cualquier defecto debido a ser de inferior calidad o a tener ésta alterada" (Decreto 2484/1967). Por ello, cuando un alimento contiene un ingrediente que no está identificado en la etiqueta, legalmente se considera adulterado.

La miel se encuentra entre los alimentos con mayor riesgo de sufrir fraude alimentario junto con el aceite de oliva, el pescado, los alimentos ecológicos, la leche, los cereales, el jarabe de arce, el café, el té, las especias, el vino y los zumos de frutas (Parlamento Europeo, 2013). Esto es debido fundamentalmente a que se trata de un edulcorante con un precio superior al resto, con un alto valor comercial, nutricional y con un amplio rango de usos en la industria alimentaria (Qiu et al., 1999).

La miel adulterada apareció en el mercado mundial en la década de 1970, debido al desarrollo industrial de los jarabes vegetales (Cordella et al., 2002), pero es ahora cuando, gracias al rápido crecimiento en la producción de miel, ha aumentado la preocupación por su adulteración (Wang et al., 2015).

Antiguamente, la práctica de la adulteración era simple, adicionando básicamente agua o azúcares, pero con el paso del tiempo se ha hecho más sofisticada con la adición de jarabes de maíz, trigo, agave o arroz. Estos jarabes se incorporan con unas características cada vez más similares en composición a la miel, lo que supone una gran dificultad para identificar su presencia (Naila et al., 2018).

Uno de los jarabes más utilizados en la adulteración de miel es el jarabe de arroz, ya que muchas de las mieles adulteradas proceden del mercado asiático, donde este producto es muy utilizado. Se trata de "mieles" más económicas, pero de peor calidad, que llegan al mercado nacional a través de importaciones a gran escala procedentes de China (White, 2000; Bogdanov \& Martin, 2002; Chen et al., 2011).

Otro tipo de adulteración de la miel es la que se produce como consecuencia de malas prácticas apícolas, en muchas ocasiones por desconocimiento de los propios apicultores. Se origina cuando el apicultor, en invierno por falta de floración o al inicio de la floración para revitalizar la colmena, adiciona jarabes azucarados a la colmena para alimentar a las abejas (Wang et al., 2014). Se trata de adulteración siempre y cuando el apicultor recoja la "pseudomiel" que hacen las abejas con estos jarabes. El producto así obtenido no se considera miel y por lo tanto es un fraude su comercialización. Otra causa importante puede ser la extracción prematura de la miel por parte del apicultor, antes de que ésta esté madura. La miel debe ser recolectada en el momento adecuado de maduración, ya que si se hace antes de tiempo el contenido de agua puede sobrepasar el $25 \%$. Este tipo de fraudes ha sido observado 
en mieles procedentes de diferentes países, pero mayoritariamente de China (Bogdanov \& Martin, 2002).

Cualquiera de estas adulteraciones ocasiona importantes beneficios económicos para los que defraudan, ya sea por un mayor rendimiento en la producción o por la adición de jarabes azucarados que son más baratos que el producto natural. Esto causa competencia desleal e importantes pérdidas económicas para aquellos comercializadores del sector que cumplan con las normas establecidas (Sivakesava \& Irudayaraj, 2002).

El sector apícola necesita aumentar su nivel de competitividad en un mercado cada vez más amenazado por importaciones masivas procedentes de países terceros, en ocasiones de dudosa calidad. Esta situación está generando que las grandes cadenas de distribución nacional e internacional exijan a los apicultores, comerciantes y envasadores, precios incluso inferiores al propio valor de mercado. Esto ha desembocado en un incremento de las prácticas fraudulentas y en competencia desleal para aquellas empresas que quieran ofrecer a sus clientes un producto que cumpla con los requisitos de calidad y seguridad que ellos esperan y la legislación exige. La situación generada está afectando a toda la cadena alimentaria, desde los productores hasta los consumidores, al abarcar diferentes aspectos: 1. Salud pública, ya que la presencia en un alimento de componentes no declarados puede provocar intoxicaciones o alergias en personas sensibles afectando tanto a los consumidores como a las administraciones (Asensio et al., 2008); 2. Legislativo, por incumplimiento de la información que aparece en la etiqueta provocando un fraude y 3 . Económico, al producirse una competencia desleal, lo que puede provocar una desestabilización de los mercados (Cordella et al., 2003). Por todo ello, es necesario que se establezcan medidas legislativas más estrictas para controlar todas las etapas de la cadena alimentaria y asegurar que las materias primas e ingredientes utilizados en la elaboración de cualquier alimento cumplan con los estándares de calidad y autenticidad requeridos para ellos. Es tanta la preocupación por la adulteración de la miel, que entre los factores de calidad propuestos por el Codex Alimentarius FAO/OMS (2001), se encuentra la autenticidad, además de la higiene y la frescura.

En la actualidad, para productores y autoridades reguladoras es una prioridad garantizar la autenticidad y pureza de la miel, ya que las alertas alimentarias vienen en los últimos años reflejando esta problemática (tabla 1.1) (FDA, 2019). 
Tabla 1.1. Alertas relativas a mieles adulteradas en diferentes países (FDA, 2020).

\begin{tabular}{ll}
\hline \multicolumn{1}{c}{ Origen } & Fecha de publicación \\
\hline España & 23 Mayo 2019 \\
El Salvador & 22 Octubre 2018 \\
El Salvador & 22 Octubre 2018 \\
México & 14 Agosto 2018 \\
Turquía & 30 Marzo 2013 \\
Arabia Saudí & 6 Febrero 2013 \\
Malasia & 2 Octubre 2012 \\
Vietnam & 12 Septiembre 2012 \\
Nueva Zelanda & 12 Junio 2012 \\
Turquía & 3 Octubre 2011 \\
\hline
\end{tabular}

En este sentido, la Comisión Europea está fomentando el desarrollo de métodos analíticos que complementen o sustituyan a los existentes (Directiva Europea 2001/110/EC).

\subsection{Métodos para verificar la autenticidad de la miel}

La tendencia en los métodos analíticos para detectar y cuantificar la adulteración de la miel se está dirigiendo hacia la búsqueda de técnicas fáciles, baratas y rápidas, que permitan a la industria garantizar su seguridad, calidad y autenticidad sin tener que realizar grandes inversiones económicas. Para ello, es necesario avanzar en el desarrollo de nuevas metodologías innovadoras con la mayor automatización posible. Estas técnicas no necesariamente deben basarse en la identificación de un compuesto determinado, sino más bien en la recogida de un conjunto elevado de datos que se relacionen con ciertas características de las mieles.

En este apartado se ofrece una descripción general de los métodos tradicionales y los actuales utilizados para verificar la autenticidad de la miel. Hasta el momento ninguna de estas metodologías resulta concluyente en sí misma, por lo que se necesita realizar una batería de análisis para la identificación de cada tipo de adulterante (jarabe de arroz, trigo, maíz, etc.). Además, estos métodos deben ser llevados a cabo por personal experto en laboratorios especializados, lo que genera un coste muy elevado para la industria. Por ello, es necesario continuar con la búsqueda de técnicas novedosa que permitan una verificación fácil y rápida de la miel adulterada evitando de esta manera su incorporación a la cadena alimentaria. Por ello, algunos métodos emergentes en esta línea están siendo motivo de estudio en la actualidad. 


\subsubsection{Métodos clásicos}

\subsubsection{Métodos clásicos en uso}

\section{Análisis melisopalinológico}

La miel contiene una determinada cantidad de polen $\mathrm{y} / \mathrm{o}$ elementos de mielada, procedentes de las diferentes especies florales a las que la abeja acude durante la recolección del néctar y/o secreciones azucaradas. Estas partículas quedan adheridas al cuerpo de la abeja, y transportadas hasta el panal. Por ello, el análisis melisopalinológico, o análisis polínico, proporciona una huella digital de la procedencia botánica de una miel, así como de la zona geográfica en la que ha sido cosechada (Persano-Oddo \& Bogdanov, 2004). El análisis melisopalinológico se realiza mediante el reconocimiento microscópico de la morfología de los granos de polen/elementos de mielada de las diferentes especies botánicas, junto a la frecuencia de aparición de cada una de ellas.

Para poder definir una miel como monofloral, el contenido de polen de la especie vegetal dominante debe $s e r \geq 45 \%$. Como excepción cabría destacar las mieles en las que el polen puede estar supra-representado como la miel de castaño (75\%) o eucalipto (70\%) (Vieitez, 1951; Terradillos, 1988; Aira et al., 1990; Seijo et al., 1992a; Seijo et al., 1992b; Jato et al., 1992; Seijo, 1994; Seijo \& Jato, 1998; Seijo et al., 2001; Seijo \& Jato, 2001; Orantes et al., 2018), y aquellas en las que el polen puede estar infra-representado, como la miel de azahar (15\%) o romero (12\%) (Celis \& Díez, 1995; Sáenz \& Gómez, 2000; Rodríguez, 2015; Orantes et al., 2018). La mayor dificultad de este análisis se haya en la correcta identificación del polen y posterior interpretación de los resultados, así como en la discriminación de las especies melíferas y/o nectaríferas. Por ello, los técnicos encargados de este análisis deben tener una amplia experiencia en el reconocimiento de la morfología y otros aspectos de los pólenes procedentes de las diferentes especies botánicas (Juan-Borrás, 2016).

No existe un método oficial para llevar a cabo la identificación polínica, aunque sí que hay diferentes protocolos recomendados. Hoy en día, el método establecido en la mayoría de los laboratorios europeos es el elaborado por la International Commission for Bee Botany en 1978 (Louveaux et al., 1978). Esta metodología fue implementada y validada posteriormente por Von Der Ohe et al. en 2004, probando la consistencia del método en un ensayo interlaboratorio en el que participaron nueve países europeos.

La relación entre la cantidad de néctar utilizado para producir la miel y la proporción de pólenes en el sedimento polínico de ésta depende, en gran medida, de una serie de factores (Del Baño-Breis, 2000): 
- Factor primario: el aporte procedente de la flor en la que pecorea la abeja. Los granos de polen caen en el néctar de la flor, el cual es succionado por las abejas. Este fenómeno es influenciado por diferentes factores como la arquitectura floral o la distancia entre la fuente nectarífera y la colmena.

- Factor secundario: el aporte procedente del microambiente que hay en el interior de la colmena. Los granos de polen sedimentan en la miel debido a que éstos entran en la colmena por la piquera (por corrientes de aire o por la propia abeja).

- Factor terciario: el aporte procedente del modo de extracción de la miel del panal. Dependiendo de la manera en la que se extrae la miel, la cantidad de polen en la misma será mayor o menor. En el caso de la extracción por prensado, este aporte es importante, ya que las celdillas que contienen polen son también prensadas y su contenido pasa a formar parte del producto final.

La eliminación parcial o total del polen de la miel está específicamente prohibida y, además, la nueva Directiva 2014/63/UE indica que "el polen entra en la colmena como resultado de la actividad de las abejas y está presente en la miel de forma natural". Aunque es un fraude, en ocasiones la miel se somete a ultrafiltrado.

Para obtener miel filtrada, ésta es diluida normalmente con agua, se calienta y pasa a través de unos filtros de malla muy pequeña aplicando altas presiones $y$, finalmente, se elimina el exceso de humedad. En esta "miel sin polen" es imposible identificar su fuente botánica/geográfica, por lo que se utiliza fraudulentamente para mezclar con miel convencional (Schneider, 2011).

\section{Análisis sensorial}

La aceptación de un producto alimentario por el consumidor y la decisión de volver a comprarlo depende en gran medida de su calidad sensorial, por ello este factor es de vital importancia para productores y envasadores de miel. Se trata de un parámetro subjetivo, en el que intervienen sensaciones visuales, táctiles, olfativas y gustativas, pero que puede ser objetivo cuando se lleva a cabo por paneles de expertos entrenados y cualificados capaces de reconocer y diferenciar tipos de miel (DíazMoreno, 2009).

Por ello, el análisis sensorial aporta información para conocer el origen botánico/geográfico de una miel, además de permitir identificar y detectar algunos defectos de la misma, como la fermentación y los olores/sabores extraños. Si la finalidad es determinar su procedencia botánica, y obtener una correcta clasificación, es necesario que el técnico conozca las características organolépticas que derivan de las diferentes variedades de miel. Para facilitar esta tarea, el grupo de trabajo de la IHC (International Honey Commision) creó una rueda de atributos sensoriales característicos de la miel (odour and aroma wheel for honey) (figura 1.5), que 
proporciona una herramienta muy útil para la definición sensorial de las mieles (Piana et al., 2004).

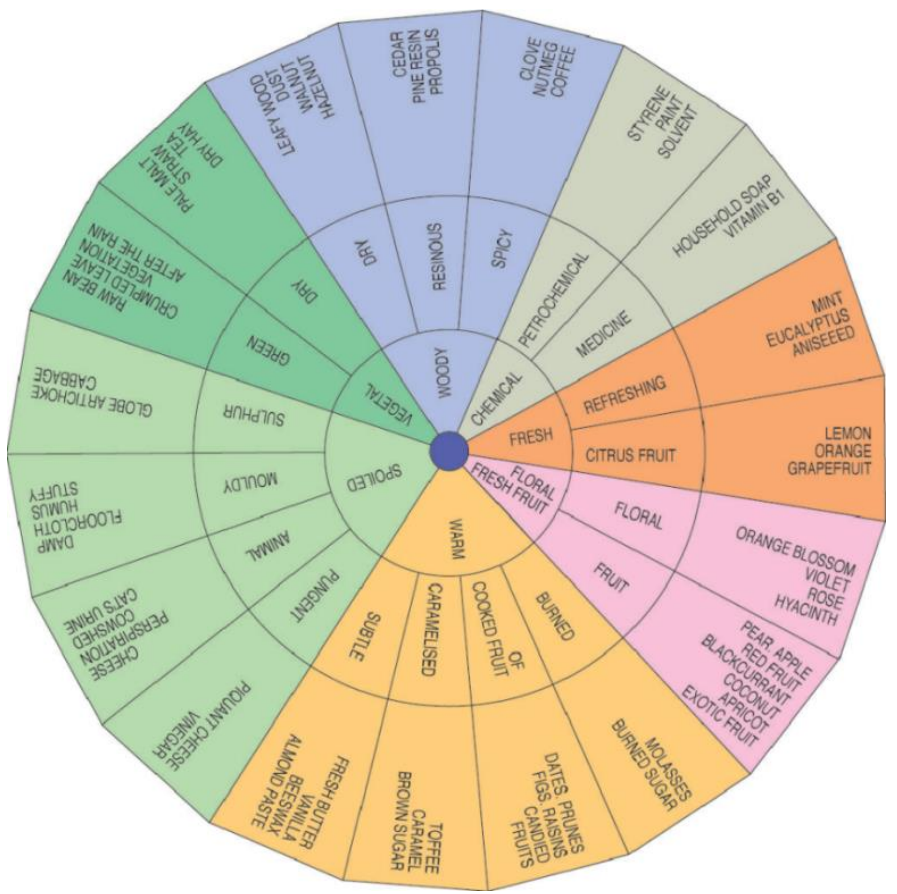

Figura 1.5. Rueda de olor y aroma de la miel (International Honey Commision, 2001).

\section{Análisis físico-químicos}

Los análisis físico-químicos que se realizan en la miel (BOE 145/1986) determinan ciertas propiedades que complementan el proceso de reconocimiento del origen botánico/geográfico. Los niveles de algunas características físico-químicas son específicas de determinados tipos de miel y, por lo tanto, pueden ayudar en su clasificación (Rodríguez, 2015).

\section{- Conductividad eléctrica}

Es la propiedad que tiene la miel de permitir el paso de corriente eléctrica. Permite distinguir con facilidad entre mieles gracias a su correlación, principalmente, con el contenido de sales minerales $y$, en menor medida, con ácidos orgánicos, iones inorgánicos, macromoléculas de proteínas, granos de polen, esporas y en algunos casos mohos (Sáenz \& Gómez, 2000; Persano-Oddo \& Piro, 2004). La medida de la conductividad se realiza mediante un conductímetro a $20{ }^{\circ} \mathrm{C}$ y su resultado se expresa en $\mathrm{mS} / \mathrm{cm}$ (BOE 145/1986). En mieles florales su valor se encuentra entre 0.1-0.7 mS/cm, mientras que las mieles de mielada pueden llegar a valores superiores a $1 \mathrm{mS} / \mathrm{cm}$ (Sáenz \& Gómez, 2000). Según la legislación, $0.8 \mathrm{mS} / \mathrm{cm}$ es el límite máximo para las primeras y el límite mínimo para las segundas. La única excepción es la miel de madroño, eucalipto, tilo, brezo y árbol de té para las no se indica ningún valor (Real Decreto 1049/2003). 
La conductividad se puede relacionar con el color de la miel, siendo mayor en las mieles de color oscuro (brezo, castaño, mielada, aguacate) y menor en las mieles de colores más claros (romero, azahar, naranjo) (Rodríguez, 2015; Visquert, 2014).

- Color

Es un parámetro muy importante para la clasificación de mieles monoflorales. Es la propiedad física percibida de manera más inmediata y es muy útil a la hora de identificar tipos de mieles. El color de las mieles puede variar desde blanco agua, pasando por tonos ámbar, hasta casi negro (figura 1.6). Algunas mieles monoflorales presentan tonalidades típicas que las pueden diferenciar de otras mieles. Es el caso de la miel de girasol, que tiene un color amarillo brillante, o la miel de tomillo o brezo, que tienen un color verdoso o rojizo (Juan-Borrás, 2016). Como anteriormente se ha comentado, el color viene influenciado por la presencia de pigmentos (carotenos y xantofilas) localizados en el néctar de las flores, y de compuestos fenólicos, como los flavonoides (Huidobro et al., 1984).

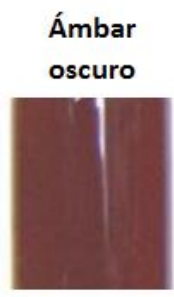

$>114$

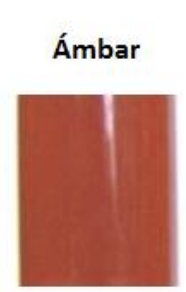

86-114

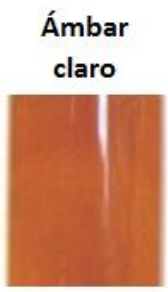

51-85

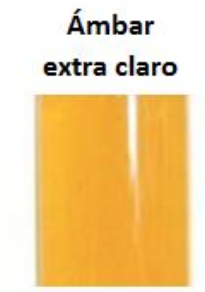

35-50

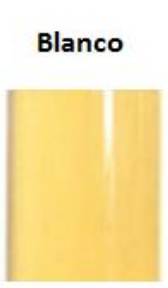

18-34

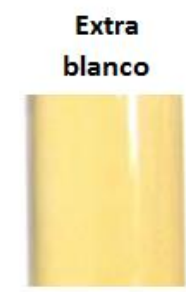

9-17

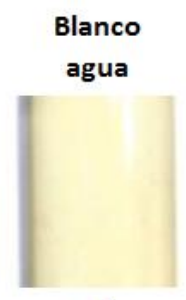

$<8$

Figura 1.6. Escala Pfund de color de la miel (León, 2013).

El colorímetro PFund es el método más extensamente utilizado para medir el color y se basa en la comparación óptica de la miel en una escala de color (figura 1.6). Otras técnicas que se pueden utilizar son las que miden la reflectancia o transmitancia de la muestra; son los equipos conocidos como espectrofotómetros o colorímetros triestímulos (espacios cromáticos CIELAB) (Juan-Borrás, 2016).

- $p H$

El $\mathrm{pH}$, medido con pH-metro, determina el grado de alcalinidad o acidez de la miel, la cual viene dada por la mayor o menor presencia de ácidos orgánicos y aminoácidos. La miel tiene un valor de pH comprendido entre 3.5 y 6.5. En general, valores de $\mathrm{pH}$ inferiores a 4 corresponden a mieles de néctar y mayores a los de mielatos (Bogdanov, 2011).

\subsubsection{Otros métodos clásicos}

Además de los anteriormente comentados, otros métodos han sido propuestos por muchos autores para intentar resolver el problema de la autentificación de las mieles, 
pero, a día de hoy, no están consolidados como técnicas aplicables para este fin. Entre ellos, cabría mencionar el análisis de compuestos fenólicos, aminoácidos, proteínas, minerales y oligoelementos, ácidos orgánicos y vitaminas.

\section{Compuestos fenólicos}

Los compuestos fenólicos son metabolitos secundarios de los vegetales, necesarios para el desarrollo de la planta y para la defensa de la misma frente a infecciones por microorganismos. La miel, al proceder de las plantas, contiene alguno de estos compuestos presentes en ellas (Tomás-Barberán et al., 1994). Su identificación en la miel tuvo una gran importancia al reconocerles su papel como marcadores objetivos del origen floral/geográfico (Bogdanov, 1989; Tomás-Barberán et al., 2001). En los últimos años varios estudios han corroborado esta afirmación demostrando que el análisis de flavonoides es de gran utilidad para determinar el origen botánico/geográfico y para la caracterización de mieles de distintos países: España (Escriche et al., 2011; Escuredo et al., 2012; Escriche et al., 2014), Mozambique (Tanleque-Alberto \& Escriche, 2020), Burkina Faso (Meda et al., 2005), Italia (Blasa et al., 2006; Pichichero et al., 2009), Cuba (Álvarez -Suárez et al., 2012), Portugal (Estevinho et al., 2008), etc.

Entre los métodos más usados para el análisis de flavonoides destaca: HPLC-UV (Tomás-Barberán et al., 2001; Escriche et al., 2011; Escriche et al., 2014), HPLC-MS (Gheldof et al., 2002; Álvarez -Suárez et al., 2012), la electroforesis capilar (ArráezRomán et al., 2006; Herrero-Martínez et al., 2007) y la cromatografía de gases (Berahia et al., 1993).

\section{Aminoácidos}

El análisis de los aminoácidos presentes en una miel puede ayudar a la identificación de su origen botánico y geográfico. Pirini et al. en 1992 aplicando GC-MS afirmaron que los perfiles de aminoácidos podían relacionarse con el origen botánico de una miel, mientras que las relaciones entre las concentraciones de diversos aminoácidos podían determinar el geográfico. Mieles de diferente origen botánico (acacia, cítrico, castaño, rododendro, romero y tilo) contenían diferentes aminoácidos como arginina, triptófano y cistina, que los hacía característicos de esas mieles. En cambio, si se estudiaba el perfil general de los mismos podía diferenciar también el origen geográfico de las mieles (Cometto et al., 2003; Iglesias et al., 2004; Senyuva et al., 2009).

Por otra parte, el aminoácido prolina (que representa un $50 \%$ de estos compuestos en la miel), se usa como índice de calidad referido a la maduración de la miel y de posibles adulteraciones, ya que, si las abejas han sido alimentadas con azúcar comercial o si la miel ha sido recogida antes de tiempo, es decir, inmadura, el contenido en prolina será 
anormalmente bajo (White \& Rudyj, 1978). Los aminoácidos libres se suelen determinar por cromatografía líquida y, con menor frecuencia, por cromatografía de gases (Bogdanov et al., 2004).

\section{Proteínas}

En el caso del contenido en proteínas, las mieles que provengan de plantas con mucha cantidad de polen tendrán mayor porcentaje proteico, ya que el polen de las plantas está compuesto principalmente por proteínas. Esto ocurre en las mieles de castaño o viborera (León, 2013). Un análisis de proteínas por electroforesis de gel de poliacrilamidas junto con la aplicación de un análisis discriminante permitió clasificar mieles gallegas (Rodríguez-Otero et al., 1990). Sin embargo, el estudio concluyó en que el análisis del perfil de aminoácidos proporcionaba una información más apropiada.

\section{Minerales y oligoelementos}

El contenido de minerales y oligoelementos de la miel se ve afectado en gran medida por la contaminación ambiental, por lo que podría ser un método orientativo para la detección del origen geográfico de la miel (Sevimli et al., 1992; Rodríguez-Otero et al., 1995; Anklam, 1998). Por el contrario, no se ha podido observar una diferenciación clara entre mieles del mismo origen floral según su contenido en minerales (Latorre et al., 1999; De Lorenzo, 2002). Sin embargo, sí se ha observado que las mieles oscuras, y particularmente los mielatos, son más ricos en elementos minerales (GonzálezParamás et al., 2000; González-Miret et al., 2005; Pohl, 2009).

Tradicionalmente el contenido de cenizas de una miel se ha empleado para medir el contenido en minerales, pero, en la actualidad se prefiere medir la conductividad eléctrica de la miel disuelta en agua, debido a la rapidez, precisión y bajo coste de esta técnica (Acquarone et al., 2007). Para la identificación individual de los diferentes oligoelementos, las técnicas más utilizadas son: la espectroscopía de absorción atómica con llama (FAAS) o con atomizadores electrotérmicos (ETAAS), así como la emisión de plasma de inducción con detección óptica (ICP-OES) o de masas (ICP-MS) (Pohl, 2009).

\section{Ácidos orgánicos}

El estudio del perfil de ácidos orgánicos, junto con la posterior aplicación de técnicas estadísticas, puede dar información sobre mieles de diferentes fuentes. Es el caso de la miel de rewarewa de Nueva Zelanda (Knightea excelsa), en la que se han identificado treinta y dos ácidos dicarboxílicos alifáticos mediante GC, proponiéndose como marcadores dos de ellos (ácido 2-metoxibutanodioico y ácido 4-hidroxi-3-metil-trans2-pentenodioico) (Wilkins \& Lu, 1995). 


\section{Vitaminas}

El contenido en vitaminas de la miel es muy bajo, pero su concentración varía mucho dependiendo del origen floral (Bogdanov et al., 2008). Por ejemplo, las mieles de menta de agua (Mentha aquatica) y tomillo (Thymus spp.) contienen una elevada concentración de vitamina C (Griebel \& Hess, 1940; Ortiz Valbuena, 1992). Por el contrario, en otras variedades de mieles esta vitamina es muy baja o inexistente (Gheldof et al., 2002).

\subsubsection{Métodos actuales}

\section{Resonancia magnética nuclear (RMN)}

La resonancia magnética nuclear, hoy en día, se está consolidando como un método de referencia para identificar una posible adulteración de la miel. Se basa en evaluar el comportamiento de ciertos núcleos atómicos en presencia de un campo magnético externo. Esta técnica proporciona información detallada sobre la estructura molecular de la muestra, pudiendo identificar y cuantificar de forma simultánea una gran cantidad de compuestos, incluso en matrices complejas, como es el caso de la miel. Se trata de una técnica no destructiva y muy sensible que ha ido ganando una amplia aceptación en el campo alimentario, y de forma muy arraigada para el análisis de miel.

El RMN permite obtener un perfil completo de la composición intrínseca del producto. Cada miel es diferente en su composición química, lo que le otorga un carácter organoléptico único e individual. Esto permite que dicha técnica pueda determinar el origen botánico y geográfico de diferentes mieles (Boffo et al., 2012; Spiteri et al., 2015), e incluso cuantificar determinados compuestos añadidos a la miel como azúcar de caña refinada, de remolacha, de arroz, jarabe de maíz con alto contenido de fructosa o jarabe de maltosa (Cotte et al., 2003; Bertelli et al., 2010; Boffo et al., 2012; Davide \& Massimo, 2010; Ohmenhaeuser et al., 2013; De Oliveira et al., 2014; Ribeiro et al., 2014), por comparación de los resultados obtenidos con una base de datos de muestras de mieles con cobertura mundial.

Análisis de la relación de isótopos de carbono estable (SCIRA)

SCIRA determina la relación de isótopos de carbono ${ }^{13} \mathrm{C} /{ }^{12} \mathrm{C}$ para detectar principalmente adulteraciones con azúcares $\mathrm{C} 4$ como el jarabe de maíz y el jarabe de azúcar de caña. Este método compara la proporción de isótopos de carbono de una miel con los de su fracción proteica. Esta proporción varía en función de la planta (por el tipo de fotosíntesis que realiza) y su cálculo se realiza mediante la siguiente ecuación: ${ }^{13} \mathrm{C} /{ }^{12} \mathrm{C}=\mathrm{d}^{13} \mathrm{C}$ (\%o). Este método puede detectar una adición de azúcares superior al 7\% (Zábrodská \& Vorlová, 2015). Esta técnica ha sido utilizada en diversos estudios demostrando ser efectivo para la identificación y cuantificación de la 
adulteración en la miel (Padovan et al., 2003; Cabanero et al., 2006; Cotte et al., 2007; Elfleing \& Raezke, 2008; Souza-Kruliski et al., 2010; Fei et al., 2011; Adnan et al., 2012; Simsek et al., 2012; Tosun, 2013) e incluso para la identificación del origen botánico y geográfico de la miel (Kropf et al., 2010; Bontempo et al., 2017).

\section{Actividad enzimática}

La actividad enzimática es un parámetro indicador de la frescura de la miel, ya que algunas de las enzimas presentes en la ella, como las diastasas, descienden con el calentamiento y tiempo de almacenamiento (Visquert, 2015). Sin embargo, este parámetro también se utiliza para la clasificación de mieles debido a que el contenido diastásico de las mieles difiere con el origen botánico (tabla 1.2) (Juán-Borrás, 2016). Además, es útil para detectar la adulteración de miel, bien por adición de jarabes de azúcares invertidos (HFCS) producidos enzimáticamente a partir de $\beta$-amilasa y $\psi$ amilasa, o bien por la adición de enzimas ( $\beta$-fructofuranosidasa), que compensan la disminución de actividad enzimática por la adición de estos jarabes (Fei et al. 2012; Zábrodská \& Vorlová, 2015). Por ello, un método útil para detectar estas adulteraciones se basa en la comparación de la actividad enzimática (diastasa) antes y después de que la miel pase por un tratamiento térmico. El calor destruye la diastasa, pero no las enzimas adicionadas, por lo que si después de este tratamiento se detecta actividad enzimática, ésta será debida a la presencia de enzimas resistentes adicionadas en la adulteración (Juan-Borrás, 2016).

Tabla 1.2. Contenido diastásico en diferentes mieles. Unidades expresadas como valores de la escala Schade (Juan-Borrás, 2016).

\begin{tabular}{lc}
\hline Origen botánico & Índice diastásico (ID) \\
\hline Azahar & 4.25 \\
Trébol & 5.73 \\
Pimienta & 13.2 \\
Milflores & 22.0 \\
Eucalipto & 24.0 \\
Trigo sarraceno & 36.8 \\
\hline
\end{tabular}

La medida de la actividad enzimática (diastasa) se puede realizar mediante 2 procedimientos: 1 . Método del BOE 145/1986 en el que se determina la velocidad de hidrólisis del almidón en una disolución de miel y se mide el punto final de la reacción por espectrofotometría a una absorbancia de 660nm, y 2. Método Phadebas, descrito por la IHC, basado en la medida de la hidrolización de un sustrato estandarizado ("pastillas Phadebas") por la acción de la enzima diastasa. En ambos procedimientos, la reacción producida da una solución azulada que, dependiendo de su intensidad, indicará la cantidad de enzima presente en la muestra de miel. La absorbancia medida es directamente proporcional a la actividad diastática de la muestra (Juan-Borrás, 2016). 


\section{Contenido en azúcares}

El contenido de azúcares de una miel está relacionado con la procedencia botánica (Juan-Borrás et al., 2014). Por ejemplo, la miel de néctar de flores y la miel de mielada tienen diferencias en su composición, siendo el mielato menos dulce debido a su menor contenido en monosacáridos y mayor en oligosacáridos como la melecitosa y la rafinosa (ausentes ambos en las mieles provenientes de néctar de flores) (Donner, 1977). La relación de los monosacáridos fructosa y glucosa (F/G) difiere entre variedades de miel: altos ratios de $F / G$ se identifican con mieles de acacia y castaño, y bajos ratios F/G con mieles de girasol, colza y diente de león (Persano-Oddo \& Piro, 2004).

La composición de azúcares en la miel también puede proporcionar información sobre su adulteración, ya que la miel se adultera mediante la adición de jarabes azucarados. Por ejemplo, es posible detectar jarabes de remolacha (Elflein \& Raezke, 2008), jarabes de almidón (Wang et al., 2015) o jarabes de maíz ricos en fructosa (HFCS) (Sivakesava \& Irudayaraj, 2001; Kelly et al, 2006; Ruíz-Matute et al. 2007; Morales et al. 2008; Megherbi et al. 2009).

El método oficial para determinar la composición glucídica de la miel se basa en la medida de los azúcares reductores y la sacarosa aparentes mediante el método de Fehling (BOE 145/1986). Sin embargo, hoy en día se aplican mayoritariamente técnicas cromatográficas por ser más precisas y rápidas. De esta manera se identifica cada sacárido individualmente y no en conjunto como ocurre con el método de Fehling (León, 2013).

Actualmente, los azúcares de la miel se suelen analizar por cromatografía líquida (HPLC) con detección de índice de refracción (IR), detección de la dispersión de luz (ELSD) o iónico (PAD). También se utiliza la cromatografía de gases con ionización de llama (FID). Ésta última presenta una mayor sensibilidad para detectar azúcares minoritarios, pero necesita una etapa previa de derivatización de la muestra, lo que la convierte en una metodología más compleja y no recomendable en análisis de rutina.

Otro método utilizado para la detección de azúcares, debido a su rapidez y facilidad en el análisis, son los kits enzimáticos, normalmente para fructosa, glucosa y sacarosa. No se trata de un método preciso, pero da una información rápida a los laboratorios de control de calidad de la miel.

\subsubsection{Métodos emergentes}

Debido a la problemática que plantean los métodos anteriormente descritos, recientemente se están proponiendo otras técnicas que, si bien están establecidas en otros ámbitos científicos, son totalmente novedosas en el contexto de la verificación 
de la autenticidad de una miel. Sin embargo, es todavía incierto y ambiguo el impacto que estas tecnologías novedosas tendrán en el futuro.

\section{Espectroscopía Raman}

La espectroscopía Raman es una técnica fotónica de alta resolución que puede aportar información química y estructural de cualquier compuesto orgánico permitiendo su identificación. Esto es debido a que un haz de luz monocromático incide sobre la muestra, dispersándose una parte de ella de forma inelástica, lo que genera un cambio de su frecuencia, que es característico de la naturaleza química y del estado físico de la muestra.

Esta técnica ha demostrado ser una herramienta simple, rápida y no destructiva, muy útil tanto para la diferenciación botánica de las mieles (Mignani et al., 2016; Oroian \& Ropciuc, 2018) como para la detección de miel adulterada por jarabes alimentarios (Paradkar \& Irudayaraj, 2002; Li et al. 2012; Ozbalci et al., 2013; Sugar \& Bour, 2016).

\section{Espectroscopía infrarroja con transformada de Fourier (F-TIR)}

La técnica de F-TIR ofrece información molecular de una muestra por efecto de su interacción con un haz de luz, en la longitud de onda de infrarrojo, mediante un espectro de absorbancia (o transmitancia). Esta metodología se suele utilizar en combinación con análisis multivariante, como componentes principales (PCA), para diferenciar entre grupos de muestras. Esta técnica ha sido empleada tanto para identificar el origen botánico y geográfico (Almeida-Muradiana et al., 2014) como para detectar la adulteración de la miel (Sivakesava \& Irudayaraj, 2001; Paradkar \& Irudayaraj, 2002; Kelly et al., 2006; Wang et al., 2010; Rios-Corripio et al., 2012, Subari et al., 2012; Se et al., 2018).

\section{Componentes volátiles}

El análisis de compuestos volátiles de las mieles se viene utilizando desde hace décadas para su caracterización botánica. Sin embargo, esta técnica hoy en día se contempla como una valiosa herramienta para garantizar la procedencia de las especies vegetales de las que proceden las mieles. El estudio del perfil aromático de las mieles, mediante el análisis de los componentes volátiles por GC-MS, es uno de los métodos más prometedores para la diferenciación de mieles en base a su monofloralidad (Verzera et al., 2001; Bogdanov et al., 2004; Escriche et al., 2009, Tanleque-Alberto et al., 2019), tanto si éstas proceden del néctar de las flores como de los mielatos de las secreciones de las plantas (Serra, 1988; Radovic et al, 2001; Alissandrakis, 2003; Serra-Bonvehí \& Ventura-Coll, 2003).

Es muy importante tener en cuenta tanto el procedimiento de aislamiento de los compuestos como el método de detección, ya que influyen significativamente en los 
compuestos que se obtienen (Bouseta et al., 1992; Radovic et al., 2001; Soria et al., 2003; Palá-Paúl et al., 2004; Sanz et al., 2004; Alissandrakis et al., 2005; De la Fuente, 2005; Cuevas-Glory et al., 2007; Castro-Vázquez et al., 2009; Montenegro et al., 2009; Manyi-Loh et al., 2011; Kadar et al., 2011; Plutowska et al., 2011; Juan-Borrás et al., 2014).

Recientes publicaciones reportan un gran número de compuestos identificados en diferentes tipos de miel, que son característicos de distintas fuentes florales y distintas procedencias (Serra, 1988; Anklam, 1998; Radovic et al., 2001; Verzera et al., 2001; Soria et al., 2002; Guyot-Declerck et al., 2002; Alissandrakis, 2003; Serra-Bonvehí \& Ventura-Coll, 2003; Alissandrakis et al., 2007; Escriche et al., 2009; Kaskoniene \& Venskutonis, 2010; Escriche et al., 2011; Castro-Vázquez et al., 2014; Juan-Borrás et al., 2014). Por ejemplo, la miel de azahar (Citrus spp.) se caracteriza por la presencia en ella del metilantranilato (MA). El MA es un compuesto volátil específico del néctar de la miel de cítricos, por lo que su presencia en la miel indica que las abejas han recogido el néctar de las flores de cítricos (Serra, 1988; Ferreres et al., 1994; White \& Bryant, 1996; Castro-Vázquez et al., 2007; Kadar et al., 2011). Por ello, el MA se usa como marcador en este tipo de mieles cuando el nivel de contenido en polen es muy bajo, lo cual ocurre con habitualidad (Sesta et al., 2008; Juan-Borrás et al., 2015). También se conocen otras sustancias aromáticas características de ciertas mieles como el formaldehído y acetaldehído en las mieles de colza y trébol, el deshidrovomifoliol en la miel de brezo y las dicetonas en la miel de eucalipto (Bouseta \& Collin, 1995).

\section{Calorimetría diferencial de barrido (DSC)}

La técnica de DSC permite determinar la cantidad de calor que absorbe o libera una sustancia cuando se mantiene a una temperatura determinada, o cuando se calienta o enfría a una velocidad constante en un determinado intervalo de temperaturas. Hoy en día es una técnica consolidada en el campo de la ciencia de materiales y de las sustancias alimentarias, debido a su elevado grado de sensibilidad, rápida velocidad de análisis, así como a la poca cantidad de muestra y poca preparación que requiere. Cada sustancia tiene su propia composición y características intrínsecas y por lo tanto, difiere en sus propiedades térmicas y termoquímicas (temperatura de transición vítrea, entalpía de fusión, entalpía de cristalización, etc.). A pesar de todo ello, son escasos los trabajos reportados en los que se propone esta técnica para el análisis de mieles y de sus adulterantes (Lupano, 1997; Cordella et al., 2002 y 2003). Por ello, para que en el contexto de la adulteración de la miel esta técnica pueda llegar a ser concluyente, es necesario seguir investigando el comportamiento térmico de las mieles tanto en lo que respecta a su procedencia botánica, geográfica así como el de los distintos jarabes que se pueden utilizar para su adulteración. 
Reacción en cadena de la polimerasa (PCR)

La reacción en cadena de la polimerasa se basa en la amplificación en miles de copias de un fragmento de ADN. Se encuentra entre las técnicas más prometedoras para la determinación de la calidad y la adulteración de los productos alimenticios como la carne (Kesme et al., 2012; Safdar et al., 2014; Chen et al., 2015) o los mariscos (Rasmussen et al., 2010; Rodríguez-Ramírez et al., 2011; Fernandes et al., 2017), ofreciendo resultados de alta especificidad y sensibilidad (Meira et al., 2017). En la miel, esta técnica ha sido utilizada para la identificación del origen botánico (Laube et al., 2010; Guertle et al., 2014; Soares et al., 2015); sin embargo, su idoneidad para detectar la adulteración de otros productos de origen animal pone de manifiesto que también puede ayudar a la detección de la miel adulterada.

\section{Lenguas electrónicas}

La lengua electrónica consiste en un sistema multisensor no específico que genera una huella digital de la muestra utilizando procedimientos matemáticos basados en la formación de "patrones de reconocimiento". Para el tratamiento de los datos generados por la lengua electrónica se requiere, además, del empleo de herramientas estadísticas multivariantes, entre las que destacan las redes neuronales artificiales (RNA), análisis por componentes principales (PCA), análisis discriminante lineal (LDA) y análisis de conglomerados (CA) (Campos et al., 2013).

Las lenguas electrónicas son equipos de bajo coste y de respuesta rápida, por ello se encuentran entre las técnicas analíticas más prometedoras. Este sistema ha sido utilizado ampliamente para clasificar alimentos líquidos (Veloso et al., 2016) y sólidos (Campos et al., 2010), así como para la detección de adulteraciones alimentarias (Bougrini et al., 2014). En el contexto de la miel, ha permitido diferenciar muestras según su origen botánico y geográfico (Días et al., 2008; Escriche et al., 2012; Tiwari et al., 2013; Bougrini et al., 2016; Juan- Borrás et al., 2017), además de discriminar mieles puras de mieles adulteradas (Zakaria et al., 2011; Cai et al., 2013; Bougrini et al., 2016; Ropciuc et al., 2017). Sin embargo, en la gran mayoría de los casos se aplicó una lengua electrónica con voltametría cíclica, no teniendo en cuenta la ventaja que sobre ésta ofrece la voltametría de pulsos, con una mayor resolución y sensibilidad (Bataller et al., 2013), siendo conveniente seguir investigando por esta vía.

\subsection{Bibliografía}

Acquarone, C., Buera, P., \& Elizalde, B. (2007). Pattern of pH and electrical conductivity upon honey dilution as a complementary tool for discriminating geographical origin of honeys. Food Chemistry, 101, 695-703. 
Adnan, S., Mine, B., \& Ahmet, C. G. (2012). 13C/12C pattern of honey from Turkey and determination of adulteration in commercially available honey samples using EAIRMS. Food Chemistry, 130, 1115-1121.

Aira, J. M., Ramil-Rego, P., \& Saa-Otero, M. P. (1990). Identificación polínica de Ericaceae en mieles gallegas. Acta Botánica Malacitana, 15, 27-32.

Al, M. L., Daniel, D., Moise, A., Bobis, O., Laslo, L., \& Bogdanov, S. (2009). Physicochemical and bioactive properties of different floral origin honeys from Romania. Food Chemistry, 112, 863-867.

Alissandrakis, E., Daferera, D., Tarantilis, P. A., Polissiou, M., \& Harizanis, P. C. (2003). Ultrasound-assisted extraction of volatile compounds from citrus flowers and citrus honey. Food Chemistry, 82, 575-582.

Alissandrakis, E., Tarantilis, P. A., Harizanis, P. C., \& Polissiou, M. (2005). Evaluation of four isolation techniques for honey aroma compounds. Journal of the Science of Food and Agriculture, 85, 91-97.

Alissandrakis, E., Tarantilis, P. A., Harizanis, P. C., \& Polissiou, M. (2007).Comparison of the Volatile Composition in Thyme Honeys from Several Origins in Greece. Journal of Agricultural and Food Chemistry, 55, 8152-8157.

Almeida-Muradiana, L. B., Sousa, R. J., Barth, O. M., \& Gallmann, P. (2014). Preliminary data on Brazilian monofloral honey from the northeast region using FT-IR ATR spectroscopic, palynological, and color analysis. Química Nova, 37, 716-719.

Alqarni, A. S., Owayss, A. A., Mahmoud, A. A., \& Hannan, M. A. (2014). Mineral content and physical properties of local and imported honeys in Saudi Arabia. Journal of Saudi Chemical Society, 18, 618-625.

Álvarez-Suárez, J. M., Tulipani, S., Romandini, S., Bertoli, E., \& Battino, M. (2010). Contribution of honey in nutrition and human health: a review. Mediterranean Journal of Nutrition and Metabolism, 3, 15-23.

Álvarez-Suárez, J. M., Giampieria, F., González-Paramás, A. M., Damianic, E., Astolfid, P., \& Martínez-Sanchez, G. (2012). Phenolics from monofloral honeys protect human erythrocyte membranes against oxidative damage. Food and Chemical Toxicology, 50, 1508-1516.

Álvarez-Suárez, J. M., Gasparrini, M., Forbes-Hernández, T. Y., Mazzoni, L., \& Giampieri, F. (2014). The Composition and Biological Activity of Honey: A Focus on Manuka Honey. Foods, 3, 420-432.

Anklam, E. (1998). A review of the analytical methods to determine the geographical and botanical origin of honey. Food Chemistry, 63, 549-562.

Arráez-Román, D., Gómez-Caravaca, A. M., Gómez-Romero, M., Segura-Carretero, A., \& Fernández-Gutierrez, A. (2006). Identification of phenolic compounds in 
rosemary honey using solid-phase extraction by capillary electrophoresiselectrospray ionization-mass spectrometry. Journal of Pharmaceutical and Biomedical Analysis, 41, 1648-1656.

Asensio, L., González, I., García, T., \& Martín, R. (2008). Determination of food authenticity by enzyme-linked immunosorbent assay (ELISA). Food Control, 19, 18.

Bataller, R., Campos, I., Alcañíz, M., Gil-Sánchez, L., García-Breijo, E., Martínez-Máñez, R., Pascual, L., Soto, J., \& Vivancos, J. L. (2013). A humid electronic nose based on pulse voltammetry: A proof-of-concept design. Sensors and Actuators B: Chemical, 186, 666-673.

Belitz H. D., \& Grosch W. (1997). Química de los Alimentos. Ed. Acribia. Zaragoza.

Belitz, H., Grosch, W., \& Schieberle, P. (2014). Food chemistry. Ed. Springer-Verlag. Berlín.

Berahia, T., Cerrati, C., Sabatier, S., \& Amiot, M. J. (1993). Gas chromatographymass spectrometry analysis of flavonoids I honey. Science des Aliments, 13, 15-24.

Bertelli, D., Lolli, M., Papotti, G., Bortolotti, L., Serra, G., \& Plessi, M. (2010). Detection of Honey Adulteration by Sugar Syrups Using One-Dimensional and TwoDimensional High- Resolution Nuclear Magnetic Resonance. Journal Agriculture and Food Chemistry, 58, 8495-8501.

Bertoncelj, J., Doberšek, U., Jamnik, M., \& Golob, T. (2007). Evaluation of the phenolic content, antioxidant activity and colour of Slovenian honey. Food Chemistry, 105, 822-828.

Biluca, F., Della-Betta, F., De Oliveira, G., Pereira, L., Gonzaga, L., Costa, A., \& Fett, R. (2014). 5-HMF and carbohydrates content in stingless bee honey by CE before and after thermal treatment. Food Chemistry, 159, 244-249.

Blasa, M., Candiracci, M., Accorsi, A., Piacentini, M. P., Albertini, M. C., \& Piatti, E. (2006). Raw Millerfiori honey is packed full of antioxidants. Food Chemistry, 97, 217-222.

Blog de apicultura. La tienda del apicultor. https://www.latiendadelapicultor.com/blog /que-extractor-de-miel-elegir-tipos-y-modelos/ Accessed 21/02/2020.

BOE 145/1986. Orden de 12 de junio de 1986 por la que se aprueban los métodos oficiales de análisis para la miel.

Boffo, E. F., Tavares, L. A., Tobias, A. C. T., Ferreira, M. M. C., \& Ferreira, A. G. (2012). Identification of components of Brazilian honey by $\mathrm{H}$ NMR and classification of its botanical origin by chemometric methods. LWT - Food Science and Technology, 49, 55-63. 
Bogdanov, S. (1989). Determination of pinocembrin in the honey by using HPLC. Journal of Apicultural Research, 28, 55-57.

Bogdanov S., Martin P. (2002). Honey Authenticity: a Review. http://www.beehexagon.net/files/file/fileE/Honey/AuthenticityRevue_Internet.pdf Accessed 28/02/2020.

Bogdanov, S., Ruoff, K., \& Persano-Oddo, L. (2004). Physico-chemical methods for the characterization of unifloral honeys: a review. Apidologie, 35, S4-S17.

Bogdanov, S., Haldimann, M., Luginbuhl, W., \& Gallmann, P. (2007). Minerals in honey: environmental, geographical and botanical aspects. Journal of Apicultural Research, 46, 269-275.

Bogdanov, S., Jurendic, T., Sieber, R., \& Gallmann, P. (2008). Honey for nutrition and health: a review. Journal of the American College of Nutrition, 27, 677-689.

Bogdanov S. (2011). The Honey Book. http://www.bee-hexagon.net/honey/ Accessed $15 / 03 / 2019$.

Bontempo, L., Camin, F., Ziller, L., Perini, M., Nicolini, G., \& Larcher, R. (2017). Isotopic and elemental composition of selected types of Italian honey. Measurement, 98, 283-289.

Bougrini, M., Tahri, K., Haddi, Z., Saidi, T., Bari, N. E., \& Bouchikhi, B. (2014). Detection of adulteration in argan oil by using an electronic nose and a voltammetric electronic tongue. Journal of Sensors, 10 pages.

Bougrini, M., Tahri, K., Saidi, T., Hassani, N. E. A. E.,Bouchikhi, B., \& Bari, N. E. (2016). Classification of Honey According to Geographical and Botanical Origins and Detection of Its Adulteration Using Voltammetric Electronic Tongue. Food Analytical Methods, 9, 2161-2173.

Bouseta, A., \& Collin, S. (1995). Optimized Likens-Nickerson methodology for quantifying honey flavors. Journal of Agricultural and Food chemistry, 43, 18901897.

Bouseta, A., Collins, S., \& Dufour, J. P. (1992). Characteristic aroma profiles of unifloral honeys obtained with dynamic headspace GC-MS system. Journal of Apicultural Research, 31, 96-109.

Buleo, R., M. (2012). Análisis y propuestas de mejora de una empresa dedicada a la producción y comercialización de miel ubicada en Minglanilla (Cuenca). Trabajo Final de Grado. Universidad Politécnica de Valencia.

Cabanero, A. I., Recio, J. L., \& Rupérez, M. (2006). Liquid chromatography coupled to isotope ratio mass spectrometry: A new perspective on honey adulteration detection. Journal of Agricultural and Food Chemistry, 54, 9719-9727. 
Cai, J., Wu, X., Yuan, L., Han, E., Zhou, L., \& Zhou, A. (2013). Determination of Chinese Angelica honey adulterated with rice syrup by an electrochemical sensor and chemometrics. Analytical Methods, 5, 2324-2328.

Campos, I., Masot, R., Alcañíz, M., Gil, L., Soto, J., Vivancos, J. L., Garcia-Breijo, E., Labrador, R. H., Barat, J. M., \& Martínez-Máñez, R. (2010). Accurate concentration determination of anions nitrate, nitrite and chloride in minced meat using voltammetric electronic tongue. Sensors and Actuators B: Chemical, $149,71-78$.

Campos, I., Bataller, R., Armero, R., Gandía, J. M., Soto, J., Martinez-Mañez, R., \& GilSánchez, L. (2013).Monitoring grape ripeness using a voltammetric electronic tongue. Food Research International, 54, 1369-1375.

Castro-Vázquez , L., Díaz-Maroto, M. C., \& Pérez-Coello, M. S. (2007). Aroma composition and new chemical markers of Spanish citrus honeys. Food Chemistry, 103, 601-606.

Castro-Vázquez, L., Díaz-Maroto, M. C., González-Viñas, M. A., \& Pérez-Coello, M. S. (2009). Differentiation on monofloral citrus, rosemary, eucalyptus, lavender, thyme and heather honeys based on volatile composition and sensory descriptive analysis. Food Chemistry, 112, 1022-1030.

Castro-Vázquez, L., León-Ruiz, V., Alañon, M. E., Pérez-Coello, M. S., \& González-Porto, A. V. (2014). Floral origin markers for authenticating Lavandin honey (Lavandula angustifolia $\mathrm{x}$ latifolia). Discrimination from Lavender honey (Lavandula latifolia). Food Control, 37, 362-370.

Cavia, M. (2002). Estudio del envejecimiento de mieles de Burgos y Galicia: Influencia de la granulación inducida. Tesis Doctoral. Universidad de Burgos.

Cavia, M. M., Fernández-Muiño, M. A., Gómez-Alonso, E., Montes-Pérez, M. J., Huidobro, J. F., \& Sancho, M. T. (2002). Evolution of fructose and glucose in honey over one year: influence of induced granulation. Food Chemistry, 78, 157161.

Cavia, M. M., Fernández-Muino, M. A., Alonso-Torre, S. R., Huidobro, J. F., \& Sancho, M. T. (2007). Evolution of acidity of honeys from continental climates: Influence of induced granulation. Food Chemistry, 100, 1728-1733.

Celis, M., \& Díez, M. J. (1995). Análisis polínico de mieles en la cabrera baja (montes de León, España). Acta Botanica Malacitana, 20, 91-96.

Cervera, S. S., \& Cervera, M. M. S. (1994). Humedad, cenizas y conductividad eléctrica de mieles de La Rioja. Zubía, 12, 143-158. 
Chen, L., Xue, X., Ye, Z., Zhou, J., Chen, F., \& Zhao, J. (2011). Determination of Chinese honey adulterated with high fructose corn syrup by near infrared spectroscopy. Food Chemistry, 128, 1110-1114.

Chen, A., Wei, C., Chen, G., Zhao, Y., \& Yang, S. (2015). Duplex PCR approach for the detection and quantification of donkey, horse and mule in raw and heat processed meat products. International Journal of Food Science and Technology, 50, 834-839.

Codex Alimentarius (2001). Draft revised standard for honey. Council Directive 2001/110/EC of 20 December 2001 relating to honey. Official Journal of the European Communities L10, 47-52.

Codex Alimentarius FAO-OMS (2001). Programa Conjunto FAO/OMS Sobre Normas Alimentarias. Ginebra, 2-7 de julio de (2001).

Cometto, P. M., Faye, P. F., Paola, R. D., Naranjo, R. D. D. P., Rubio, M. A., \& Aldao, M. A. J. (2003). Comparison of free amino acids profile in honey from three Argentinean regions. Journal of Agricultural and Food Chemistry, 51, 5079-5087.

Comisión Europea, 2016. Informe de la Comisión al Parlamento Europeo y al Consejo sobre la aplicación de las medidas relativas al sector apícola del Reglamento (UE) n. $.1308 / 2013$ del Parlamento Europeo y del Consejo por el que se crea la organización común de mercados de los productos agrarios. Bruselas, 7.12.2016. $\operatorname{COM}(2016) 776$ final.

Conti, M. E. (2000). Lazio region (central Italy) honeys: a survey of mineral content and typical quality parameters. Food Control, 11, 459-463.

Cordella, C., Antinelli, J. F., Aurieres, C., Faucon, J. P., Cabrol-Bass, D., \& Sbirrazzuoli, N. (2002). Use of differential scanning calorimetry (DSC) as a new technique for detection of adulteration in honeys. 1. Study of adulteration effect on honey thermal behavior. Journal of Agriculture Food Chemistry, 50, 203-208.

Cordella, C., Faucon, J. P., Cabrol-Bass, D., \& Sbirrazzuoli, N. (2003). Application of DSC as a tool for honey floral species characterization and adulteration detection. Journal of Thermal Analysis and Calotimetry, 71, 275-286.

Cotte, J., Casabianca, H., Chardon, S., Lheritier, J., \& Grenier-Loustalot, M. F. (2003). Application of carbohydrate analysis to verify honey authenticity. Journal of Chromatography A, 1021, 145-155.

Cotte, J., Casabianca, H., Lhéritier, J., Perrucchietti, C., Sanglar, C., Waton, H., \& Grenier-Loustalot, M. F. (2007). Study and validity of $13 \mathrm{C}$ stable carbon isotopic ratio analysis by mass spectrometry and $2 \mathrm{H}$ site-specific natural isotopic fractionation by nuclear magnetic resonance isotopic measurements to 
characterize and control the authenticity of honey. Analytica Chimica Acta, 582, 125-136.

Crane, E. (1975). Honey: a comprehensive survey. Ed. Heinemann. London.

Crane, E. (1990). The traditional hive products: honey and beeswax. En Bees and Beekeeping. Science, practice and world resources, Heinemann Newnes: Oxford, U.K., 1990, 388-451.

Cuevas-Glory, L. F., Pino, J. A., Santiago, L. S., \& Sauri-Duch, E. (2007). A review of volatile analytical methods for determining the botanical origin of honey. Food Chemistry, 1032-1043.

Davide, B., \& Massimo, L. (2010). Detection of honey adulteration by sugar syrups using one-dimensional and two-dimensional highresolution nuclear magnetic resonance. Journal of Agricultural and Food Chemistry, 58, 8495-8501.

Decreto 2484/1967 de 21 de septiembre, por el que se aprueba el texto del Código Alimentario Español, BOE número 248, de 17 de octubre.

De la Fuente, E., Martinez-Castro, I., \& Sanz, J. (2005). Characterization of Spanish unifloral honeys by solid phase microextraction and gas chromatography-mass spectrometry. Journal of Separation Science, 28, 1093-1100.

De la Fuente, E., Sanz, M., Martínez-Castro, I., Sanz, J., \& Ruíz-Matute, A. (2007). Volatile and carbohydrate composition of rare unifloral from Spain. Food Chemistry, 105, 84-93.

Del Baño Breis, F. (2000). Mieles y Pólenes: Palinoteca de la Región de Murcia. Ed. Consejería de Agricultura, Agua y Medio Ambiente, Región de Murcia.

De Lorenzo, C. (2002). La miel de Madrid. Ed. Consejería de Economía e Innovación Tecnológica. Comunidad de Madrid.

De Lorenzo, C., Guadalix, M., González, M. M., Navarro, T., Pérez, R. A., Sanz, M. L., Martínez-Castro, I., Pueyo, E., Polo, M. C., Soria, A. C., \& Sanz, J. (2002). La miel de Madrid. Ed. Consejería de Economía e Innovación Tecnológica. Comunidad de Madrid.

De Oliveira, R., Teixeira, E., Da Silva, C., Guerra, M. L., Conte, C., \& Oliveira de Jesús, E. F. (2014). Detection of honey adulteration of high fructose corn syrup by low field Nuclear Magnetic Resonance (LF1H NMR). Journal of Food Engineering, 135, 39-43.

Días, L. A., Peres, A. M., Villas-Boas, M., Rocha, M. A., Estevinho, L., \& Machado, A. A. S. C. (2008). An electronic tongue for honey classification. Microchim Acta, 163, 97-102. 
Díaz-Moreno, A. (2009). La influencia de las condiciones de almacenamiento sobre la calidad físico-química y biológica de la miel. Tesis doctoral. Universidad de Zaragoza.

Directiva 2014/63/UE del Parlamento Europeo y del Consejo, de 15 de mayo de 2014, por la que se modifica la Directiva 2001/110/CE relativa a la miel.

Directiva Europea 2001/110/EC of 20 December 2001 relating to honey. Official Journal of the European Communities L10, 47-52.

Donner, L. W. (1977). The sugar of honey. A review. Journal of Science and Food Agricultural, 28, 443-456.

Elfleing, L., \& Raezke, K. (2008). Improved detection of honey adulteration by measuring differences between $13 \mathrm{C} / 12 \mathrm{C}$ stable carbon isotope ratios of protein and sugar compounds with a combination of elemental analyser-isotope ratio mass spectrometry and liquid chromatography-isotope ratio mass spectrometry (g13C-EA/LC-IRMS). Apidologie, 39, 574.

Escriche, I., Visquert, M., Juan-Borrás, M., \& Fito, P. (2009). Influence of simulated industrial termal treatments on the volatile fractions of different varieties of honey. Food Chemistry, 112, 329-338.

Escriche, I., Kadar, M., Juan-Borrás, M., \& Domenech, E. (2011). Using flavonoids, phenolic compounds and headspace volatile profile for botanical authentication of lemon and orange honeys. Food Research International, 44, 1504-1513.

Escriche, I., Kadar, M., Domenech, E., \& Gil-Sanchez, L. (2012). A potentiometric electronic tongue for the discrimination of honey according to the botanical origin. Comparison with traditional methodologies: Physicochemical parameters and volatile profile. Journal of Food Engineering, 109, 449-456.

Escriche, I., Kadar, M., Juan-Borrás, M., \& Domenech, E. (2014). Suitability of antioxidant capacity, flavonoids and phenolic acids for floral authentication of honey. Impact of industrial thermal treatment. Food chemistry, 142, 135-143.

Escriche, I., Oroian, M., Visquert, M., Gras, M. L., \& Vidal, D. (2016). Rheological Properties of Honey from Burkina Faso: Loss Modulus and Complex Viscosity Model-ing. International Journal of Food Properties, 19, 2575-2586.

Escriche, I., Tanleque-Alberto, F., Visquert, M., \& Oroian, M. (2017). Physico-chemical and rheological characterization of honey from Mozambique. LWT - Food Science and Technology, 86, 108-115.

Escuredo, O., Silva, L., Valentao, P., Seijo, M. C., \& Andrade, P. (2012). Assessing Rubus honey value: pollen and phenolic compounds content and antibacterial capacity. Food Chemistry, 130, 671-678. 
Escuredo, O., Dobre, I., Fernández-González, M., \& Seijo, M. C. (2014). Contribution of botanical origin and sugar composition of honeys on the crystallization phenomenon. Food Chemistry, 149, 84-90.

Estevinho, L., Pereira, A. P., Moreira, L., Dias, L. G., \& Pereira, E. (2008). Antioxidant and antimicrobial effects of phenolic compounds extracts of northeast Portugal honey. Food and Chemical Toxicology, 46, 3774-3779.

Fattori, S. (2004). La miel: propiedades, composición y análisis físico-químico. Ed. Apimondia.

FDA (2020). Import Alert 36-01 "Adulteration of Honey". https://www.accessdata.fda.gov/cms_ia/importalert_108.html Accessed 04/06/2020.

Fei, X., Wu, B., Shen, C., Ding, T., Li, L., \& Lu, Y. (2011). Honey adulteration detection using liquid chromatography/elemental analysis-isotope ratio mass spektrometry. Chinese Journal of Chromatography, 29, 5-19.

Fei, X., Wu, B., Shen, C., Zhang, R., Ding, T., \& Li, L. (2012). Determination of exogenous gamma-amylase residue in honey. Chinese Journal of Chromatography, 30, 777781.

Fernandes, T. J. R., Costa, J., Oliveira, M. B. P. P., \& Mafra, I. (2017). DNA barcoding coupled to HRM analysis as a new and simple tool for the authentication of Gadidae fish species. Food Chemistry, 230, 49-57.

Fernández-Uriel, P. (2011). “Dones del cielo. Abeja y miel en el Mediterráneo antiguo". Ed. Universidad Nacional de Ecuación a Distancia (UNED), Madrid.

Ferreira, I. C. F. R., Aires, E., Barreira, J. C. M., \& Estevinho, L. M. (2009). Antioxidant activity of Portuguese honey samples: Different contributions of the entire honey and phenolic extract. Food Chemistry, 114, 1438-1443.

Ferreres, F., Giuer, J. M., \& Tomás-Barberán, F. A. (1994). A comparation study of hesperetin and methyl anthranilate as markers of the floral origin of citrus honey. Journal Science Food Agriculture, 65, 371-372.

Gallina A., Stocco N., \& Mutinelli F. (2010). Karl Fischer Titration to determine moisture in honey: A new simplified approach. Food control, 21, 942-944.

García-Breijo E. (2005). Diseño de un sistema multisensor en tecnología thick-film; fabricación, caracterización y estudio de su aplicabilidad a la medida de parámetros físico-químicos. Tesis doctoral. Universidad Politécnica de Valencia.

Gheldof, N., \& Engeseth, N. J. (2002). Antioxidant capacity of honeys from various floral sources based on the determination of oxygen radical absorbance capacity and inhibition of in vitro lipoprotein oxidation in human serum samples. Journal Agricultural and Food Chemistry, 50, 3050-3055. 
Gheldof, N., Wang, X. H., \& Engeseth, N. (2002). Identification and quantification of antioxidant components of honeys from various floral sources. Journal of Agricultural and Food Chemistry, 50, 5870-5877.

Gómez, A. (2004). Mieles de España y Portugal. Conocimiento y cata. Barcelona. España, 2004, Vol. 3, 44-56.

Gómez-Pajuelo, A. (2004). Origen botánico de la miel, in Montagud (Eds.), Mieles de España y Portugal. Barcelona, 50-56.

González-Miret, M. L., Terrab, A., Herranz, D., Fernández-Recamales, M. A., \& Heredia, F. J. (2005). Multivariate correlation between color and mineral composition of honey and by their botanical origin. Journal of Agricultural and Food Chemistry, 53, 2574-2580.

González-Paramás, A. M., Gómez-Bárez, J. A., García-Villanova, R. J., Rivas- Palá, T., Ardanuy-Albajar, R., \& Sánchez-Sánchez, J. (2000). Geographical discrimination of honeys by using mineral composition and common chemical quality parameters. Journal of the Science of Food and Agriculture, 80, 157-165.

Griebel, C., \& Hess, G. (1940). The vitamin C content of flower nectar of certain Labiatae. Zeitschrift für Untersuchung der Lebensmittel, 79, 168-171.

Guertler, P., Eicheldinger, A., Muschler, P., Goerlich, O., \& Busch, U. (2014). Automated DNA extraction from pollen in honey. Food Chemistry, 149, 302-306.

Guler, A., Bakan, A., Nisbet, C., \& Yavuz, O. (2007). Determination of important biochemical properties of honey to discriminate pure and adulterated honey with sucrose (Saccharum officinarum L.) syrup. Food chemistry, 105, 1119-1125.

Guyot-Declerck, C., Renson, S., Bouseta, A., \& Collin, S. (2002). Floral quality and discrimination of Lavandula stoechas.Lavandula angustifolia, and Lavandula angustifolia x Latifolia honey. Food Chemistry, 79, 453-459.

Herrero-Martínez, J. M., Oumada, F. Z., Rosés, M., Bosch, E., \& Rafols, C. (2007). Determination of flavonoid aglycones in several food samples by mixed micellar electrokinetic chromatography. Journal Separation Science, 30, 2493-2500.

Horn, H. (1996). Intensive Practical Course of Honey Analysis. Landesanslalt für Bienenkunde. Universität Hohenheim-Sttutgart (Germany).

Huang, L., Liu, H., Zhang, B., \& Wu, D. (2015). Application of electronic nose with multivariate analysis and sensor selection for botanical origin identification and quality determination of honey. Food and Bioprocess Technology, 8, 359-370.

Huidobro, J. F., \& Sigmal, J. (1984). Determinación del color y la turbidez en las mieles. Anales de Bromatología, 36, 225-245. 
Iglesias, M. T., De Lorenzo, C., Polo, M. C., Martín-Álvarez, P. J., \& Pueyo, E. (2004). Usefulness of amino acids composition to discriminate between honeydew and floral honeys. Application to honeys from a small geographic area. Journal of Agricultural and Food Chemistry, 52, 84-89.

International Honey Commission (IHC), Minutes of the IHC meeting: Louvain-la-Neuve (2001).

Instituto Nacional de Farmacología y Bromatología (1978). Contribución a la Caracterización Química de la Jalea Real y a su Detección con Mezclas de Miel. Boletín interno №21., Argentina.

Jato, V., Iglesias, M. I., \& Álvarez, E. (1992). Variaciones interanuales del espectro polínico de mieles orensanas. Historia Natural, 91, 115-122.

Juan-Borrás, M., Domenech, E., Hellebrandova, M., \& Escriche, I. (2014). Effect of country origin on physicochemical, sugar and volatile composition of acacia, sunflower and tilia honeys. Food Research International, 60, 86-94.

Juan-borrás, M., Domenech, E., Conchado, A., \& Escriche, I. (2015), Physicochemical quality parameters at the reception of the honey packaging process: Influence of type of honey, year of harvest and beekeeper. Journal of Chemistry, 1-6.

Juan-Borrás, M., Periche, A., Domenech, E. \& Escriche, I. (2015). Correlation be-tween methyl anthranilate level and percentage of pollen in Spanish citrus honey. International Journal of Food Science \& Technology, 50, 1690-1696.

Juan-Borrás, M., 2016. Herramientas analíticas en la clasificación de mieles en base a criterios de calidad e inocuidad. Tesis Doctoral. Universidad Politécnica de Valencia.

Juan-Borrás, M., Soto, J., Gil- Sánchez, L., Pascual- Maté, A., \& Escriche, I. (2017). Antioxidant activity and physico- chemical parameters for the differentiation of honey using a potentiometric electronic tongue. Journal of the Science of Food and Agriculture, 97, 2215-2222.

Juan, T. (2001). Identificación y cuantificación de flavonoids en mieles españolas de diferentes orígenes botánicos y geográficos. Tesis Doctoral. Universidad de Zaragoza.

Juszczak, L., Soch, R., Roznowski, J., Fortuna, T., \& Nalepka, K. (2009). Physicochemical properties and quality parameters of herbhoneys. Food Chemistry, 113, 538-542.

Kadar, M.A., Escriche I., Juan-Borrás M., Carot J.M., \& Domenech E. (2011). Volatiles fraction composition and physicochemical as tools for differential of lemon blossom honey and orange blossom honey. Journal of the Science Food and Agriculture, 91, 2768-2776. 
Kaskoniene, V., \& Venskutonis, P. R. (2010). Floral Markers in Honey of Various Botanical and Geographic Origins: A Review. Comprehensive Reviews in Food Science and Food Safety, 9, 620-634.

Kelly, J. D., Petisco, C., \& Downey, G. (2006). Application of Fourier transform midinfrared spectroscopy to the discrimination between Irish artisanal honey and such honey adulterated with various sugar syrups. Journal of agricultural and food chemistry, 54, 6166-6171.

Kesmen, Z., Yetiman, A. E., Sahin, F., \& Yetim, H. (2012). Detection of chicken and turkey meat in meat mixtures by using real-time PCR assays. Journal of Food Science, 77, 167-173.

Kropf, U., Golob, T., Emer, M. N., Kump, P., Korošec, M., Bertoncelj, J., \& Ogrinc, N. (2010). Carbon and nitrogen natural stable isotopes in Slovene honey: Adulteration and botanical and geographical aspects. Journal of Agricultural and Food Chemistry, 58, 12794-12803.

Latorre, M. J., Peña, R., Pita, C., Botana, A., García, S., \& Herrero, C. (1999). Chemometric classification of honeys according to their type II. Metal content data. Food Chemistry, 66, 263-268.

Laube, I., Hird, H., Brodmann, P., Ullmann, S., Schöne-Michling, M., Chisholm, J., \& Broll, H. (2010). Development of primer and probe sets for the detection of plant species in honey. Food Chemistry, 118, 979-986.

León, V. (2013). Caracterización, determinación de vitaminas hidrosolubles y actividad antioxidante de mieles monoflorales de castilla la mancha. Tesis Doctoral. Universidad de Alcalá.

Li, S., Shan, Y., Zhu, X., Zhang, X., \& Ling, G. (2012). Detection of honey adulteration by high fructose corn syrup and maltose syrup using Raman spectroscopy. Journal Food Composition Analisys, 28, 69-74.

Louveaux, J., Maurizio, A., \& Vorwohl, G. (1978). Methods of Melissopalynology. Bee World, 59, 139-157.

Lupano, C. E. (1997). DSC study of honey granulation stored at various temperatures. Food Research International, 30, 683-688.

Manyi-Loh, C. E., Roland, N., \& Clarke, A. M. (2011). Volatile Compounds in Honey: A Review on Their Involvement in Aroma, Botanical Origin Determination and Potential Biomedical Activities. International Journal of Molecular Sciences, 12, 9514-9532.

Meda, A., Lamien, C. E., Romito, M., Millogo, J., \& Nacoulma, O. G. (2005). Determination of the total phenolic, flavonoid and proline contents in Burkina 
Fasan honey, as well their radical scavenging activity. Food chemistry, 91, 571577.

Megherbi, M., Herbreteau, B., Faure, R., \& Salvador, A. (2009). Polysaccharides as a marker for detection of corn sugar syrup addition in honey. Journal of Agricultural and Food Chemistry, 57, 2105-2111.

Meira, L., Costa, J., Villa, C., Ramos, F., Oliveira, M. B. P. P., \& Mafra, I. (2017). EvaGreen real-time PCR to determine horse meat adulteration in processed foods. LWT-Food Science and Technology, 75, 408-416.

Men, H., Gao, H., Li, J., Liu, J., \& Zhang, Y. (2014). Fuzzy ARTMAP for the adulterated honey discrimination with voltammetric electronic tongue. Sensors \& Transducers, 178, 40-46.

Mieldeabeja.net (2019). https://mieldeabejas.net/es/blog/news/el-polen-de-abeja Accessed 02/12/2019.

Mignani, A. G., Ciaccheri, L., Mencaglia, A. A., Sanzo, R. D., Carabetta, S., \& Russo, M. (2016). Dispersive Raman spectroscopy for the nondestructive and rapid assessment of the quality of southern Italian honey types. Journal of Lightwave Technology, 34, 4479-4485.

Ministerio de Agricultura, Pesca y Alimentación, 2018a. "El sector apícola en cifras: Principales indicadores económicos", Subdirección General de Productos Ganaderos, Dirección General de Producciones y Mercados Agrarios. Mayo, 2018.

Ministerio de Agricultura, Pesca y Alimentación, 2018b. Precios miel - campaña 2017/2018. Subdirección general de estadística. Mayo 2018.

Montenegro, G., Gómez, M., Casaubon, G., Belancic, A., Mujica, A. M., \& Peña, R. C. (2009). Analysis of volatile compounds in three unifloral native Chilean honeys. International Journal of Experimental Botany, 78, 61-65.

Morales, V., Corzo, N., \& Sanz, M. L. (2008). HPAEC-PAD oligosaccharide analysis to detect adulterations of honey with sugar strupe. Food Chemistry, 107, 922-928.

Naila, A., Flint, S. H., Sulaiman, A. Z., Ajit, A., \& Weeds, Z. (2018). Classical and novel approaches to the analysis of honey and detection of adulterants. Food Control, 90, 152-165.

Nayik, G. A., Bhat, F. M., Muzaffar, K., Gull, A., Wani, S. A., Shah, T. R., \& Nanda, V. (2014). Honey: Its history and religious significance: A review. Universal Journal of Pharmacy, 03, 5-8.

Nota de presa, 2019a. "Comienza el trámite oficial para modificar la norma de calidad de la miel". Ministerio de Agricultura, Pesca y Alimentación. 
Nota de prensa, 2019a. "Transposición de la Directiva UE sobre calidad de la miel en la legislación española". Comunicación COAG, CEACCU y CECU.

Ohashi, K., Natori, S., \& Kubo, T. (1999). Expression of amylase and glucose oxidase in the hypopharyngeal gland with an age-dependent role change of the worker honeybee (Apis mellifera L.). European Journal of Biochemistry, 265, 127-133.

Ohmenhaeuser, M., Monakhova, Y. B., Kuballa, T. \& Lachenmeier, D. W. (2013). Qualitative and Quantitative Control of Honeys Using NMR Spectroscopy and Chemometrics. Analytical Chemistry, 9 pages.

Orantes, J., Gonell, F., Torres, C., \& Gómez-Pajuelo, A. (2018). Guía de mieles monoflorales ibéricas. Laboratorios Apinevada. Pajuelo consultores apícolas. Versión 2.

Oroian, M., \& Escriche, I. (2015). "Antioxidants: characterization, natural sources, extraction and analysis". Food Research International, 74, 10-36.

Oroian, M., \& Ropciuc, S. (2018). Botanical authentication of honeys based on Raman spectra. Journal of Food Measurement and Characterization, 12, 545-554.

Ortiz Valbuena, A. (1992). Contribución a la Denominación de Origen de la miel de la Alcarria. Tesis Doctoral. Universidad Complutense de Madrid.

Ozbalci, B., Boyaci, I.K., Topcu, A., Kadilar, C., \& Tamer, U. (2013). Rapid analysis of sugars in honey by processing Raman spectrum using chemometric methods and artificial neural networks. Food Chemistry, 136, 1444-1452.

Padovan, G. J., De Jong, D., Rodrigues, L. P., \& Marchini, J. S. (2003). Detection of adulteration of commercial honey samples by the $13 \mathrm{C} / 12 \mathrm{C}$ isotopic ratio. Food Chemistry, 82, 633-636.

Palá-Paúl, J., Brophy, J. J., Goldsack, R. J., \& Fontaniella, B. (2004). Analysis of the volatile components of Lavandula canariensis (L.) Mill., a Canary Islands endemic species, growing in Australia. Biochemical Systematics and Ecology, 32, 55-62.

Paradkar, M. M., \& Irudayaraj, J. (2002). Discrimination and classification of beet and cane inverts in honey by FTRaman spectroscopy. Food Chemistry, 76, 231-239.

Parlamento Europeo, 2013. Informe sobre la crisis alimentaria, los fraudes en la cadena alimentaria y el control al respecto (2013/2091(INI)). http://www.europarl.europa.eu/sides/getDoc.do?pubRef=//EP//TEXT+REPORT+A7-2013-0434+0+DOC+XML+VO//ES Accessed 06/04/2019.

Persano-Oddo L., \& Bogdanov S. (2004). Determination of honey botanical origin: problems and issues. Apidologie, 35, S2-S3.

Persano-Oddo L., \& Piro R. (2004). Main European unifloral honeys: descriptive sheets, Apidologie, 35, S38-S81. 
Piana, G., Ricciardelli-D’albore, G., \& Isola, A. (1989). La miel. Ediciones Mundi-Prensa. Madrid.

Piana, L., Persano-Oddo, L., Bentabol, A., Bruneau, E., Bogdanov S., \& Guyot, S. (2004). Sensory analysis applied to honey: state of the art. Apidologie, 35, S26-S37.

Pichichero, E., Canuti, L., \& Canini, A. (2009). Characterisation of the phenolic and flavonoid fractions and antioxidant power of Italian honeys of different botanical origin. Journal of the Science of Food and Agricultural, 89, 609-616.

Pirini, A, Conte, L. S, Francioso, O., \& Lercker, G. (1992). Capillary gas chromatographic determination of free amino acids in honey as a means of discrimination between different botanical sources. Journal of High Resolution Chromatography, 15, 165-170.

Plan Estatal de investigación científica, técnica e innovación 2013-2016. Ministerio de Economía y Competitividad. Gobierno de España.

Plutowska, B., Chmiel, T., Dymerski, T., \& Wardencki, W. (2011). A headspace solidphase microextraction method development and its application in the determination of volatiles in honeys by gas chromatography. Food Chemistry, $126,1288-1298$.

Pohl, P. (2009). Determination of metal content in honey by atomic absorption and emission spectrometries. Trends in Analytical Chemistry, 28, 117-128.

Qiu, P. Y., Ding, H. B., Tang, Y. K, \& Xu, R. J. (1999). Determination of Chemical Composition of Commercial Honey by Near-Infrared Spectroscopy. Journal of Agriculture Food Chemistry, 47, 2760-2765.

Radovic, B. S., Careri, M., Mangia, A., Musci, M., Gerboles M., \& Anklam E. (2001). Contribution of dynamic headspace GC-MS analysis of aroma compounds to authenticity testing of honey. Food Chemistry, 72, 511-520.

Rasmussen, R. S., Morrissey, M. T., \& Walsh, J. (2010). Application of a PCR-RFLP method to identify salmon species in U.S. commercial products. Journal of Aquatic Food Product Technology, 19, 3-15.

Real Decreto 1049/2003. Norma de calidad relativa a la miel (BOE $n=186$ ), publicado el 1 de agosto de 2003, 30181-30183.

Real Decreto 473/2015, de 12 de junio, por el que se modifica el Real Decreto 1049/2003, de 1 de agosto, por el que se aprueba la Norma de calidad relativa a la miel.

Reglamento (UE) 1169/2011 del Parlamento Europeo y del Consejo de 25 de octubre de 2011 sobre la información alimentaria facilitada al consumidor y por el que se modifican los Reglamentos (CE) 1924/2006 y (CE) 1925/2006 del Parlamento Europeo y del Consejo, y por el que se derogan la Directiva 87/250/CEE de la 
Comisión, la Directiva 90/496/CEE del Consejo, la Directiva 1999/10/CE de la Comisión, la Directiva 2000/13/CE del Parlamento Europeo y del Consejo, las Directivas 2002/67/CE, y 2008/5/CE de la Comisión, y el Reglamento (CE) 608/2004 de la Comisión.

Ribeiro, R. D. O. R., Marsico, E. T., Da Silva, C. C., Monteiro, M. L. G., Junior, C. C., \& De Jesus, E. F. O. (2014). Detection of honey adulteration of high fructose corn syrup by low field nuclear magnetic resonance (LF $1 \mathrm{H}$ NMR). Journal of Food Engineering, 135, 39-43.

Rios-Corripio, M. A., Rojas-López, M., \& Delgado-Macuil, R. (2012). Analysis of adulteration in honey with standard sugar solutions and syrups using attenuated total reflectance-Fourier transform infrared spectroscopy and multivariate. CYTA - Journal of Food, 10, 119-122.

Rodríguez, M., S. (2015). Estudio de las características de las mieles de castaño y de mielada producidas en Galicia. Tesis Doctoral. Universidad de Vigo.

Rodriguez-Otero, J. L., Paseiro, P., Simal, J., \& Cepeda, A. (1990). Intento de caracterización de las mieles naturales de Galicia mediante las fracciones proteicas separadas por electroforesis. In Anales de Bromatologia (Vol. 42, No. 1, pp. 83-98). Sociedad Española de Bromatologia.

Rodríguez-Otero, J. L., Paseiro, P., Simal, J., Terradillos, L., \& Cepeda, A. (1995). Silicon, phosphorus, sulphur, chlorine and ash contents of Spanish commercial honeys. Zeitschrift für Lebensmittel-Untersuchung und Forschung, 200, 233-234.

Rodríguez-Ramírez, R., González-Córdova, A. F., \& Vallejo-Cordoba, B. (2011). Review: Authentication and traceability of foods from animal origin by polymerase chain reaction-based capillary electrophoresis. Analytica Chimica Acta, 685, 120-126.

Ropa D. (2010). Comparison of Mineral and Enzyme Levels in Raw and Processed Honey. Wisconsin: Ropa Science Research.

Ropciuc, S., Oroian, M., Paduret, S., \& Buculei, A. (2017). Honeydew honey adulteration: e-tongue and physicochemical analyses. Food and Environment Safety-Journal of Faculty of Food Engineering, 16, 98-103.

Ruíz, L. (2011). Libro Intermiel. Interprofesional de la Miel y los Productos Apícolas. Momentos Miel. Diseño y maquetación: Alcandora Publicidad. Depósito legal: M47914-2011.

Ruíz-Matute, A. I., Soria, A. C., Martínez-Castro, I., \& Sanzm M. L. (2007). A new methodology based on GC-MS to detect honey adulteration with commercial syrups. Journal of Agricultural and Food Chemistry, 55, 7264-7269.

Sáenz C., \& Gómez C. (2000). Mieles españolas. Características e identificación mediante el análisis del polen. Ed. Mundi-Prensa. Madrid. 
Safdar, M., Junejo, Y., Arman, K., \& Abasıyanık, M. F. (2014). A highly sensitive and specific tetraplex PCR assay for soybean, poultry, horse and pork species identification in sausages: Development and validation. Meat Science, 98, 296300.

Sanz, J., Soria, A. C., \& García-Vallejo, M. C. (2004). Analysis of volatile components of Lavandula luisieri L. by direct thermal desorption-gas chromatography-mass spectrometry. Journal of Chromatography A, 1024, 139-146.

Schneider, A. (2011). Ultra-filtering Removes Pollen, Hides Honey Origins. https://www.foodsafetynews.com/2011/11/tests-show-most-store-honey-isnthoney/ Accessed 01/03/2019.

Se, K. W., Ghoshal, S. K., Wahab, R. A., Raja Ibrahim, R. K., Lani, M. N. (2018). A simple approach for rapid detection and quantification of adulterants in stingless bee (Heterotrigona itama) honey. Food Research International, 105, 453-460.

Seijo, M. C., Aira, M. J., Iglesias, I., \& Jato, M. V. (1992a). Palynological characterization of honey from La Coruña province (NW Spain). Journal of Apicultural Research, 31, 149-155.

Seijo M. C., Rodríguez, M. J. A., \& Rodríguez, M. V. J. (1992b). Evolución del espectro polínico en muestras de miel y néctar de un colmenar de Tomiño (Pontevedra). Botanica Complutensis, 17, 87-98.

Seijo, M. C. (1994). Caracterización de la miel de Galicia a través del espectro polínico. Tesis Doctoral, Universidad de Vigo.

Seijo, M. C., \& Jato, M. V. (1998). Palynological characterization of honeys from Galicia (Northwest Spain). Grana, 37, 285-292.

Seijo, M. C., \& Jato, M. V. (2001). Distribution of Castanea pollen in Galician honeys (NW Spain). Aerobiologia, 17, 255-259.

Seijo, M. C., Jato, M. V., \& Iglesias, I. (2001). Pollen combinations of honeys from Galicia (Spain) and their geographical distributio. Apiacta, 36, 1-11.

Senyuva, H. Z., Gilbert, J., Silici, S., Charlton, A., Dal, C., Gurel, N., \& Cimen, D. (2009). Profiling Turkish honeys to determine authenticity using physical and chemical characteristics. Journal of Agricultural and Food Chemistry, 57, 3911-3919.

Serra, J. (1988). Determinación de antranilato de metilo en la miel de cítricos (Citrus sp.) del Levante Espanol, y su influencia en la actividad diastásica de la miel, Alimentaria, 197, 37-40.

Serra-Bonvehí J., \& Ventura F. (1995). Characterization of Citrus honey produced in Spain. Journal of Agricultural and Food Chemistry, 43, 2053-2057. 
Serra-Bonvehí, J., \& Ventura-Coll, F. (2003). Flavour index and aroma profiles of fresh and processer honeys. Journal of the Sicence of food Agriculture, 83, 275-282.

Sesta, G., Piana, L., Persano-Oddo, L., Lusco, L., \& Belligoli, P. (2008). Methyl anthranilate in Citrus honey. Analytical method and suitability as a chemical marker. Apidologie, 39, 334-342.

Sevimli, H., Bayulgen, N., \& Varinlioglu, A. (1992). Determination of trace elements in honey by INAA in Turkey. Journal of radioanalytical and nuclear chemistry, 165, 319- 325.

Silici, S., Uluozlu, O. D., Tuzen, M., \& Soylak, M. (2008). Assessment of trace element levels in Rhododendron honeys of Black Sea Region, Turkey. Journal of Hazardous Materials, 156, 612-618.

Simsek, A., Bilsel, M., \& Goren, A. C. (2012). 12C/ 13C pattern of honey from Turkey and determination of adulteration in commercially available honey samples using EAIRMS. Food Chemistry, 130, 1115-1121.

Sivakesava, S., \& Irudayaraj, J. (2001). A rapid spectroscopic technique for determining honey adulteration with corn syrup. Journal of Food Science, 66, 787-791.

Sivakesava, S., \& Irudayaraj, J. (2002). Classification of simple and complex sugar adulterants in honey by mid-infrared spectroscopy. International Journal of Food Science and Technology, 37, 351-360.

Soares, S., Amaral, J. S., Oliveira, M. B. P. P., \& Mafra, I. (2015). Improving DNA isolation from honey for the botanical origin identification. Food Control, 48, 130-136.

Soria, A. C., González, M. M., \& Sans, J. (2002). Los componentes volátiles y el aroma. La miel de Madrid, 121-136.

Soria, A. C., Martínez-Castro, I., \& Sanz, J. (2003). Analysis of volatile composition of honey by solid phase microextraction and gas chromatography-mass spectrometry. Journal of Separation Science, 26, 793-801.

Souza-Kruliski, C. R., Ducatti, C., Filho, V. W. G., Orsi, R. O., \& Silva, E. T. (2010). A study of adulteration in brazilian honeys by carbon isotope ratio. Cięncia $e$ Agrotecnologia, 34, 434-439.

Spiteri, M., Jamin, E., Thomas, F., Rebours, A., Lees, M., Rogers, K. M., \& Rutledge, D. N. (2015). Fast and global authenticity screening of honey using $1 \mathrm{H}-\mathrm{NMR}$ profiling. Food Chemistry, 189, 60-66.

Suárez, S. (2009). Determinación de aniones y cationes en la miel mediante electroforesis capilar. Tesis Doctoral. Universidad de Santiago de Compostela. 
Subari, N., Saleh, J. M., Shakaff, A. Y. M., \& Zakaria, A. (2012). A hybrid sensing approach for pure and adulterated honey classification. Senzore, 12, 1402214040.

Sugar, J., \& Bour, P. (2016). Quantitative analysis of sugar composition in honey using 532- nm excitation Raman and Raman optical activity spectra. Journal of Raman Spectroscopy, 47, 1298-1303.

Tanleque-Alberto, F., Juan-Borrás, \& Escriche, I. (2019). Quality parameters, pollen and volatile profiles of honey from North and Central Mozambique. Food Chemistry, $277,543-553$.

Tanleque-Alberto, F., \& Escriche, I. (2020). Antioxidant characteristics of honey from Mozambique based on specific flavonoids and phenolic acid compounds. Journal of Food Composition and Analysis, 86, 103377.

Terradillos, L. A. (1988). Estudio microscópico de/sedimento de la miel y su aplicación en la caracterización de la miel de Galicia. Tesis doctoral. Universidad de Santiago.

Tiwari, K., Tudu, B., Bandyopadhyay, R., \& Chatterjee, A. (2013). Identification of monofloral honey using voltammetric electronic tongue. Journal of Food Engineering, 117, 205-210.

Tomás-Barberán F. A, Ferreres F., Ortiz A., \& Fernández M. C. (1994). Estudio sobre el contenido en flavonoides de las Mieles de La Alcarria: su aplicación a la caracterización Geográfico-Botánica. Convenio de colaboración entre el Consejo Superior de Investigaciones Científicas y la Junta de Comunidades de Castilla-La Mancha.Ed, CSIC. ISBN: 8460618323.

Tomás-Barberán, F., Martos, I., Ferreres, F., Branka S., R., \& Anklam, E. (2001). HPLC flavonoid profiles as markers for the botanical origin of European unifloral honeys. Journal of the science of food and agriculture, 81, 485-496.

Tosun, M. (2013). Detection of adulteration in honey samples added various sugar syrups with $12 \mathrm{C} / 13 \mathrm{C}$ isotope ratio analysis method. Food Chemistry, 138, 16291632.

Tuzen, M., Silici, S., Mendil, D., \& Soylak, M. (2007). Trace element levels in honeys from different regions of Turkey. Food Chemistry, 103, 325-330.

Ulloa, P. A., Guerra, R., Cavaco, A. M., de Costa, A. M. R., Figueira, A. C., Brigas, A. F. (2013). Determination of the botanical origin of honey by sensor fusion of impedance etongue and optical spectroscopy. Computers and Electronics in Agriculture, 94, 1-11.

Vanhanen, L. P., Emmertz, A., \& Savage, G. P. (2011). Mineral analysis of mono-floral New Zealand honey. Food Chemistry, 128, 236-240. 
Veloso, A. C. A., Días, L. G., Rodrígues, N., Pereira, J. A., \& Peres, A. M. (2016). Sensory intensity assessment of olive oils using an electronic tongue. Talanta, 146, 585593.

Verzera, A., Campisi, S., Zappalá,M., \& Bonaccorsi, I. (2001). SPME-GC-MS analysis of honey volatile components for the characterization of different floral origin. American laboratory News, 18-21.

Vieitez, E. (1951). El polen de las mieles de Galicia. Anales Edafología y Fisiología Vegetal, 10, 79-99.

Visquert, M., Vargas, M., \& Escriche, I. (2014). Effect of postharvest storage con-ditions on the colour and freshness parameters of raw honey. International Journal of Food Science and Technology, 49, 181-187.

Visquert, M. (2015). Influencia de las condiciones térmicas en la calidad de la miel. Tesis Doctoral. Universidad Politécnica de Valencia.

Viuda-Martos, M., Ruiz-Navajas, Y., Fernandez-Lopez, J., \& Perez-Alvarez, J. A., (2008) Functional Properties of Honey, Propolis and Royal Jelly. Journal of Food Science, 73, 117-118.

Von Der Ohe, W., Persano-Oddo, P., Piana, L, Morlot, M., \& Martin P. (2004). Harmonized methods of melissopalynology. Apidologie, 35, S18-S25.

Wang, J., Kliks, M. M., Jun, S., Jackson, M., \& Li, Q. X. (2010). Rapid analysis of glucose, fructose, sucrose, and maltose in honeys from different geographic regions using Fourier transform infrared spectroscopy and multivariate analysis. Journal Food Science, 75, 208-214.

Wang, J., Xue, X., Du, X., Cheng, N., Chen, L., Zhao, J., Zheng, J., \& Cao, W. (2014). Identification of acacia honey adulteration with rape honey using liquid chromatography-electrochemical detection and chemometrics. Food Analytical Methods, 7, 2003-2012.

Wang, S., Guo, Q., Wang, L., Lin, L., Shi, H., Cao, H., \& Cao, B. (2015). Detection of honey adulteration with starch syrup by high performance liquid chromatography. Food Chemistry, 172, 669-674.

Wei, K., Abdul, R., Nuratiqah, S., \& Krishna, S. (2019). Detection techniques for adulterants in honey: Challenges and recent trends. Journal of Food Composition and Analysis, 80, 16-32.

White, J. W. (1978). Advances in Food Research Volume 24, Pag iii-vii, 1-378. Capitulo: Honey Original Research Article, 287-374, ISBN: 978-0-12-016424-0. Edited by C.O. Chicheste.

White, J. W., \& Rudyj, O. N. (1978). The protein content in honey. Journal of Apicultural Research, 17, 234-238. 
White, J., \& Siciliano, J. (1980). Hydroxymetylfurfural and honey adulteration. Journal Association Official Analyst Chesmistry, 63, 7-10.

White, J., W., \& Bryant, V. M. (1996). Assessing Citrus honey quality: pollen and methyl anthranilate content. Journal of Agricultural and Food Chemistry, 44, 3423-3425.

White, J. W. (2000). Isotope ratio testing of honey: Demystifying the internal standard test. American Bee Journal, 140, 318-321.

Wie, Z., Wang, J., \& Liao, W. (2009). Technique potential for classification of honey by electronic tongue. Journal of Food Engineering, 94, 260-266.

Wilkins, A. L., \& Lu, Y. (1995). Extractives from New Zealand honeys. 5. Aliphatic dicarboxylic acids in New Zealand rewarewa (Knightea excelsa) honey. Journal of Agricultural and Food Chemistry, 43, 3021-3025.

Zábrodská, B., \& Vorlová, L. (2015). Adulteration of honey and available methods for detection- a review. Acta Veterinaria Brunensis, 83, 85-102.

Zakaria, A., Shakaff, A. Y. M., Masnan, M. J., Ahmad, M. N., Adom, A. H., Jaafar, M.N., Ghani, S. A., Abdullah, A. H., Aziz, A. H. A., Kamarudin, L. M., Subari, N., \& Fikri, N. A. (2011). A biomimetic sensor for the classification of honeys of different floral origin and the detection of adulteration. Senzore, 11, 7799-7822. 

2. OBJETIVOS 



\section{Objetivos}

\subsection{Objetivo general}

La presente tesis doctoral tiene como principal objetivo avanzar en el esclarecimiento de la autenticidad de la miel aplicando técnicas analíticas emergentes en este campo. Todo ello con la finalidad de facilitar la identificación de fraudes durante la comercialización de la miel relacionados con su clasificación botánica y geográfica, así como con su adulteración por adición de jarabes.

\subsection{Objetivos específicos}

Para alcanzar el objetivo general se han planteados los siguientes objetivos específicos:

2.2.1. Evaluar la capacidad de la fracción volátil (analizada mediante GC-MS) en la diferenciación de mieles de diferente procedencia botánica.

2.2.2. Evaluar la capacidad de una lengua electrónica voltamétrica (basada en sensores metálicos inespecíficos) en la discriminación de mieles de diferente procedencia geográfica.

2.2.3. Evaluar la capacidad del análisis de las propiedades térmicas de la miel (mediante calorimetría diferencial de barrido) para la identificación de la adición de jarabes azucarados en miel.

2.2.4. Evaluar la capacidad de la técnica de PCR (PCR convencional y PCR en tiempo real) en la identificación de adición de melaza en miel.

2.2.5. Evaluar la capacidad de una lengua electrónica voltamétrica (basada en sensores metálicos inespecíficos) en la identificación de adición de jarabes azucarados en mieles de diferente procedencia botánica. 

3. RESULTADOS 

3.1. Volatile profile in the accurate labelling of monofloral honey.

The case of lavender and thyme honey

Isabel Escriche, Lara Sobrino-Gregorio, Andrea Conchado, Marisol Juan-Borrás

Food Chemistry, 226, 61-68 (2017) 



\section{ABSTRACT}

The proliferation of hybrid plant varieties without pollen, such as lavender, has complicated the classification of specific types of honey. This study evaluated the correlation between the proclaimed type of monofloral honey (lavender or thyme) as appears on the label with the actual percentage of pollen. In addition, physicochemical parameters, colour, olfato-gustatory profile, and volatile compounds were tested. All the samples labelled as lavender were wrongly classified according to the usual commercial criteria (minimum $10 \%$ of pollen Lavandula spp.). In the case of lavender honey, there was significant agreement between commercial labelling and classification through organoleptic perception (81.8\%), and above all between the commercial labelling and the volatile compounds (90.9\%). For thyme honey, agreement for both parameters was $90.0 \%$. These results offer compelling evidence that the volatile compounds are useful for the classification of lavender honey with low levels of pollen since this technique agrees well with the organoleptic analysis.

Keywords: accurate labelling; lavender honey classification; thyme honey; volatile compounds; GC-MS.

\section{Introduction}

Thyme and lavender honey, although limited in production, are highly appreciated due to their organoleptic characteristics. Both, thyme (Thymus spp.) and lavender (Lavandula spp.) plants belong to the botanical family Labiatae and are part of the autochthonous Mediterranean vegetation, sharing environmental characteristics and botanical habitat and pollinating agents. These types of honey have a characteristic sweet flavour with sour notes, but may have salty notes when harvested late and/or contain some honeydew secretions. Thyme honey has an intense persistent aroma and its colour ranges from a very light amber to amber with red highlights. Lavender honey has a distinctive aroma, which is very characteristic of the lavender plant. Its colour varies from amber to very light amber, being clearer when purer, and darker due to a higher content of oak honeydew (Mateu, 2002).

The monoflorality of honey is determined by the botanical species that bees visit to obtain the nectar from flowers or the secretions of plants. Honey can be classified as belonging to a specific botanical origin when a certain percentage of pollen of this botanical species is present. The required percentage varies depending on the botanical species in question; for example, ranges between 10 and $20 \%$ for orange blossom honey or 70 and $90 \%$ for eucalyptus honey (Persano-Oddo \& Piro, 2004; JuanBorrás et al., 2015). However, pollen may be under represented, which causes problems in the botanical classification of honey (Persano-Oddo \& Piro, 2004; Juan- 
Borrás et al., 2015, ANIPAM, 2008; The Apis Information Resource Center website, 2016). This problem has been observed in citrus honey because citrus trees sometimes produce nectar before the anther produces pollen, or the nectar comes from sterile hybrid varieties of citrus trees which are characterized by their small amounts of pollen (Juan-Borrás et al., 2015).

In the case of lavender honey, the problem is similar because the percentage of pollen is usually very low or even non-existent. This is because in recent years the lavender crop has consisted of hybrid varieties without pollen, which therefore is not present in the nectar or the honey (Persano-Oddo \& Piro, 2004). This problem for the honey sector has been noticed by the laboratories which carry out the botanical classification of honey.

For this reason, it is recommendable to complement the results of pollen analysis with other determination techniques, such as physicochemical (Bogdanov et al., 2004; Kádár et al., 2011), organoleptic (González-Viñas et al., 2003; Castro-Vázquez et al., 2009), or chromatographic ones. Among the chromatographic techniques, special attention should be paid to the identification of specific minority components such as volatile compounds (Kádár et al., 2011; Juan-Borrás et al., 2014).

While some physicochemical parameters (colour, moisture, acidity, etc.) can vary between types of honey, contributing to some extent to their organoleptic characteristics, it is evident that in monofloral honey, flavour/aroma is the most distinctive pattern. Although all types of honey have a common intrinsic flavour/aroma, every nectar from blossom or secretions from plants give different specific aromas and flavours that strongly influence their distinguishing features. It has been shown that different honeys have certain specific compounds which some authors consider to be "fingerprints" or "markers", which may be useful in their botanical classification (Alissandrakis et al., 2007; Kaskoniene \& Venskutonis, 2010; Kádár et al., 2011; Juan-Borrás et al., 2014; Castro-Vázquez et al., 2014). For instance, methylanthranilate is important for the identification of orange blossom honey since this compound is only present in orange blossom nectar (Juan-Borrás et al., 2015); likewise, formaldehyde and acetaldehyde in rape and clover honey, respectively; acetone in fir honey and diketones, sulphur compounds and alkanes in eucalyptus honey, among others (Bouseta et al., 1992; Da Silva et al., 2016).

Currently, the beekeeping sector is aware of the importance of increasing the offer of monofloral honey, especially from a particular geographical origin. For this reason, whenever it is possible, honey is marketed specifying its botanical origin on the label in order to inform consumers and to increase producers' profit margins. Guarantying authenticity and differentiated quality, means that companies can increase the range of honey varieties on the market. Although there are numerous works related to pollen, physicochemical parameters, and the volatile profile of different types of unifloral honey; as far as the authors know, there is no research focused on the 
relationship between this information and what appears on the label in terms of monoflorality. Therefore, the objective of this study was to investigate the correlation between the proclaimed type of monofloral honey (lavender or thyme) as appears on the label with the actual percentage of pollen, physicochemical parameters, colour, olfato-gustatory profile, as well as, volatile compounds. All this with the aim of evaluating the effectiveness of these techniques in the accurate classification of these monofloral honeys.

\section{Material and methods}

\subsection{Honey samples}

Honey samples, labelled as lavender or thyme and harvested in 2015 from the Valencian Region (Spain), were purchased locally from different retail outlets. Three batches of each available brand on the market (11 lavender and 10 thyme) were acquired. Therefore, a total of 66 honey samples were analyzed.

\subsection{Melissopalynological analysis}

Figure 3.1.1 shows micrographs of grains of pollen of Lavandula spp. (A) and Thymus spp. (B) at 400x magnification. Light micrographs are shown in the top row (A1 and B1) and DIC (differential interference contrast optics) micrographs at the bottom (A2 and B2).
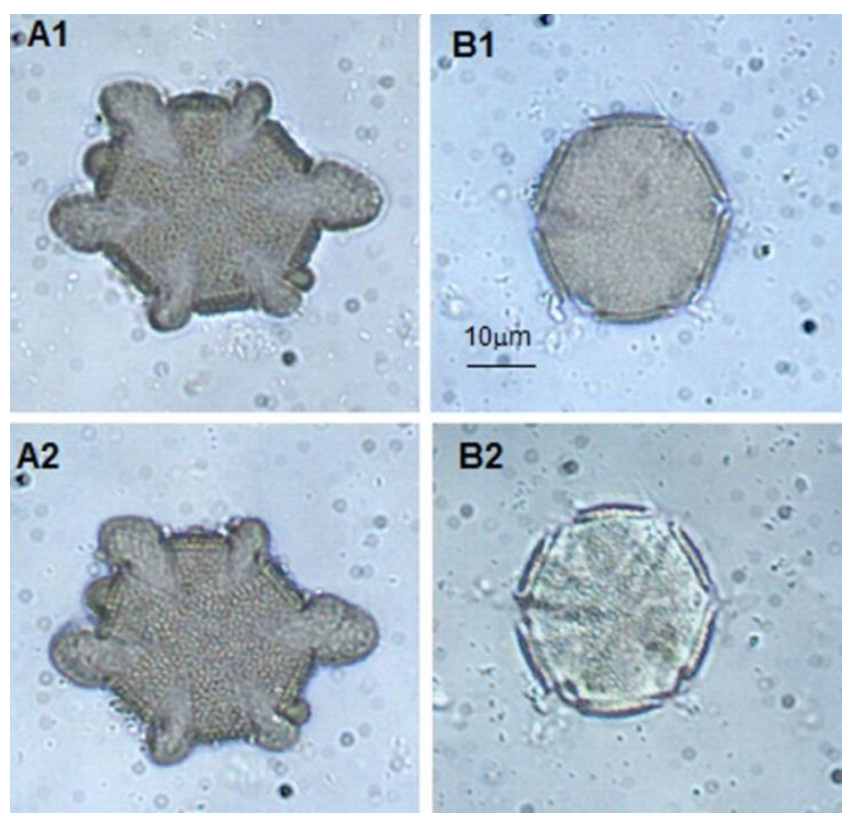

Figure 3.1.1. Pictures at $400 \times$ magnification of pollen of Lavandula spp. (A) and Thymus spp. (B). A1 and B1- Light micrographs. A2 and B2 - DIC (differential interference contrast optics) micrographs. 
The percentage of pollen from lavender and thyme present in each sample was quantified following the criteria of the International Commission for Bee Botany (Von Der Ohe et al., 2004). A light microscope (Zeiss Axio Imager, Göttingen, Germany) at a magnification power of $\times 400$ with DpxView LE image analysis software attached to a DeltaPix digital camera was used.

\subsection{Physicochemical and colour analysis}

Hydroxymethylfurfural content (HMF), moisture content, conductivity, ${ }^{\circ}$ Brix and $\mathrm{pH}$ were analyzed in accordance with the Harmonized Methods of the European Honey Commission (Bogdanov, 2009). HMF was determined by HPLC-UV methodology using a ZORBAX Eclipse Plus C18 column $(4.6 \times 150 \mathrm{~mm}, 5 \mu \mathrm{m}$ particle size, Agilent Technologies, USA). Water-methanol (90:10, v:v), with a flow rate of $1 \mathrm{~mL} / \mathrm{min}$ was used as a mobile phase. The detector was set to $285 \mathrm{~nm}$. EZChrom Elite system software was used for HPLC data processing.

Water activity $\left(\mathrm{a}_{\mathrm{w}}\right)$ was evaluated at $25{ }^{\circ} \mathrm{C}\left( \pm 0.2{ }^{\circ} \mathrm{C}\right)$ using an electronic dewpoint water activity meter, Aqualab Series 4 model TE (Decagon Devices, Pullman,Washington, USA), equipped with a temperature-control system.

Colour was measured using a millimetre Pfund scale (C 221 Honey Color Analyzer, Hanna Instruments).

\subsection{Volatile compound analysis: Extraction and GC-MS analysis}

Volatile compounds were extracted by purge and trap at $45^{\circ} \mathrm{C}$ for $20 \mathrm{~min}$ and trapped in a glass tube packed with Tenax TA (20-35 mesh), then purified nitrogen (100 mL $\min ^{-1}$ ) was bubbled through the sample (Escriche et al., 2011). Next, the compounds were thermally desorbed at $220{ }^{\circ} \mathrm{C}$ for $10 \mathrm{~min}$ (at $10 \mathrm{~mL} \mathrm{~min}^{-1}$ helium flow) (TurboMatrix TD, Perkin ElmerTM, CT-USA), cryofocused in a cold trap at $-30{ }^{\circ} \mathrm{C}$, then the cold trap was heated to $250{ }^{\circ} \mathrm{C}$ (at a rate of $99^{\circ} \mathrm{C} / \mathrm{s}$ ) which transferred them onto the capillary column.

A GC-MS (Finnigan TRACETM MS, TermoQuest, Austin, USA) with a DB-WAX capillary column (SGE, Australia) (60 m length, $0.32 \mathrm{~mm}$ i.d., $1.0 \mu \mathrm{m}$ film thickness) was used to separate the volatile compounds. Helium at a flow rate of $1 \mathrm{~mL} \mathrm{~min}^{-1}$ was used as the carrier gas. The temperature programme was: from $40{ }^{\circ} \mathrm{C}$ (2-minute hold time) to 190 ${ }^{\circ} \mathrm{C}$ at $4{ }^{\circ} \mathrm{Cmin}^{-1}$ (11-minute hold time) and finally to $220^{\circ} \mathrm{C}$ at $8{ }^{\circ} \mathrm{C} \mathrm{min}^{-1}$ (8-minute hold time). Electron impact mass spectra were logged in impact ionization mode at $70 \mathrm{eV}$ (mass range of $\mathrm{m} / \mathrm{z}$ 33-433). A total of 3 extracts were obtained for each sample. 2Pentanol was used as an internal standard. The identification of isolated volatile compounds was performed by comparing their mass spectra, retention times and linear retention indices with those obtained from authentic standards from: SigmaAldrich (San Louis, Missouri and Acros Organics, Geel, Belgium) and Fluka (Buchs, 
Schwiez, Switzerland). The compounds for which it was not possible to find authentic standards were tentatively identified by comparing their mass spectra $(\mathrm{m} / \mathrm{z}$ values of the most important ions) with spectral data from the National Institute of Standards and Technology 2002 library (always considering more than $80 \%$ percent probability value), as well as linear retention indices and spectral data published in the literature.

All the physicochemical, colour and volatile compound analysis were performed in triplicate.

\subsection{Sensory analysis}

The samples were evaluated organoleptically based on their monofloral olfatogustatory profile. This analysis was carried out by experienced staff in the honey quality control laboratory at the Universitat Politècnica of València (Spain). A scale from 0 to 3 was used to score the perceived intensity (ISO, 2003). Tasters placed a small amount of honey (aprox. $5 \mathrm{~g}$ ) on their tongue, diluted it with saliva and projected it toward the back of their mouth to evaluate the flavour and aromas via the retronasal route. Then, the honey was swallowed slowly, and the taste persistence was evaluated. This procedure was followed for all samples.

\subsection{Statistical analysis}

An analysis of variance (ANOVA) (using Statgraphics Centurion for Windows) was applied to evaluate the physicochemical parameters, colour, volatile compounds, and phenolic and flavonoid compounds, according to the type of honey (lavender or thyme). The method used for multiple comparisons was the LSD test (least significant difference) with a significance level $\alpha=0.05$. In addition, data were analyzed using a principal component analysis (PCA) applying the software Unscrambler X.10. The number of components extracted was based on the Kaiser criterion (1960) that suggests keeping all principal components with eigenvalues higher than 1 (Kaiser, 1960). This solution was not rotated using orthogonal or obliquus rotation. Subsequently, Stepwise Linear Discriminant Analysis (SLDA) was applied (using SPSS.18) to the loadings of these seven principal components with the aim of differentiating between varieties of honey. This analysis permitted identification of the principal components with better predictive power, by means of a unique discriminant function.

\section{Results and discussion}

\subsection{Physicochemical and colour characterization}


Table 3.1.1. Olfato-gustatory profile and average values of the physicochemical parameters and colour of each of the brands commercially labelled as lavender or thyme honey. $\mathrm{L}=$ lavender; $\mathrm{T}=$ thyme. Brand codes refer to the average percentage of pollen of Lavandula spp. (L) and (Thymus spp.). The organoleptic score of the brands was based on their monofloral (lavender or thyme) olfato-gustatory profile, perception intensity from 0 (absence) to 3 (very intense).

\begin{tabular}{|c|c|c|c|c|c|c|c|c|c|}
\hline Brand Codes & $\begin{array}{c}\text { Olfato-gustatory } \\
\text { profile }\end{array}$ & $\begin{array}{l}\text { Commercial } \\
\text { information }\end{array}$ & $\begin{array}{l}\text { Moisture } \\
\text { (g/100g) }\end{array}$ & $\begin{array}{l}\text { Electrical conductivity } \\
\mathrm{S} / \mathrm{cm}\end{array}$ & ${ }^{\circ}$ Brix & pH & $a_{w}$ & Colour & $\begin{array}{c}\mathrm{HMF} \\
(\mathrm{mg} / \mathrm{kg})\end{array}$ \\
\hline L1-T8 & (2)lavander & lavander & $15.60(0.01)$ & $0.250(0.006)$ & $82.65(0.01)$ & $3.95(0.01)$ & $0.53(0.01)$ & $47(1)$ & $4.51(0.01)$ \\
\hline L3-T12 & (3)lavander & lavander & $15.27(0.12)$ & $0.330(0.001)$ & $83.07(0.06)$ & $3.94(0.01)$ & $0.49(0.01)$ & $66(1)$ & 15.49 (1.9) \\
\hline L3-TO & (1)lavander & lavander & $18.07(0.12)$ & $0.330(0.001)$ & $80.40(0.01)$ & $3.85(0.01)$ & $0.60(0.01)$ & $89(1)$ & 44.74 (1.6) \\
\hline L7-TO & (3)lavander & lavander & $14.80(0.01)$ & $0.180(0.001)$ & $83.40(0.01)$ & $3.78(0.01)$ & $0.54(0.01)$ & $80(1)$ & 48.19 (1.6) \\
\hline L1-T26 & (0)lavander; (1)thyme & lavander & $15.40(0.01)$ & $0.600(0.001)$ & $82.82(0.08)$ & $4.40(0.01)$ & $0.53(0.01)$ & $81(1)$ & $10.09(0.8)$ \\
\hline L3-TO & (1)lavander & lavander & $15.60(0.01)$ & $0.500(0.015)$ & $82.62(0.03)$ & $4.23(0.01)$ & $0.52(0.01)$ & $77(1)$ & $8.48(0.2)$ \\
\hline L4-TO & (2)lavander & lavander & $16.60(0.01)$ & $0.320(0.010)$ & $81.53(0.06)$ & $4.02(0.01)$ & $0.55(0.01)$ & $61(1)$ & $4.85(0.2)$ \\
\hline L5-TO & (3)lavander & lavander & $19.60(0.01)$ & $0.480(0.010)$ & $78.73(0.06)$ & $4.05(0.01)$ & $0.59(0.01)$ & $51(1)$ & $4.75(0.5)$ \\
\hline L1-T8 & (0)lavander; (1)thyme & lavander & $15.80(0.01)$ & $0.490(0.006)$ & $82.43(0.03)$ & $3.98(0.01)$ & $0.50(0.01)$ & $70(1)$ & $8.81(0.5)$ \\
\hline LO-TO & (1)lavander & lavander & $17.40(0.01)$ & $0.250(0.010)$ & $80.80(0.01)$ & $3.89(0.01)$ & $0.55(0.01)$ & $40(1)$ & $8.40(1.3)$ \\
\hline LO-TO & (1)lavander & lavander & $13.73(0.12)$ & $0.350(0.006)$ & $84.00(0.01)$ & $4.23(0.01)$ & $0.49(0.01)$ & $68(1)$ & $16.48(0.9)$ \\
\hline T16-L3 & (1)thyme; (1)lavander & thyme & $16.60(0.01)$ & $0.330(0.006)$ & $81.60(0.01)$ & $3.84(0.01)$ & $0.58(0.01)$ & $60(1)$ & $4.29(0.4)$ \\
\hline T14-L0 & (1)thyme & thyme & $17.60(0.01)$ & $0.570(0.006)$ & $80.60(0.01)$ & $4.11(0.01)$ & $0.58(0.01)$ & $74(1)$ & $0.93(0.3)$ \\
\hline T14-L0 & (2)thyme & thyme & $15.60(0.01)$ & $0.400(0.015)$ & $82.50(0.01)$ & $4.80(0.01)$ & $0.55(0.01)$ & $78(1)$ & $1.63(0.5)$ \\
\hline T12-L0 & (1)thyme & thyme & $16.80(0.01)$ & $0.420(0.017)$ & $81.60(0.01)$ & $3.94(0.01)$ & $0.56(0.01)$ & $71(1)$ & $6.07(0.7)$ \\
\hline T11-L0 & (1)thyme & thyme & $15.60(0.01)$ & $0.420(0.021)$ & $82.50(0.01)$ & $4.18(0.01)$ & $0.49(0.01)$ & $78(1)$ & $10.18(1.2)$ \\
\hline T12-L0 & (1)thyme & thyme & $16.60(0.01)$ & $0.160(0.001)$ & $81.60(0.01)$ & $3.83(0.01)$ & $0.49(0.01)$ & 47 (1) & $58.88(0.9)$ \\
\hline T11-L0 & (1)thyme & thyme & $17.60(0.35)$ & $0.340(0.006)$ & $80.67(0.09)$ & $3.85(0.01)$ & $0.53(0.01)$ & $84(1)$ & 48.75 (1.3) \\
\hline T11-L0 & (1)thyme & thyme & $15.80(0.20)$ & $0.500(0.001)$ & $82.40(0.08)$ & $3.90(0.01)$ & $0.48(0.01)$ & $72(1)$ & $8.52(0.6)$ \\
\hline T13-L0 & (1)thyme & thyme & $16.20(0.01)$ & $0.340(0.006)$ & $82.03(0.06)$ & $3.91(0.01)$ & $0.56(0.01)$ & $81(1)$ & $12.44(0.3)$ \\
\hline T13-L0 & (1)thyme & thyme & $16.40(0.01)$ & $0.640(0.006)$ & $81.70(0.01)$ & $4.31(0.01)$ & $0.58(0.01)$ & $69(1)$ & $6.64(0.7)$ \\
\hline \multicolumn{10}{|l|}{ ANOVA } \\
\hline F-ratio & & & $2.73 \mathrm{~ns}$ & $1.46 \mathrm{~ns}$ & $2.16 \mathrm{~ns}$ & $0.26 \mathrm{~ns}$ & $0.15 \mathrm{~ns}$ & & \\
\hline
\end{tabular}

ns: Non significant 
Table 3.1.1 shows the average values of the quantified physicochemical parameters (HMF, moisture, electrical conductivity, oBrix, $\mathrm{pH}$ and aw) and the colour of the three batches of each brand commercially labelled as lavender or thyme honey.

The code for each brand refers to the average percentage of Lavender spp. (L) and Thyme spp. $(T)$ pollen. The organoleptic scores of these samples were based on the monofloral (lavender or thyme) olfato-gustatory profile of the first named type of pollen, the perception intensity being measured from absence $(0)$ to very intense (3). For example, the code "L1-T8 (2)" means that this brand has an average of $1 \%$ lavender pollen and $8 \%$ thyme pollen, and the (2) represents an intermediate olfato-gustatory intensity of lavender.

In the present work all the honey samples labelled as thyme satisfied the commercial criterion about the percentage of pollen (minimum 10\% of pollen Thymus spp.), since they ranged from 11 to $16 \%$. However, this was not the case for the group of samples labelled as lavender, as the pollen ranged between 0 and $7 \%$ when their commercial minimum criterion is also $10 \%$ Lavandula spp. pollen. The International Honey Commission in a study carried out with 84 European lavender and 253 thyme honey samples (Persano-Oddo \& Piro, 2004), reported a slightly higher average percentage of Lavandula spp. pollen (between $1 \%$ and 19\%) than those observed in the present work. On the contrary, the average Thymus spp. pollen content was higher in Italian and Greek thyme honey ( $26 \% \pm 18$ and $40 \% \pm 16.4$, respectively). The different species of thyme involved in each case may be the main reason for these differences (PersanoOddo \& Piro, 2004). It seems evident that the "samples labelled as lavender" used in the present study are sold only following the criterion of aroma/flavour reminiscent of this flower (organoleptic analysis) since this type of sample did not met the pollinic criteria. This is not surprising since, as noted above, currently lavender honey is underrepresented in pollen due to the proliferation of hybrid varieties used in the perfume industry (Guyot-Declerck et al., 2002; Von Der Ohe et al., 2004; ANIPAM, 2008; The Apis Information Resource Center website, 2016). Therefore, it is obvious that the pollen percentage criterion is unrealistic at least referring to lavender honey.

This table also illustrates the ANOVA results (F-ratio and significant differences) obtained for the factor "type of labelled honey" carried out for the physicochemical parameters. Significant differences were not found between the two types of labelled honey (lavender and thyme) for any of the parameters analysed. This is because in both groups of samples all the parameters analysed are in the same range of values: moisture (13.73-19.60 and $15.60-17.60 \mathrm{~g} / 100 \mathrm{~g})$; electrical conductivity $(0.180-0.600$ and $0.160-0.640 \mathrm{~S} / \mathrm{cm}$ ), ${ }^{\circ}$ Brix (78.73-84.00 and 80.60-82.50); $\mathrm{pH}(3.78-4.40$ and 3.834.80); $\mathrm{a}_{\mathrm{w}}$ (0.49-0.60 and 0.48-0.58) and colour (40.00-89.00 and 47.00-84.00), respectively. These values agree with the results obtained for European lavender and thyme honey in the before mentioned study (Persano-Oddo \& Piro, 2004), where the physicochemical reported data were: moisture (15.20-18.10 and 14.00-17.00 g/100g); 
electrical conductivity $(0.120-0.310$ and $0.250-0.540 \mathrm{~S} / \mathrm{cm}) ; \mathrm{pH}(3.50-4.00$ and $3.50-$ 4.10); and colour (20.30-45.00 and 35.00-74.5), respectively. It is important to point out that in the present work the colour Pfund for lavender honey was about double that in the European study, probably due to the influence of the vegetation present in the surroundings.

In relation to HMF a large amount of variation was observed: from 4.51 to $48.19 \mathrm{mg} / \mathrm{kg}$ in the case of lavender honey, and from 0.93 to $58.88 \mathrm{mg} / \mathrm{kg}$ for thyme honey. In both types of honey, two brands clearly exceeded the maximum of $40 \mathrm{mg} / \mathrm{kg}$ (Council Directive 2001/110 relating to honey, 2002), with values of 44.74 and $48.19 \mathrm{mg} / \mathrm{kg}$ in lavender honey, and 48.75 and 58.88 in thyme honey. This shows that these samples were not properly handled, or the time between harvesting and retail sale was too long.

The information given by the physicochemical parameters and the colour shows that neither of them permits differentiation between honey from the same geographical habitat labelled as lavender or thyme, as is the case of the two types of honey studied here.

The volatile compounds that are liberated during the tasting and ingestion of honey decisively influences the aroma/flavour perceived. Therefore, it is logical to think that the volatile fraction of honey contains potentially usable information for the differentiation of lavender honey from other types of honey with which it might be confused.

\subsection{Olfato-gustatory profile and volatile compound characterization}

Around 30 major volatile compounds were identified and semiquantified in the volatile fractions of honey samples, including alcohols, aldehydes, ketones, acids, esters, terpenes and nitrogen compounds. The average values, standard deviation, and the ANOVA result of the volatile compounds analysed in both types of honey are shown in Table 3.1.2.

Alcohols, as in other types of honey, were abundant in the analysed samples. All of them had 2-propanol, 2-butanol and 1-butanol in similar amounts. Ethanol was more common in thyme honey samples, although without significant differences between both groups. The alcohol 1-hexanol was present in significantly greater amounts in the samples labelled as lavender; some authors propose 1-hexanol, among other compounds, as a typical marker of lavender honey. In fact, in the present study 1hexanol was identified in almost all the brands labelled as lavender (average value of $4.2 \mu \mathrm{g} / \mathrm{kg}$ ) and only in one brand labelled as thyme (T16-L3) with an average value in this brand of $1.4 \mu \mathrm{g} / \mathrm{kg}$. The existence of lavender pollen in this last sample shows that the honeybees visited lavender flowers too, which could explain the occurrence of 1- 
hexanol in this sample. The large amount of 1-hexanol found in lavender honey is in line with the results obtained in other studies of Spanish lavender honey (CastroVázquez et al., 2009; Castro-Vázquez et al., 2014).

Table 3.1.2. Volatile compounds (average values and standard deviation) in samples labelled as lavender or thyme honey. The data were calculated (ug/ $\mathrm{kg}$ of honey) assuming a response factor equal to one.

\begin{tabular}{|c|c|c|c|c|c|}
\hline Volatile compounds & RI cal & ID & $\begin{array}{c}\text { Samples labelled } \\
\text { as lavender } \\
\text { Mean (SD) }\end{array}$ & $\begin{array}{c}\text { Samples labelled } \\
\text { as thyme } \\
\text { Mean (SD) }\end{array}$ & $\begin{array}{c}\text { ANOVA } \\
\text { F ratio }\end{array}$ \\
\hline \multicolumn{6}{|l|}{ Alcohols } \\
\hline 2 Propanol & 947 & $\mathrm{MS} ; \mathrm{RI}$ & $1.2(1.1)$ & $1.6(1.5)$ & $0.3^{\mathrm{ns}}$ \\
\hline Ethanol & 957 & $M S ; R I$ & $20.3(13.3)$ & $38.1(20.6)$ & $3.6^{\mathrm{ns}}$ \\
\hline 2 Butanol & 1047 & St;MS;RI & $8.5(6.1)$ & $6.4(9.0)$ & $0.2^{\mathrm{ns}}$ \\
\hline 2 Methyl-3-buten-2 ol & 1065 & $M S ; R I$ & $6.1(3.3)$ & $5.2(1.9)$ & $0.5^{\mathrm{ns}}$ \\
\hline 1 Butanol & 1175 & St;MS;RI & $2.4(3.1)$ & $3.8(6.5)$ & $0.2^{\mathrm{ns}}$ \\
\hline 2 Methyl-1-propanol & 1119 & St;MS;RI & $6.7(2.3)$ & $9.5(2.3)$ & $0.69^{\text {ns }}$ \\
\hline 2 Methyl-1-butanol & 1185 & St;MS;RI & $7.7(4.4)$ & $8.9(5.9)$ & $0.2^{\mathrm{ns}}$ \\
\hline 3 Methyl-3-buten-1-ol & 1277 & St;MS;RI & $6.3(2.9)$ & $5.2(2.4)$ & $0.78^{\mathrm{ns}}$ \\
\hline 2 Methyl-2-buten-1-ol & 1349 & $M S ; R I$ & $3.0 \cdot(2.1)$ & $1.4(1.3)$ & $3.2^{\mathrm{ns}}$ \\
\hline 1 Hexanol & 1476 & St;MS;RI & $4.2(2.2)$ & $0.1(0.5)$ & $15.9^{* *}$ \\
\hline \multicolumn{6}{|l|}{ Aldehydes } \\
\hline 3-methyl-1-butanal & 912 & St;MS;RI & $1.6(2.4)$ & $<0.001$ & $2.37^{*}$ \\
\hline 2-methyl-1-butanal & 920 & $M S ; R I$ & $0.3(0.5)$ & $2.6(2.5)$ & $6.9^{*}$ \\
\hline Hexanal & 1065 & St;MS;RI & $3.2(2.4)$ & $0.6(1.2)$ & $8.9^{* *}$ \\
\hline Heptanal & 1160 & St;MS;RI & $9.2(6.9)$ & $19.7(2.8)$ & $1.35^{\mathrm{ns}}$ \\
\hline Furfural & 1460 & St;MS;RI & $3.2(4.6)$ & $2.9(4.5)$ & $0.02^{\mathrm{ns}}$ \\
\hline Phenylacetaldehyde & 1609 & $\mathrm{MS} ; \mathrm{RI}$ & $1.0(1.0)$ & $2.8(1.6)$ & $1.8^{\mathrm{ns}}$ \\
\hline \multicolumn{6}{|l|}{ Ketones } \\
\hline Acetone & 814 & $\mathrm{MS} ; \mathrm{RI}$ & $1.0(0.3)$ & $2.0(0.9)$ & $4.7^{*}$ \\
\hline 2-Butanone & 910 & St;MS;RI & $1.7(0.7)$ & $2.6(1.9)$ & $2.2^{\mathrm{ns}}$ \\
\hline 2,3 Butanedione & 970 & $\mathrm{MS} ; \mathrm{RI}$ & $2.8(1.9)$ & $7.4(7.7)$ & $3.5^{\mathrm{ns}}$ \\
\hline 1-Hydroxy-2-propanone & 1268 & $M S ; R I$ & $2.2(1.2)$ & $2.9(1.4)$ & $1.2^{\mathrm{ns}}$ \\
\hline 3-Hydroxy-2-butanone & 1322 & St;MS;RI & $2.6(1.4)$ & $4.8(3.0)$ & $1.9^{\text {ns }}$ \\
\hline \multicolumn{6}{|l|}{ Acids } \\
\hline Acetic acid & 1486 & St;MS;RI & $2.3(1.4)$ & $0.9(0.5)$ & $5.4^{*}$ \\
\hline \multicolumn{6}{|l|}{ Esters } \\
\hline Ethyl acetate & 909 & St;MS;RI & $1.1(1.4)$ & $1.4(1.2)$ & $0.6^{\mathrm{ns}}$ \\
\hline \multicolumn{6}{|l|}{ Terpenes } \\
\hline Linalool & 1670 & St;MS;RI & $3.6(0.15)$ & $4.9(0.15)$ & $4.8^{*}$ \\
\hline Hotrienol & 1737 & $\mathrm{MS} ; \mathrm{RI}$ & $2.7(1.1)$ & $0.3(0.2)$ & $35.8^{* * *}$ \\
\hline \multicolumn{6}{|l|}{ Nitrogen compounds } \\
\hline 2-Methyl-propanenitrile & 1022 & St;MS;RI & $<0.001$ & $0.23(0.35)$ & $2.5^{\mathrm{ns}}$ \\
\hline 2-Methyl-butanenitrile & 1158 & $\mathrm{MS} ; \mathrm{RI}$ & $<0.001$ & $0.17(0.27)$ & $3.9^{\text {ns }}$ \\
\hline \multicolumn{6}{|c|}{$\begin{array}{l}\text { ns: Non significant; } \mathrm{P}<0.05 ;{ }^{* *} \mathrm{P}<0.01 ;{ }^{* * * *} \mathrm{P}<0.001 \\
\mathrm{RI} \text { cal: Linear retention indices calculated } \\
\text { ID: Method of identification, MS (comparison with mass spectrum stored in NIST library), St (comparison of } \\
\text { retention time and mass spectrum with those of authentic standards), RI (comparison of linear retention indices } \\
\text { with the literature) }\end{array}$} \\
\hline
\end{tabular}


In the present study, the levels of methyl alcohols in the two groups of honeys were not found to be significantly different by the ANOVA. However, among them, 2methyl-3-buten-2-ol, 3-methyl-3-buten-1-ol, and 2-methyl-2-buten-1-ol, where more abundant in samples labelled as lavender and 2-methyl-1-propanol and 2-methyl-1butanol in thyme samples. Apparently, the methyl alcohols contribute to the typically fresh aroma of this type of honey (Bouseta et al., 1992; Castro-Vázquez et al., 2009; Da Silva et al., 2016).

Aldehydes such as 3-methyl-1-butanal, 2-methyl-1-butanal, hexanal, heptanal furfural and phenylacetaldehyde, were also identified. Phenylacetaldehyde, described as having a honey-like aroma was present in most of the thyme honey samples and in very few of those labelled as lavender. This agrees with the results obtained for Greek thyme honey (Alissandrakis et al., 2007; Karabagias et al., 2014), and for Spanish thyme honey (Castro-Vázquez et al., 2009). However, other authors reported the importance of phenylacetaldehyde to characterize lavender honey from different botanical species (Guyot-Declerck et al., 2002). In the present study, only a few samples of lavender showed the presence of this compound.

Many authors considered that hexanal is one of the compounds most responsible for the characteristic flavour of lavender honey (Bouseta et al., 1992; Guyot-Declerck et al., 2002; Manyi-Loh et al., 2011). In fact, in the present work the importance of hexanal is of note as it appeared in almost all the samples labelled as lavender (reaching values of $5.0 \mu \mathrm{g} / \mathrm{kg}$ ) and in T16-L3. Although this sample had a high enough percentage of pollen to be classified as thyme, it is noteworthy that it had the organoleptic characteristics and aromatic notes typical of lavender honey, as well as the presence of pollen from this plant.

The two groups of analysed samples showed opposing behaviour in terms of methyl aldehydes with significant differences between them; 3-methyl-1-butanal was almost exclusively found in the group of honey samples labelled as lavender, whereas 2methyl-1-butanal in those of thyme.

Different ketones were present in almost all the samples analysed: acetone; 2butanone, 2,3 butanedione 1-hydroxy-2-propanone, and 3-hydroxy-2-butanone. In general, ketones are very common in different types of European honey, acetone being one of the major volatile compounds detected (Da Silva et al., 2016). In the present work, all the ketones identified were more abundant in thyme honey than honey labelled as lavender, although only for acetone the differences were significant between the two groups.

Acetic acid and ethyl acetate were the only acid and ester identified, respectively. Acetic acid showed significant differences between groups, being present in all the samples labelled as lavender (average value of $2.3 \mu \mathrm{g} / \mathrm{kg}$ ) and only in three of the thyme samples. However, not significant differences were found for ethyl acetate. 
$\beta$-Linalool and hotrienol (3,7-dimethyl-1,5,7 octatrien-3-ol) were the only honey terpenes identified in the present work. Different studies reported that the derivatives of $\beta$-linalool originated from flowers visited by honeybees are found only in specific types of honey (Da Silva et al., 2016). Several authors highlighted the importance of hotrienol in lavender honey, compared to other types of honey (Castro-Vázquez et al., 2009; Castro-Vázquez et al., 2014; Jerkovic \& Kus, 2014). In the present work, $\beta$ linalool was identified in both honey samples, although was significantly higher in those of thyme, whereas hotrienol was almost exclusively found in the samples labelled as lavender (reaching values up to $4.8 \mu \mathrm{g} / \mathrm{kg}$ ). Other volatile terpenes such as thymol or carvacrol, which were reported by other authors in thyme honey, were not found in this study. This was probably due to the different botanical species or the analytical extraction procedures applied for these compounds (Cacho et al., 2015).

Only four brands labelled as thyme showed small amounts of short-chain nitrogen compounds (2-methyl-propanenitrile, 2-methyl-butanenitrile). Unsurprisingly, nitrile derivatives could be present in honey samples, even becoming important compounds in the headspace fraction (Moreira \& De Maria, 2005), in some cases reaching $21.7 \%$ of the total volatile compounds (Kaškoniene et al., 2008). For instance, phenylacetonitrile was reported as very abundant in thyme honey from Greece (Alissandrakis et al., 2007).

With the aim of transforming the initial set of volatile compound variables into a more reduced set of linearly uncorrelated variables, a principal component analysis was performed. This analysis was carried out using the average values from the three repetitions for each sample of honey. Seven components were extracted according to the Kaiser criterion (1960) (Kaiser, 1960), explaining 95.5\% of the total variance. The first component (PC1) explained $40 \%$ and was positively correlated with ethyl acetate, 2,3-butanedione, 2-methyl-propanenitrile, 2-methyl-1-propanol, 3-methylbutanenitrile, 1-butanol, 2-methyl-1-butanol, among others. The second component (PC2 explained 22.0\%) was positively correlated with 1-hexanol, hotrienol, hexanal, acetic acid and 2-methyl-2-buten-1-ol, and others. Figure 3.1.2 shows the scores and loadings for the two principal components. The score codes correspond to those explained in Table 3.1.1. Proximity between samples labelled as lavender or thyme, indicates similar behavior in terms of the volatile profile. The loading plot confirms that certain compounds are responsible for differentiation between the two groups. Ethyl acetate, 2,3-butanedione, 2-methyl-propanenitrile and 1-butanol, associated with PC1, as well as 1-hexanol, hotrienol, hexanal, corresponding to PC2, are characteristic of thyme and lavender honey, respectively. 


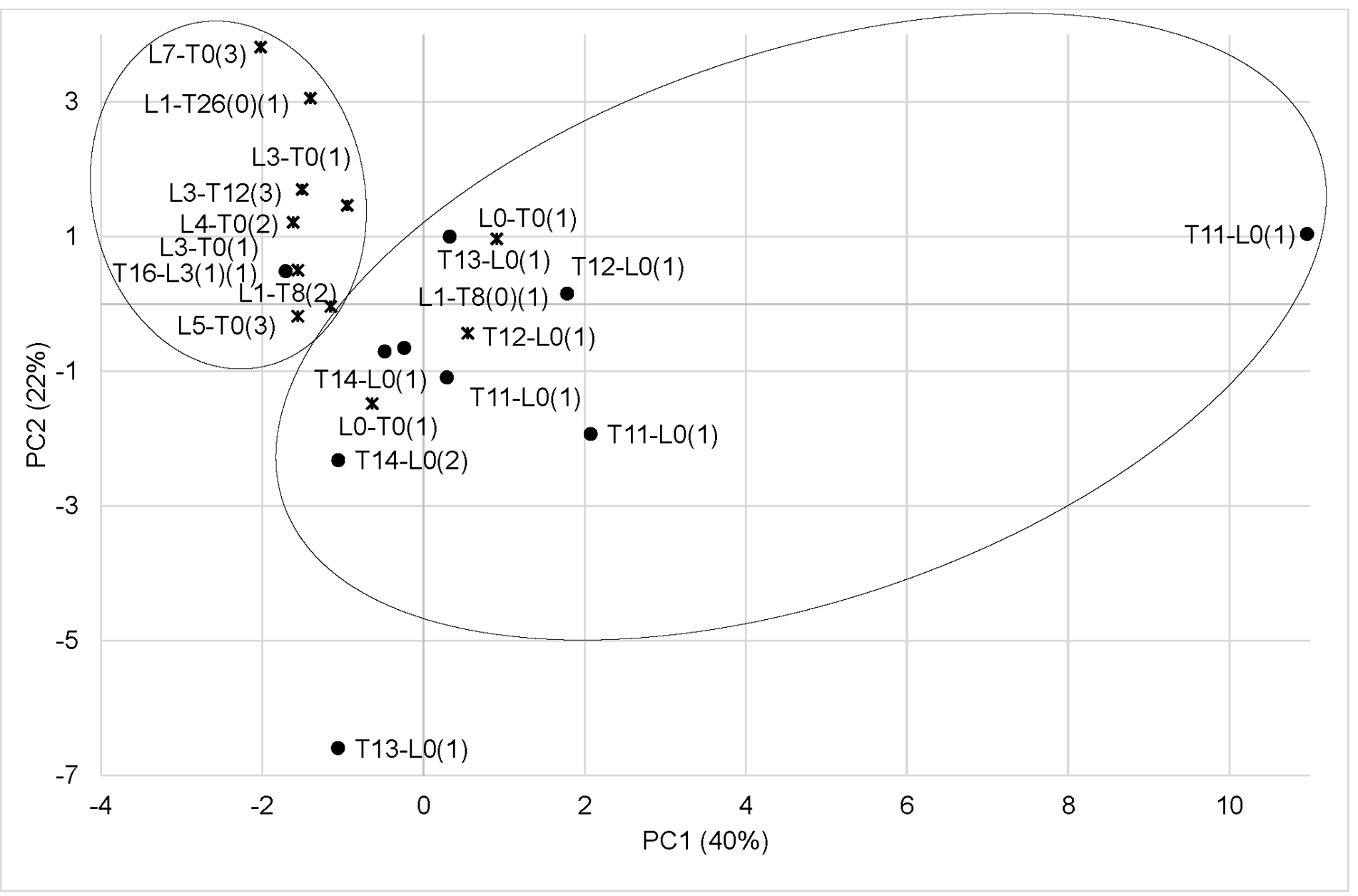

Figure 3.1.2. (2.a) Scores (brand samples) and (2.b) loading (volatile compounds) plots of the first two components. (L) and (T) = percentage of Lavender spp. and Thyme spp. pollen. 
b

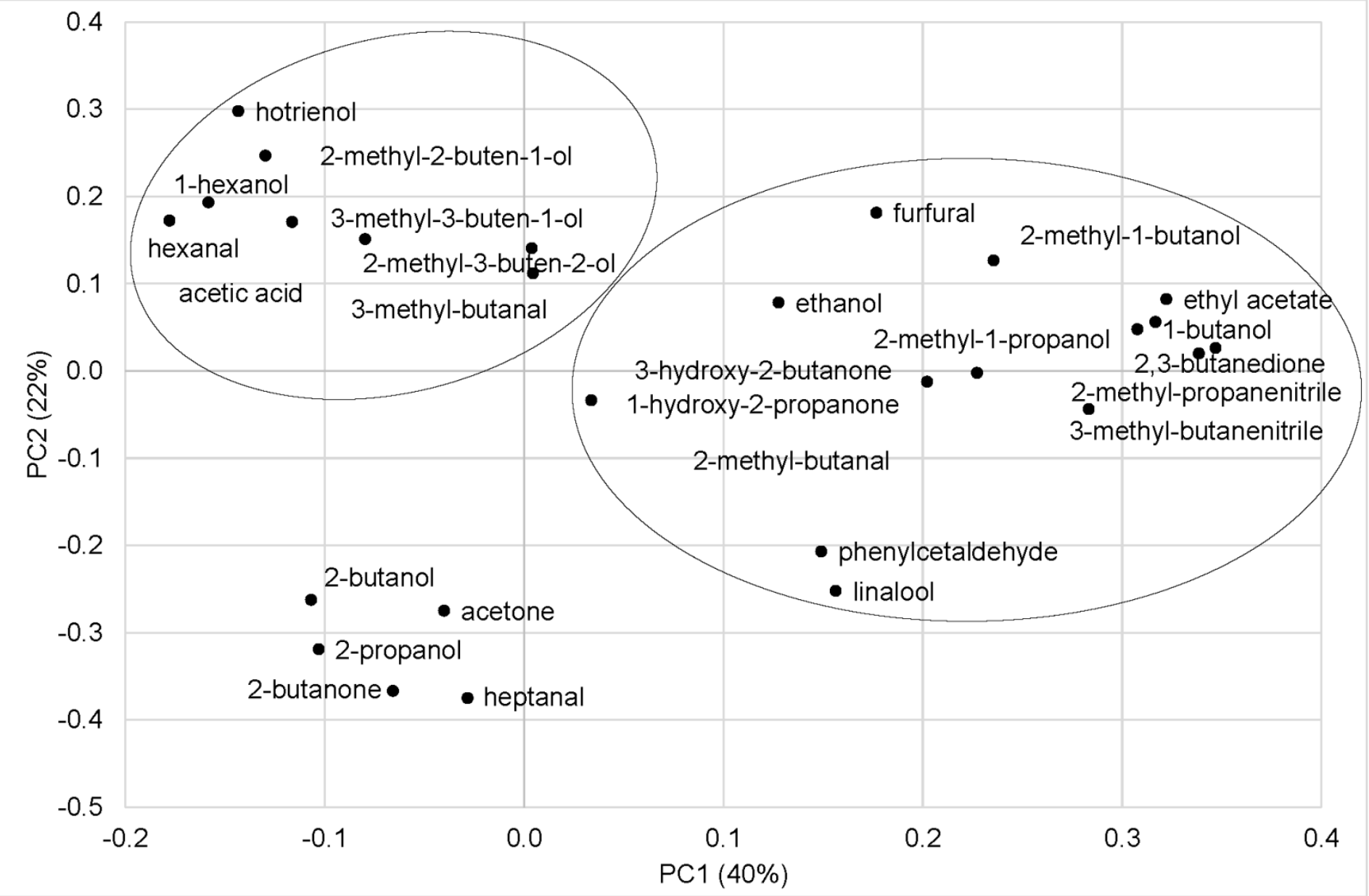

Figure 3.1.2. (2.a) Scores (brand samples) and (2.b) loading (volatile compounds) plots of the first two components. $(\mathrm{L})$ and $(\mathrm{T})=$ percentage of Lavender spp. and Thyme spp. pollen. 
Furthermore, the third component (11.5\%) was positively correlated to octane and 3methyl-3-buten-1-ol, while the fourth (8.6\%), fifth (5.8\%), sixth (4.4\%) and seventh (3.2\%) components were mainly correlated with ethanol, furfural, acetone and 2methyl-butanal, and 3-methyl-butanal, respectively.

Once the variability of the initial set of volatile compound variables was reduced to seven principal components, a discriminant analysis was applied to examine the predictive power of each principal component when distinguishing between groups. That is to say, the previous seven principal components extracted using PCA were subsequently used as predictors of honey type in the discriminant analysis. As a result of this analysis, only one statistically significant canonical function was obtained. This function explained $100 \%$ of the total variance (Wilks' lambda=0.462, $d f=7, p=0.101$; Canonical correlation coefficient $=0.734$ ), and also discriminates correctly between honey labelled as lavender or thyme in $85.7 \%$ of the samples. The discriminant function values at the group centroids were -1.186 for lavender and 0.890 for thyme.

The standardized coefficients of discriminant functions for each principal component used as a predictor were: PC1 (0.731); PC2 (-0.819); PC3 (0.323); PC4 (0.227); PC5 (0.586); PC6 (0.363) and PC7 (-0.088). These data reveal that the second component showed the highest predictive power of the discriminant function, followed by the first component. This shows that the compounds most involved in the distinction between the two types of honey were: 1-hexanol, hotrienol, hexanal, acetic acid and 2-methyl2-buten-1-ol.

The results of the discriminant analysis are shown in Figure 3.1.3. Next to the code for each sample appears the organoleptic score based on its monofloral (lavender or thyme) olfato-gustatory profile as was described in Table 3.3.1. Samples of thyme honey fell in the left region of the map, whereas the rest of the samples were placed on the right, though both varieties obtained negative scores for this discriminant function. 


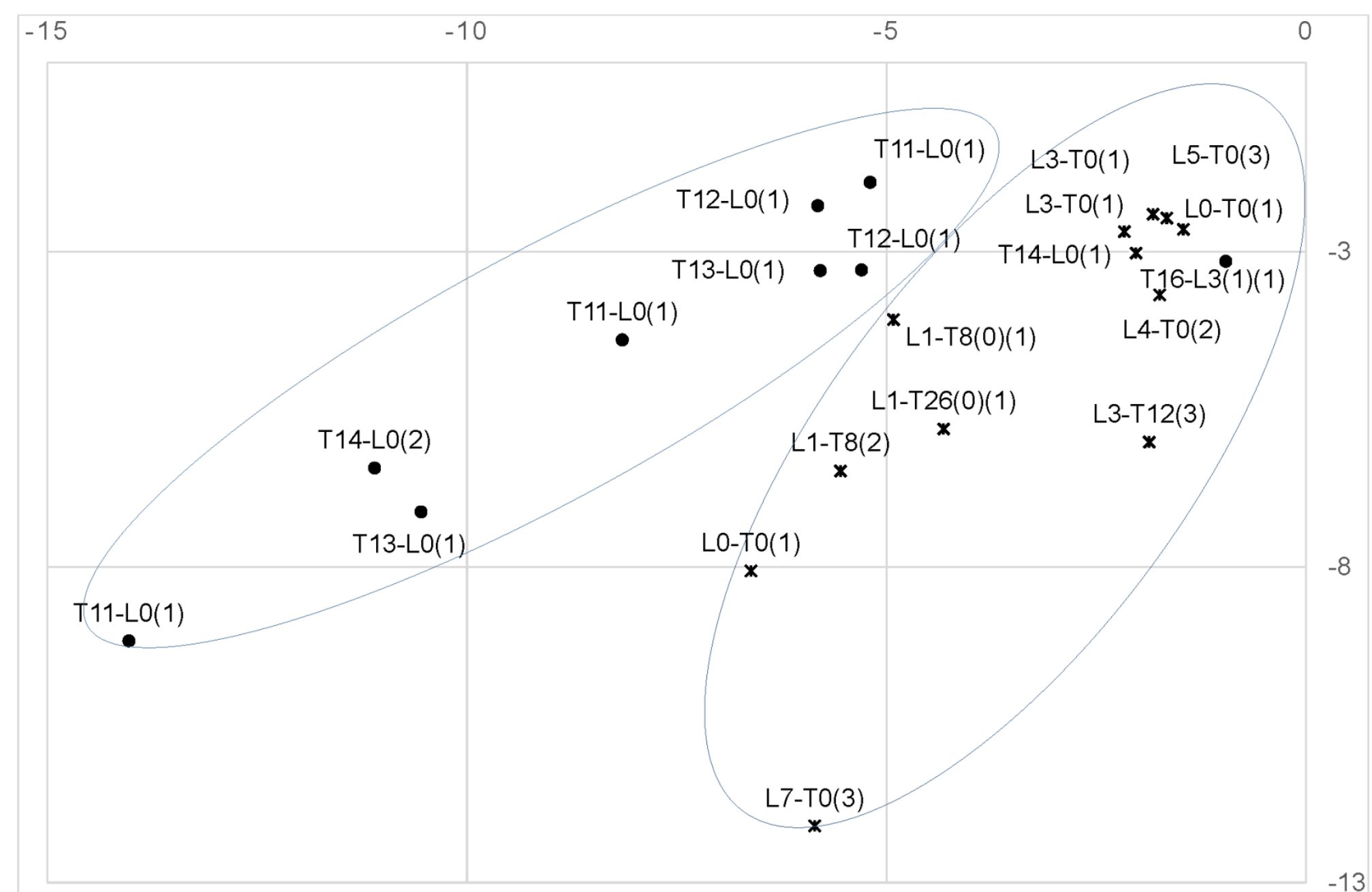

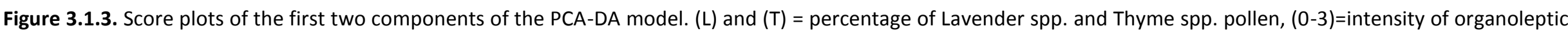
perception of the first named honey. 
Table 3.1.3 summarizes the information concerning commercial labelling and possible classifications of samples according to several criteria: percentage of pollen, olfatogustatory profile and volatile compound obtained from discriminant analysis. Additionally, chi-square tests are shown to assess the relationship between commercial labelling and the classification provided by each criterion.

Table 3.1.3. Comparison of commercial labelling and possible classifications of samples according to presence of pollen, organoleptic profile and volatile compounds.

\begin{tabular}{|c|c|c|c|c|}
\hline Brand Code & $\begin{array}{c}\text { Commercial } \\
\text { labelling }\end{array}$ & Pollen & $\begin{array}{c}\text { Olfato-gustatory } \\
\text { profile }\end{array}$ & $\begin{array}{c}\text { Volatile } \\
\text { compound }\end{array}$ \\
\hline L1-T8 & Lavender & Polyfloral & Lavender & Lavender \\
\hline L3-T12 & Lavender & Thyme & Lavender & Lavender \\
\hline L1-T8 & Lavander & Polyfloral & Thyme & Thyme \\
\hline L3-TO & Lavander & Polyfloral & Lavander & Lavander \\
\hline L7-T0 & Lavander & Polyfloral & Lavander & Lavander \\
\hline L1-T26 & Lavander & Thyme & Thyme & Lavander \\
\hline L3-TO & Lavander & Polyfloral & Lavander & Lavander \\
\hline L4-TO & Lavander & Polyfloral & Lavander & Lavander \\
\hline L5-TO & Lavander & Polyfloral & Lavander & Lavander \\
\hline LO-TO & Lavander & Polyfloral & Lavander & Lavander \\
\hline LO-TO & Lavander & Polyfloral & Lavander & Lavander \\
\hline T14-L0 & Thyme & Thyme & Thyme & Thyme \\
\hline T14-L0 & Thyme & Thyme & Thyme & Thyme \\
\hline T12-L0 & Thyme & Thyme & Thyme & Thyme \\
\hline T11-L0 & Thyme & Thyme & Thyme & Thyme \\
\hline T12-L0 & Thyme & Thyme & Thyme & Thyme \\
\hline T11-L0 & Thyme & Thyme & Thyme & Thyme \\
\hline T11-L0 & Thyme & Thyme & Thyme & Thyme \\
\hline T13-L0 & Thyme & Thyme & Thyme & Thyme \\
\hline T16-L3 & Thyme & Thyme & Lavander & Lavander \\
\hline T13-L0 & Thyme & Thyme & Thyme & Thyme \\
\hline $\begin{array}{l}\% \text { of samples conform the } \\
\text { information given on the } \\
\text { Lavander label }\end{array}$ & - & $0 \%$ & $81.8 \%$ & $90.9 \%$ \\
\hline $\begin{array}{l}\% \text { of samples conform the } \\
\text { information given on the } \\
\text { thyme label }\end{array}$ & - & $100 \%$ & $90.0 \%$ & $90.0 \%$ \\
\hline$\chi^{2}$ (p-value) & - & - & $10.83(0.001)$ & $13.74(0.000)$ \\
\hline
\end{tabular}

None of the samples labelled as lavender should have been classified as such according to the pollen content (minimum $10 \%$ of Lavandula spp. pollen). Actually, they should be classified as polyfloral with the exception of two of them that could be classified as thyme honey. However, the organoleptic perception (in $81.8 \%$ of these samples) and the volatile profile (in 90.9\%) conform to the information given on the samples labelled as lavender. Regarding thyme honey, the information on the label is correct for all samples considering the pollen content (100\%). With the exception of one sample, all of them showed the characteristic olfato-gustatory profile and volatile profile of thyme 
honey $(90.0 \%$ in both cases). Chi-square tests confirm that there is a significant association between the commercial labelling and the classification given by the organoleptic perception $(\chi 2=10.83, p=0.001)$ and overall by the volatile compounds $(x 2=13.74, p=0.000)$.

\section{Conclusion}

This paper highlights the importance of a detailed review of the information that appears on commercial labels. Besides, the need to identify alternative analytic techniques to help organizations provide more accurate content in their labelling processes is underlined.

This work contributes to reinforcing the usefulness of the volatile fraction of honey to provide more accurate honey labelling. The results offer compelling evidence that the volatile compound profile can be used for the classification of lavender type honey since this technique agrees quite well with the organoleptic analysis. The volatile analysis has a clear advantage over the pollinic one in the case of lavender honey.

In general, when pollen content is under-represented, volatile analysis could be a complementary technique to the pollinic one. Obviously, this analysis would only be recommended when honey has specific identifiable organoleptic characteristics.

The present findings have important implications for solving problems in the honey sector regarding the correct classification of underrepresented monofloral honey. Organizations may benefit from this new approach to volatile information, and consumers may buy honey products with guaranteed botanical origin. Considering these results, there are still some undefined sources of unreliability that may influence the final classification of samples containing a mixture of lavender and thyme characteristics. We are aware that the research needs to be expanded to include a greater number of samples from a wider time period.

\section{Acknowledgment}

The authors thank the Generalitat Valenciana (Spain) for funding the project AICO/2015/104.

\section{References}

Alissandrakis, E., Tarantilis, P. A., Harizanis, P. C., \& Polissio, M. (2007). Comparison of the Volatile Composition in Thyme Honeys from Several Origins in Greece. Journal of Agricultural and Food Chemistry, 55, 8152-8157. 
ANIPAM (Asociación Nacional Interprofesional de plantas aromáticas y medicinales) (2008). Estudio de la situación actual del lavandín súper y del coriandro en el marco del proyecto de cooperación territorial nuevas alternativas agrarias. http://www.anipam.es/menu/documentos-pam.html. Accessed 10/12/16.

Bogdanov, S., Ruoff, K., \& Persano-Oddo, L. (2004). Physico-chemical methods for the characterisation of unifloral honeys: a review. Apidologie, 35, 4-17.

Bogdanov, S. (2009). Harmonized methods of the International Honey Commission. http://www.bee-hexagon.net/en/network.htm. Accessed 17/09/2016.

Bouseta, A., Collins, S., \& Dufour, J. P. (1992). Characteristic aroma profiles of unifloral honeys obtained with dynamic headspace GC-MS system. Journal Apicultural Research, 31, 96-109.

Cacho, J. I., Campillo, N., Viñas, P., \& Hernández-Córdoba, M. (2015). Evaluation of three headspace sorptive extraction coatings for the determination of volatile terpenes in honey using gas chromatography-mass spectrometry. Journal of Chromatography A, 1399, 18-24.

Castro-Vázquez, L., Díaz-Maroto, M. C., González-Viñas, M. A., \& Pérez Coello, M. S. (2009). Differentiation of monofloral citrus, rosemary, eucalyptus, lavender, thyme and heather honeys based on volatile composition and sensory descriptive analysis. Food Chemistry, 112, 1022-1030.

Castro-Vázquez, L., Leon-Ruiz, V., Alañon, M. E., Pérez-Coello, M. S., \& González-Porto, A. V. (2014). Floral origin markers for authenticating Lavandin honey (Lavandula angustifolia $x$ latifolia). Discrimination from Lavender honey (Lavandula latifolia). Food Control, 37, 362-370.

Council Directive 2001/110 relating to honey (2002). Official Journal of the European Communities. L10, 47-52.

Da Silva, P. M., Gauche, C., Gonzaga, L. V., Costa, A. C. O., \& Fett, R. (2016). Honey: Chemical composition, stability and authenticity. Food Chemistry, 196, 309-323.

Escriche, I., Kadar, M., Juan-Borrás, M., \& Domenech, E. (2011). Using flavonoids, phenolic compounds and headspace volatile profile for botanical authentication of lemon and orange honeys. Food Research International, 44, 1504-1513.

González-Viñas, M. A., Moya, A., \& Cabezudo, M. A., (2003). Description of the sensory characteristics of spanish unifloral honeys by free choice profiling. Journal of Sensory Studies, 18, 103-113.

Guyot-Declerck, C., Renson, S., Bouseta, A., \& Collin, S. (2002). Floral quality and discrimination of Lavandula stoechas, Lavandula angustifolia, and Lavandula angustifolia x Latifolia honey. Food Chemistry, 79, 453-459. 
ISO 4121:2003 (2003). International Organization for Standardization Guidelines for the use of quantitative response scales.

Jerkovic, I., \& Kus, P. M. (2014). Terpenes in honey: occurrence, origin and their role as chemical biomarkers. RSC Advances, 4, 31710-31728.

Juan-Borrás, M., Domenech, E., Hellebrandova, M., \& Escriche, I. (2014). Effect of country origin on physicochemical, sugar and volatile composition of acacia, sunflower and tilia honeys. Food Research International, 60, 86-94.

Juan-Borrás, M., Domenech, E., Conchado, A., \& Escriche, I. (2015). Physicochemical, quality parameters at the of the honey packaging process: Influence of type of honey, year of harvest and beekeeper. Journal of Chemistry (online). Article ID 929658, pages: 1-6 http://dx.doi.org/10.1155/2015/929658.

Juan-Borrás, M., Domenech, E., \& Escriche, I. (2015). Correlation between methyl anthranilate level and percentage of pollen in Spanish citrus honey. International Journal of Food Science and Technology, 50, 1690-1696.

Kádár, M., Juan-Borrás, M., Carot, J. M., Domenech, E., \& Escriche, I. (2011). Volatile fraction composition and physicochenical parameters as tools for the differentiation of lemon blossom honeys and orange blossom honey. Journal of Science of Food and Agriculture, 91, 2768-2776.

Kaiser, H. F. (1960). The application of electronic computers to factor analysis. Educational and Psychological Measurement, 20, 141-151.

Kaskoniene, V., Venskutonis, P. R., \& Ceksteryte, V. (2008). Composition of volatile compounds of honey of various floral origin and beebread collected in Lithuania. Food Chemistry, 111, 988-977.

Kaskoniene, V., \& Venskutonis, P. R. (2010). Floral Markers in Honey of Various Botanical and Geographic Origins: A Review. Comprehensive Reviews in Food Science and Food Safety, 9, 620-634.

Karabagias, I. K., Badeka, A., Kontakos, S., Karabournioti, S., \& Kontominas, M. G. (2014). Characterization and classification of Thymus capitatus (L.) honey according to geographical origin based on volatile compounds, physicochemical parameters and chemometrics. Food Research International, 55, 363-372.

Manyi-Loh, C. E., Roland, N., \& Clarke, A. M. (2011). Volatile Compounds in Honey: A Review on Their Involvement in Aroma, Botanical Origin Determination and Potential Biomedical Activities. International Journal of Molecular Science, 12, 9514-9532.

Mateu, I. (2002). Flora valenciana de interés apícola. Mètode, 33, 45-50. 
Moreira, R. F. A., \& de María, C. A. B. (2005). Investigation of the aroma compounds from headspace and aqueous solution from the cambara (Gochnatia velutina) honey. Flavour and Fragrance Journal, 20, 13-17.

Persano-Oddo, L., \& Piro, R. (2004). Main European unifloral honeys: descriptive sheets. Apidologie, 35, 38-81.

Pollen viability and natural hybridization of Central European species

The Apis Information Resource Center website (2016). Lavender Provence's Prime, Problematic Honey Plant. http://beekeep.info/letters-from-france/frenchbeekeeping-2/lavender-provences-prime-problematic-honey-plant/. Accessed 15/12/2016.

Von Der Ohe, W., Persano-Oddo, L., Piana, M. L., Morlot, M., \& Martin, P. (2004). Harmonized methods of melissopalynology. Apidologie, 35, 18-25. 
3.2. Using an automatic pulse voltammetric electronic tongue to verify the origin of honey from Spain, Honduras and Mozambique

Lara Sobrino-Gregorio, Fernando Tanleque-Alberto, Román Bataller, Juan Soto, Isabel Escriche

Journal of Science of Food and Agriculture, 100, 212-217 (2020) 



\section{ABSTRACT}

Background: The growing need to classify the origin of honey in a simple way, is leading to the development of affordable analytical equipment that is in-line and manageable enabling rapid on-site screening. Therefore, the aim of this work was to evaluate whether an electronic tongue (made of four metallic electrodes: Ir, Rh, Pt, Au) based on potential multistep pulse voltammetry with electrochemical polishing is able to differentiate between honey samples from Spain, Honduras and Mozambique.

Results: It has been demonstrated for the first time that an automatic pulse voltammetry, in combination with a PCA statistical analysis, is able to differentiate honey samples from these three countries. A PLS analysis predicted the level of certain physicochemical parameters; the best result being for conductivity and moisture with correlation coefficients of 0.948 and 0.879 , whereas the weakest correlation was for the sugars.

Conclusion: The tool proposed in this study could be applied to ensure the country origin of the three types of multifloral honey here considered. It also offers promising perspectives for expanding the knowledge of the provenance of honey. All this could be achieved once a comprehensive database with the information generated by this electronic tongue has been created.

Keywords: honey; country-origin; pulse-voltammetric-electronic-tongue; physicochemical parameters.

\section{Introduction}

Nowadays, consumers are increasingly interested in the possibility of choosing among different honeys with specific characteristics. The world market demands special honeys with different attributes such as geographical origin, organoleptic properties and/or attributable therapeutic properties (Kaskoniene \& Venskutonis, 2010; Soares et al., 2017). In countries where the standard of living is precarious (such as Mozambique and Honduras) and where apiculture does not play an important role, but has the potential to increase the sustainability of communities, promoting the origin of honey could be a good option in protecting and marketing this traditional food (Escriche et al., 2017; Hassani et al., 2018).

To date, melissopalynological analysis (based on the identification and quantification of the percentage of pollen) is the technique "of choice" used to classify honey according to botanical and/or geographical origin. Since this technique is very tedious and requires very skilful specialists, the new analytical tendencies to discriminate honeys are moving towards the development of more simple, environmentally friendly 
and inexpensive methodologies that permit real-time and on-site screening (Bougrini et al., 2016). This is the case of the electronic tongue system, a qualitative analytical technique that allows the classification or identification of samples. Its usefulness depends on the composition of the sensor array in combination with a multivariate analysis tools (PCA, LDA, CA, etc.), due to the enormous amount of data generated (Benedetti et al., 2004; Dias et al., 2008; Wei et al., 2009).

Electronic tongue systems have been widely used for classifying liquid and solid foodstuffs. In the specific case of honey, most of the reported papers dealt with the differentiation of samples according to their botanical origin (Dias et al., 2008; Wei et al., 2009; Major et al., 2011; Wei \& Wang, 2011; Escriche et al., 2012; Garcia-Breijo et al., 2013; Tiwari et al., 2013; Sousa et al., 2014; Bougrini et al., 2016; Juan-Borrás et al., 2017). Electronic tongue methodology was also useful in discriminating authentic honeys from adulterated ones (Oroian et al., 2018). However, the geographical origin has been considered in very few occasions and when used, in most cases was focused only on areas belonging to the same country (Wei et al., 2009; Wei \& Wang, 2011). Highlighting the few exceptions are works reported by Bougrini et al. (2016) and Hassani et al. (2018) where samples of honey from different countries were analysed using almost exclusively a cyclic voltammetric electronic tongue, but, as far it is known, pulse voltammetry electronic tongue has never been used for this purpose.

For all the above, the goal of the present study was to evaluate whether an electronic tongue based on potential multistep pulse voltammetry is able to differentiate between honey samples coming from Spain, Honduras and Mozambique. In addition, the recognition ability of the electronic tongue was correlated with classical analytical parameters.

\section{Materials and methods}

\subsection{Samples}

Sixty multifloral honey samples from three different countries were used in this study: 20 from Mozambique, 20 from Honduras and 20 from Spain. Mozambiquean samples came from the provinces of Nampula, Zambezia, Manica, Sofala, which were obtained using traditional beehives and harvesting methods (Nampula and Zambezia) or more modern methods (Sofala and Manica). Honduran samples were provided by Lencas communities located in the department of Comayagua municipality of Siguatepeque (central Honduras), in an area of environmental interest due to its proximity to Cerro Azul Meámbar National Park. Spanish samples were supplied by transhumant Valencian beekeepers that were collected in different regions of the country. 
None of the samples exhibited signs of fermentation or granulation before initiating the analyses.

\subsection{Analytical parameters}

\subsubsection{Pollen analysis}

Pollen analysis was based on the extraction of pollen grains from $10 \mathrm{~g}$ of honey (JuanBorrás et al., 2014). Each sample was dissolved in $20 \mathrm{~mL}$ of acidulated water (sulfuric acid, 5\%) and after a first centrifugation the sediment was re-dissolved with distilled water and centrifuged one more time. The observation of pollen sediment slides was carried out using a light optical microscope (Zeiss Axiolab, Göttingen, Germany). A minimum of 600 pollen grains per sample were counted. To recognize the different types of pollen, general palynological databases (Palynological Database, 2019), as well as specific from Spain (Carretero, 1989), Honduras (Callejas, 2006), and Mozambique (Schüler \& Hemp, 2016; Tanleque-Alberto et al., 2019) were used together with the reference collection of the laboratory.

In Table 3.2.1 is shown the race of the honeybee from the three countries, as well as the percentage of pollen from the predominant botanical species, and the other pollen types identified in honey sample from the three countries. The abundance of each taxa (frequency of pollen appearance) was categorized as follows: dominant or predominant pollen (> 45\%); secondary pollen (16-45\%); important minor pollen (315\%); minor pollen (1-3\%) and pollen present (<1\%) (Tanleque-Alberto et al., 2019). 
Table 3.2.1. Melissopalynological results of the analyzed honey from Spain, Honduras and Mozambique.

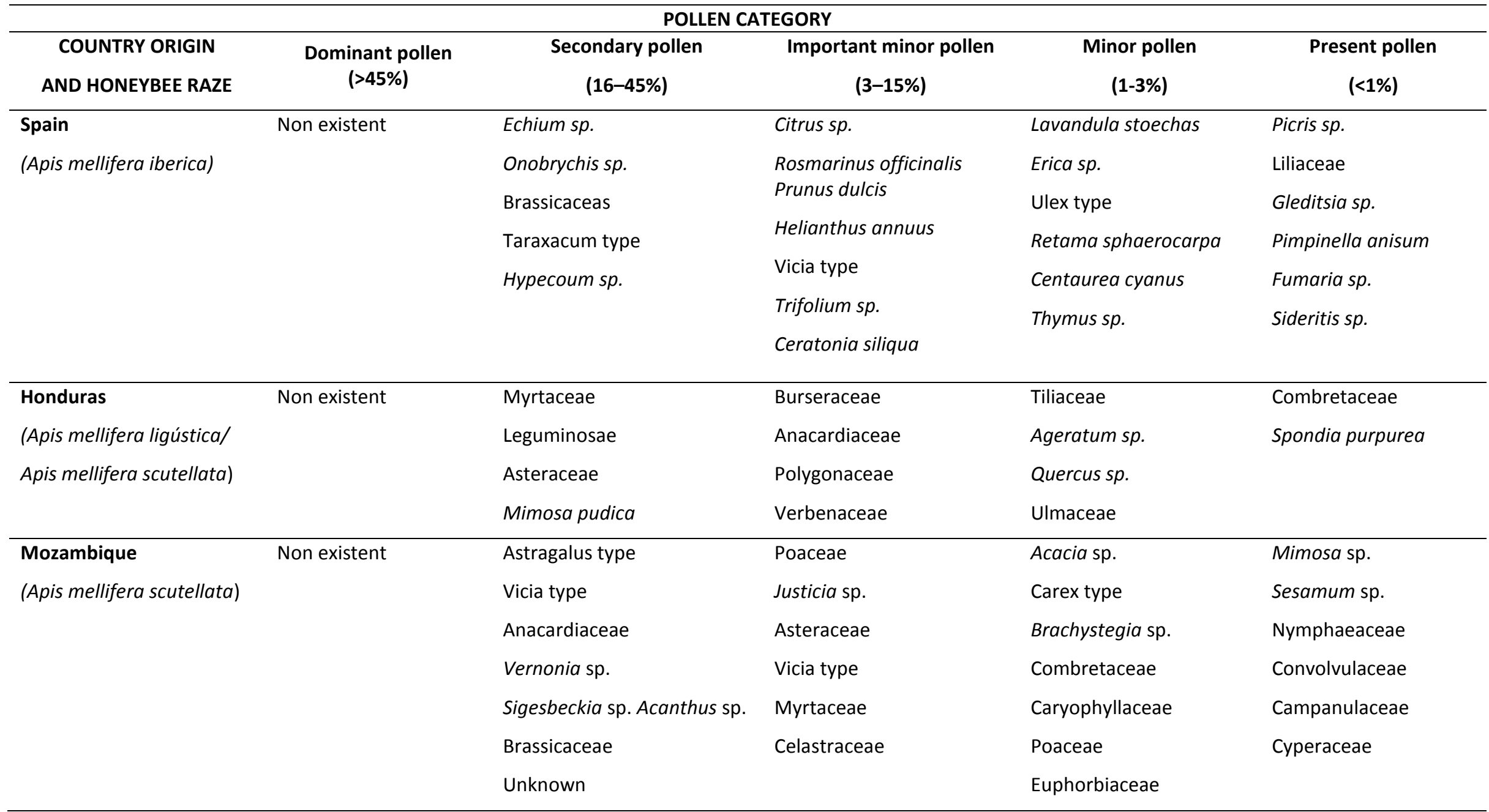




\subsubsection{Moisture}

Moisture content was obtained by using a refractometer (Abbe-type model T1; Atago, Bellevue, WA, USA) and the Chataway tables in accordance with the Harmonized Methods of the European Honey Commission (Bogdanov, 2009).

\subsubsection{Electrical conductivity}

Electrical conductivity was determined by conductimetry (Crison Instrument, Barcelona, Spain, model C830) in accordance with the Harmonized Methods of the European Honey Commission (Bogdanov, 2009).

\subsubsection{Colour}

Colour was measured using a millimetre Pfund scale C221 Honey Colour Analyzer (Hanna Instruments, Eibar, Spain).

\subsubsection{Sugar content}

Liquid Cromatograph (Agilent Technologies modelo 1120 Compact LC, Germany) with an Evaporative Light Scattering Detector (ELSD Agilent Technologies 1200 Series, Germany) and a Waters Carbohydrate column ( $4.6 \times 250 \mathrm{~mm}, 4 \mu \mathrm{m})$ was used to analyse the major sugars (fructose and glucose) (Bogdanov, 2009).

Water and acetonitrile (20/80), in isocratic mode, at a flow rate of $0.8 \mathrm{~mL} / \mathrm{min}$ was used as mobile phase. The elution was finished in 14 minutes. The detector conditions were: $50{ }^{\circ} \mathrm{C}, 3.5$ bars of gas pressure $\left(\mathrm{N}_{2}\right)$ and gain=6. EZChrom Elite system software was used for data processing. Calibration curves of the corresponding external standards were used for quantification. The limits of quantification of both sugars were $0.1 \mathrm{~g} / 100 \mathrm{~g}$ honey.

\subsection{Voltammetric electronic tongue analysis}

A previous dilution in water (up to $50 \mathrm{~mL}$ ) of the sample was only necessary to start the voltammetric analysis. For each iteration $8 \mathrm{~g}$ (in dry matter) of sample was weighed, being dry matter equal to 100 minus moisture (in percentage). The reason for this procedure was to standardize the quantity of sample used for each measurement, since the moisture content was different for all honey samples.

The pulse voltammetry measurements were carried out in an equipment, based on a potentiostat, designed at the Universitat Politècnica de València (Institute of Molecular Recognition and Technological Development-IDM) (Campos et al., 2013). In the present work, 40 pulses of 50 ms were applied. Figure 3.2.1 shows a typical distribution of voltages (similar to a stair case) in increasing or decreasing steps of 200 
$\mathrm{mV}$ between $+1 \mathrm{~V}$ and $-1 \mathrm{~V}$ (to avoid water electrolysis). The potential was set to zero after each increment.

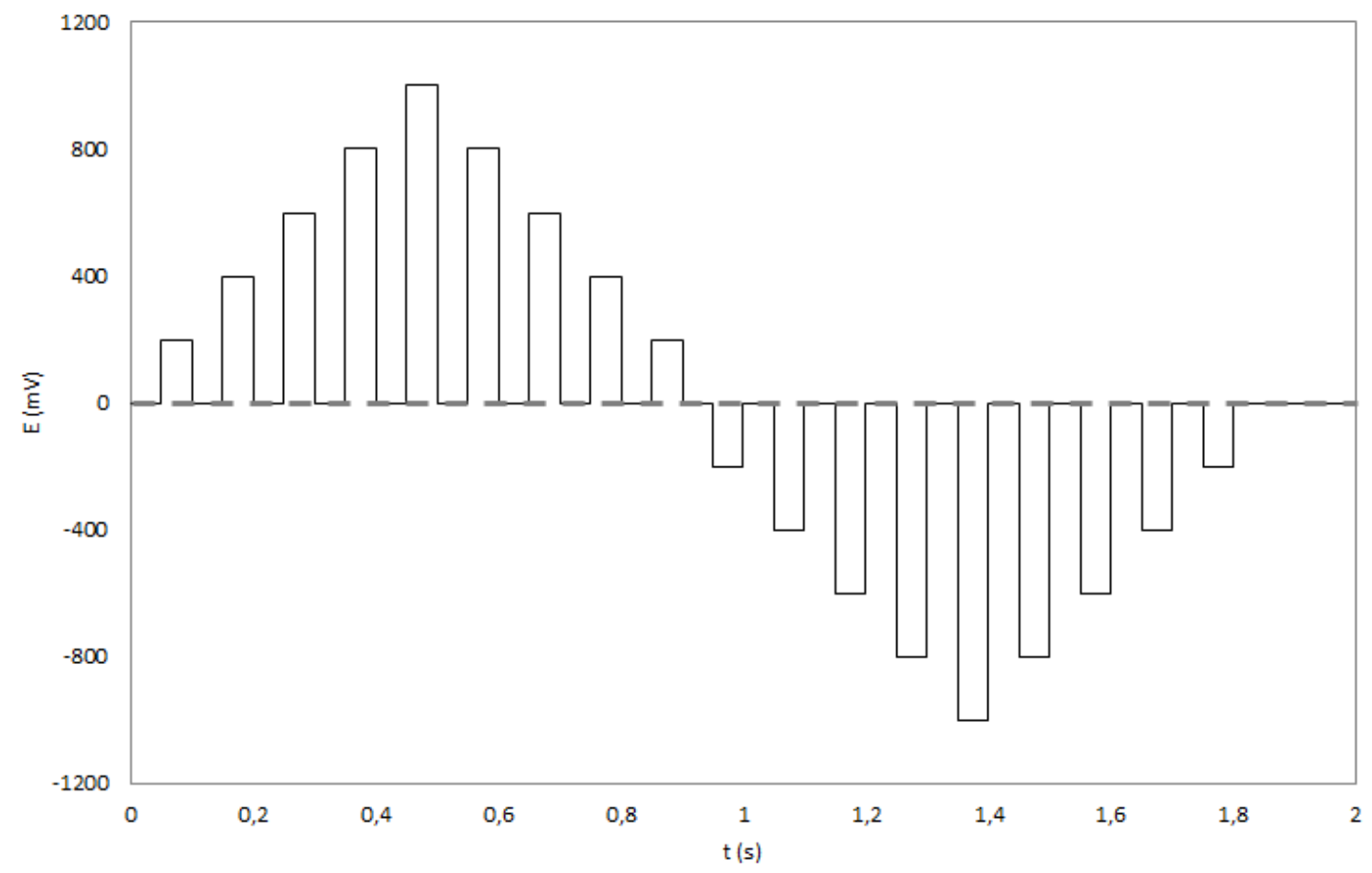

Figure 3.2.1. Typical voltammetric pulse pattern.

Four working electrodes (Ir, Rh, Pt and Au) were used in the voltammetry tests. The electronic tongue body consisted in these electrodes placed inside a stainless-steel cylinder. In all cases a calomel electrode was used as reference and a stainless steel circular piece as counter electrode. This device included an innovative electrochemical polishing of the working electrodes previously describe by Sobrino-Gregorio et al. (2018).

An in-house specific software designed by Campos et al. (2013) permitted the controlling of both the pumping system and the measurement of the equipment. The described electronic tongue was patented by Bataller et al. (2016).

All samples were analysed in triplicate.

\subsection{Statistical analysis}

An analysis of variance (ANOVA) using Statgraphics Centurion 16.1 was applied to study the influence of the country origin of honey on each the analytical parameter (moisture, electrical conductivity, colour fructose and glucose). Least Significant Difference (LSD) at significance level $\alpha=5 \%$ was used to analyse the differences between samples. A full residual analysis was previously carried out for checking the assumptions of ANOVA, which indicated that this analysis was suitable for all the dataset. In this respect, independence (each sample was randomly selected and 
independent), homoscedasticity (by means of Levene's test) and normality (by means of a normal probability plot) were all tested.

Multivariate statistical analysis techniques were used to analyse the data generated by the electronic tongue response. Principal Components Analysis (PCA) was applied to discriminate between samples and Partial Least Square (PLS) to correlate the data of electronic tongue with each one of the analytical parameters. The PLS model was calibrated with $66 \%$ of the data set and validated with the remaining $33 \%$ and the assessment was carried out by comparing real versus predicted physicochemical analysis. The parameters considered in the model were: correlation coefficient $\left(r^{2}\right), a, b$ (from the simplest linear model: $y=a x+b$ ) and the root mean square error of prediction (RMSEP), as the most common metric obtained to measure the accuracy of this methodology (Bataller et al., 2012).

The multivariate statistical analysis was performed with Solo 8.6 software (Eigenvector Research, Inc., Wenatchee, Washington, DC, USA).

\section{Results and discussion}

\subsection{Analytical parameters}

Table 3.2.2 shows the average and standard deviation values of the quantified analytical parameters (moisture, electrical conductivity, colour and, fructose and glucose content) in the honey samples from Spain, Honduras and Mozambique). In addition, this table illustrates the ANOVA results (F-ratio and significant differences) obtained for each analytical parameter considering the factor "country origin". Significant differences were found between the three countries for all the parameters analysed. Considering the bigger the F-ratio is, the greater the effect the factor has over one variable, the electrical conductivity (688.8) was the parameter most affected for the country of origin, followed by colour (407.7), while the sugar contents (19.0 for glucose and 6.8 for fructose) were less affected. The biggest average values of electrical conductivity $(1.254 \mathrm{mS} / \mathrm{cm})$ and colour $129 \mathrm{~mm}$ Pfund) corresponded to samples from Mozambique whereas moisture $(20.7 \mathrm{~g} / 100 \mathrm{~g})$ and fructose $(42.8 \mathrm{~g} / 100$ g) to samples from Honduras. On the contrary, the smallest values of all the parameters analysed were found in Spanish samples (average of $16.5 \mathrm{~g} / 100 \mathrm{~g}, 0.426$ $\mathrm{mS} / \mathrm{cm}, 68 \mathrm{~mm}$ Pfund and $38.8 \mathrm{~g} / 100 \mathrm{~g}$ for moisture, electrical conductivity, colour and fructose, respectively), except for glucose, where it obtained the highest value (34.0 $\mathrm{g} / 100 \mathrm{~g})$. 
Table 3.2.2. Mean and standard deviation values of moisture, electrical conductivity, colour, fructose and glucose found in honey from different countries (Mozambique, Honduras and Spain) and ANOVA results (F-ratio and significant differences).

\begin{tabular}{|c|c|c|c|c|c|}
\hline & $\begin{array}{l}\text { Moisture } \\
\text { (g/100 g) }\end{array}$ & $\begin{array}{l}\text { Electrical conductivity } \\
\qquad(\mathrm{mS} / \mathrm{cm})\end{array}$ & $\begin{array}{c}\text { Colour } \\
\text { (mmPfund) }\end{array}$ & $\begin{array}{l}\text { Fructose } \\
\text { (g/100 g) }\end{array}$ & $\begin{array}{l}\text { Glucose } \\
\text { (g/100 g) }\end{array}$ \\
\hline Mozambique & $19.5(1.5) b$ & $1.254(0.157) c$ & $129(18) c$ & $41.2(3.2) \mathrm{b}$ & $32.4(2.1) a$ \\
\hline Honduras & $20.7(1.3) \mathrm{c}$ & $0.496(0.162) b$ & $75(12) b$ & $42.4(4.6) c$ & $33.4(3.1) b$ \\
\hline Spain & $16.5(0.7) a$ & $0.426(0.060) a$ & $68(6) a$ & $38.8(0.5) a$ & $34.0(0.9) \mathrm{c}$ \\
\hline \multicolumn{6}{|l|}{ ANOVA } \\
\hline F-ratio & $179.5^{* * *}$ & $688.8 * * *$ & $407.7^{* * *}$ & $6.8^{* *}$ & $19.0 * * *$ \\
\hline
\end{tabular}

According to findings in other studies related to honey from different origins, moisture content values obtained herein (Table 3.2.1) are in the same range as: Africa [Southern African, from 15.3 to $21.7 \mathrm{~g} / 100 \mathrm{~g}$ (Zandamela, 2008; Serem \& Bester, 2012); North Africa, from 14.2 to $22.1 \mathrm{~g} / 100 \mathrm{~g}$ ] (Belay et al., 2013; Escriche et al., 2016); Southern and Central American honey, from 16.4 to $19.4 \mathrm{~g} / 100 \mathrm{~g}$ (Do Nascimento et al., 2018); or European from, 15.2 to $19.9 \mathrm{~g} / 100 \mathrm{~g}$ (Kadar et al., 2011). On the contrary, in other African honey, higher and lower values of electrical conductivity and colour were found: $4.18 \mathrm{mS} / \mathrm{cm}$ and $56 \mathrm{~mm}$ Pfund from Yemen; $1.98 \mathrm{mS} / \mathrm{cm}$ and $73 \mathrm{~mm}$ Pfund from Egypt; $0.67 \mathrm{mS} / \mathrm{cm}$ and $89 \mathrm{~mm}$ Pfund from Kashmir or $0.53 \mathrm{mS} / \mathrm{cm}$ and $113 \mathrm{~mm}$ Pfund from Saudi (Sohaimy et al., 2015).

The differences in the levels of moisture detected between countries could be due to the beekeeping practices: harvesting of honey must be done when honeybees have operculated honey. In this respect, the local climate could also have an influence (Tanleque-Alberto et al., 2019). The electrical conductivity and colour are related to the type of vegetation visited by the honeybees. In general, both parameters are higher when honey came from exudates of plants and lower in the case that honeybees collect nectar from flowers. In the same way, the concentration of sugars is influenced by the vegetation surrounding the hives (Escriche et al., 2012; Escriche et al., 2017; Tanleque-Alberto et al., 2019).

\subsection{Voltammetric electronic tongue analysis}

\subsubsection{Differentiation of honey samples}

Figure 3.2.2 shows, as an example, the pattern of the signal obtained by applying the corresponding potential pulse to the honey samples from the three countries considered in this work. There is a clear differentiation between the signals obtained for the three countries demonstrating that these are affected by the origin of samples. The highest signal corresponds to honey from Spain, followed by Mozambique and Honduras. 


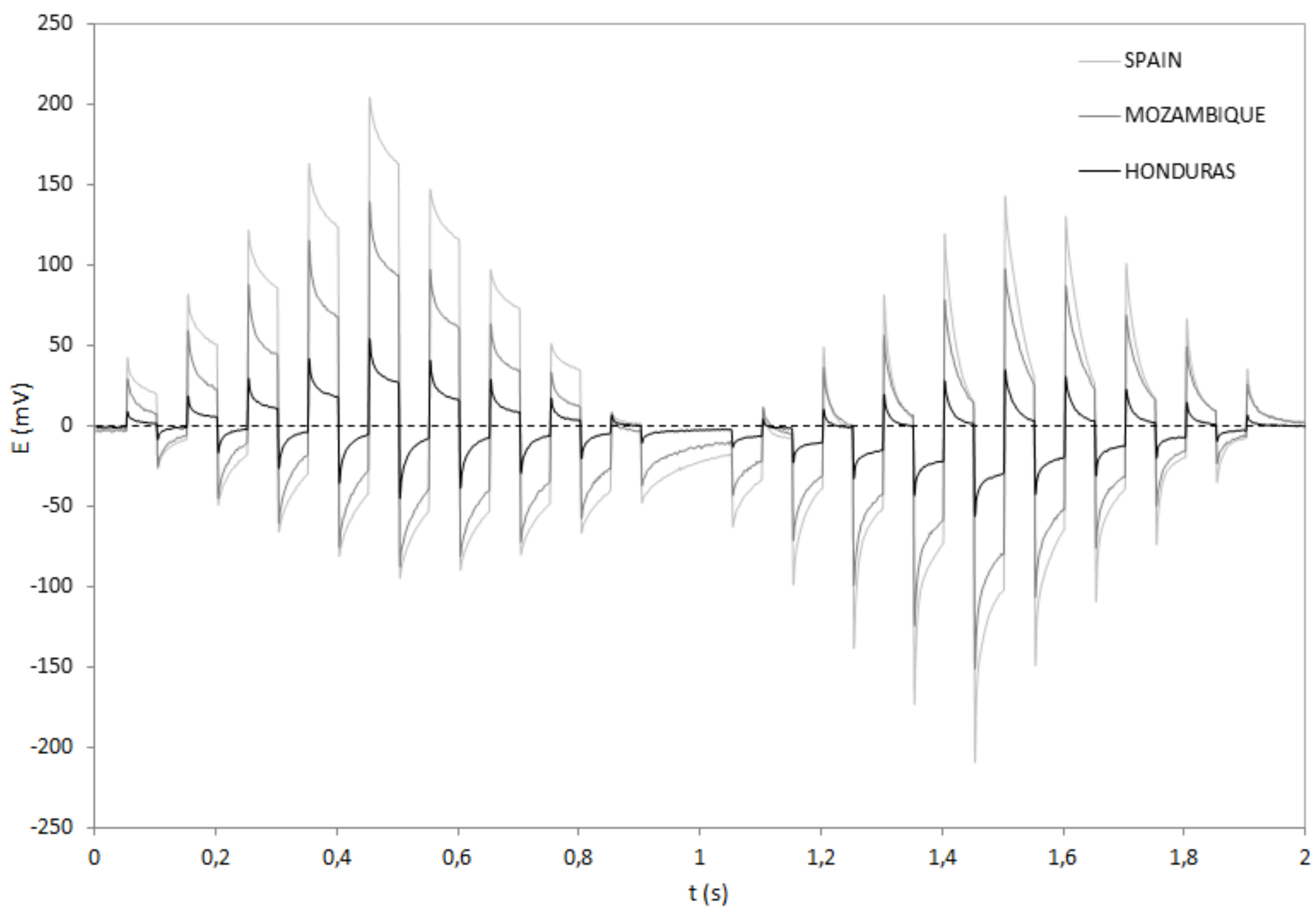

Figure 3.2.2. Electrochemical trace of the layered sequence of the potential for honey samples from three different countries: Mozambique, Honduras and Spain. 
A PCA analysis, from the data generated by electronic tongue, was applied in order to show if there was a spontaneous differentiation of the samples studied. Figure 3.2.3 shows the score plot of this analysis, in which the first two principal components together explain $89.96 \%$ of the data variability, specifically $78.29 \%$ by PC1 and $11.67 \%$ by PC2. Discrimination between Mozambique samples and those from the other two countries is mainly determined by the $X$ axis (PC1), where the honey samples of Mozambique are in the left of the score graph and the others, in the right. Since, proximity between samples indicates similar behaviour in terms of the electrochemical response of the sensors, small differences between Honduras and Spanish samples in the $X$ axis (PC1) were found. However, these two origins are differentiated by PC2, where Spanish honey is in the upper half and Honduras honey in the lower half.

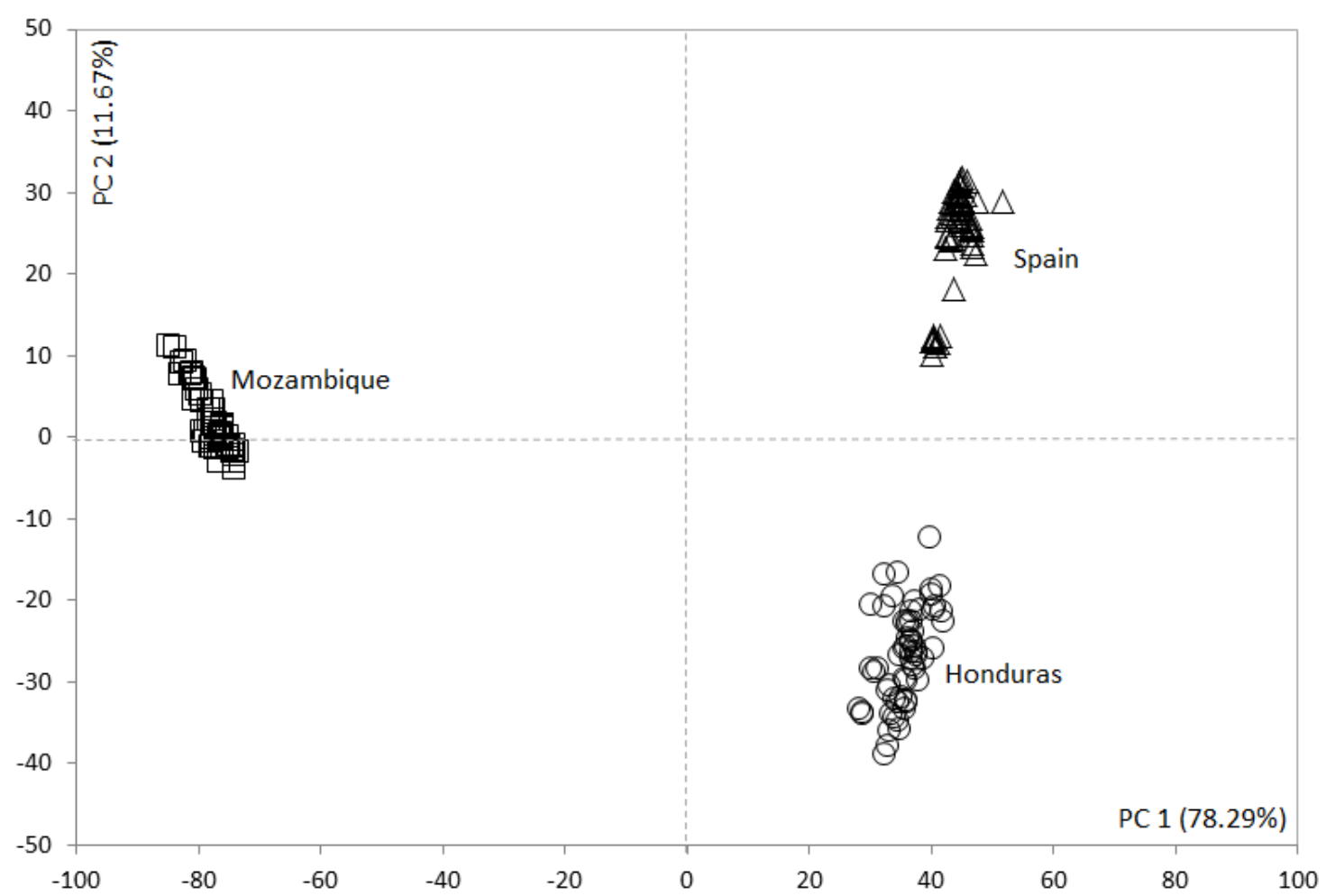

Figure 3.2.3. Score plot of the PCA performed on multifloral honey samples from three different countries: Mozambique, Honduras and Spain.

Similar results were reported by Hassani et al. (2018) where a cyclic voltammetry was used as an electronic tongue. Bougrini et al. (2016) applying a cyclic voltammetry also obtained an acceptable discrimination of honey originated from different countries, but only explaining $63 \%$ of the variability of the data with the first two components. 


\subsubsection{PLS analysis}

A Partial Least Square (PLS) analysis was applied in order to verify whether the data provided by the electronic tongue could be useful in predicting the analytical parameters: moisture, electrical conductivity, colour and sugars content. Five PLS models of prediction were created (origin $\times 5$ physicochemical analysis) with the voltammetric experimental data obtained. Table 3.2.3 shows the PLS prediction results (number of latent variables, the regression coefficient, slope, intercept and RMSEP) for the five models obtained. The best results were for the conductivity, moisture and colour with correlation coefficients of $0.948,0.879$ and 0.864 , respectively. The weakest correlation was for the sugars (fructose: 0.201 and glucose: 0.094). Hassani et al. (2018) obtained better results applying cyclic voltammetry but using different parameters: phenols (0.997), HMF (0.996), total acidity (0.991) and proteins (0.969). In order to quantitatively describe the accuracy in prediction, the slope and the intercept were calculated (Table 3.2.3). Moreover, parameter RMSEP (root mean square error of prediction) was also determined to evaluate the precision of the model. Thus, the PLS model is better when the slope value approaches 1 and when the RMSEP value comes close to 0 . The best results in terms of accuracy were for colour (0.954), moisture (0.886) and conductivity (0.874) and, in terms of precision: conductivity (0.097) followed by the moisture (0.772). In this case, the worst model was for colour (10.845). On the contrary, in terms of precision, Hassani et al. (2018) obtained a better result in colour (value of 0.103 ). In the same study, the errors ranged between 0.015 for sucrose and 0.184 for free acidity.

Table 3.2.3. PLS prediction results obtained from the validation data for the multifloral honeys with analytical parameters.

\begin{tabular}{llllll}
\hline $\begin{array}{c}\text { Analytical } \\
\text { Parameters }\end{array}$ & $\begin{array}{c}\text { No. latent } \\
\text { variables }\end{array}$ & $\begin{array}{l}\text { Correlation } \\
\text { coefficient }\end{array}$ & Slope & Intercept & RMSEP \\
\hline Conductivity & 3 & 0.948 & 0.874 & 0.101 & 0.097 \\
Moisture & 6 & 0.879 & 0.886 & 2.226 & 0.772 \\
Colour & 5 & 0.864 & 0.954 & 5.150 & 10.845 \\
Fructose & 3 & 0.201 & 0.229 & 31.344 & 3.147 \\
Glucose & 2 & 0.094 & 0.096 & 29.143 & 4.618 \\
\hline
\end{tabular}

\section{Conclusions}

This work successfully demonstrated that an automatic pulse voltammetry electronic tongue system (made of $\mathrm{Ir}, \mathrm{Rh}, \mathrm{Pt}, \mathrm{Au}$ ), with electrochemical cleaning and polishing, can be applied in a simple way to differentiate honey samples from Spain, Honduras and Mozambique. This tool, in combination with a PCA multivariate analyses offers encouraging perspectives for expanding the knowledge of the geographical origin of 
honey. The present findings might help to solve the necessity to have manageable and on-site analytical equipment that enables a rapid screening and also a more affordable instrument for the apiculture sector. However, future studies on the current topic are recommended, in order to create a wider and more comprehensive database of different types of honey from as many geographical origins as possible.

\section{Acknowledgment}

This study forms part of the projects funded by the "Ministerio de economía y competitividad", "Agencia Estatal de Investigación" and "Fondo Europeo de Desarrollo Regional" (AGL2016-77702-R) and by the Programa ADSIDEO-cooperación 2016 del Centro de Cooperación al Desarrollo de la Universitat Politècnica de València of Spain, for which the authors are grateful.

\section{References}

Bataller, R., Campos, I., Laguarda-Miro, N., Alcañiz, M., Soto, J., Martínez-Máñez, R., Gil, L., García-Breijo, E., \& Ibáñez-Civera, J. (2012). Glyphosate detection by means of a voltammetric electronic tongue and discrimination of potential interferents. Sensors, 12, 17553-17568.

Bataller, R., Martínez-Bisbal, M. C., Alcañiz, M., Berlanga-Clavijo, J. G., Carbó-Mestre, N, Folch, E., \& Tormos, I. (2016). Sistema y método de control de la calidad del agua en plantas de tratamiento. P201631405 (patent).

Belay, A., Solomon, W. K., Bultossa, G., Adgaba, N., \& Melaku, S. (2013). Physicochemical properties of the Harenna forest honey, Bale, Ethiopia. Food Chemistry, 141, 3386-3392.

Benedetti, S., Mannino, S., Sabatini, A. G., \& Marcazzan, G. L. (2004). Electronic nose and neural network use for the classification of honey. Apidologie, 35, 397-402.

Bogdanov, S. (2009). Harmonized methods of the International Honey Commission (2009). http://www.terezinka.cz/vcely/Med/IHCmethods_e.pdf. Accessed 10/02/2019.

Bougrini, M., Tahri, K., Saidi, T., Hassani, N. E. A. E., Bouchikhi, B., \& Bari, N. E. (2016). Classification of honey according to geographical and botanical origins and detection of its adulteration using voltammetric electronic tongue. Food Analytical Methods, 9, 2161-2173.

Callejas, M. C. (2006). Desarrollo de la norma técnica para polen en Honduras. https://bdigital.zamorano.edu/bitstream/11036/5380/1/AGI-2006-T005. Pdf. Accessed 10/02/2019. 
Campos, I., Bataller, R., Armero, R., Gandia, J. M., Soto, J., Martínez-Máñez, R., \& GilSánchez, L. (2013). Monitoring grape ripeness using a voltammetric electronic tongue. Food Research International, 54, 1369-1375.

Carretero, J. L. (1989). Análisis polínico de la miel. Ediciones Mundi-Prensa. Madrid, España.

Dias, L. A., Peres, A. M., Vilas-Boas, M., Rocha, M. A., Estevinho, L., \& Machado, A. (2008). An electronic tongue for honey classification. Microchimica Acta, 163, 97102.

Do Nascimento, K. S., Sattler, J. A. G., Macedo, L. F. L., González, C. V. S., De Melo, I. L. P., Da Silva Araújo, E.,... \& De Almeida-Muradian, L. B. (2018). Phenolic compounds, antioxidant capacity and physicochemical properties of Brazilian Apis mellifera honeys. LWT - Food Science and Technology, 91, 85-94.

Escriche, I., Kadar, M., Domenech, E., \& Gil-Sánchez, L. (2012). A potentiometric electronic tongue for the discrimination of honey according to the botanical origin. Comparison with traditional methodologies: Physicochemical parameters and volatile profile. Journal of Food Engineering, 109, 449-456.

Escriche, I., Oroian, M., Visquert, M., Gras, M. L., \& Vidal, D. (2016). Rheological properties of honey from Burkina Faso: Loss modulus and complex viscosity modeling. International Journal of Food Properties, 19, 2575-2586.

Escriche, I., Tanleque-Alberto, F., Visquert, M., \& Oroian, M. (2017). Physicochemical and rheological characterization of honey from Mozambique. LWT - Food Science and Technology, 86, 108-115.

Garcia-Breijo, E., Garrigues, J., Sanchez, L. G., \& Laguarda-Miro, N. (2013). An embedded simplified Fuzzy ARTMAP implemented on a microcontroller for food classification. Sensors, 13, 10418-10429.

Hassani, N. E. A. E., Tahri, K., Llobet, E., Bouchikhi, B., Errachid, A., Zine, N., \& Bari, N. E. (2018). Emerging approach for analytical characterization and geographical classification of Moroccan and French honeys by means of a voltammetric electronic tongue. Food Chemistry, 243, 36-42.

Juan-Borrás, M., Soto, J., Gil-Sánchez, L., Pascual-Maté, A., \& Escriche, I. (2017). Antioxidant activity and physico-chemical parameters for the differentiation of honey using a potentiometric electronic tongue. Journal of the Science of Food and Agriculture, 97, 2215-2222.

Kadar, M., Juan-Borrás, M., Carot, J. M., Domenech, E., \& Escriche, I. (2011). Volatile fraction composition and physicochemical parameters as tools for the differentiation of lemon blossom honey and orange blossom honey. Journal of the Science of Food and Agriculture, 91, 2768-2776. 
Kaskoniene, V., \& Venskutonis, P. R. (2010). Floral markers in honey of various botanical and geographic origins: a review. Comprehensive Reviews in Food Science and Food Safety, 9, 620-634.

Major, N., Markovic, K., Krpan, M., Saric, G., Hruskar, M., \& Vahcic, N. (2011). Rapid honey characterization and botanical classification by an electronic tongue. Talanta, 85, 569-574.

Oroian, M., Padure,t S., \& Ropciuc, S. (2018). Honey adulteration detection: voltammetric e-tongue versus official methods for physicochemical parameter determination. Journal of the Science of Food and Agriculture, 98, 4304-4311.

Palynological Database on line. https://www.paldat.org/info. Accessed 10/02/2019.

Schüler, L., \& Hemp, A. (2016). Atlas of pollen and spores and their parent taxa of Mt Kilimanjaro and tropical East Africa. Quaternary International, 425, 301-386.

Serem, J. C., \& Bester, M. J. (2012). Physicochemical properties, antioxidant activity and cellular protective effects of honeys from southern Africa. Food Chemistry, 133, 1544-1550.

Soares, S., Amaral, J. S., Oliveira, M. B. P. P., \& Mafra, I. (2017). A comprehensive review on the main honey authentication issues: production and origin. Comprehensive Reviews in Food Science and Food Safety, 16, 1072-1100.

Sobrino-Gregorio, L., Bataller, R., Soto, J., \& Escriche, I. (2018). Monitoring honey adulteration with sugar syrups using an automatic pulse voltammetric electronic tongue. Food Control, 91, 254-260.

Sohaimy, S. A. E., Masry, S. H. D., \& Shehata, M. G. (2015). Physicochemical characteristics of honey from different origins. Annals of Agricultural Science, 60, 279-287.

Sousa, M. E. B. C., Dias, L. G., Veloso, A. C. A., Estevinho, L., Peres, A. M., Machado, A. A. S. C. (2014). Practical procedure for discriminating monofloral honey with abroad pollen profile variability using an electronic tongue. Talanta, 128, 284292.

Tanleque-Alberto, F., Juan-Borrás, M., \& Escriche, I. (2019). Quality parameters, pollen and volatile profiles of honey from North and Central Mozambique. Food Chemitry, 277, 543-553.

Tiwari, K., Tudu, B., Bandyopadhyay, R., \& Chatterjee, A. (2013). Identification of monofloral honey using voltammetric electronic tongue. Journal of Food Engineering, 117, 205-210.

Wei, Z., \& Wang, J. (2011). Classification of monofloral honeys by voltammetric electronic tongue with chemometrics method. Electrochimca Acta, 56, 49074915. 
Wei, Z., Wang, J., \& Liao, W. (2009), Technique potential for classification of honey by electronic tongue. Journal of Food Engineering, 94, 260-266.

Zandamela, E. M. F. (2008). Caracterización Fisicoquímica y Evaluación Sanitaria de la miel de Mozambique. Tesis Doctoral. Universitat Autónoma de Barcelona. 

3.3. Thermal properties of honey as affected by the addition of sugar syrup Lara Sobrino-Gregorio, María Vargas, Amparo Chiralt, Isabel Escriche Journal of Food Engineering, 213, 69-75 (2017) 



\section{ABSTRACT}

Ensuring the authenticity of honey is a priority for producers and regulatory authorities. The aim of this work was to evaluate the thermal properties (using a Differential Scanning Calorimeter "DSC") of ten types of sugar syrup, six types of honey and mixtures of sunflower honey with all these syrups at different proportions simulating the adulteration of honey (ratio honey/syrup: 80/20; 90/10; 95/05). The glass transition temperature ( $\mathrm{Tg}$ midpoint) ranged from 60.2 으 $\mathrm{C}$ to 67.3 으 $\mathrm{C}$ in honey samples and from $32.8{ }^{\circ} \mathrm{C}$ to $95.8{ }^{\circ} \mathrm{C}$ in syrup samples. The differences in sugar composition of the syrups mainly affect their thermal properties. In the adulterated samples, the glass transition temperature was affected by the type of syrup, proportionally to the adulteration level. These results offer compelling evidence that the DSC can be used for the identification of addition of syrup to honey, although to be conclusive a greater number of honey types must be considered.

Keywords: Differential scanning calorimetry; adulteration; glass transition; honey; syrup.

\section{Introduction}

Food fraud is the economically motivated adulteration of any edible product for financial gain. Many food fraud databases reporting these incidents in Europe in recent years have highlighted that honey is highly vulnerable to food fraud as it represents about the $90 \%$ of all entries related to sweeteners (Food Fraud Database, 2016; FoodSHIELD, 2016; RASFF, 2016). Honey adulteration has to be seen from different perspectives: (1) Public Health, as it involves the presence of uncontrolled ingredients that can cause serious health problems when the adulterant is toxic, or allergenic in sensitive people (Everstine et al., 2013); (2) Legal, as it is strictly forbidden to add anything to honey; this requirement is established in Codex Alimentarius and has been adopted by E.U. legislation and some U.S. states (Codex Alimentarius Commission, 1981; Europa, 2010; United States Food and Drug Administration, 2011); and (3) Economic, by unfair competition involving the industry, distributors and the livelihood of beekeepers, leading to a destabilization of markets. Therefore, guaranteeing the authenticity of honey has become a very imperative matter for the international honey market (processors, retailer, beekeepers), regulatory authorities and consumers.

Honey can be exposed to fraud worldwide. One of the most common types of adulteration of honey involves its dilution with other less expensive (three to five fold) sugar syrups such as corn, cane, agave and specially rice syrup, among others. Rice syrup is widely used in some Asian countries, which are the origin of most of the European and U.S. imports (United States International Trade Commission, 1994). The 
importance of detecting the presence of this kind of syrup in honey is proven by the existence of classical analytical techniques that are used specifically for this syrup.

In recent years, a large number of analytical methods have been used to differentiate genuine honey from adulterated. Among them, SCIRA (stable carbon isotope mass spectrometry), reflectance-Fourier transform infrared spectroscopy and NMR spectroscopy are the most recognized (Elflein \& Raezke, 2008; Bertelli et al., 2010; Boffo et al., 2012; Rios-Corripio et al., 2012; Ohmenhaeuser et al., 2013; De Oliveira et al., 2014). These techniques are very expensive, requiring highly specialized equipment and are time-consuming. Moreover, in order to get conclusive results for one sample it would be necessary to use the results obtained by applying the combination of several of these techniques. The industrial laboratories do not have this instrumental capability; therefore, the major bottleneck in the application of these techniques is the limited number of samples that can be analysed in specialized laboratories due to both, time and financial restrictions.

The new tendency in analysis is focused on the development of alternative analytical procedures that not only enable rapid screening, but are also cheaper and greener than the traditional ones (Juan-Borrás et al., 2016). Among them, differential scanning calorimetry (DSC) has some advantages over other classical detection methodologies; it is a relatively fast technique that does not require any solvent and thus it is environmental friendly technique. Moreover, this technique uses a very small amount of sample and little preparation. Several investigations have already used DSC to study the adulteration of different kinds of food since this technique facilitates the analysis of various food components such as proteins, fats and carbohydrates (Dahimi et al., 2014; Tomaszewska-Gras, 2016). The use of DSC to assess the authenticity of sweeteners is based on the fact that each of them has its intrinsic characteristics and composition. However, there is very limited data in the literature about using melting curves for the assessment of honey authenticity; among them, the work reported by Cordella et al. in 2002, stands out. This paper proved that DSC could be a powerful technique for detecting the presence of beet and cane syrup in honey samples. Nevertheless, to be conclusive, it would be necessary to increase the number type of samples analysed both for honey and syrups. In addition, previous published studies (Lupano, 1997; Cordella et al., 2002) did not take into account the possible artefact provoked by the presence of water in the sample, since the plasticizer effect of water can distort the results of the thermal properties. In this sense, the present work presents an improvement over previous studies since samples were submitted to Iyophilization to remove the water content for samples.

The aim of this work was to apply DSC to evaluate adulteration of honey by the addition of different types of syrup. 


\section{Materials and methods}

\subsection{Materials}

Six types of raw honey harvested in 2016 in different areas of Spain, provided by the company Melazahar (Montroy, Valencia), were used in this study: sunflower (Helianthus annuus); orange blossom (Citrus spp.), rosemary (Rosmarinus officinalis), heather (Erika spp.), polyfloral honey and forest. This botanical categorization was performed by means of pollen analysis, which was quantified following the recommendations of the International Commission for Bee Botany (Von Der Ohe et al., 2004). Furthermore, in the present study syrups from different origins were used: agave (Natural Bioaprica, Spain), maple (Maple Joe, Canada), sugar cane (Ingenio Nuestra Señora del Carmen, Spain), barley (La Finestra sul Cielo, Italy); corn (Roquette Laissa, Spain); five types of rice syrup from different brands: Arroz biocesta, Spain (rice I); Danival, France (rice II); Mandolé, Spain (rice III), La Finestra sul Cielo, Italy (rice IV); and brown rice (Mitoku Macrobiotic, Japan).

The samples evaluated in the present work were: 6 types of pure honey, 10 types of pure syrup and the mixture of sunflower honey with all the types of syrup at different proportions simulating the adulteration of honey (ratio honey/syrup: 80/20; 90/10; 95/05).

\subsection{Moisture evaluation}

Water content of samples was determined using a refractrometer (Abbe-type model T1 Atago, U.S.A.) and the Chataway tables in accordance with the Harmonized Methods of the European Honey Commission (Bogdanov, 2009). The residual moisture of samples was obtained by calculating the weight difference before and after lyophilization using an analytical balance (PB303-L, Mettler Toledo).

\subsection{Sugar Analysis}

Fructose, glucose, sucrose and maltose were analyzed as described by Bogdanov et al., (1997) using a Liquid Cromatograph (Agilent Technologies modelo 1120 Compact LC, Germany) with an Evaporative Light Scattering Detector (Agilent Technologies modelo 1200 Series, Germany) and a Waters Carbohydrate column (4.6 x 250 mm, $4 \mu \mathrm{m})$. The separation of the different sugars was performed in isocratic mode with water and acetonitrile $(20 / 80)$ at a flow rate of $0.8 \mathrm{~mL} / \mathrm{min}$. The elution was finished in 14 minutes. Detector conditions were: temperature $50{ }^{\circ} \mathrm{C}$, gas pressure $\left(\mathrm{N}_{2}\right) 3.5$ bars and gain $=6$. The analysis of the data was performed with the software EZChrom Elite. Quantification of sugars was carried out using the calibration curves of the 
corresponding external standards. The quantification limits of the four sugars studied were $0.1 \mathrm{~g} / 100 \mathrm{~g}$ honey.

\subsection{Protein content}

Protein content was measured by Kjeldahl procedure (AOAC, 2000). In order to avoid the interference that pollen could cause in the quantification of proteins, honey samples were previously centrifuged.

\subsection{Differential Scanning Calorimetry (DSC)}

\subsubsection{Sample preparation}

Before determination of the thermal properties of the samples, the first step was to remove their moisture since previous studies demonstrate that moisture greatly interferes with the measurements of these properties (Kántor et al., 1999). It was possible to remove more than $98 \%$ of water by lyophilization (LyoAlfa, Telstar, Spain). Since honey and syrups do not have freezable water, it was necessary to dilute them in distilled water (1 g sample/10 g water) before lyophilization (Ospina, 2014). Diluted samples were placed in aluminium containers ( $5 \mathrm{~mL}$ in each container) and frozen at $40{ }^{\circ} \mathrm{C}$ for $24 \mathrm{~h}$, at $130 \mathrm{mmHg}$. In order to remove the residual moisture, lyophilized samples were introduced in a desiccator with $\mathrm{P}_{2} \mathrm{O}_{5}$ (Panreac, Barcelona, Spain) to reach constant weight.

\subsubsection{DSC determination}

Thermal properties of the samples were obtained by means of a Differential Scanning Calorimeter (Mettler Toledo, DSC1, Suiza) equipped with an intracooler. Nitrogen (99.99\% purity at $20 \mathrm{~mL} / \mathrm{min}$ ) was the purge gas used. The equipment was calibrated with indium $\left(\Delta \mathrm{H}_{\mathrm{f}}=28.5 \mathrm{~J} / \mathrm{g}\right)$ and zinc $\left(\Delta \mathrm{H}_{\mathrm{f}}=103.7 \mathrm{~J} / \mathrm{g}\right)$. Dehydrated samples of 9-10 mg were weighed into aluminium pans (40 $\mu \mathrm{L}$, ME-26763, AL-CRUCIBLES) covered and sealed on the sample platform and then micro-perforated. All samples were subjected to the following temperature cycle: from $25^{\circ} \mathrm{C}$ to $-40{ }^{\circ} \mathrm{C}$ (rate of $10{ }^{\circ} \mathrm{C} / \mathrm{min}$ ); from -40 ${ }^{\circ} \mathrm{C}$ to $110{ }^{\circ} \mathrm{C}$ (rate of $10{ }^{\circ} \mathrm{C} / \mathrm{min}$ ) and held for $5 \mathrm{~min}$. After that a cooling scan was applied from $110^{\circ} \mathrm{C}$ to $-40^{\circ} \mathrm{C}$ and finally the temperature was increased to $120^{\circ} \mathrm{C}$.

The glass transition temperature at the beginning ( $\mathrm{Tg}$ onset) and in the middle ( $\mathrm{Tg}$ midpoint) of each sample was obtained using Mettler Toledo DSC STARe SW 9.20 software. The analysis of each sample was carried out in triplicate. 


\subsection{Statistical Analysis}

An analysis of variance (ANOVA) using Statgraphics Centurion 16.1 was applied to study the influence of the type of honey, syrup and their mixtures on the thermal properties (Tg onset and Tg midpoint) and sugar content of the samples. LSD (Least Significant Difference) at significance level $\alpha=5 \%$ was used to analyse the differences between samples.

In addition, the data were analysed using Principal Components Analysis (PCA), applying the software Unscrambler X.10. The variables analysed by PCA were centered and weighted in order to compensate for the different scales of the variables. Statistical assumptions for this analysis were checked previously, which indicated that PCA analysis was suitable for the dataset (KMO $>0.8$, Barlett's statistic $p>0.001$ ). For all the PCA analyses carried out in this study, the internal consistency and reliability of each component was assessed using Cronbach's alpha ( $a>0.9)$.

\section{Results and Discussion}

\subsection{Sugar content and glass transition temperature of pure honey and pure syrup samples}

Table 3.3.1 shows the main sugars (fructose, glucose, sucrose and maltose), total proteins ( $\mathrm{g} / 100 \mathrm{~g}$ dry matter) and glass transition temperature obtained for the different representative types of raw pure honey: three monofloral honey samples (sunflower, orange blossom and rosemary), two honeydew honey samples (forest and heather) and one polyfloral honey. The same parameters were analysed in ten types of pure syrup samples from different sources: rice from different brands (I, II, III, IV), brown rice, corn, maple, barley, sugar cane and agave. In addition, this table shows the ANOVA results (F-ratio and significant differences) obtained for the factors "type of honey", "type of syrup" and "honey samples and syrup samples". 
Table 3.3.1. Major sugars, total proteins and glass transition temperature (Tg onset and Tg midpoint) of pure honey and syrup samples. Mean values and standard deviation (in brackets).

\begin{tabular}{|c|c|c|c|c|c|c|c|}
\hline \multirow{2}{*}{ Sample } & \multicolumn{5}{|c|}{ Major sugars (g/100 g dm) } & \multicolumn{2}{|c|}{ Glass transition temperature $\left({ }^{\circ} \mathrm{C}\right)$} \\
\hline & Fructose & Glucose & Sucrose & Maltose & Total Proteins & Tgonset & $\operatorname{Tg}_{\text {Midpoint }}$ \\
\hline \multicolumn{8}{|l|}{ Pure honey } \\
\hline Forest & $37(4)^{a, 5}$ & $23.9(1.2)^{a, 3,4}$ & $<0.05^{1}$ & $<0.05^{a, 1}$ & $0.71(0.08)^{c, 10}$ & $50.5(0.3)^{\mathrm{a}, 6}$ & $60.2(0.5)^{a, 5}$ \\
\hline Heather & $44(2)^{b, 6}$ & $28(3)^{a, b, 5}$ & $<0.05^{1}$ & $1.44(0.09)^{c, 1}$ & $0.40(0.07)^{b, 9}$ & $54.6(0.5)^{b, 6,7}$ & $64.5(0.4)^{b, 5,6,7}$ \\
\hline Polyfloral & $52(5)^{c, d, 7}$ & $31(3)^{b, c, 5,6}$ & $<0.05^{1}$ & $0.21(0.09)^{\mathrm{b}, 1}$ & $0.42(0.03)^{b, 9}$ & $57(2)^{b, 7,8}$ & $67(3)^{b, 6,7}$ \\
\hline Sunflower & $46(3)^{b, c, 6}$ & $40.5(1.3)^{d, 7}$ & $<0.05^{1}$ & $<0.05^{\mathrm{a}, 1}$ & $0.24(0.00)^{a, 5,6,7,8}$ & $65(3)^{c, 9,10}$ & $72.0(1.3)^{c, 8,9}$ \\
\hline Orange blossom & $54(2)^{d, 7,8}$ & $34(2)^{c, 6}$ & $<0.05^{1}$ & $<0.05^{a, 1}$ & $0.25(0.03)^{a, 6,7,8}$ & $65.23(0.13)^{c, 9}$ & $75.27(0.13)^{d, 9,10}$ \\
\hline Rosemary & $55.3(0.6)^{d, 8}$ & $34(3)^{c, 6}$ & $<0.05^{1}$ & $<0.05^{\mathrm{a}, 1}$ & $0.18(0.07)^{a, 2,3,4,5}$ & $69.5(1.8)^{d, 10}$ & $77.3(0.6)^{d, 10}$ \\
\hline ANOVA F-ratio & $15.49 *$ & $15.65^{*}$ & & $352.26^{*}$ & $36.89 *$ & $57.55^{*}$ & $69.84^{*}$ \\
\hline \multicolumn{8}{|l|}{ Pure syrup } \\
\hline Rice I & $<0.05^{A, 1}$ & $24(3)^{D, 4}$ & $<0.05^{A, 1}$ & $32(4)^{C, D, 3}$ & $0.3(0.3)^{C, D, 7,8,9}$ & $59(2)^{\mathrm{F}, 8}$ & $68(3)^{E, 7,8}$ \\
\hline Rice II & $<0.05^{\mathrm{A}, 1}$ & $34(4)^{F, 6}$ & $<0.05^{A, 1}$ & $28(3)^{B, C, 2}$ & $0.15(0.09)^{A, B, C, 1,2,3,4}$ & $33(5)^{B, C, 3,4}$ & $39(7)^{B, C, 2}$ \\
\hline Rice III & $<0.05^{A, 1}$ & $20.4(0.6)^{c, 3}$ & $<0.05^{A, 1}$ & $27.3(1.5)^{B, 2}$ & $0.4(0.2)^{D, 8,9}$ & $30(2)^{B, 2,3}$ & $37(4)^{B, C, 1,2}$ \\
\hline Rice IV & $<0.05^{\mathrm{A}, 1}$ & $51.1(1.2)^{\mathrm{H}, 8}$ & $<0.05^{A, 1}$ & $37(4)^{E, 4}$ & $0.093(0.006)^{A, B, 1,2,3}$ & $28(3)^{B, 2}$ & $40(4)^{A, B, 2,3}$ \\
\hline Brown rice & $<0.05^{A, 1}$ & $3.99(1.12)^{\mathrm{B}, 2}$ & $<0.05^{\mathrm{A}, 1}$ & $52(2)^{F, 5}$ & $0.22(0.09)^{B, C, D, 5,6,7}$ & $88(3)^{\mathrm{H}, 11}$ & $95.83(1.05)^{G, 11}$ \\
\hline Corn & $9(3)^{c, 3}$ & $41.3(1.7)^{\mathrm{G}, 7}$ & $<0.05^{\mathrm{A}, 1}$ & $32.9(0.7)^{\mathrm{D}, 3}$ & $0.03(0.01)^{A, 1}$ & $23(4)^{A, 1}$ & $32.8(1.7)^{A, 1}$ \\
\hline Barley & $3.93(0.05)^{B, 2}$ & $23(2)^{C, D, 3,4}$ & $<0.05^{A, 1}$ & $61(2)^{G, 6}$ & $1.10(0.07)^{E, 11}$ & $37(3)^{c, 4}$ & $45(2)^{c, 3}$ \\
\hline Maple & $<0.05^{\mathrm{A}, 1}$ & $<0.05^{\mathrm{A}, 1}$ & $85.94(1.06)^{c, 3}$ & $<0.05^{\mathrm{A}, 1}$ & $0.07(0.02)^{A, B, 1,2}$ & $44(2)^{\mathrm{D}, 5}$ & $53(2)^{D, 4}$ \\
\hline Sugar cane & $25(3)^{D, 4}$ & $28(2)^{E, 5}$ & $31.73(1.03)^{B, 2}$ & $<0.05^{\mathrm{A}, 1}$ & $0.10(0.05)^{A, B, 1,2,3}$ & $53.5(1.6)^{\mathrm{E}, 6,7}$ & $63(3)^{E, 5,6}$ \\
\hline Agave & $97(3)^{\mathrm{E}, 9}$ & $8(3)^{B, 2}$ & $0.33(0.13)^{A, 1}$ & $<0.05^{\mathrm{A}, 1}$ & $0.04(0.01)^{A, 1,2}$ & $66.4(1.6)^{G, 9,10}$ & $75.18(1.09)^{F, 9,10}$ \\
\hline ANOVA F-ratio & $1105.59 *$ & $173.79 *$ & 10515.39* & $306.94 *$ & $28.87^{*}$ & $156.55^{*}$ & $107.01 *$ \\
\hline $\begin{array}{l}\text { ANOVA F-ratio } \\
\text { (syrup and honey samples) }\end{array}$ & $527.03 *$ & $108.84^{*}$ & $10847.8^{*}$ & $485.59 *$ & $29.74^{*}$ & 157.03* & $118.75^{*}$ \\
\hline
\end{tabular}

Different letters in the same column indicate differences $(* \mathrm{p}<0.001)$ between honey samples $(\mathrm{a}-\mathrm{d})$, syrup samples $(\mathrm{A}-\mathrm{H})$ or honey samples and syrup samples $(1-11)$ 
As expected, fructose was the most dominant sugar followed by glucose in all cases (Persano-Oddo \& Piro, 2004). In this study, the monofloral honey samples (rosemary, orange blossom and sunflower) had the highest fructose level (average = 55.3, 54 and $46 \mathrm{~g} / 100 \mathrm{~g} \mathrm{dm}$, respectively). The same occurs for glucose, but in this case sunflower honey showed a significantly high concentration (average $=40.5 \mathrm{~g} / 100 \mathrm{~g} \mathrm{dm}$ ), whereas rosemary honey samples and orange blossom showed average values of $34 \mathrm{~g} / 100 \mathrm{~g}$ $\mathrm{dm}$. It is common to find high levels of glucose in sunflower honey samples, even if they come from different countries (Juan-Borrás et al., 2014). The sucrose content was less than $0.05 \mathrm{~g} / 100 \mathrm{~g} \mathrm{dm}$ in all cases. In general, the level of this sugar is not important in honey although some specific types of honey such as acacia and hedysarum honey could contain values above $2.5 \mathrm{~g} / 100 \mathrm{~g}$ and $3 \mathrm{~g} / 100 \mathrm{~g}$, respectively (Persano-Oddo et al. 1995; Juan-Borrás et al., 2014). Maltose is also a minor sugar; its content in different types of monofloral and forest honey is quite low, not exceeding $1.5 \mathrm{~g} / 100 \mathrm{~g}$ (Persano-Oddo et al., 1995). In this work the maltose content in polyfloral honey $(0.21 \mathrm{~g} / 100 \mathrm{~g} \mathrm{dm})$ and heather honey $(1.44 \mathrm{~g} / 100 \mathrm{~g} \mathrm{dm})$ was higher than the amount found in the rest of the samples. In general, the sugar composition of the honey samples analyzed in the present study are in the usual range, considering that sugar content strongly depends on the type of flowers/plant secretions used by the bees, and therefore varies with the type of honey.

As expected, proteins were present in low concentrations in all honey samples (Mohammed \& Kamran, 2012). The total protein content ranged from $0.18 \mathrm{~g} / 100 \mathrm{~g} \mathrm{dm}$ in rosemary honey samples to $0.71 \mathrm{~g} / 100 \mathrm{~g} \mathrm{dm}$ in forest honey.

In general, the analysed syrup samples showed significant differences in terms of sugar content as compared to honey samples, especially in the case of fructose. Unlike honey, all rice syrup samples showed significantly low fructose content. On the contrary, agave syrup showed a significantly high fructose content, which is two times higher than the typical level found in honey samples. There was a wide range of variability in terms of glucose content: from $0.05 \mathrm{~g} / 100 \mathrm{~g} \mathrm{dm}$ in maple syrup to 51.1 $\mathrm{g} / 100 \mathrm{~g} \mathrm{dm}$ in rice IV syrup sample. In general, the glucose concentration in the rice syrup samples was in the same range as that found in honey samples, except for brown rice ( $3.99 \mathrm{~g} / 100 \mathrm{~g} \mathrm{dm}$ ). As shown for honey samples, and with the exception of sugar cane and agave syrup, sucrose was present in negligible amounts in the syrup samples $(<0.05 \mathrm{~g} / 100 \mathrm{~g} \mathrm{dm})$. On the contrary, sucrose-rich syrup samples showed negligible amounts of maltose $(<0.05 \mathrm{~g} / 100 \mathrm{~g} \mathrm{dm})$.

Maltose content in the syrup samples was significantly higher than the above mentioned content of this sugar in pure honey samples. The level of maltose was especially important in brown rice syrup $(52 \mathrm{~g} / 100 \mathrm{~g} \mathrm{dm}$ ) and barley syrup (61 g/100 g $\mathrm{dm})$.

The protein content of syrup samples was very similar or even lower than the protein content of honey samples, except for barley syrup (1.1 g/100 g dm). 
Figure 3.3.1 shows the typical DSC thermograms and the glass transition obtained for honey and syrup samples ( $1^{\text {st }}$ and $2^{\text {nd }}$ heating scan). The glass transition temperature obtained in the second scan was slightly higher, which points to a loss of some residual water during the first heating of the sample. Thus, the values that are shown in Table 1 were obtained from the second scan, in which it is supposed that all the samples are almost completely anhydrous. As shown in Table 3.3.1, the highest values of glass transition temperature ( $\mathrm{Tg}$ onset and Tg midpoint) were found for monofloral honey samples, which are also the ones that showed the highest fructose level. Sunflower honey showed intermediate values of the Tg midpoint.

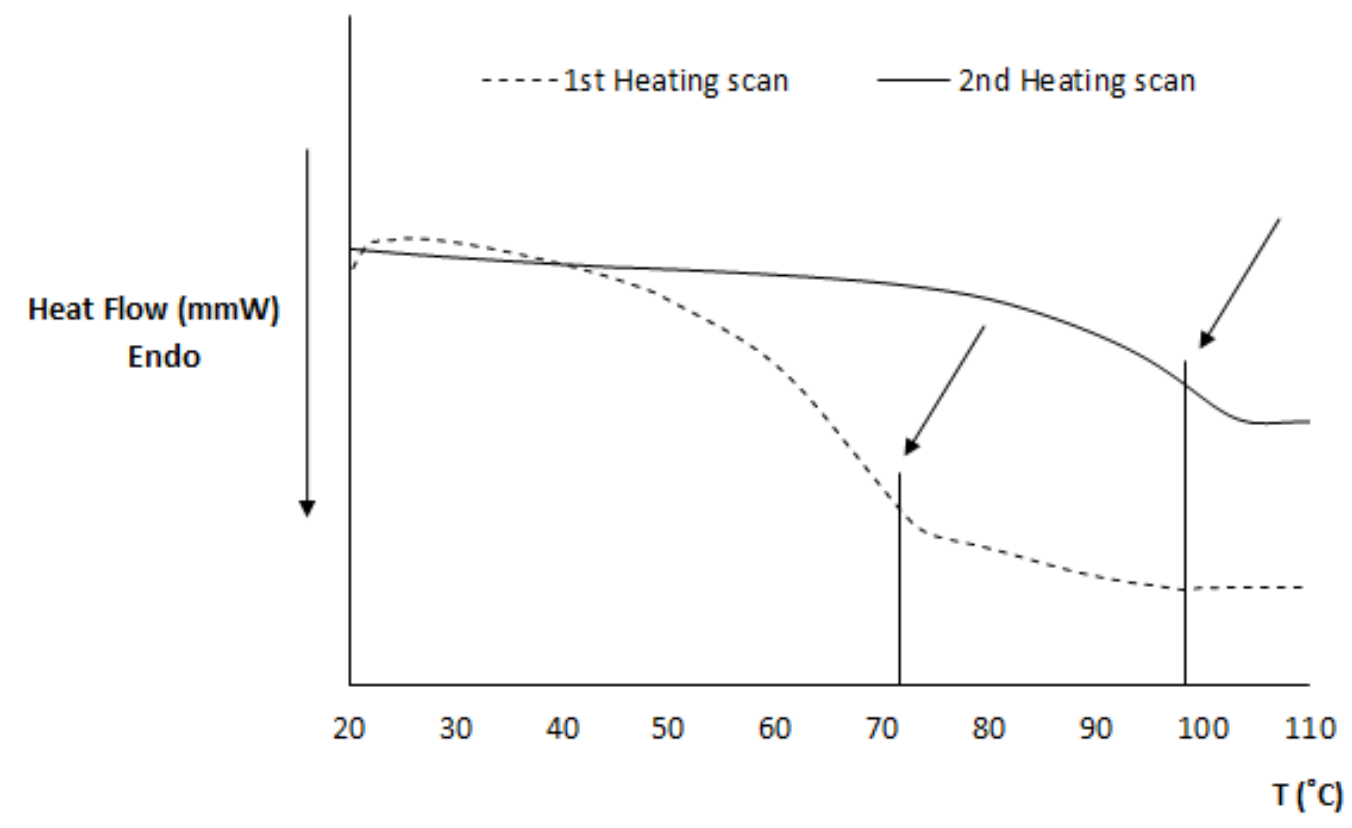

Figure 3.3.1. Typical $1^{\text {st }}$ and $2^{\text {nd }}$ heating scan of honey and syrup samples.

Syrup samples showed a wider range of variability of glass transition temperature values ( $\mathrm{Tg}$ midpoint ranging from $32.8{ }^{\circ} \mathrm{C}$ to $95.8^{\circ} \mathrm{C}$ ) than those obtained for honey samples ( $\mathrm{Tg}$ midpoint ranging from $60.2{ }^{\circ} \mathrm{C}$ to $77.3{ }^{\circ} \mathrm{C}$ ); this is because the syrup samples, unlike honey samples, have a very varied sugar composition.

Sunflower and orange blossom honey samples showed intermediate behaviour in terms of $\mathrm{Tg}$ and sugar composition. However, sunflower is more common and can be found worldwide (Juan-Borrás et al., 2014), thus this type of honey was the one chosen to evaluate the impact of adulteration with different amounts of syrup.

\subsection{Effect of syrup on the thermal properties of honey}

Figure 3.3.2 shows, as an example, different typical DSC thermograms of sunflower honey samples adulterated with $20 \%$ of rice IV, sugar cane and brown rice syrups. While in all the pure honey samples evaluated in the present study only a glass transition temperature was detected, in some of the adulterated samples two glass 
transition temperatures appeared. Thus, in order to evaluate the effect of the addition of syrup on the thermal behaviour of the samples, the temperature of the second glass transition was chosen in all cases.
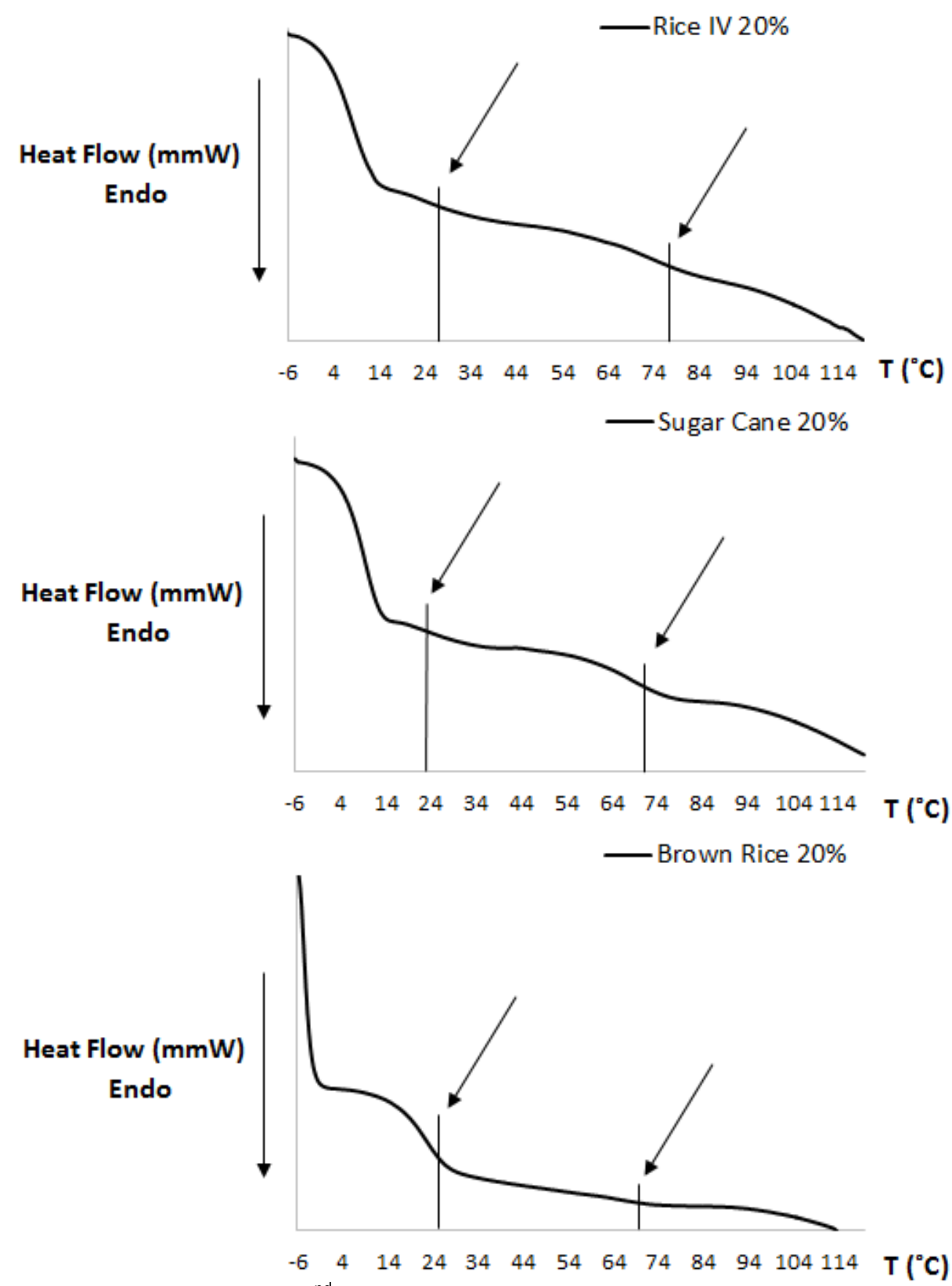

Figure 3.3.2. Typical DSC curves ( $2^{\text {nd }}$ heating scan) of adulterated samples with two glass transition temperatures.

Table 3.3.2 shows the glass transition temperature and the estimated sugar and protein content of sunflower honey samples adulterated with different levels of the evaluated samples of syrup. The glass transition temperature was affected by the type of syrup and the adulteration level, the interaction between these two factors was also significant. The addition of increasing amounts of syrup led to a significant decrease in the glass transition value of the samples except for agave, corn and brown rice. Barley 
and maple syrup addition at $20 \%$ led to the highest decrease in the glass transition temperature (approx. $50^{\circ} \mathrm{C}$ ). These two types of syrup showed the highest level of maltose and sucrose, respectively.

Table 3.3.2. Glass transition temperature ( $\mathrm{Tg})$ and estimated composition of adulterated samples. Mean values and standard deviation, in brackets.

\begin{tabular}{|c|c|c|c|c|c|c|c|c|}
\hline \multirow{2}{*}{ Syrup } & \multirow{2}{*}{ Sample } & \multicolumn{2}{|c|}{ Glass transition temperature $\left({ }^{\circ} \mathrm{C}\right)$} & \multicolumn{5}{|c|}{ Estimated Composition $(\mathrm{g} / 100 \mathrm{~g} \mathrm{dm})$} \\
\hline & & Tg Onset2 & Tg $g_{\text {Midpoint2 }}$ & Fructose & Glucose & Sucrose & Maltose & Proteins \\
\hline \multirow{3}{*}{ Agave (A) } & H80:A20 & $68.9(1.6)^{g, 1}$ & $77.8(0.8)^{f, 1}$ & 55.67 & 34.32 & 0.06 & 0.00 & 0.205 \\
\hline & H90:A10 & $68(2)^{g, 2}$ & $75.7(1.9)^{f, 2}$ & 50.79 & 37.45 & 0.03 & 0.00 & 0.224 \\
\hline & H95:A5 & $62.8(0.1)^{g, 3}$ & $70.56(0.05)^{f, 3}$ & 48.38 & 39.00 & 0.02 & 0.00 & 0.233 \\
\hline \multirow{3}{*}{ Maple (M) } & H80:M20 & $11.8(1.3)^{\mathrm{b}, 1}$ & $17.6(0.5)^{b, 1}$ & 38.58 & 34.00 & 13.85 & 0.00 & 0.215 \\
\hline & H90:M10 & $69.7(0.4)^{\mathrm{b}, 2}$ & $77.9(0.6)^{b, 2}$ & 42.37 & 37.34 & 6.76 & 0.00 & 0.229 \\
\hline & H95:M5 & $63.9(1.9)^{b, 3}$ & $73.9(1.4)^{b, 3}$ & 44.20 & 38.96 & 3.34 & 0.00 & 0.236 \\
\hline \multirow{3}{*}{ Rice IV (RIV) } & H80:RIV20 & $66.5(0.4)^{\mathrm{h}, 1}$ & $73.84(0.05)^{g, 1}$ & 36.92 & 42.61 & 0.00 & 7.27 & 0.213 \\
\hline & H90:RIV10 & $68.7(1.7)^{\mathrm{h}, 2}$ & $76.2(0.9)^{\mathrm{g}, 2}$ & 41.46 & 41.57 & 0.00 & 3.63 & 0.228 \\
\hline & H95:RIV5 & $70.9(1.8)^{\mathrm{h}, 3}$ & $80.05(0.04)^{g, 3}$ & 43.73 & 41.05 & 0.00 & 1.81 & 0.235 \\
\hline \multirow{3}{*}{ Rice I (RI) } & H80:RI20 & $53.9(1.2)^{c, 1}$ & $63.6(1.4)^{c, 1}$ & 36.75 & 37.27 & 0.00 & 6.43 & 0.258 \\
\hline & H90:RI10 & $54.5(0.3)^{c, 2}$ & $63.6(0.5)^{c, 2}$ & 41.36 & 38.90 & 0.00 & 3.22 & 0.250 \\
\hline & H95:RI5 & $59(3)^{c, 3}$ & $69(3)^{c, 3}$ & 43.68 & 39.72 & 0.00 & 1.61 & 0.246 \\
\hline \multirow{3}{*}{ Rice II (RII) } & H80:RII20 & $58.7(1.6)^{e, 1}$ & $69.9(1.4)^{\mathrm{e}, 1}$ & 36.83 & 39.27 & 0.00 & 5.65 & 0.224 \\
\hline & H90:RII10 & $60.6(1.5)^{\mathrm{e}, 2}$ & $71(2)^{e, 2}$ & 41.41 & 39.90 & 0.00 & 2.82 & 0.233 \\
\hline & H95:RII5 & $59.8(0.2)^{\mathrm{e}, 3}$ & $69.7(0.7)^{e, 3}$ & 43.70 & 40.22 & 0.00 & 1.41 & 0.238 \\
\hline \multirow{3}{*}{ Brown Rice (BR) } & H80:BR20 & $66(2)^{f, 1}$ & $73.8(0.6)^{e, 1}$ & 36.71 & 33.16 & 0.00 & 10.53 & 0.238 \\
\hline & H90:BR10 & $57.7(0.6)^{f, 2}$ & $68(1)^{e, 2}$ & 41.34 & 36.84 & 0.00 & 5.27 & 0.240 \\
\hline & H95:BR5 & $61.9(0.8)^{\mathrm{f}, 3}$ & $71.6(0.5)^{e, 3}$ & 43.66 & 38.69 & 0.00 & 2.64 & 0.241 \\
\hline \multirow{3}{*}{ Rice III (RIII) } & H80:RIII20 & $57.0(1.3)^{d, 1}$ & $65(2)^{d, 1}$ & 36.82 & 36.52 & 0.00 & 5.43 & 0.268 \\
\hline & H90:RIII10 & $57.7(0.3)^{d, 2}$ & $67.8(0.8)^{d, 2}$ & 41.40 & 38.53 & 0.00 & 2.72 & 0.255 \\
\hline & H95:RIII5 & $59.2(1.5)^{\mathrm{d}, 3}$ & $70.5(1.9)^{\mathrm{d}, 3}$ & 43.70 & 39.53 & 0.00 & 1.36 & 0.249 \\
\hline \multirow{3}{*}{ Sugar Cane (SC) } & $\mathrm{H} 80: \mathrm{SC} 20$ & $63(3)^{g, 1}$ & $70.9(1.5)^{f, 1}$ & 41.92 & 38.14 & 6.26 & 0.00 & 0.214 \\
\hline & H90:SC10 & $66.75(1.25)^{g, 2}$ & $76.6(0.7)^{f, 2}$ & 43.96 & 39.34 & 3.12 & 0.00 & 0.228 \\
\hline & H95:SC5 & $68.4(0.9)^{g, 3}$ & $77.5(1.3)^{\mathrm{f}, 3}$ & 44.97 & 39.94 & 1.56 & 0.00 & 0.235 \\
\hline \multirow{3}{*}{ Barley (B) } & H80:B20 & $20(6)^{a, 1}$ & $26(5)^{a, 1}$ & 37.66 & 37.07 & 0.00 & 12.15 & 0.413 \\
\hline & H90:B10 & $53.2(1.2)^{a, 2}$ & $62.5(0.5)^{a, 2}$ & 41.83 & 38.81 & 0.00 & 6.07 & 0.328 \\
\hline & H95:B5 & $59.9(1.3)^{a, 3}$ & $69(4)^{a, 3}$ & 43.91 & 39.67 & 0.00 & 3.03 & 0.285 \\
\hline \multirow{3}{*}{ Corn (C) } & $\mathrm{H} 80: \mathrm{C} 20$ & $72.9(0.4)^{\mathrm{h}, 1}$ & $80.4(1.5)^{h, 1}$ & 38.50 & 40.69 & 0.00 & 6.66 & 0.200 \\
\hline & H90:C10 & $67.6(0.9)^{\mathrm{h}, 2}$ & $76(2)^{h, 2}$ & 42.24 & 40.61 & 0.00 & 3.34 & 0.221 \\
\hline & $\mathrm{H} 95: \mathrm{C5}$ & $68.2(1.5)^{h, 3}$ & $78.5(0.8)^{h, 3}$ & 44.11 & 40.57 & 0.00 & 1.67 & 0.232 \\
\hline \multicolumn{2}{|l|}{$\begin{array}{l}\text { ANOVA F-ratio } \\
\text { (type of syrup) }\end{array}$} & $209.03^{*}$ & $231.76 *$ & & & & & \\
\hline \multicolumn{2}{|l|}{$\begin{array}{l}\text { ANOVA F-ratio } \\
\text { (adulteration level) }\end{array}$} & $262.94 * * *$ & $375.08^{*}$ & & & & & \\
\hline \multicolumn{2}{|c|}{$\begin{array}{l}\text { Interaction } \\
\text { (syrup / adulteration level) }\end{array}$} & $135.58^{*}$ & $157.11 *$ & & & & & \\
\hline
\end{tabular}

Different letters in the same column indicate differences $\left({ }^{*} \mathrm{p}<0.001\right)$ due to the type of syrup $(\mathrm{a}-\mathrm{h})$ or adulteration level (1-3). 
For the purpose of evaluating from a descriptive point of view, the global effect of the level of adulteration of honey on its glass transition temperature and the composition of adulterated samples (sugars and proteins), a principal component analysis (PCA) was performed (Figure 3.3.3) including the results reported in Table 3.3.1 and 3.3.2. This analysis was carried out using the average values for each sample. This unsupervised procedure permitted checking whether there was a spontaneous classification from the data obtained, without previously defining the categories of the samples.

In this PCA plot (Figure 3.3.3) the pure syrup samples with the exception of agave syrup are all located in the left quadrants, while the pure honey samples are all placed in the right quadrants. This figure shows that the different types of honey (placed in the inferior right quadrant) and adulterated samples are well differentiated. Samples containing $20 \%$ maple or barley syrup and $80 \%$ sunflower honey were in the same position as the pure syrup samples. In this figure, PC1 is the component that explains the difference between samples: pure syrup, adulterated sunflower honey samples and different types of honey. Glass transition temperature, fructose and maltose content are the variables that had the highest influence on the differences between samples, fructose and glass transition temperature being positively correlated. 


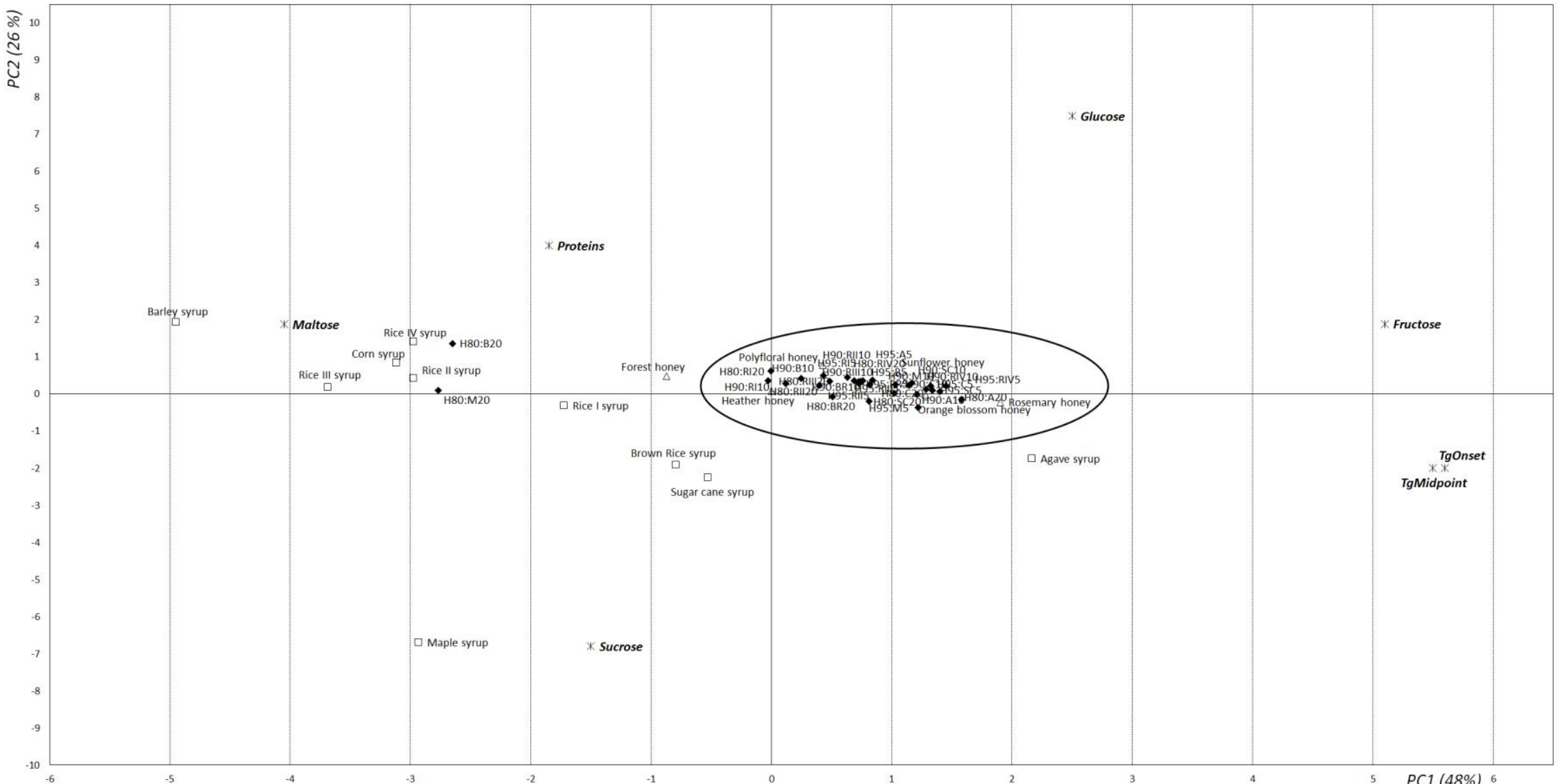

Figure 3.3.3. PCA biplot (scores and loadings) of the variables (Tg onset, Tg midpoint, fructose, glucose, sucrose, maltose and proteins) and samples: 10 types of pure syrups (agave, maple, sugar cane, barley, corn, brown rice and rice I-IV), 6 types of pure honey (sunflower; orange blossom, rosemary, heather, forest and polyfloral honey), and mixtures of sunflower honey with all the syrups at different proportions simulating the adulteration of honey (honey/syrup: 80/20; 90/10; 95/05). 


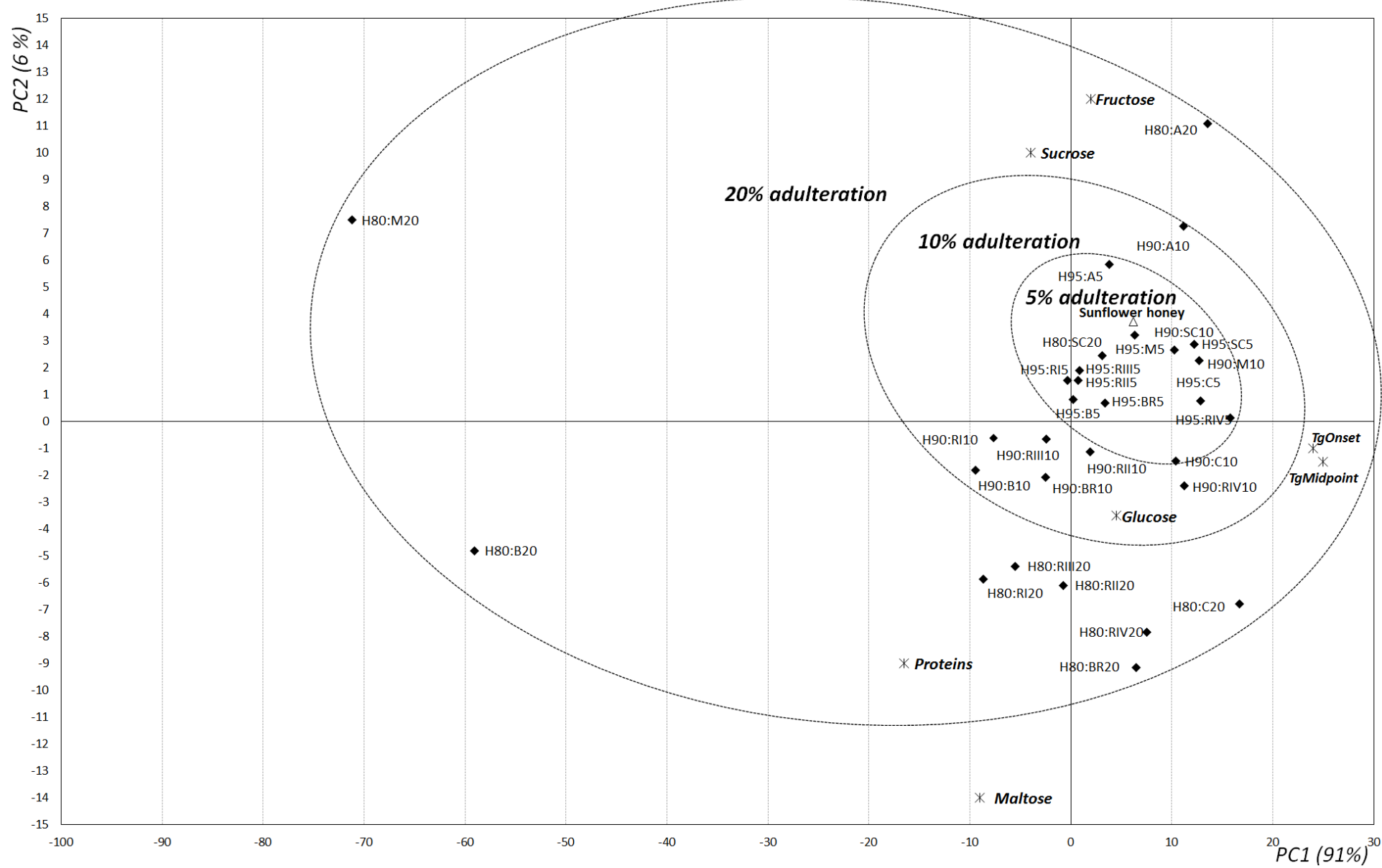

Figure 3.3.4. PCA biplot (scores and loadings) of the variables (Tg onset, Tg midpoint, fructose, glucose, sucrose, maltose and proteins) and mixtures of sunflower honey with all the syrups at different proportions simulating the adulteration of honey (honey/syrup: 80/20; 90/10; 95/05). 
In order to discuss the influence of the addition of different proportions of syrup to honey in more detail, a second PCA (Figure 3.3.4) was carried out considering only the samples located in the highlighted area in Figure 3: mixtures with sunflower honey and different types of pure honey. Figure 3.3.4 shows the PCA bi-plot of scores and loading obtained. In this case, three components explain $97 \%$ of the total variance. PC1 explains $91 \%$ and is mainly positively correlated with the glass transition temperature, located at the right end of PC1. The second component, PC2, explains $6 \%$ and is positively correlated with fructose and negatively with maltose. In general, adulterated samples are located around pure sunflower honey; the lower the adulteration level the shorter the distance between pure honey and the samples containing syrup. The differences of adulteration level $(20 \%, 10 \%$ or $5 \%)$ are shown in the plot by means of circles. Almost all H80:20 samples (80\% pure honey and 20\% syrup) are in the external circle; H90:10 samples (90\% pure honey and 10\% syrup) are in the centre circle and $\mathrm{H}: 95: 5$ samples (95\% pure honey and 5\% syrup) are very close to pure honey samples. In general, the increase in adulteration level promoted a movement towards the left quadrant, except for agave syrup, which showed an opposite trend due to its high fructose content. For each adulteration level, the rice syrups especially samples RI, RII and RIII, exhibited similar behavior in terms of the parameters analyzed.

It is important to point out that for some syrup types the effect of the highest adulteration level on the thermal properties of honey is more marked. This is the case of H80:M20 and H80:B20 samples. Moreover, sugar cane syrup is the one that showed the lowest effect on all the evaluated parameters since all the samples containing this syrup are located near pure honey at all adulteration levels and inside the circle for $5 \%$ adulteration level.

\section{Conclusions}

The addition of sugar syrup promoted significant changes in the thermal properties of adulterated samples, in proportion to the adulteration level, compared to pure honey samples. The evaluation of the thermal properties of honey by means of Differential Scanning Calorimetry provided information about the possible presence of added sugar syrup in sunflower honey. Further studies are required to validate these results in other types of honey.

\section{Acknowledgments}

The authors thank the Generalitat Valenciana (Spain) and the Spanish Government for funding the AICO/2015/104 project. 


\section{References}

AOAC International (2000). Official Methods of Analysis. 17르ed. Gaithersburg, USA.

Bertelli, D., Lolli, M., Papotti, G., Bortolotti, L., Serra, G., \& Plessi, M. (2010). Detecction of adulteration by sugar syrups using one-dimensional and two-dimensional high-resolution Nuclear Magnetic Resonance. Journal of Agricultural and Food Chesmistry, 58, 8495-8501.

Boffo, E. F., Tavares, L. A., Tobias, A. C. T., Ferreira, M. M. C. \& Ferreira, A. G. (2012). Identification of components of Brazilian honey by $\mathrm{H}$ NMR and classification of its botanical origin by chemometric methods. LWT - Food Science and Technology, 49, 55-63.

Bogdanov, S., Martin, P., \& Lüllman, C. (1997). Harmonised methods of the European Honey Commission. Apidologie, extra issue, 1-59.

Bogdanov, S. (2009). Harmonized methods of the International Honey Commission. http://www.bee-hexagon.net/en/network.htm. Accessed 08/07/16.

Codex Alimentarius Commission (1981). Codex Standard for Honey. Codex Alimentarius, 12-1981:1-8.

Cordella, C., Antinelli, J. F., Aurieres, C., Faucon, J. P., Cabrol-Bass, D., \& Sbirrazzuoli, N. (2002). Use of Differential Scanning Calorimetry (DSC) as a New Tecnique for Detection of Adulteration in honeys.1. Study of Adulteration Effect on Honey Thermal Behavior. Journal of Agricultural and Food Chemistry, 50, 203-208.

Dahimi, O., Abdul Rahim, A., Mohammed, A., Sukri Hassan, M., Zam Hashari, S., Siti Mashitoh, A., \& Saadi, S. (2014). Multivariate statistical analysis treatment of DSC termal properties for animal fat adulteration. Food Chemistry, 158, 132-138.

De Oliveira, R., Teixeira, E., Da Silva, C., Guerra, M. L., Conte, C., \& Oliveira de Jesus, E. F. (2014). Detection of honey adulteration of high fructose corn syrup by low field Nuclear Magnetic Resonance (LF1H NMR). Journal of Food Engineering, 135, 39-43.

Europa (2010). Summaries of EU legislation: honey. http://europa.eu/legislation_summaries/consumers/product_labelling_and_pac kaging/I221124a_en.htm. Accessed 01/09/16.

Elfleing, L., \& Raezke, K. (2008). Improved detection of honey adulteration by measuring differences btween $13 \mathrm{C} / 12 \mathrm{C}$ stable carbon isotope ratios of protein and sugar compounds with a combination of elemental analyser - isotope ratio mass spectrometry and liquid chromatography - isotope ratio mass spectrometry (g13C-EA/LC-IRMS). Apidologie, 39, 574. 
Everstine, K., Spink, J., \& Keennedy, S. (2013). Economically motivated adulteration (EMA) of food: common characteristics of EMA incidents. Journal Food Protection, 76, 723-735.

Food Fraud Database (2016). https://www.foodfraud.org/ Accessed 02/09/16.

FoodSHIELD (2016). https://www.foodshield.org/ Accessed 02/09/16.

Juan-Borrás, M., Domenech, E., Hellebrandova, M., \& Escriche, I. (2014). Effect of country origin on physicochemical, sugar and volatile composition of acacia, sunflower and tilia honeys. Food Research International, 60, 86-94.

Juan-Borrás, M., Soto, J., Gil-Sánchez, L., Pascual-Maté, A. \& Escriche, I. (2016). Antioxidant activity and physico-chemical parameters for the differentiation of honey using a potentiometric electronic tongue. Journal of the Science of Food and Agriculture, 97, 2215-2222.

Kántor, Z., Pitsi, G., \& Thoen, J. (1999). Glass Transition Temperature of Honey as a Function of Water Content As Determined by Differential Scanning Calorimetry. Journal of Agricultural and Food Chemistry, 4, 2327-2330.

Mohammed, S. E. A., \& Kamran, M. (2012). Characterisation of natural honey proteins: implications for the floral and geographical origin of honey. International Journal of Food Science and Technology, 47, 362-368.

Lupano, C. E. (1997). DSC study of honey granulation stored at various temperatures. Food Research International, 30, 683-688.

Ohmenhaeuser, M., Monakhova, Y. B., Kuballa, T. \& Lachenmeier, D. W. (2013). Qualitative and Quantitative Control of Honeys Using NMR Spectroscopy and Chemometrics. Analytical Chemistry, 2013, 9 pages.

Persano Oddo, L., Piazza, M. G., Sabatini, A. G., \& Accorti, M. (1995). Characterization of unifloral honeys. Apidologie, 26, 453-465.

Persano-Oddo, L., \& Piro, R. (2004). Main European unifloral honeys: descriptive sheets. Apidologie, 35, 38-81.

RASFF-Food \& Feed Safety Alerts (2016).

http://ec.europa.eu/food/safety/rasff/index_en.htm Accessed 02/09/16.

Rios-Corripio, M. A., Rojas-López, M. \& Delgado-Macuil, R. (2012). Analysis of adulteration in honey with standard sugar solutions and syrups using attenuated total reflectance-Fourier transform infrared spectroscopy and multivariate. CyTA - Journal of Food, 10, 119-122.

Tomaszewska-Gras, J. (2016). Rapid quantitative determination of butter adulteration with palm oil using the DSC technique. Food Control, 60, 629-635. 
United States Food and Drug Administration (2011). Public meeting on economically motivated adulteration.

http://www.fda.gov/Newsevents/MeetingsConferencesWorkshops/ucm163619.htm.

Accesed 01/09/16.

United States International Trade Commission (1994). Honey from the People's Republic of China (Invesigation no 731-TA-722, preliminary). Government Printing Office, Washington.

Von Der Ohe, W., Persano-Oddo, L., Piana, M. L., Morlot, M., \& Martin, P. (2004). Harmonized methods of melissopalynology. Apidologie, 35, 18-25. 

3.4. Detection of honey adulteration by conventional and real-time PCR Lara Sobrino-Gregorio, Santiago Vilanova, Jaime Prohens, Isabel Escriche Food Control, 95, 57-62 (2019) 



\section{ABSTRACT}

This work applies both conventional and real-time PCR DNA amplification techniques for detecting and quantifying rice molasses in honey. Different levels of adulteration were simulated $(1,2,5,10,20,50 \%)$ using commercial rice molasses. Among the different specific genes of rice tested by PCR, the PLD1 primer was the most effective. This allowed the visualization in agarose gel of this type of adulterant up to $5-20 \%$. Moreover, by means of real-time PCR it was possible to distinguish the different levels of rice DNA, and therefore the percentage of adulteration (1-50\%). A standard curve built with the DNA serial dilutions of rice genomic DNA concentrations showed that the quantification level was between 2-5\%. These results offer compelling evidence that DNA techniques could be useful not only for the detection of adulterations of honey with rice molasses but also for the quantification of levels lower than those of conventional techniques.

Keywords: Honey authentication; conventional-PCR; real-time-PCR.

\section{Introduction}

Honey is a natural sweet substance that no alterations are permitted. This means the addition of substances, as well as the elimination of pollen or any intrinsic component is prohibited (Council Directive, 2002; Real Decreto 1049/2003). Honey is highly vulnerable to food fraud which accounts for approximately $90 \%$ of all adulterations related to sweeteners (Sobrino-Gregorio et al., 2017). Guaranteeing the purity in honey is a priority for producers and regulatory authorities in addition to avoiding economic fraud and ensuring public health. As a result, controlling this aspect of the quality in honey has become increasingly important (Cai et al., 2013; Sobrino-Gregorio et al., 2017).

Generally, honey is adulterated with other cheaper sweeteners such as sugar syrups, which could have a similar sugar composition (Cai et al., 2013). The most common adulteration is with rice syrups or rice molasses, used in some Asian countries, where most of the honey is exported to Europe, the USA and Japan (Sobrino-Gregorio et al., 2017). As a result, the European Commission is promoting the development of simple analytical methods that permit the detection of adulterated honey (Council Directive, 2002).

In recent years, a number of these methods have been used to differentiate genuine honey from adulterated ones (Ulberth, 2016; Siddiqui et al., 2017). Among them, the most used by the analytical laboratories focusing on quality control of honey are: NMR spectroscopy (although it is the most recognized, it is very expensive and timeconsuming requiring a data library to compare the results) (Bertelli et al., 2010; De 
Oliveira et al., 2014), and enzymatic activity (diastase, invertase) (Serra et al., 2000), among others. The drawback to using only one of these techniques is that results are not always conclusive. Therefore, it is necessary to use more than just one to achieve a reliable report. Furthermore, it slows down the analytical process making it very expensive (Sobrino-Gregorio et al., 2017).

With the aim of analyzing adulterations in honey, other analytical techniques have been recently reported by different authors: Fourier transformation and Raman spectroscopy (to detect the presence of inverted beet and cane syrups) (Oroian \& Ropciuc, 2017), differential scanning calorimetry (DSC) (Sobrino-Gregorio et al., 2017), high performance liquid chromatography (HPLC) to detect starch syrups (Wang et al., 2015) and stable carbon isotope mass spectrometry (SCIRA) (Elflein \& Raezke, 2008), among others. As with the techniques mentioned above these recent methodologies, alone, have not given conclusive results either.

Among the most promising techniques currently available for the determination of the quality and adulteration of food products, DNA-based methods are of increasing importance (Al-Kahtani et al., 2017; Meira et al., 2017; Lo \& Shaw, 2018). The conventional polymerase chain reaction (PCR) (for identification) and real-time PCR (for quantification) techniques, offer results of high specificity and sensitivity, reproducibility, low levels of cross-contamination and reduce analysis time (Meira et al., 2017). These methodologies have been successfully applied for the authentication of animal products like milk (Mayer, 2005), meat (Farrokhi \& Jafari Joozani, 2011; Rodríguez-Ramírez et al., 2011; Cai et al., 2012; Kesmen et al., 2012; Safdar et al., 2014; Chen et al., 2015) and seafood (Nebola et al., 2010; Rasmussen et al., 2010; Rodríguez-Ramírez et al., 2011; Fernandes et al., 2017). Specifically, in honey, this technique has only been used for the botanical origin identification (Laube et al., 2010; Guertle et al., 2014; Soares et al., 2015).

Regarding the positive results obtained in the detection of adulterations in products of animal origin, it could be considered viable that this technique can be applied to other animal by-products like honey. However, based on our current knowledge, this method has not been used for the identification of adulteration in honey. With this aim in mind, this study evaluated the capacity of conventional PCR and real-time PCR to identify and quantify the presence of rice molasses in honey samples simulating different levels of adulteration. To achieve this, a previous step was necessary to solve the difficulty of extraction and amplification of rice molasses DNA in honey. 


\section{Materials and methods}

\subsection{Sample preparation}

Orange blossom honey (Citrus spp.), provided by the company "Melazahar" (Montroy, Valencia, Spain), for this study was used. The botanical categorization was performed by means of pollen analysis, which was quantified following the recommendations of the International Commission for Bee Botany (Von Der Ohe et al., 2004). Different types of rice molasses were used as an adulterant: "Danival" (France) and "Cal Valls" (Spain), respectively codified as I and II.

The samples evaluated in the present work were: pure rice molasses, pure orange blossom honey and mixture of both in different percentages $(1,2,5,10,20$ and $50 \%$ of rice molasses, respectively) simulating the adulteration of honey. To this end, a $10 \mathrm{~g}$ sample with $45 \mathrm{~mL}$ of water was incubated at $65{ }^{\circ} \mathrm{C}$ with shaking for 30 min approximately, until the sample was completely dissolved (NucleoSpin-Food-isolation of genomic DNA from honey or pollen, 2018).

\subsection{Genomic DNA extraction}

Different protocols for extracting DNA were tested: the CTAB method (Doyle \& Doyle, 1990), the modified CTAB method (Aljanabi et al., 1999) and the commercial kit "NucleoSpin Food" (Macherey-Nagel, Germany). The latter, according to the manufacturer's instructions and the additional protocol (NucleoSpin-Food-isolation of genomic DNA from honey or pollen, 2018).

\subsection{Rice primers}

Three rice primers targeting two different rice-specific genes, used by Takabatake et al. (2015), were considered in this study to achieve sufficient DNA of suitable quality (Table 3.4.1). The specificity of the primers was demonstrated in silico comparing the primer sequences against the "nr database" using BLASTn program.

Table 3.4.1. Oligonucleotide primers used in the PCR amplifications.

\begin{tabular}{lllc}
\hline Target & \multicolumn{1}{c}{ Name } & \multicolumn{1}{c}{ Sequence 5'-3' } & Amplicon length (bp) \\
\hline \multirow{2}{*}{ SPS2 } & SPS 2-F & GGA TCA TCC CGA AAA GAT CAA C & \multirow{2}{*}{91} \\
& SPS 2-R & ATG GCA GTG GGA GAG ATT GTG & \multirow{2}{*}{68} \\
\hline \multirow{2}{*}{ PLD1 } & PLD F(KVM159) & TGG TGA GCG TTT TGC AGT CT \\
& PLD R(KVM160) & CTG ATC CAC TAG CAG GAG GTC C & \multirow{2}{*}{80} \\
\hline \multirow{2}{*}{ PLD2 } & PLD3959F & GCT TAG GGA ACA GGG AAG TAA AGT T & \\
\hline
\end{tabular}




\subsection{Conventional PCR}

Polymerase chain reaction (PCR) amplifications were carried out on a total reaction volume of $20 \mu \mathrm{L}$, containing $1 \mu \mathrm{L}$ of extracted DNA. The reaction mixture contained 6.8 $\mu \mathrm{L}$ water (Roche, Germany), $10 \mu \mathrm{L}$ of PCR buffer with deoxynucleotide triphosphates (dNTPs) (2x) $1.5 \mathrm{mM} \mathrm{Mg}$ at $1 \mathrm{x}, 1.2 \mu \mathrm{L}$ of $\mathrm{MgCl}_{2} 25 \mathrm{mM}, 0.2 \mu \mathrm{L}$ of Taq DNA polymerase $2.5 \mathrm{U} / \mu \mathrm{L}$ (Kapa3g Plant, Kapabiosystems, South Africa) and $0.4 \mu \mathrm{L}$ of each primer (10 $\mu \mathrm{M})$. In the reaction, a positive control (rice DNA extracted from a development plant of commercial variety of ssp. japonica) and a negative control (water) were included.

PCR was performed using the Thermal Cycler Mastercycler (Eppendorf, Germany) using the following conditions: $95^{\circ} \mathrm{C} / 2$ minutes followed by 30 cycles of $95^{\circ} \mathrm{C} / 15$ seconds, $60^{\circ} \mathrm{C} / 15$ seconds, $72^{\circ} \mathrm{C} / 15$ seconds, and a final extension at $72^{\circ} \mathrm{C} / 10$ minutes.

\subsection{Agarose gel electrophoresis}

The PCR products were separated using electrophoresis with a $3 \%$ agarose gel (Conda, Spain). The results were seen under UV light (transilluminator Universal Hood II (Biorad), USA). PCR band size was verified with a 100 bp molecular weight marker (FastGene 100 bp DNA Ladder, Genetics, NIPPON Genetics EUROPE GmbH).

\subsection{Real-time PCR}

The real-time polymerase chain reaction (real-time PCR) amplifications were carried out in a total reaction volume of $10 \mu \mathrm{L}$, containing $3 \mu \mathrm{L}$ of DNA extract. The reaction mixture contained $1.9 \mu \mathrm{L}$ water (Roche, Germany), $5 \mu \mathrm{L}$ of master mix 2x Sybr Fast Universal (Kapabiosystems, South Africa) and $0.05 \mu \mathrm{L}$ of each primer $(10 \mu \mathrm{M})$. In the reaction, a positive control (rice DNA extracted from a development plant of commercial variety of ssp. japonica) and a negative control (water) were included.

Real-time PCR was performed using the real-time PCR LightCycler480 (Roche, Switzerland) with the following conditions: $95^{\circ} \mathrm{C} / 10$ minutes followed by 45 cycles of $95^{\circ} \mathrm{C} / 10$ seconds, $65^{\circ} \mathrm{C} / 15$ seconds, $72^{\circ} \mathrm{C} / 15$ seconds. Finally, a melting curve was performed by heating $95^{\circ} \mathrm{C} / 1$ minute, cooling down $40^{\circ} \mathrm{C} / 1$ minute, and heating again from $60^{\circ} \mathrm{C}$ to $95^{\circ} \mathrm{C}$, performing 25 acquisitions per $1^{\circ} \mathrm{C}$.

\subsection{Rice DNA concentrations}

Serial dilutions of rice genomic DNA (100.00, 50.00, 25.00, 12.50, 6.25, 3.13, 1.56 and $0.78 \mathrm{ng} / \mu \mathrm{L}$ ) were amplified by real-time PCR to build the standard curve required to determine the DNA concentration in the samples.

All experiments (conventional PCR, real time PCR and the DNA concentration curve) were carried out at least 4 times. 


\section{Results and discussion}

\subsection{Optimization of DNA extraction}

The complexity of honey and the highly processed molasses influences the low amounts available of target DNA of these products (Dyshlyuk et al., 2014; Soares et al., 2015). Therefore, the first obstacle to overcome was to have access to sufficient quantity and quality of target DNA that is a necessary condition to be amplified by the PCR later.

With the conventional protocols, CTAB and the modified CTAB, the results were unsatisfactory since no DNA from molasses could be amplified. In consequence the CTAB-based methods were discarded. Only the commercial kit "NucleoSpin Food" provided high quantity and quality DNA extracts, and consequently was selected. In this respect, in other processed food matrixes, the chaotropic solid-phase extraction "NucleoSpin Food" kit has proved more efficient than CTAB protocols (Garino et al., 2017).

\subsection{Conventional PCR for pure rice molasses}

The agarose gel images of PCR products, obtained from conventional PCR reactions, using three species-specific primers for rice detection (SPS2, PLD1 and PLD2) in pure rice molasses (I and II), are shown in Figure 3.4.1.A and 3.4.1.B.

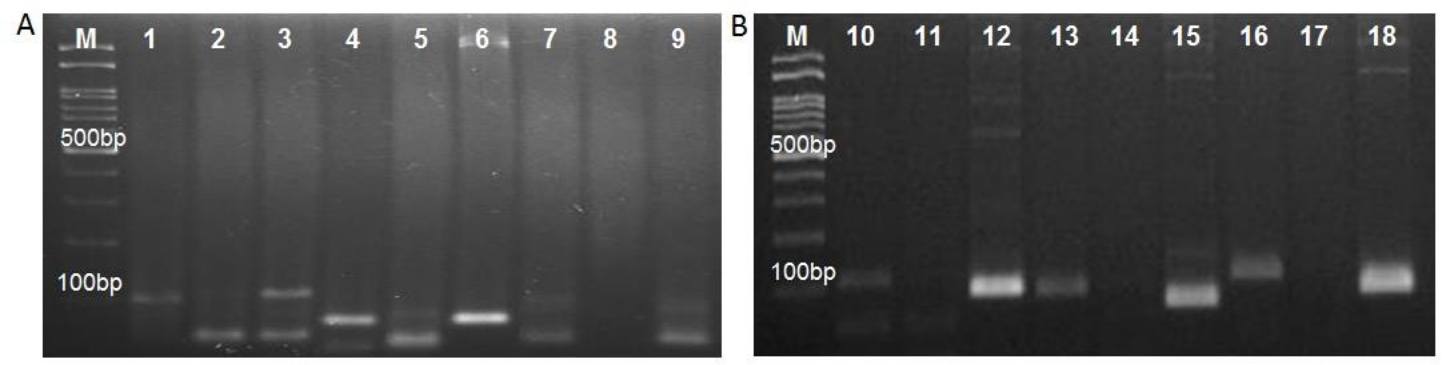

Figure 3.4.1. Agarose gel electrophoresis of PCR products for pure molasses (I and II) using rice primers (SPS2, PLD1 and PLD2). Figure 3.4.1.A: M: marker; 1-3: pure molasses I, negative and positive control with SPS2 primers; 4-6: pure molasses I, negative and positive control with PLD1 primers; 7-9: pure molasses I, negative and positive control with PLD2 primers. Figure 3.4.1.B: M: marker; 10-12: pure molasses II, negative and positive control with SPS2 primers; 13-15: pure molasses II, negative and positive control with PLD1 primers; 16-18: pure molasses II, negative and positive control with PLD2 primers.

In Figure 3.4.1.A the lines represent the PCR products that use rice primers (SPS2, PLD1 and PLD2) for pure molasses I. In this figure, the pure molasses I with PLD1 primers (line 4) had a visible amplification, with a strong and defined band, similar to the positive control with these primers (line 6). The pure molasses I with SPS2 primers (line 
1) also resulted in a visible but less intense amplification. The same occurs with its corresponding positive control (line 3). Molasses I with PLD2 primers (lines 7) and the positive control with these primers (line 9), do not show the expected result since their amplifications were very diffused and weak, probably due to the degradation caused by heat and filtration during the elaboration of the molasses (Caldwell, 2017; Mano et al., 2017). In all three cases, the negative control was as it did developing visible amplifications (lines 2, 5 and 8).

Lines of Figure 3.4.1.B represent the PCR products that use rice primers (SPS2, PLD1 and PLD2) for pure molasses II. In this figure, the results are very similar for the three types of primers. Molasses II (lines 10, 13 and 16, respectively) showed amplifications with the three types of primers, but always less intense than the positive control (lines 12,15 and 18, respectively). Again, by not obtaining any amplification implies the negative control was correct (lines 11, 14 and 17).

Considering these results, the two best primers were SPS2 and PLD1 since they provided the best amplification results, producing clear bands of both pure molasses (I and II). For this reason, these primers were chosen for the subsequent experiments.

\subsection{Conventional PCR for honey, rice molasses and rice molasses mixtures}

Figure 3.4.2.A and 3.4.2.B shows the agarose gel images of PCR products, obtained from conventional PCR reactions, using two species-specific primers for rice detection (SPS2 and PLD1), in pure rice molasses I, pure orange blossom honey and mixture of both in different percentages $(1,2,5,10,20$ and 50\%, respectively) simulating the adulteration of honey. 

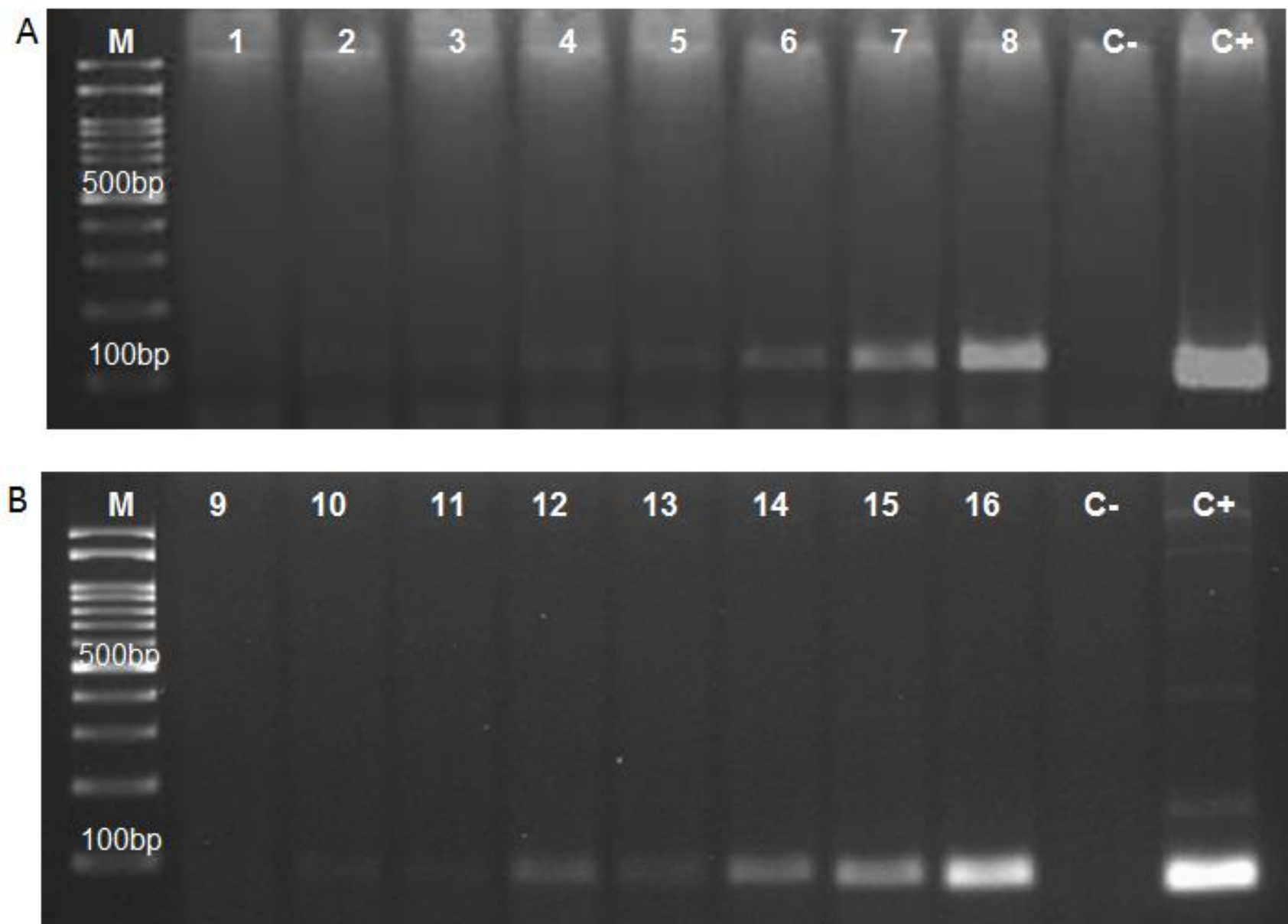

Figure 3.4.2. Agarose gel electrophoresis of PCR products for honey mixtures containing rice molasses I using rice primers (SPS2 and PLD1). Figure 3.4.2.A: M: marker; 1: pure honey with SPS2 primers; 2-7: honey mixed with 1, 2, 5 10, 20, 50\% rice molasses I with SPS2 primers; 8: pure molasses I with SPS2 primers; C-: negative control with SPS2 primers; C+: positive control with SPS2 primers. Figure 3.4.2.B: M: marker; 9: pure honey with PLD1 primers; 10-15: honey mixed with 1, 2, 5 10, 20, 50\% rice molasses I with PLD1 primers; 16: pure molasses I with PLD1 primers; C-: negative control with PLD1 primers; C+: positive control with PLD1 primers. 
Lines of Figure 3.4.2.A and 3.4.2.B, respectively, represent PCR products for pure molasses I that use SPS2 and PLD1 rice primers. The absence of a visible amplification in the honey sample (lines 1 for SPS2 and 9 for PLD1), and in the negative control (C-), demonstrates the absence of rice DNA. This is a clear indication that this honey has not been adulterated with this type of molasses. Furthermore, it is observed that with the addition of $1 \%$ and $2 \%$ of molasses (lines 2, 3 for SPS2 and 10, 11 for PLD1) amplification bands are visible, but they are very faint. On the contrary, from $5 \%$ to 50\% of molasses (lines 4-7 for SPS2 and lines 12-15 for PLD1) there are definite amplifications that increase in intensity. Finally, the pure molasses I (lines 8 for SPS2 and 16 for PLD1) can be found with the most intense band next to the positive control band $(C+)$. Summarizing, the same results were obtained for both primers, although PLD1 showed the most intense amplification.

On the other hand, Figure 3.4.3.A and 3.4.3.B displays the agarose gel images of PCR products, obtained from conventional PCR reactions, using two species-specific primers for rice detection (SPS2 and PLD1) in pure rice molasses II, pure orange blossom honey, and mixture of both in different percentages $(1,2,5,10,20$ and 50\%, respectively) simulating the adulteration of honey. 

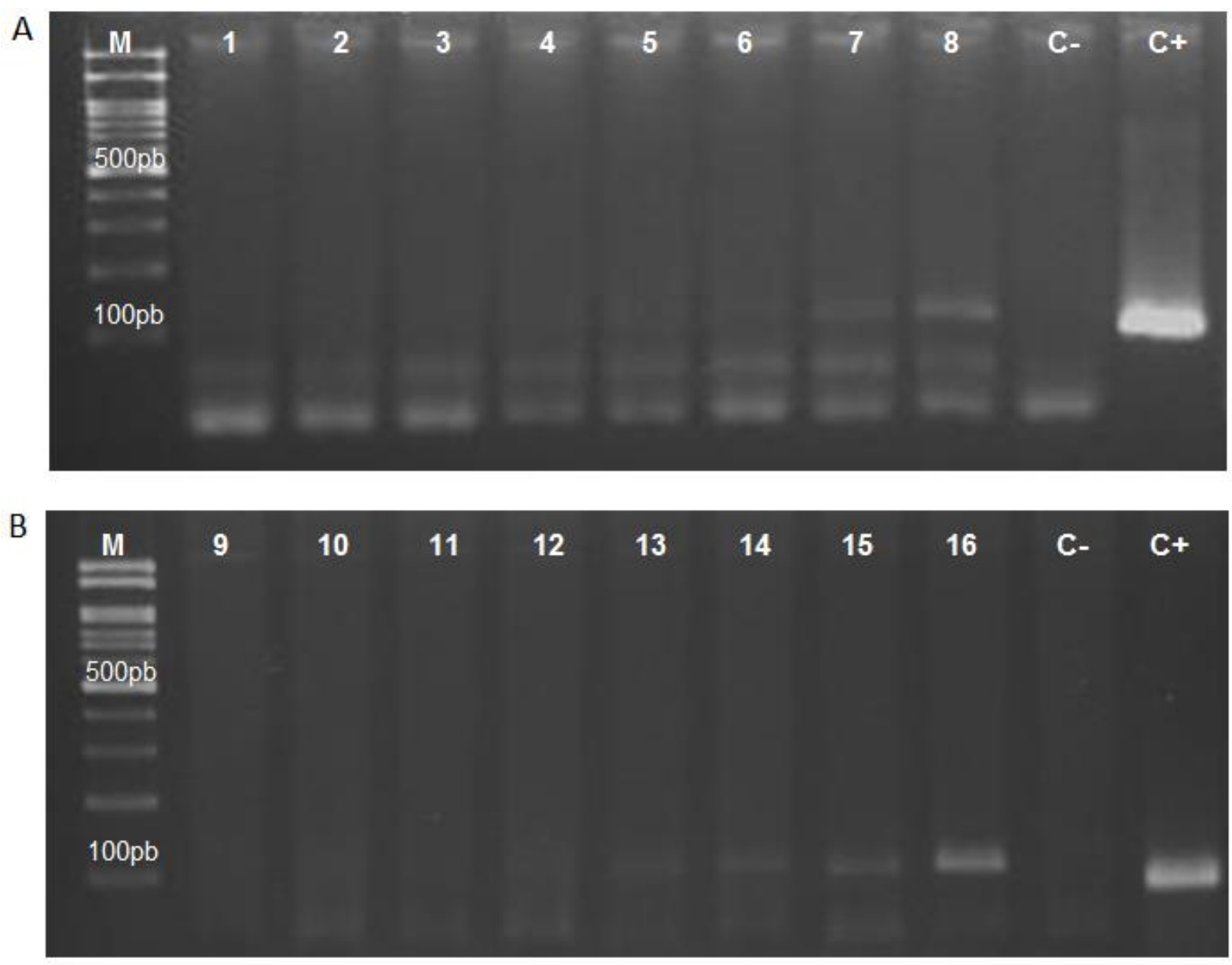

Figure 3.4.3. Agarose gel electrophoresis of PCR products for honey mixtures containing rice molasses II using rice primers (SPS2 and PLD1). Figure 3.4.3.A: M: marker; 1 : pure honey with SPS2 primers; 2-7: honey mixed with 1, 2, 5 10, 20, 50\% rice molasses II with SPS2 primers; 8: pure molasses II with SPS2 primers; C-: negative control with SPS2 primers; C+: positive control with SPS2 primers. Figure 3.4.3.B: M: marker; 9: pure honey with PLD1 primers; 10-15: honey mixed with 1, 2, 5 10, 20, 50\% rice molasses II with PLD1 primers; 16: pure molasses I with PLD1 primers; C-: negative control with PLD1 primers; C+: positive control with PLD1 primers. 
Lines of Figure 3.4.3.A and 3.4.3.B, respectively, represent PCR products for pure molasses II using SPS2 and PLD1 rice primers. In this case, up to $10 \%$ adulteration (lines 5 for SPS2 and 13 for PLD1) does not produce a visible amplification. For adulteration between $10 \%$ and 20\%, the bands are very weak (lines 5, 6 for SPS2 and 13, 14 for PLD1) and more defined amplifications appearing for $50 \%$ and for pure molasses II (lines 7, 8 for SPS2 and 15, 16 for PLD1). In both cases (Figure 3.A and 3.B) something similar occurs, although in Figure 3.B (PLD1 primers) the amplification for $10 \%$ and $20 \%$ are better appreciated. The differences among both molasses in the amplification results obtained is a possible consequence of the variations in the heating and filtering processes used for obtaining them, which may affect DNA integrity (Caldwell, 2017; Mano et al., 2017).

These conventional PCR experiments were repeated at least 4 times obtaining the same banding pattern, which indicates the reproducibility of the results and the integrity of the DNA samples. In all cases the controls ( $C+$ and $C-)$ verified the results obtained.

\subsection{Real time PCR amplification}

Figure 3.4.4 shows, as an example, a representative picture of a real-time PCR result for pure honey $(\mathrm{H})$ and honey with different percentages of pure rice molasses $(\mathrm{I}$ and II), simulating the same levels of adulteration as in conventional PCR. All levels of adulteration can be appreciated in the corresponding order $(1,2,5,10,20$ and 50\%). However, the adulteration of honey-molasses II with PLD1 primer showed no differences between $1 \%$ and $2 \%$ (Figure 3.4.4.D). 


\section{A}

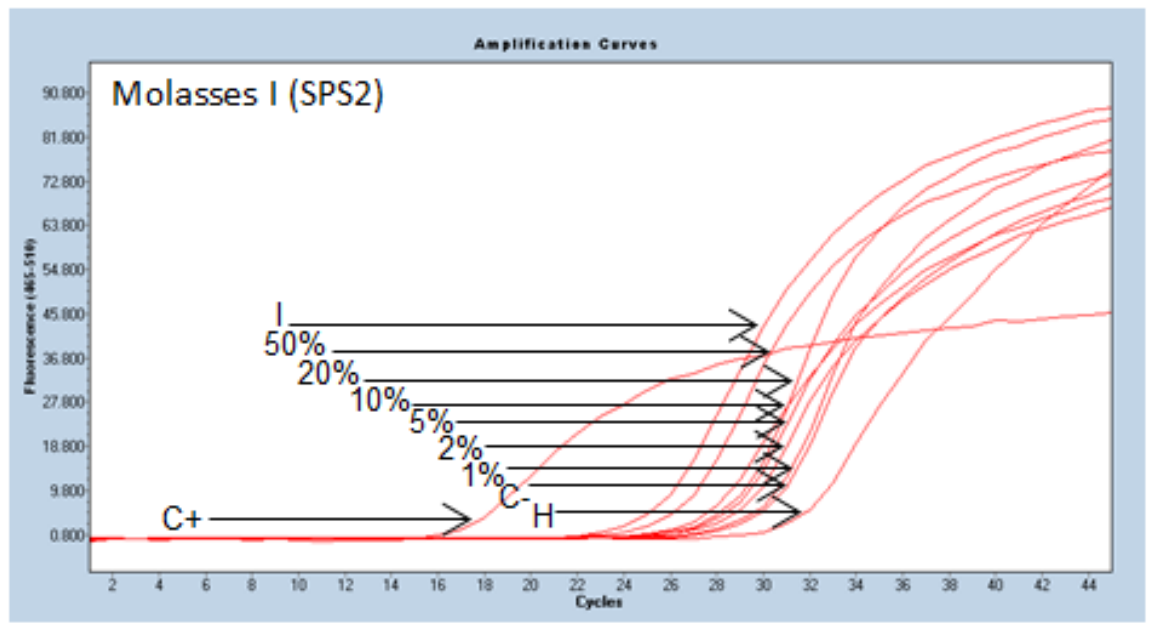

$\mathrm{C}$

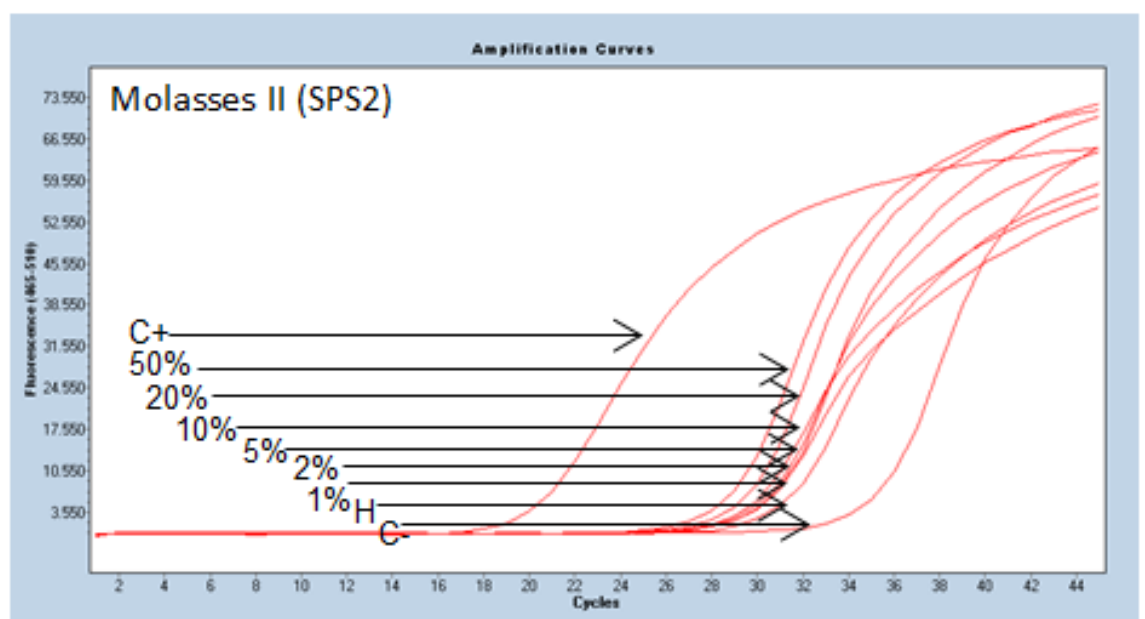

$\mathrm{B}$

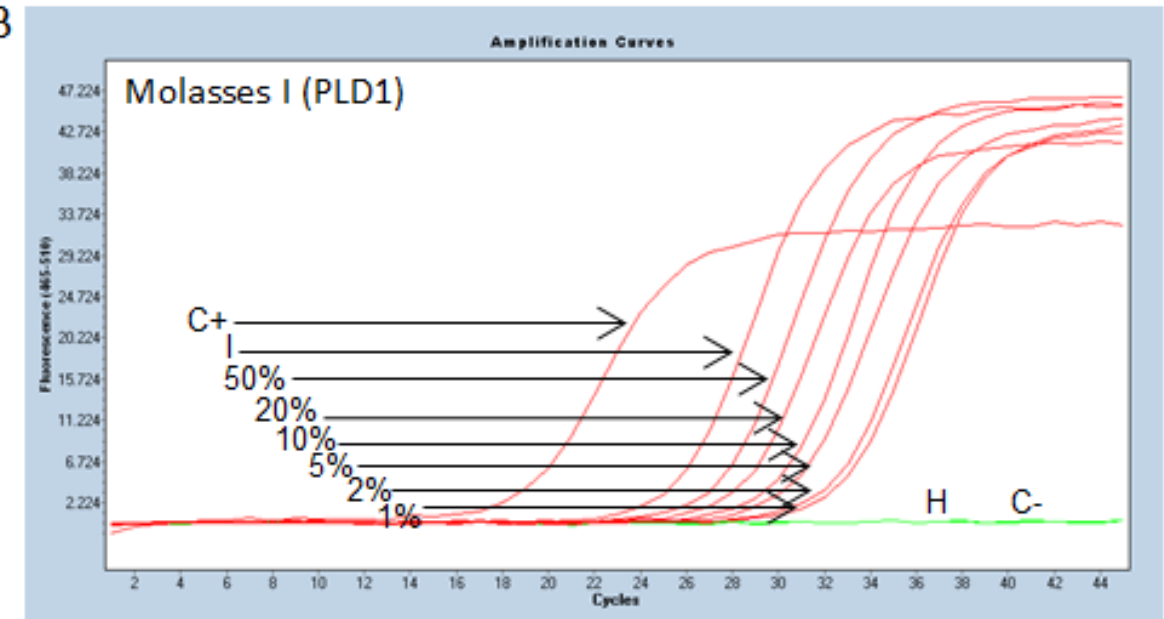

D

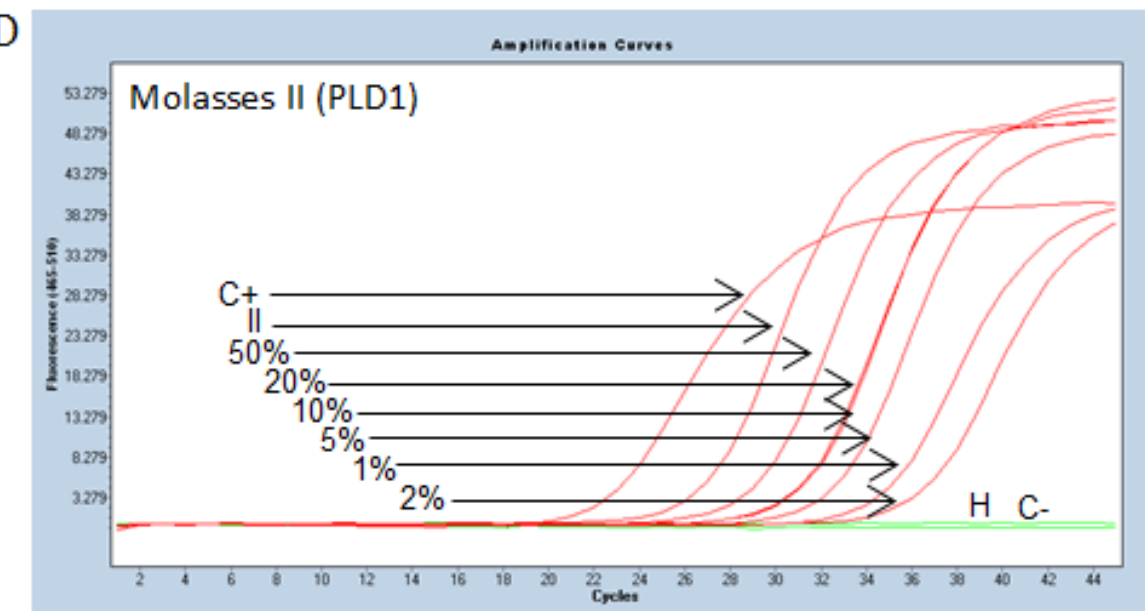

Figure 3.4.4. Example of a $P C R$ amplification plot for honey containing different percentages of rice molasses simulating the adulteration $(1,2,5,10,20$ and $50 \%)$. A: molasses I using SPS2; B: molasses I using PLD1; C: molasses II using SPS2; D: molasses II using PLD1. Abbreviations: I (molasses I), II (molasses II), H (honey), C+ (positive control) and C- (negative control). 
When observing in more detail the $\mathrm{Cp}$ values (crossing point-PCR-cycle), the order was altered in some cases. For molasses I and II using primers SPS2 (Figure 4.A and 4.C), the difference between each of the adulteration samples is very small. This causes an incorrect order in their Cp values: 50\% (26.14), 20\% (27.22), 5\% (28.17), 2\% (28.49), $10 \%(28.50), 1 \%(29.68)$ and honey $(\mathrm{H})(31.33)$ with molasses I. In relation to molasses II: 50\% (28.53), 20\% (29.18), 10\% (29.22), 1\% (29.68), 5\% (29.84), 2\% (30.20) and honey (H) (30.75).

For molasses I and II using primers PLD1 (Figure 3.4.4.B and 3.4.4.D) the results are much better. In this case, the order of the levels of adulteration (in both molasses types) is as follows based on their Cp value: $50 \%(27.45,29.12), 20 \%(28.42,31.13)$, $10 \%(29.95,31.27), 5 \%(30.68,32.57), 1 \%(32.25,34.65), 2 \%(32.74,36.27)$. Only $1 \%$ and $2 \%$ are altered, with very little differences between them, however, a clear difference is observed with respect to pure honey $(H)$. Using PLD1 primer increased and ordered values higher than $5 \%$ are considered satisfactory.

In all cases, the positive control has the smallest value of $\mathrm{Cp}$, followed by the corresponding rice molasses. In the case of negative controls, it has the $\mathrm{Cp}$ value of the highest value with SPS2 (29.62 in Figure 4.A and 34.94 in Figure 3.4.4.C) or completely negative, as it appears in the analyses carried out with the PLD1 primer (Figure 3.4.4.B and 3.4.4.D).

The results demonstrated the specificity and sensitivity of the real-time PCR analyses for rice molasses detection over the conventional PCR (Lubis et al., 2017), and more in the case of PLD1. Since these primers have an amplicon smaller than the rest (68bp), they have the capacity to amplify smaller DNA chains or highly degraded DNA (Wiseman, 2002). It is possible to affirm that combining real-time PCR with PLD1 primer could be considered the perfect screening or semi-quantitative technique for the detection of rice molasses in honey. For this reason, these primers were chosen for the subsequent experiment.

Similar results were obtained in all real time PCR experiments which demonstrated how well the results can be reproduced. In addition, the melting curve analysis showed that there was non-specific amplification in none of the experiment.

\subsection{Rice DNA concentrations}

To know the concentration of DNA present in the samples a standard curve was built plotting the $C p$ values against the logarithms of DNA serial dilutions of rice genomic DNA concentrations (100.00, 50.00, 25.00, 12.50, 6.25, 3.13, 1.56 and $0.78 \mathrm{ng} / \mu \mathrm{L}$ ) (Figure 3.4.5). The regression coefficient of 0.999 highlights the good correlation existing in the range established between $\mathrm{Cp}$ values and log concentrations of rice template DNA. Table 3.4.2 shows the calculated rice DNA concentrations (from the standard curve) for all the samples evaluated in this study. These values ranged from 
0.395 to 0.017 and 0.132 to $0.003 \mathrm{ng} / \mu \mathrm{L}$ rice $\mathrm{DNA}$, for rice molasses I and II, respectively. A progressive and ordered decrease of these concentrations is observed in relation to the lowering of the adulteration level. It can be stated that for both molasses it was not possible to differentiate between $2 \%(0.012$ and $0.001 \mathrm{ng} / \mu \mathrm{L})$ and $1 \%(0.017$ and $0.003 \mathrm{ng} / \mu \mathrm{L})$ of adulteration since the values obtained between these percentages are very close. This situation is common in real-time PCR analyses when DNA is highly degraded (Alonso-Rebollo et al., 2017). Nevertheless, between $2 \%$ and $5 \%$, a clear differentiation is observed, therefore between these both concentrations an acceptable limit of quantification could be established.

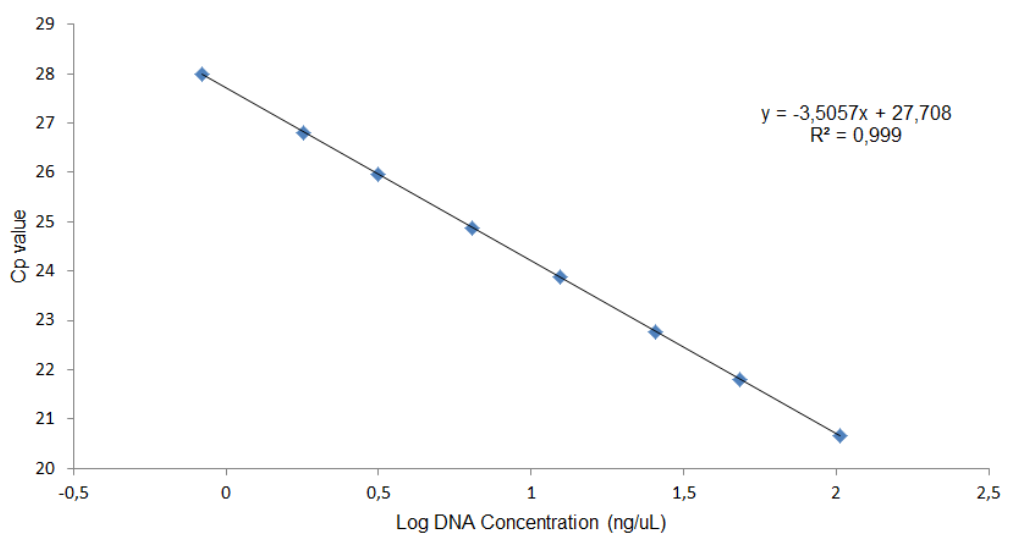

Figure 3.4.5. Rice genomic DNA standard curve where $C p$ value was plotted against Log DNA concentration $(\mathrm{ng} / \mu \mathrm{L})$ of DNA standard solution.

Table 3.4.2. Cp values (mean values and standard deviation), Log of concentrations and rice DNA concentrations in pure rice molasses $\mathrm{I}$ and $\mathrm{II}$, pure orange blossom honey, and mixture of both in different percentages $(1,2,5,10,20$ and $50 \%$, respectively) simulating the adulteration of honey

\begin{tabular}{llll}
\hline $\begin{array}{c}\text { Percentage of rice molasses } \\
\text { added to pure honey }\end{array}$ & \multicolumn{1}{c}{ Cp value } & \multicolumn{1}{c}{$\begin{array}{c}\text { Log of } \\
\text { Concentration }\end{array}$} & \multicolumn{1}{c}{$\begin{array}{c}\text { Calculated rice DNA } \\
\text { concentration (ng/ } \boldsymbol{\mu L} \text { ) }\end{array}$} \\
\hline $\begin{array}{l}\text { Rice molasses I } \\
0 \% \text { (pure honey) }\end{array}$ & ND & ND & ND \\
$1 \%$ & $32.25(0.32)$ & -1.773 & 0.017 \\
$2 \%$ & $32.74(0.21)$ & -1.913 & 0.012 \\
$5 \%$ & $30.68(0.06)$ & -1.325 & 0.047 \\
$10 \%$ & $29.95(0.17)$ & -1.117 & 0.076 \\
$20 \%$ & $28.42(0.19)$ & -0.680 & 0.209 \\
$50 \%$ & $27.45(0.21)$ & -0.404 & 0.395 \\
$100 \%$ (pure molasses I) & $25.56(0.05)$ & 0.136 & 1.366 \\
\hline Rice molasses II & & & \\
$0 \%$ (pure honey) & ND & $N D$ & 0.003 \\
$1 \%$ & $34.65(1.02)$ & -2.457 & 0.001 \\
$2 \%$ & $36.27(1.65)$ & -2.919 & 0.014 \\
$5 \%$ & $32.57(0.52)$ & -1.864 & 0.032 \\
$10 \%$ & $31.27(0.21)$ & -1.493 & 0.035 \\
$20 \%$ & $31.13(0.04)$ & -1.453 & 0.132 \\
$50 \%$ & $29.12(0.16)$ & -0.880 & 0.590 \\
$100 \%$ (pure molasses II) & $26.84(0.33)$ & -0.230 & 57.521 \\
\hline Controls & & & ND \\
Positive Control & $20.74(0.04)$ & 1.760 & \\
Negative Control & ND & $N D$ & \\
\hline
\end{tabular}


Considering the difficulty of the studied matrices (honey and molasses), in relation to the low amounts of target DNA, the capability of detecting a level of adulteration around $2-5 \%$ is considered an excellent result. Furthermore, it is important to point out that the techniques that are currently established to detect the incorporation of this specific type of molasses in honey is not able to guarantee a detection of adulteration below $10 \%$ of adulteration (Xue et al., 2013).

Using the same technique as in this study, similar identification adulteration percentages were reported by Al-Kahtani et al. (2017) when detecting pork meat in chicken meat, since pork DNA below $5 \%$ adulteration was not detected. Nevertheless, in the case of other types of meat (beef, camel, rabbit, goat and sheep) the same authors detected up to $1 \%$ adulteration.

\section{Conclusions}

This paper has presented for the first time that the PCR technique can be applied to quantify the presence of rice molasses in honey. This novel approach has been introduced to detect this kind of fraud in a bee product in which any type of addition is allowed. It was demonstrated that by using an appropriate genomic DNA extraction, it is possible to overcome the main obstacle in accessing sufficient quantity and quality of target DNA that is a necessary condition, to be amplified by the PCR later. Several specific genes of rice were used by conventional PCR technique, which allows the detection of this type of adulterant in honey. Furthermore, by means of real-time PCR it was also possible to distinguish the different levels of rice DNA present in mixtures of honey and rice molasses. By means of a standard curve (built with the DNA serial dilutions of rice genomic DNA concentrations) it was possible to quantify the amount of rice DNA and therefore to estimate more accurately the level of adulteration (up to 2-5\%). The percentage of quantification achieved by PCR technique implies a better advantage over other more expensive and time-consuming methodologies that are not able to reach a level lower than $10 \%$. However, further clarification is necessary to determine whether these findings could be applied to the detection of other kinds of molasses in honey, since the limiting factor could be the DNA extraction corresponding to the species from which the respective molasses are obtained.

\section{Acknowledgements}

This study is part of part of the projects funded by the "Agencia Estatal de Investigación" (AGL2016-77702-R) and by the "Generalitat Valenciana" (AICO/2015/104) of Spain, for which the authors are grateful. 


\section{References}

Aljanabi, S. M., Forget, L., \& Dookun, A. (1999). An improved and rapid protocol for the isolation of polysaccharide- and polyphenol- free sugarcane DNA. Plant Molecular Biology Reporter, 17, 1-8.

Al-Kahtani, H. A., Ismail, E. A., \& Ahmed, M. A. (2017). Pork detection in binary meat mixtures and some commercial food products using conventional and real-time PCR techniques. Food Chemistry, 219, 54-60.

Alonso-Rebollo, A., Ramos-Gómez, S., Busto, M. D., \& Ortega, N. (2017). Development and optimization of an efficient qPCR system for olive authentication in edible oils. Food Chemistry, 232, 827-835.

Bertelli, D., Lolli, M., Papotti, G., Bortolotti, L., Serra, G., \& Plessi, M. (2010). Detecction of adulteration by sugar syrups using one-dimensional and two-dimensional high-resolution Nuclear Magnetic Resonance. Journal of Agricultural and Food Chemistry, 58, 8495-8501.

Cai, H., Gu, X., Scanlan, M., Ramatlapeng, D., \& Lively, C. (2012). Real-time PCR assays for detection and quantitation of porcine and bovine DNA in gelatin mixtures and gelatin capsules. Journal of Food Composition and Analysis, 25, 83-87.

Cai, J., Wu, X., Yuan, L., Han, E., Zhou, L., \& Zhou. A. (2013). Determination of Chinese Angelica honey adulterated with rice syrup by an electrochemical sensor and chemometrics. Analytical Methods, 5, 2324-2328.

Caldwell, J. M. (2017). Food analysis using organelle DNA and the effects of processing on assays. Annual Review of Food Science and Technology, 8, 57-74.

Chen, A., Wei, C., Chen, G., Zhao, Y., \& Yang, S. (2015). Duplex PCR approach for the detection and quantification of donkey, horse and mule in raw and heat processed meat products. International Journal of Food Science and Technology, $50,834-839$.

Council Directive 2001/110 Relating to Honey (2002). Official Journal of the European Communities L10, 2002, 47-52.

De Oliveira, R., Teixeira, E., Da Silva, C., Guerra, M. L., Conte, C., \& Oliveira de Jesus, E. F. (2014). Detection of honey adulteration of high fructose corn syrup by low field Nuclear Magnetic Resonance (LF1H NMR). Journal of Food Engineering, 135, 39-43.

Doyle, J.J., \& Doyle, J.L. (1990). Isolation of plant DNA from fresh tissue. Focus, 12, 1315.

Dyshlyuk, L. S., Golubtsova, Y. V., Novoselov, M. V., \& Shevyakova, K. A. (2014). Investigation of methods of DNA extraction from plant origin objects and foods 
based on them. Vestnik Voronežskogo Gosudarstvennogo Universiteta Inženernyh Tehnologij, 3, 142-145.

Elfleing, L., \& Raezke, K. (2008). Improved detection of honey adulteration by measuring differences between $13 \mathrm{C} / 12 \mathrm{C}$ stable carbon isotope ratios of protein and sugar compounds with a combination of elemental analyser-isotope ratio mass spectrometry and liquid chromatography-isotope ratio mass spectrometry (g13C-EA/LC-IRMS). Apidologie, 39, 574.

Farrokhi, R., \& Jafari-Joozani, R. (2011). Identification of pork genome in commercial meat extracts for Halal authentication by SYBR green I real-time PCR. International Journal of Food Science and Technology, 46, 951-955.

Fernandes, T. J. R., Costa, J., Oliveira, M. B. P. P., \& Mafra, I. (2017). DNA barcoding coupled to HRM analysis as a new and simple tool for the authentication of Gadidae fish species. Food Chemistry, 230, 49-57.

Garino, C., De Paolis, A., Coïsson, J. D., Bianchi, D. M., Decastelli, L., \& Arlorio, M. (2016). Sensitive and specific detection of pine nut (Pinus spp.) by real-time PCR in complex food products. Food Chemistry, 194, 980-985.

Guertler, P., Eicheldinger, A., Muschler, P., Goerlich, O., \& Busch, U. (2014). Automated DNA extraction from pollen in honey. Food Chemistry, 149, 302-306.

Kesmen, Z., Yetiman, A. E., Sahin, F., \& Yetim, H. (2012). Detection of chicken and turkey meat in meat mixtures by using real-time PCR assays. Journal of Food Science, 77, 167-173.

Laube, I., Hird, H., Brodmann, P., Ullmann, S., Schöne-Michling, M., Chisholm, J., \& Broll, H. (2010). Development of primer and probe sets for the detection of plant species in honey. Food Chemistry, 118, 979-986.

Lo, Y., \& Shaw, P. (2018). DNA-based techniques for authentication of processed food and food supplements. Food Chemistry, 240, 767-774.

Lubis, H., Salihah, N. T., Hossain, M. M., \& Ahmed, M. U. (2017). Development of fast and sensitive real-time $\mathrm{qPCR}$ assay based on a novel probe for detection of porcine DNA in food sample. LWT-Food Science and Technology, 84, 686-692.

Mano, J., Nishitsuji, Y., Kikuchi, Y., Fukudome, S. I., Hayashida, T., Kawakami, H., \& Takabatake, R. (2017). Quantification of DNA fragmentation in processed foods using real-time PCR. Food Chemistry, 226, 149-155.

Mayer, H. K. (2005). Milk species identification in cheese varieties using electrophoretic, chromatographic and PCR techniques. International Dairy Journal, 15, 595-604. 
Meira, L., Costa, J., Villa, C., Ramos, F., Oliveira, M. B. P. P., \& Mafra, I. (2017). EvaGreen real-time PCR to determine horse meat adulteration in processed foods. LWT-Food Science and Technology, 75, 408-416.

Nebola, M., Borilova, G., \& Kasalova, J. (2010). PCR-RFLP analysis of DNA for the differentiation of fish species in seafood samples. Bulletin of the Veterinary Institute in Pulawy, 54, 49-53.

NucleoSpin-Food-isolation of genomic DNA from honey or pollen". http://catalog.takara-bio.co.jp/PDFS/SP_gDNAFood_honey.pdf. Accessed $13 / 01 / 2018$.

Oroian, M., \& Ropciuc, S. (2017). Botanical authentication of honeys based on Raman spectra. Journal of Food Measurement and Characterization. https://doi.org/10.1007/s11694-017-9666-3.

Rasmussen, R. S., Morrissey, M. T., \& Walsh, J. (2010). Application of a PCR-RFLP method to identify salmon species in U.S. commercial products. Journal of Aquatic Food Product Technology, 19, 3-15.

Real Decreto 1049/2003 (2003). Norma de calidad relativa a la miel (BOE no 186), 30181-30183.

Rodríguez-Ramírez, R., González-Córdova, A. F., \& Vallejo-Cordoba, B. (2011). Review: Authentication and traceability of foods from animal origin by polymerase chain reaction-based capillary electrophoresis. Analytica Chimica Acta, 685, 120-126.

Safdar, M., Junejo, Y., Arman, K., \& Abasıyanık, M. F. (2014). A highly sensitive and specific tetraplex PCR assay for soybean, poultry, horse and pork species identification in sausages: Development and validation. Meat Science, 98, 296300.

Serra, J., Soliva, M., \& Muntane, J. (2000). Invertase activity in fresh and processed honeys. Journal of the Science of Food and Agriculture, 80, 507-512.

Siddiqui, A. J., Musharraf, S. G., Choudhary, M. I., \& Rahman, A. (2017). Application of analytical methods in authentication and adulteration of honey. Food Chemistry, 217, 687-698.

Soares, S., Amaral, J. S., Oliveira, M. B. P. P., \& Mafra, I. (2015). Improving DNA isolation from honey for the botanical origin identification. Food Control, 48, 130136.

Sobrino-Gregorio, L., Vargas, M., Chiralt, A., \& Escriche, I. (2017). Thermal properties of honey as affected by the addition of sugar syrup. Journal of Food Engineering, $213,69-75$.

Takabatake, R., Onishi, M., Futo, S., Minegishi, Y., Noguchi, A., Nakamura, K., Kondo, K., Teshima, R., Mano, J., \& Kitta, K. (2015). Comparison of the specificity, stability, 
and PCR efficiency of six rice endogenous sequences for detection analyses of genetically modified rice. Food Control, 150, 949-955.

Ulberth, F. (2016). Chap 26, Advances in Testing for Adulteration in Honey, in Advances in Food Authenticity Testing, Woodhead Publishing Series in Food Science. Technology and Nutrition, 729-753.

Von Der Ohe, W., Persano, L., Piana, M. L., Morlot, M., \& Martin, P. (2004). Harmonized methods of melissopalynology. Apidologie, 35, 18-25.

Wang, S., Guo, Q., Wang, L., Lin, L., Shi, H., Cao, H., \& Cao, B. (2015). Detection of honey adulteration with starch syrup by high performance liquid chromatography. Food Chemistry, 172, 669-674.

Wiseman, G. (2002). State of the art and limitations of quantitative polymerase chain reaction. Journal of AOAC International, 85, 792-796.

Xue, X., Wang, Q., Li, Y., Wu, L., Chen, L., Zhao, J., \& Liu, F. (2013). 2-Acetylfuran-3Glucopyranoside as a novel marker for the detection of honey adulterated with rice syrup. Journal of Agricultural and Food Chemistry, 61, 7488-7493. 
3.5. Monitoring honey adulteration with sugar syrups using an automatic pulse voltammetric electronic tongue

Lara Sobrino-Gregorio, Román Bataller, Juan Soto, Isabel Escriche

Food Control, 91, 254-260 (2018) 



\section{ABSTRACT}

The new tendency to detect adulterated honey is the development of affordable analytical equipment that is in-line and manageable, enabling rapid on site screening. Therefore, the aim of this work was to apply an electronic tongue based on potential multistep pulse voltammetry, in combination with multivariate statistical techniques to detect and quantify syrup in honey. Pure monofloral honey (heather, orange blossom and sunflower), syrup (rice, barley and corn), and samples simulating adulterated honey with different percentages of syrup $(2.5,5,10,20$ and 40) were evaluated. An automatic, electrochemical system for cleaning and polishing the electronic tongue sensors (Ir, Rh, Pt, Au) significantly improved the repeatability and accuracy of the measurements. PCA analysis showed that the proposed methodology is able to distinguish between types of pure honey and syrup, and their different levels of adulterants. A subsequent PLS analysis successfully predicted the level of the adulterants in each honey, achieving good correlations considering the adjusting parameters. The best results being for sunflower honey adulterated with corn syrup and heather honey with barley syrup $\left(r^{2}=0.997\right)$, and heather with corn $\left(r^{2}=0.994\right)$ whereas the weakest was found for heather honey adulterated with brown rice syrup $\left(r^{2}=0.763\right)$ and orange blossom honey with corn syrup $\left(r^{2}=0.879\right)$. The measurement system here proposed could be a very quick and effective option for the honey packaging sector with the finality of providing information about a characteristic as important as the adulteration of honey.

Keywords: honey adulteration; syrups; pulse voltammetry; electronic tongue.

\section{Introduction}

Honey is a nutritional natural sweetener highly valued for its healing properties (Padovan et al., 2003; Cabanero et al., 2006; Ruíz-Matute et al., 2010; Bázár et al., 2016; Naila et al., 2018). The European Commission has stipulated that nothing should be added to honey (European Commission, 2002), but the limited availability and its price have provided major incentives for adulteration (Anklam, 1998). Honey is adulterated mainly with cheaper sweeteners such as sugar syrups that simulate its own sugar composition (Cai et al., 2013; Li et al., 2017; Sobrino-Gregorio et al., 2017; Naila et al., 2018). Adulterated honey affects the international honey market and the economy of the producers. In addition, it could have negative effects on consumer's nutrition and health (Tosun, 2013). Therefore, guaranteeing the authenticity of honey has become a very important issue for everyone involved in the food chain (SobrinoGregorio, 2017). 
In recent years, a large number of analytical methods have been used to differentiate genuine honey from adulterated. Among them, the most recognized are NMR spectroscopy (Bertelli et al., 2010; Davide \& Massimo, 2010; Boffo et al., 2012; Ohmenhaeuser et al., 2013; De Oliveira et al., 2014) and stable carbon isotopic ratio mass spectrometry (SCIRA) (Elfleing \& Raezke, 2008; Adnan et al., 2012; Simsek et al., 2012; Tosun, 2013). Another commonly used method is the reflectance-Fourier transforms infrared spectroscopy (Rios-Corripio et al., 2012; Oroian \& Ropciuc, 2017), high performance liquid chromatography (HPLC) to detect starch syrups (Wang et al., 2015), enzymatic activity (diastase, invertase) (Serra et al., 2000), specific markers (Xue et al., 2013) and differential scanning calorimetry (DSC) (Cordella et al., 2002 y 2003; Sobrino-Gregorio et al., 2017).

However, using these techniques individually the results obtained are not always conclusive, therefore, to guarantee the purity in honey the combination of several of them is required. Moreover, these techniques are very expensive, they require highly specialized equipment and are time-consuming (Sobrino-Gregorio et al., 2017).

To identify the authenticity of honey the industry needs to have simple, fast and easy to handle techniques without the need for expensive equipment and highly skilled workers (Bougrini et al., 2016; Juan-Borrás et al., 2017). Furthermore, the honey sector does not require data of exact levels of adulteration of honey, since any type of addition is prohibited. Only with a screening technique that able is to detect the slightest adulteration is enough.

Among the most promising techniques that fulfill this requirement, in addition to being more environmentally friendly than the usual methods, the electronic tongue has the advantage, as it can be an alternative tool to the traditional analytic methods (Bougrini et al., 2016). Unlike the traditional methods, electronic tongues do not obtain information about the nature of the compounds under consideration, but only present a digital fingerprint of the food material (Ghasemi-Varnamkhasti et al., 2010). It is also a qualitative analytical technique that permits recognition, classification or identification of samples, depending on the composition of the sensor array and the mathematical procedure adopted for data treatment.

Electronic tongue systems are based on an array of sensors with low selectivity while being sensitive to several components in the measured sample (cross-sensitivity). The signals collected by these sensors are processed by means of pattern recognition tools in order to generate prediction models that allow the classification of the samples and the quantification of some of their physicochemical properties (Gutés et al., 2007).

There are several alternatives to electronic tongue systems, the voltammetric being one of the most used (Martínez-Mañez et al., 2005; Winquist et al., 2005; Lvova et al., 2006), which has different advantages: high sensitivity, versatility, simplicity, robustness and good signal to noise ratio (Winquisk, 2008). 
These techniques, using arrays of electrodes, is at present the most popular for the design of electronic tongue systems, which include linear voltammetry, differential pulse voltammetry (Bataller et al., 2013), stripping voltammetry and over all cyclic voltammetry (Campos et al., 2010). Cyclic voltammetry is the most widely used technique (Bollo et al., 2004; De Beer et al., 2004; Dogan et al., 2005) and the obtained voltammogram permits the characterisation of electrochemical processes (oxidationreduction) over a wide potential range. On the other hand, pulse voltammetry is used when higher sensitivity and resolution are required, allowing the detection of lower concentrations of compounds (Escobar et al., 2013). In all cases the enormous amount of data generated by these systems must be processed using appropriate multivariate analysis techniques such as PCA (principal component analysis), LDA (linear discriminant analysis) or CA (cluster analysis) (Benedetti et al., 2004; Dias et al., 2008; Wei et al., 2009).

Electronic tongue systems are capable of identifying and classifying liquid samples such as wine, beer, coffee, milk, juices, teas and vegetable oils (Schreyer \& Mikkelsen, 2000; Parra et al., 2004; Apetrei et al., 2005; Huang et al., 2007; Chen et al., 2008; MorenoCodinachs et al., 2008; Rodríguez-Méndez et al., 2008; He et al., 2009; Oliveri et al., 2009; Gutiérrez et al., 2010; Gutierrez-Capitan et al., 2013; Apetrei \& Apetrei, 2014; Veloso et al., 2016). Moreover, it is used in quality assessment of solid foods such as meat, fish, fruit and vegetables (Han et al., 2008; Rodríguez-Méndez et al., 2009; Campos et al., 2010; Labrador et al., 2010). In the context of discriminating different classes within the same food type, it has been successfully used in honey, specifically focused on its differentiation according to its botanical and geographical origin (Dias et al., 2008; Wei et al., 2009; Wei \& Wang, 2011; Major et al., 2011; Escriche et al., 2012; Garcia-Breijo et al., 2013; Tiwari et al., 2013; Sousa et al., 2014; Bougrini et al., 2016; Juan-Borrás et al., 2017).

One of the most promising applications of the electronic tongue systems is the detection of food adulterations. Good results have been reported in the identification of sunflower oil introduced in argan oil (Bougrini et al., 2014) or in the case of goat milk adulterated with bovine milk (Dias et al., 2009). However, little research about the use of electronic tongue systems to identify adulteration of honey has been reported using pulse voltammetry (Men et al., 2014) or cyclic voltammetry (Bougrini et al., 2016; Ropciuc et al., 2017). However, the application of pulse voltammetry, in the above context, could provide important advantages since it has higher sensitivity and resolution (Bataller et al., 2013).

Nevertheless, an important problem that limits the use of electronic tongues as a technique for on-line quality controls is that of sensor system cleaning. In the aim to solve this, a mechanical system was developed by Swedish Sensor Center for polishing the electrodes of the electronic tongues (Olsson et al., 2006). However, it significantly limits the utility of the technique in controlling automated processes, as it requires 
high maintenance and costs. As a cheaper and easier alternative, the same group proposed the use of electropolishing to clean the electronic tongues (Holmin et al., 2004). The procedure consists of applying a high enough voltage to oxidize the surface of the electrodes, and to apply proper cathodic voltage to regenerate the different metal surfaces. Although studies using this technique were promising, the methodology was not optimized for systems that have high concentrations or high levels of contaminant load. Honey falls within the group of substances for which there is no well-defined electropolishing methodology.

Taking this into consideration, the aim of this study was to optimize an adequate electropolishing system to investigate the capacity of a pulse voltammetric electronic tongue, which consisted of a set of metal electrodes, to differentiate the presence of syrups in honey samples simulating various levels of adulteration.

\section{Materials and methods}

\subsection{Samples preparation}

Three types of raw honey harvested in 2016, provided by the company Melazahar (Montroy, Valencia), were used in this study: sunflower (Helianthus annuus); orange blossom (Citrus spp.) and heather (Erica spp.). They were selected based on their different physicochemical characteristics (Juan-Borrás et al., 2015). The botanical categorization of all the batches was carried out by means of pollinic analysis following the recommendations of the International Commission for Bee Botany (Von Der Ohe et al., 2004). Microscopic examination, identification and the interpretation of pollen types were carried out by an experienced pollen analyst, using pollen slides and references (Sáenz \& Gómez, 2000; Persano-Oddo \& Piro, 2004). Furthermore, three kinds of syrups from different origins were used: barley (La Finestra sul Cielo, Italy); corn (Roquette Laissa, Spain) and brown rice (Mitoku Macrobiotic, Japan).

The samples evaluated in the present work were: three pure syrups, three pure honeys and a mixture of both in different percentages $(40,20,10,5$ and $2.5 \%$, respectively) simulating the adulteration of honey. In each case, $8 \mathrm{~g}$ of sample (considered on a dry basis) were used. For this, the moisture content was obtained by using a refractometer (Abbe-type model T1; Atago, Bellevue, WA, USA) and the Chataway tables in accordance with the Harmonized Methods of the European Honey Commission (Bogdanov, 2009). All samples were analysed three times achieving four repetitions for each replication. 


\subsection{Equipment}

The measuring equipment is based on a potentiostat designed in the Institute of Molecular Recognition and Technological Development (IDM) at the Universitat Politècnica de València (Campos et al., 2013). This device allows performing pulse voltammetry measurements where the potentials and lengths of the pulses can be configured for each specific application. In this particular work, 40 pulses of $50 \mathrm{~ms}$ are applied. The voltages distribution is similar to a stair case voltammetry in increasing (or decreasing) steps of $200 \mathrm{mV}$ between $+1 \mathrm{~V}$ and $-1 \mathrm{~V}$ (to avoid water electrolysis), and the potential is set to zero after each increment (Figure 3.5.1).

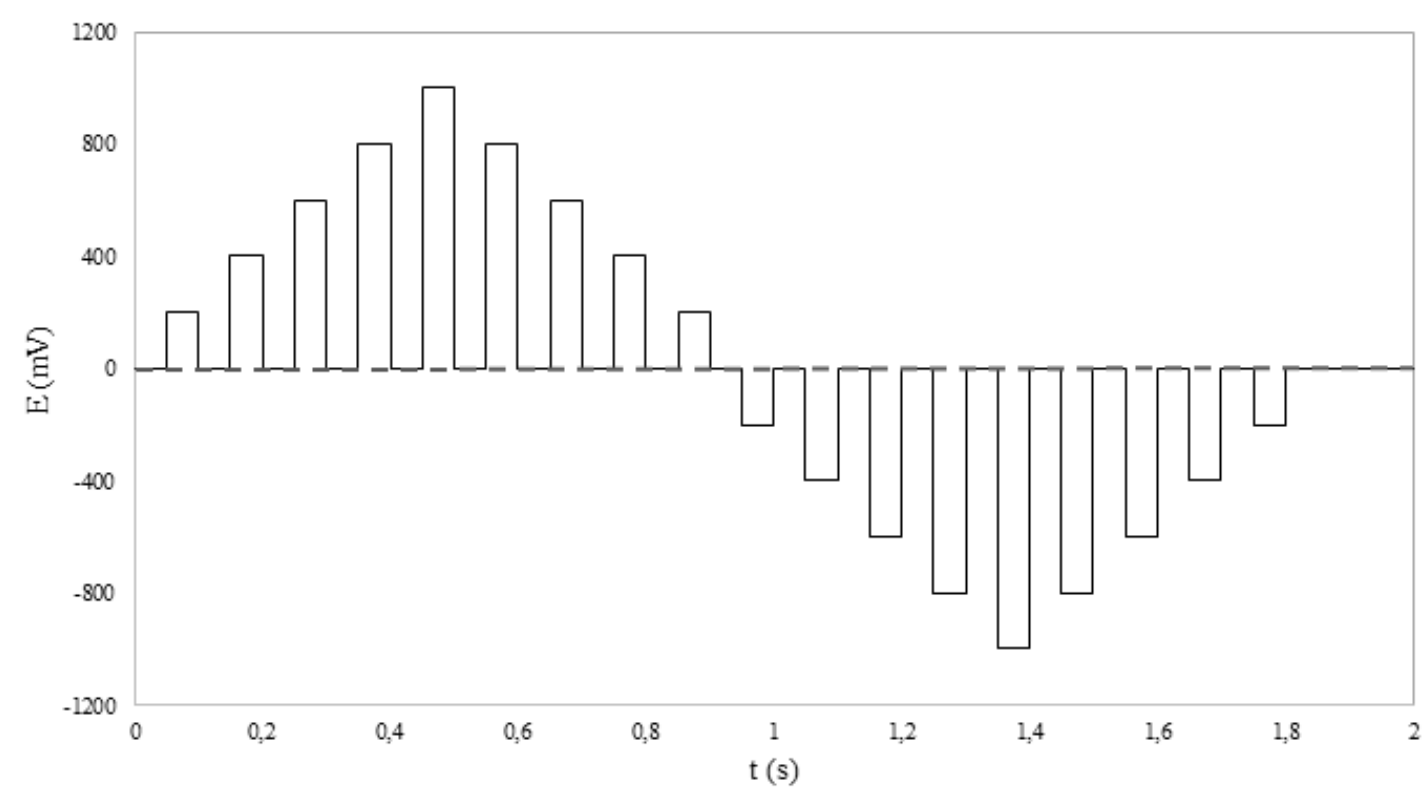

Figure 3.5.1. Voltammetric pulse pattern.

The voltammetry tests are measured with four working electrodes (Ir, Rh, Pt and $\mathrm{Au}$ ) housed inside a stainless-steel cylinder used as the electronic tongue body. A stainless steel circular piece is used as counter electrode and a calomel electrode is used as reference.

An integrated system of solenoid valves and a pump permit the automatic injection of liquid samples into a specifically designed measurement chamber. This complete system allows the implementation of an innovative electrochemical polishing of the working electrodes. For each metal, a configuration of basic or acidic solution is used when a sequence of cathodic and anodic pulse (or reversed) is applied to them. The aim is desorbing the organic material accumulated at the surface of the electrodes, and detaching any oxide layer that may have been formed (Table 3.5.1). 
Table 3.5.1. Electrochemical polishing of the working electrodes: configuration of basic or acidic solution in the sequence of cathodic and anodic pulse applied to the different metals.

\begin{tabular}{lllll}
\hline Electrodes & Cathodic pulse $(\mathbf{m V})$ & Anodic pulse $(\mathbf{m V})$ & Rest pulse $(\mathbf{m V})$ & Polishing media \\
\hline $\mathrm{Ir}$ & +900 & -500 & 0 & Acidic \\
$\mathrm{Rh}$ & +1500 & -1500 & 0 & Basic \\
$\mathrm{Pt}$ & +1800 & -500 & 0 & Acidic \\
$\mathrm{Au}$ & +1500 & -1500 & 0 & Basic \\
\hline
\end{tabular}

An in-house design of a specific software manages both the measuring equipment and the pumping system. It performs a complete set of measurements with the same setup, and stors the results for a later statistical analysis.

This system was patented in 2016, under the name "Sistema y método de control de la calidad del agua en plantas de tratamiento", which translation would be "System and method to control water quality in treatment plants", property of the company Fomento Agrícola Castellonense, S.A. and the by the Interuniversity Research Institute for Molecular Recognition and Technological Development (IDM) of the Universitat Politècnica de València, with reference number P201631405 (Bataller et al., 2016).

\subsection{Statistical analysis}

Multivariate statistical analysis techniques were used to analyse the data gathered for this study. Principal components analysis (PCA) was used to discriminate between samples and partial least square (PLS) to quantify the content of honey adulterant in the analysed samples. The PLS model was calibrated with $66 \%$ of the data set and validated with the remaining $33 \%$. Model's assessment is done by comparing real versus predicted adulteration levels. The parameters used are the correlation coefficient $\left(r^{2}\right), a, b$ (from the simplest linear model: $y=a x+b$ ) and the root mean square error of prediction (RMSEP) as the most common metric obtained to measure accuracy of this methodology (Bataller et al., 2012).

All these statistical studies have been performed with Solo 8.6 software (Eigenvector Research, Inc., Wenatchee, Washington, DC, USA).

\section{Results and discussion}

\subsection{Differentiation of pure honeys and syrups}

A PCA analysis was applied (from the data generated by the four electrodes of the electronic tongue) in order to show if there was a classification of the different types of pure samples (honeys and syrups). Figure 3.5.2 shows the score plot of this analysis, in which the first two principal components together explain $80.01 \%$ of the data variability, specifically $59.59 \%$ by PC1 and $20.42 \%$ by PC2. Discrimination between 
honeys and syrups is mainly determined by the $X$ axis (PC1), where the honey samples are in the centre of the score graph and the syrups are placed on both sides (on the left the barley and brown rice syrups, on the right the corn). Since, proximity between samples indicates similar behaviour in terms of the electrochemical response of the sensors, small differences between barley and brown rice syrups with respect to corn syrups were found. On the contrary, the type of honey is differentiated by PC2, where heather honey is in the upper half and sunflower honey in the lower, whereas orange blossom honey is in the middle.

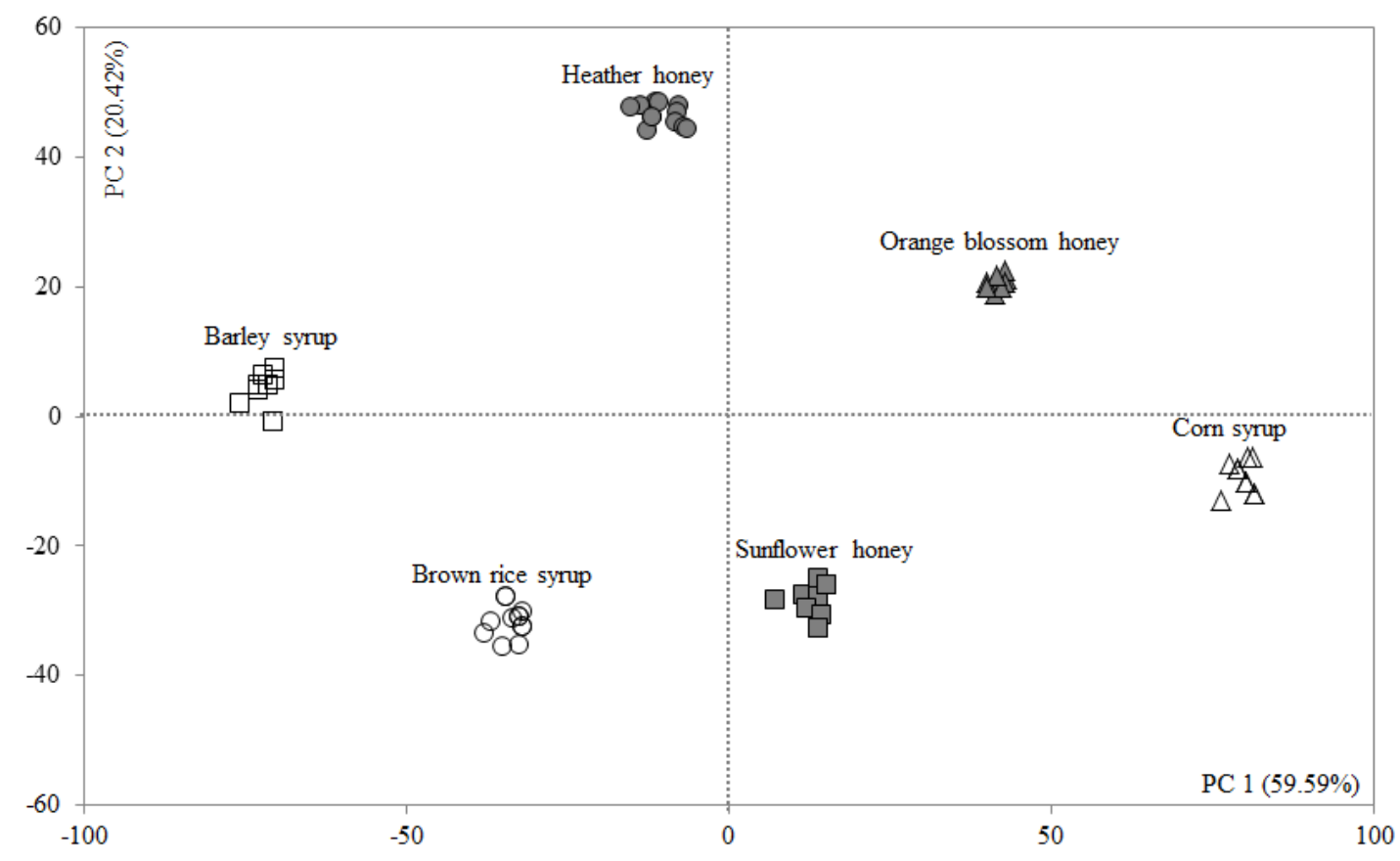

Figure 3.5.2. Score plot of the PCA performed on pure honeys (sunflower, orange blossom, heather) and pure syrups (barley, corn, brown rice) samples.

Once proven that this methodology could differentiate between all types of pure samples analysed, the next phase was to verify if this type of electronic tongue was able to discriminate honeys in which syrups have been added.

\subsection{Differentiation by adulteration levels}

Figure 3.5.3 shows, as an example, the behaviour of the signal obtained by applying the corresponding potential pulse pattern to sunflower honey adulterated with barley syrup. There is a clear differentiation between the signals obtained for syrup, pure honey and the different percentages of adulteration $(40,20,10,5$ and $2.5 \%$, respectively). It is evident that the signals are affected by the samples and the adulteration levels. The highest signal corresponds to pure syrup which progressively decreases to pure honey, going through its different and ordered stages of 
adulteration. This behaviour was in most cases constant, regardless of the type of syrup and honey.

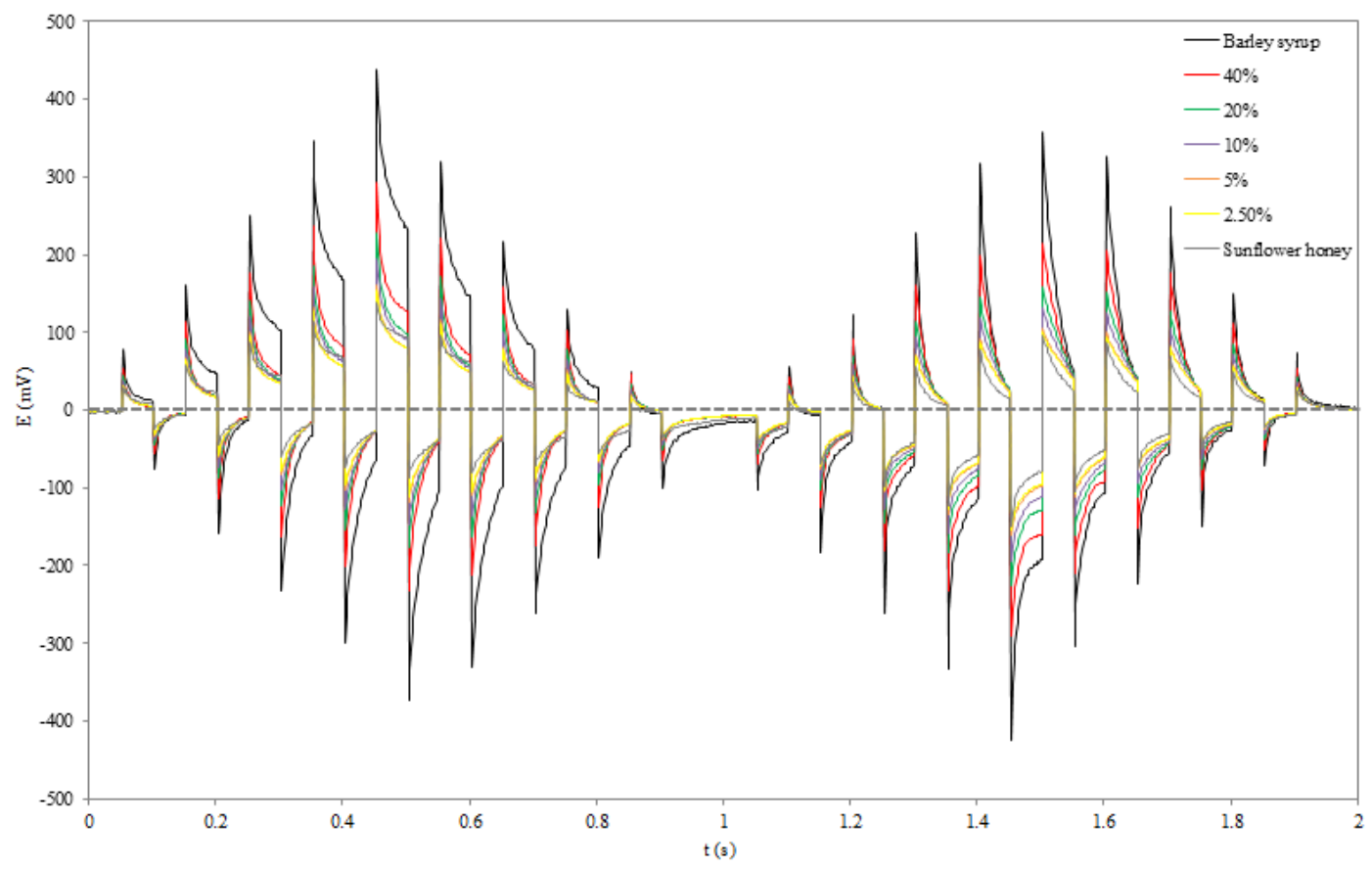

Figure 3.5.3. Electrochemical trace of the layered sequence of the potential for sunflower honey adulterated with barley syrup at different levels (40,20, 10, 5 and $2.5 \%)$.

For the purpose of evaluating from a descriptive point of view, the global effect of the electronic tongue response in the pure honeys, syrups and their corresponding adulteration levels, different Principal Component Analysis (PCA) were carried out. Figure 3.5.4 shows, as an example, the PCA performed in the case of adding barley syrup $(40,20,10,5$ and $2.5 \%)$ to the three pure honeys. In this figure (3.5.4.A to 3.5.4.C), the two principal components represent $86.5 \%$ (PC1: $52.50 \%$; PC2: $34.02 \%$ ); 83.98\% (PC1: 67.41\%; PC2: 16.57\%) and 78.87\% (PC1: 61.89\%; PC2:19.98\%) for sunflower; orange blossom and heather, respectively. Pure barley syrup and honey with $40 \%$ of barley syrup are in all cases on the left side of the plots (but in opposite quadrants), whereas the rest of the samples are placed on the right side. In all these PCA plots, a progressive, ordered and clear tendency is observed in relation to the adulteration level. The higher level $(40 \%)$ is farther away from the pure honey, whereas the lower level (2.5\%) is closer to it. 

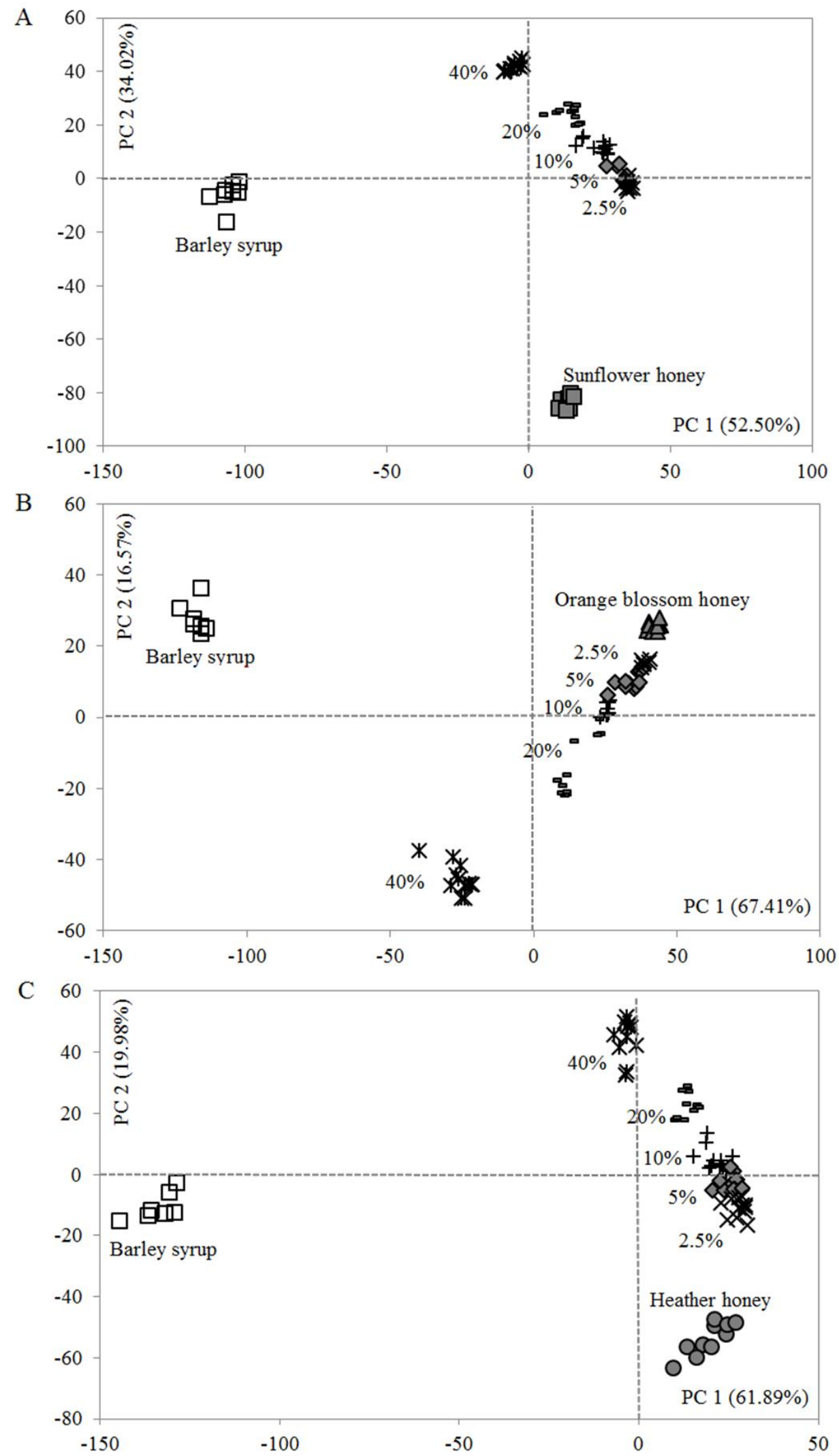

Figure 3.5.4. Scores plot of the PCA performed on barley syrup and pure honey (A: sunflower; B: orange blossom; C: heather hone), and mixtures of both in different percentages (40, 20, 10, 5 and $2.5 \%$ ) simulating the adulteration of honey. 
Similar results were reported by Bougrini et al., (2016) using cyclic voltammetry for adulteration detection, from 2 to $20 \%$, of pure honey although glucose and sacharose syrups were added. The values of adulteration detected by these authors in honey are even better than those described by them in the case of adulteration in argan oil adulterated with different proportions of sunflower oil (10 to 70\%) (Bougrini et al., 2014). Ropciuc et al. (2017), using cyclic voltammetry (with Ag and Au as working electrodes) differentiated honeys adulterated with inverted sugar and malt wort only when they did not exceed $20 \%$.

The present work confirms that using pulse voltammetry allowed for further possibilities by designing a specific pulse pattern. In addition to the automation of the electrochemical cleaning process while providing good reproducibility of the sensors and good classification results, it also permitted the detection of a wider adulteration range (up to $40 \%$ ). Moreover, among other advantages it was observed that the time required to analyse one sample using the pulse voltammetry technique is considerably less: 8 seconds to scan with the 4 electrodes; 40 seconds for 5 iterations; 12 seconds for electropolishing per electrode; 4 minutes for the final cleaning of the sensor system if 5 consecutive cleanings are performed. However, considering the protocol described by Bougrini et al. in 2016, the cleaning alone (disassembled, manual cleaning of electrodes, electrochemical cell re-assembled, etc.) takes at least $20 \mathrm{~min}$.

\subsection{PLS analysis: correlation of pulse voltammetric data with the level of adulteration}

In order to verify whether the data provided by the electronic tongue could be useful in predicting the adulteration of pure honeys (sunflower, orange blossom, heather) with syrup (barley, corn, brown rice) at different percentages (40, 20, 10, 5 and 2.5\%), a Partial Least Square (PLS) analysis was applied. Nine PLS models of prediction were created ( 3 honeys multiplied by 3 syrups) with the voltammetric experimental data obtained from the four metallic electrodes (Ir, Rh, Pt, Au). Figure 3.5.5 shows one of these PLS graphs (heather honey adulterated with barley syrup) in which measured vs. predicted values of the adulteration levels are plotted together in order to evaluate the performance of the created prediction linear model. Table 3.5.2 shows the PLS prediction results (slope, intercept, the regression coefficient, number of latent variables and RMSEP) for the nine models obtained. In most cases, there is a good result, the best one being for sunflower-corn and heather-barley with correlation coefficients of 0.997 and heather-corn with 0.994 . The weakest correlation was for heather-brown rice (0.763) and orange blossom-corn (0.879). In order to quantitatively describe the accuracy of model outputs obtained, the RMSEP were shown (Table 3.5.2). The best model in terms of capability of prediction corresponded to that obtained for heather-barley (0.834) followed by sunflower- barley (1.252). The worst model was for orange blossom-corn (5.261) and header brown-rice (5.159). 


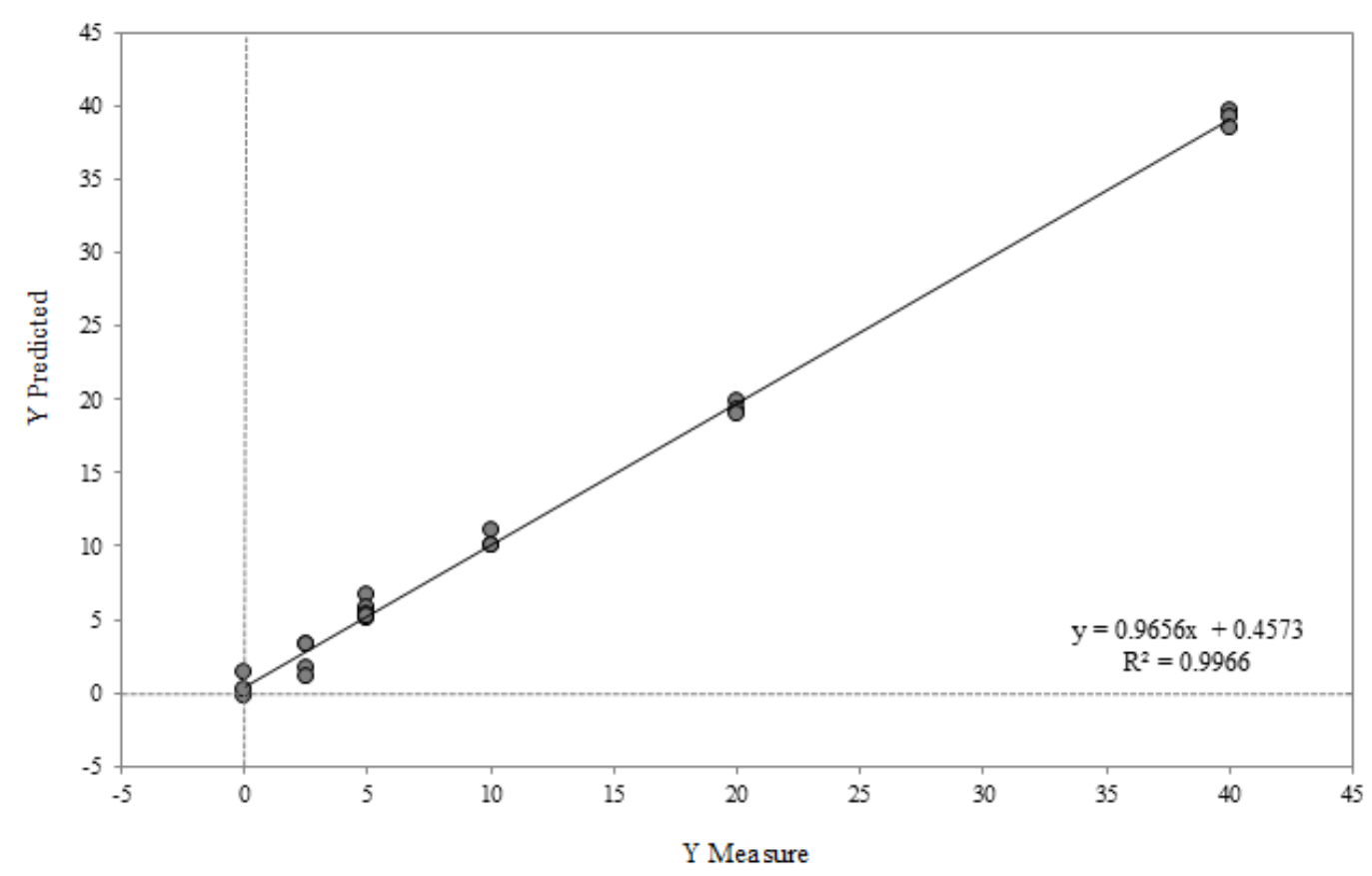

Figure 3.5.5. Predicted versus measured values of heather honey adulterated with barley syrup given by PLS model.

Table 3.5.2. PLS prediction results obtained from the validation data for the adulteration of pure honeys (sunflower, orange blossom, heather) with syrup (barley, corn, brown rice) at different percentages (40, $20,10,5$ and $2.5 \%)$.

\begin{tabular}{llllll}
\hline \multicolumn{1}{c}{ Adulterations } & $\begin{array}{c}\text { No. latent } \\
\text { variables }\end{array}$ & $\begin{array}{c}\text { Correlation } \\
\text { coefficient }\end{array}$ & Slope & Intercept & RMSEP \\
\hline Sunflower-barley & 4 & 0.991 & 0.999 & 0.206 & 1.252 \\
Sunflower-corn & 5 & 0.997 & 0.937 & 1.858 & 2.622 \\
Sunflower-brown rice & 2 & 0.949 & 0.909 & 1.073 & 3.489 \\
\hline Orange blossom- barley & 7 & 0.993 & 0.983 & 0.589 & 1.336 \\
Orange blossom-corn & 6 & 0.879 & 0.847 & 1.234 & 5.261 \\
Orange blossom- brown rice & 6 & 0.988 & 1.029 & 0.203 & 1.681 \\
\hline Heather- barley & 5 & 0.997 & 0.966 & 0.457 & 0.834 \\
Heather- corn & 5 & 0.994 & 1.012 & 0.997 & 1.479 \\
Heather- brown rice & 4 & 0.763 & 0.823 & 3.936 & 5.159 \\
\hline
\end{tabular}

Cai, et al., in 2013, applied cyclic voltammetry in Chinese Angelica honey adulterated with rice syrup (from $20 \%$ to $50 \%$ ). They were able to prove that in quantitative analysis of honey adulteration, a multiple linear regression (MLR) model fitted and predicted well with the square of the correlation coefficients ( $R c=0.921$ and $R p=0.898$ ). Other authors proposed the combination of PLS with Fuzzy ARTMAP tools to improve the classification of honey adulterated in different proportions (from 0 to $70 \%$ ) when a voltammetric electronic tongue system is applied (Men et al., 2014). 


\section{Conclusions}

This paper has presented for the first time that an innovative automatic pulse voltammetry can be applied to quantify the presence of syrups in honey. The outcome is the possibility that this type of electronic tongue (with automatic, electrochemical system for cleaning and polishing the electronic tongue sensors) permits detecting this kind of fraud in a bee product to which no addition of substances is allowed. PCA analysis demonstrated that this automatic pulse voltammetry electronic tongue system, made of four metallic electrodes (Ir, Rh, Pt, Au) was capable of not only differentiating between types of pure honey and pure syrups but also to discriminate honeys to which syrups have been added at different levels. The PLS models are capable of predicting the additions of adulterants in different types of honey, and therefore provides a powerful tool to quantify their level of incorporation.

The present findings might help to solve the necessity to have a manageable and inline analytical equipment that enables rapid on site screening and also more affordable for the apiculture sector. However, future studies on the current topic are recommended in order to create a wide and comprehensive data base of pure types of honey from different botanical and geographical origin.

\section{Acknowledgment}

This study forms part of the projects funded by the "Agencia Estatal de Investigación" (AGL2016-77702-R) and by the "Generalitat Valenciana" (AICO/2015/104) of Spain, for which the authors are grateful.

\section{References}

Adnan, S., Mine, B., \& Ahmet, C. G. (2012). 13C/12C pattern of honey from Turkey and determination of adulteration in commercially available honey samples using EAIRMS. Food Chemistry, 130, 1115-1121.

Anklam, E. (1998). A review of the analytical methods to determine the geographical and botanical origin of honey. Food Chemistry, 63, 549-562.

Apetrei, C., Rodríguez-Mendez, M. L., \& De Saja, J. A. (2005). Modified carbon paste electrodes for discrimination of vegetable oils. Sensors and Actuators B, 111-112, 403-409.

Apetrei, I. M., \& Apetrei, C. (2014). Detection of virgin olive oil adulteration using a voltammetric e tongue. Computers and Electronics in Agriculture, 108, 148-154.

Bataller, R., Campos, I., Laguarda-Miro, N., Alcañiz, M., Soto, J., Martínez-Máñez, R., Gil, L., García-Breijo, E., \& Ibáñez-Civera, J. (2012). Glyphosate Detection by 
Means of a Voltammetric Electronic Tongue and Discrimination of Potential Interferents. Sensors, 12, 17553-17568.

Bataller, R., Campos, I., Alcañiz, M., Gil-Sánchez, L., García-Breijo, E., Martínez-Máñez, R., Pascual, L., Soto, J., \& Vivancos, J. L. (2013). A humid electronic nose based on pulse voltammetry: A proof-of-concept design. Sensors and Actuators B: Chemical, 186, 666-673.

Bataller, R., Martínez-Bisbal, M. C., Alcañiz, M., Berlanga-Clavijo, J. G., Carbó-Mestre, N., Folch, E., \& Tormos, I. (2016). Sistema y método de control de la calidad del agua en plantas de tratamiento. P201631405 (patent).

Bázár, G., Romvári, R., Szabó, A., Somogyi, T., Éles, V., \& Tsenkova, R. (2016). NIR detection of honey adulteration reveals differences in water spectral pattern. Food Chemistry, 194, 873-880.

Benedetti, S., Mannino, S., Sabatini, A. G., \& Marcazzan, G. L. (2004). Electronic nose and neural network use for the classification of honey. Apidologie, 35, 397-402.

Bertelli, D., Lolli, M., Papotti, G., Bortolotti, L., Serra, G., \& Plessi, M. (2010). Detecction of adulteration by sugar syrups using one-dimensional and two-dimensional high-resolution Nuclear Magnetic Resonance. Journal of Agricultural and Food Chesmistry, 58, 8495-8501.

Boffo, E. F., Tavares, L. A., Tobias, A. C. T., Ferreira, M. M. C., \& Ferreira, A. G. (2012). Identification of components of Brazilian honey by H NMR and classification of its botanical origin by chemometric methods. LWT. Food Science and Technology, 49, 55-63.

Bogdanov, S. (2009). Harmonized methods of the International Honey Commission. http://www.terezinka.cz/vcely/Med/IHCmethods_e.pdf. Accessed 08/07/17.

Bollo, S., Nuñez-Vergara, L., \& Squella, J. (2004). Cyclic voltammetric determination of free radical species from nitroimidazopyran: A new antituberculosis agent. Journal of Electroanalytical Chemistry, 562, 9-14.

Bougrini, M., Tahri, K., Haddi, Z., Saidi, T., Bari, N. E., \& Bouchikhi, B. (2014). Detection of Adulteration in Argan Oil by Using an Electronic Nose and a Voltammetric Electronic Tongue. Journal of Sensors, 10 pages.

Bougrini, M., Tahri, K., Saidi, T., Hassani, N. E. A. E.,Bouchikhi, B., \& Bari, N. E. (2016). Classification of Honey According to Geographical and Botanical Origins and Detection of Its Adulteration Using Voltammetric Electronic Tongue. Food Analytical Methods, 9, 2161-2173.

Cabanero, A. I., Recio, J. L., \& Ruperez, M. (2006). Liquid chromatography coupled to isotope ratio mass spectrometry: A new perspective on honey adulteration detection. Journal of Agricultural and Food Chemistry, 54, 9719-9727. 
Cai, J., Wu, X., Yuan, L., Han, E., Zhou, L., \& Zhou. A. (2013). Determination of Chinese Angelica honey adulterated with rice syrup by an electrochemical sensor and chemometrics. Analytical Methods, 5, 2324-2328.

Campos, I., Masot, R., Alcañiz, M., Gil, L., Soto, J., Vivancos, J. L., Garcia-Breijo, E., Labrador, R. H., Barat, J. M., \& Martínez-Máñez, R. (2010). Accurate concentration determination of anions nitrate, nitrite and chloride in minced meat using voltammetric electronic tongue. Sensors and Actuators B: Chemical, 149, 71-78.

Campos, I., Bataller, R., Armero, R., Gandia, J. M., Soto, J., Martínez-Máñez, R., \& GilSánchez, L. (2013). Monitoring grape ripeness using a voltammetric electronic tongue. Food Research International, 54, 1369-1375.

Chen, Q., Zhao, J., \& Vittayapadung, S. (2008). Identification of the green tea grade level using electronic tongue and pattern recognition. Food Research International, 41, 500-504.

Cordella, C., Antinelli, J. F., Aurieres, C., Faucon, J. P., Cabrol-Bass, D., \& Sbirrazzuoli, N. (2002). Use of differential scanning calorimetry (DSC) as a new technique for detection of adulteration in honeys. 1. Study of adulteration effect on honey thermal behavior. Journal of Agriculture Food Chemistry, 50, 203-208.

Cordella, C., Faucon, J. P., Cabrol-Bass, D., Sbirrazzuoli, N. (2003). Application of DSC as a tool for honey floral species characterization and adulteration detection. Journal of Thermal Analysis and Calorimetry, 71, 279-290.

Davide, B., \& Massimo, L. (2010). Detection of honey adulteration by sugar syrups using one-dimensional and two-dimensional highresolution nuclear magnetic resonance. Journal of Agricultural and Food Chemistry, 58, 8495-8501.

De Beer, D., Harbertson, J. F., Kilmartin, P. A., Roginsky, V., Barsukova, T., \& Adams, D. O. (2004). Phenolics: A comparison of diverse analytical methods. American Journal of Enology and Viticulture, 55, 389-400.

De Oliveira, R., Teixeira, E., Da Silva, C., Guerra, M. L., Conte, C., \& Oliveira de Jesus, E. F. (2014). Detection of honey adulteration of high fructose corn syrup by low field Nuclear Magnetic Resonance (LF1H NMR). Journal of Food Engineering, 135, 39-43.

Dias, L. A., Peres, A. M., Vilas-Boas, M., Rocha, M. A., Estevinho, L., \& Machado, A. (2008). An electronic tongue for honey classification. Microchimica Acta, 163, 97102.

Dias, L. A., Peres, A. M., Veloso, A. C. A., Reis, F. S., Vilas-Boas, M., \& Machado, A. A. S. C. (2009). An electronic tongue taste evaluation: Identification of goat milk adulteration with bovine milk. Sensors and Actuators B, 136, 209-217. 
Dogan, B., Ozkan, S., \& Uslu, B. (2005). Electrochemical characterisation of flupentixol and rapid determination of the drug in human serum and pharmaceuticals by voltammetry. Analytical Letters, 38, 641-656.

Elfleing, L., \& Raezke, K. (2008). Improved detection of honey adulteration by measuring differences btween $13 \mathrm{C} / 12 \mathrm{C}$ stable carbon isotope ratios of protein and sugar compounds with a combination of elemental analyser-isotope ratio mass spectrometry and liquid chromatography- isotope ratio mass spectrometry (g13C-EA/LC-IRMS). Apidologie, 39, 574.

Escobar, J. D., Alcaniz, M., Masot, R., Fuentes, A., Bataller, R., Soto, J., \& Barat, J. M. (2013). Quantification of organic acids using voltammetric tongues. Food Chemistry, 138, 814-820.

Escriche, I., Kadar, M., Domenech, E., \& Gil-Sánchez, L. (2012). A potentiometric electronic tongue for the discrimination of honey according to the botanical origin. Comparison with traditional methodologies: Physicochemical parameters and volatile profile. Journal of Food Engineering, 109, 449-456.

European Commission (2002). Council Directive 2001/110/EC (20 December 2001) relating to honey. Official Journal of the European Union, L010, 47-52.

Garcia-Breijo, E., Garrigues, J., Sanchez, L. G., \& Laguarda-Miro, N. (2013). An embedded simplified Fuzzy ARTMAP implemented on a microcontroller for food classification. Sensors, 13, 10418-10429.

Ghasemi-Varnamkhasti, M., Mohtasebi, S.S., \& Siadat, M. (2010). Biomimeticbased odour and taste sensing systems to food quality and safety characterization: an overviewon basic principles and recent achievements. Journal of Food Engineering, 100, 377-387.

Gutés, A., Céspedes, F., \& Del Valle, M. (2007). Electronic tongues in flow analysis. Analytical Chimica Acta, 600, 90-96.

Gutiérrez, M., Llobera, A., Vila-Planas, J., Capdevila, F., Demming, S., \& Büttgenbach, S. (2010). Hybrid electronic tongue based on optical and electrochemical microsensors for quality control of wine. The Analyst, 135, 1718-1725.

Gutiérrez-Capitan, M., Santiago, J. L., Vila-Planas, J., Llobera, A., Boso, S., \& Gago, P. (2013). Classification and characterization of different white grape juices by using a hybrid electronic tongue. Journal of Agricultural and Food Chemistry, 61, 93259332.

Han, J., Huang, L., Gu, Z., Tian, S., \& Deng, S. (2008). Evaluation of meat quality and freshness based on the electronic tongue. Journal of Chinese Institute of Food Science \& Technology, 8 , 125-132. 
He, W., Hua, X., Zhao, L., Liao, X., Zhang, Y., \& Zhang, M. (2009). Evaluation of Chinese tea by the electronic tongue: Correlation with sensory properties and classification according to geographical origin and grade level. Food Research International, 42, 1462-1467.

Holmin, S., Krantz-Rülcker, C., \& Winquist, F. (2004). Multivariate optimisation of electrochemically pre-treated electrodes used in a voltammetric electronic tongue. Analytica Chimica Acta, 519, 39-46.

Huang, X. Y., Zhang, H. Y., \& Zhao, J. W. (2007). Research and application of electronic tongue technology in food industry. Food Science \& Technology, 7, 20-24.

Juan-Borrás, M., Doménech, E., Conchado, A., \& Escriche, I. (2015). Physicochemical quality parameters at the reception of the honey packaging process: influence of type of honey, year of harvest, and beekeeper. Journal of Chemistry, 1-6. doi:10.1155/2015/929658.

Juan-Borrás, M., Soto, J., Gil-Sánchez, L., Pascual-Maté, A., \& Escriche, I. (2017). Antioxidant activity and physico-chemical parameters for the differentiation of honey using a potentiometric electronic tongue. Journal of the Science of Food and Agriculture, 97, Issue 7, Version of Record online: 5 Oct 2016.

Labrador, R. H., Masot, R., Alcañiz, M., Baigts, D., Soto, J., \& Martínez-Mañez, R. (2010). Prediction of $\mathrm{NaCl}$, nitrate and nitrite contents in minced meat by using a voltammetric electronic tongue and an impedimetric sensor. Food Chemistry, $122,864-870$.

Li, S., Zhang, X., Shan, Y., Su, D., Ma, Q., Wen, R., \& Li, J. (2017). Qualitative and quantitative detection of honey adulterated with high-fructose corn syrup and maltose syrup by using near-infrared spectroscopy. Food Chemistry, 218, 231236.

Lvova, L., Martinelli, E., Mazzoneb, E., Pede, A., Paolesse, R., Di Natale, C., \& D’Amico, A. (2006). Electronic tongue based on an array of metallic potentiometric sensors. Talanta, 70, 833-839.

Major, N., Markovic, K., Krpan, M., Saric, G., Hruskar, M., \& Vahcic, N. (2011). Rapid honey characterization and botanical classification by an electronic tongue. Talanta, 85, 569-574.

Martínez-Máñez, R., Soto, J., Garcia-Breijo, E., Gil, L., Ibáñez, J., \& Llobet, E. (2005). An "electronic tongue" design for the qualitative analysis of natural waters. Sensors and Actuators B, 104, 302-307.

Men, H., Gao, H., Li, J., Liu, J., \& Zhang, Y. (2014). Fuzzy ARTMAP for the adulterated honey discrimination with voltammetric electronic tongue. Sensors \& Transducers, 178, 40-46. 
Moreno-Codinachs, L., Kloock, J. P., Schöning, M. J., Baldi, A., Ipatov, A., \& Bratov, A. (2008). Electronic integrated multisensor tongue applied to grape juice and wine analysis. The Analyst, 133, 1440-1448.

Naila, A., Flint, S. H., Sulaiman, A. Z., Ajit, A., \& Weeds, Z. (2018). Classical and novel approaches to the analysis of honey and detection of adulterants. Food Control, In Press, Available online 19 February 2018, https://doi.org/10.1016/j.foodcont.2018.02.027.

Ohmenhaeuser, M., Monakhova, Y. B., Kuballa, T., \& Lachenmeier, D. W. (2013). Qualitative and Quantitative Control of Honeys Using NMR Spectroscopy and Chemometrics. Analytical Chemistry, 9 Pages.

Oliveri, P., Baldo, M. A., Daniele, S., \& Forina, M. (2009). Development of a voltammetric electronic tongue for discrimination of edible oils. Analytical and Bioanalytical Chemistry, 395, 1135-1143.

Olsson, J., Winquist, F., \& Lundström, I. (2006). A self-polishing electronic tongue. Sensors and Actuators $B, 118,461-465$.

Oroian, M., \& Ropciuc, S. (2017). Botanical authentication of honeys based on Raman spectra. Journal of Food Measurement and Characterization. https://doi.org/10.1007/s11694-017-9666-3.

Padovan, G. J., De Jong, D., Rodrigues, L. P., \& Marchini, J. S. (2003). Detection of adulteration of commercial honey samples by the $13 \mathrm{C} / 12 \mathrm{C}$ isotopic ratio. Food Chemistry, 82 , 633-636.

Parra, V., Hernando, T., Rodríguez-Mendez, M. L., \& De Saja, J. A. (2004). Electrochemical sensor array made from bisphthalocyanine modified carbon paste electrodes for discrimination of red wines. Electrochimca Acta, 49, 51775185.

Persano-Oddo, L., \& Piro, R. (2004). Main European unifloral honeys: Descriptive sheets. Apidologie, 35, 38-81.

Rios-Corripio, M. A., Rojas-López, M., \& Delgado-Macuil, R. (2012). Analysis of adulteration in honey with standard sugar solutions and syrups using attenuated total reflectance-Fourier transform infrared spectroscopy and multivariate. CYTAJournal of Food, 10, 119-122.

Rodríguez-Méndez, M. L., Parra, V., Apetreri, C., Gay, M., Prieto, N., \& Martínez, J. (2008). Electronic tongue base don voltammetric electrodes modified with materials showing complementary electroactive properties. Applications Electrochimica Acta, 163, 23-31.

Rodríguez-Méndez, M. L., Gay, M., Apetreri, C., \& De Saja, J. A. (2009). Biogenic amines and fish freshness assessment using a multisensor system based on voltammetric 
Monitoring honey adulteration with sugar syrups using an automatic pulse voltammetric electronic tongue

electrodes. Comparison between CPE and screen-printed electrodes. Electrochimica Acta, 54, 7033-7041.

Ropciuc, S., Oroian, M., Paduret, S., \& Buculei, A. (2017). Honeydew honey adulteration: e-tongue and physicochemical analyses. Food and Environment Safety-Journal of Faculty of Food Engineering, 16, 98-103.

Ruíz-Matute, A. I., Weiss, M., Sammataro, D., Finley, J., \& Sanz, M. L. (2010). Carbohydrate composition of high fructose corn syrups (HFCS) used for bee feeding effect on honey composition. Journal of Agricultural and Food Chemistry, $58,7317-7322$.

Sáenz, C., \& Gómez, C. (2000). Mieles españolas. Características e Identificación Mediante el Análisis Del Polen. Ediciones Mundi-Prensa, Madrid.

Schreyer, S. K., \& Mikkelsen, S. R. (2000).Chemometric analysis of square wave voltammograms for classification and quantitation of untreated beverage samples. Sensors and Actuators B, 71, 147-153.

Serra, J., Soliva, M., \& Muntane, J. (2000). Invertase activity in fresh and processed honeys. Journal of the Science of Food and Agriculture, 80, 507-512.

Simsek, A., Bilsel, M., \& Goren, A. C. (2012). 12C/13C pattern of honey from Turkey and determination of adulterationin commercially available honey samples using EAIRMS. Food Chemistry, 130, 1115-1121.

Sobrino-Gregorio, L., Vargas, M., Chiralt, A., \& Escriche, I. (2017). Thermal properties of honey as affected by the addition of sugar syrup. Journal of Food Engineering, 213, 69-75.

Sousa, M. E. B. C., Dias, L. G., Veloso, A. C. A., Estevinho, L., Peres, \& Machado, A. M. (2014). Practical procedure for discriminating monofloral honey with abroad pollen profile variability using an electronic tongue. Talanta, 128, 284-292.

Tiwari, K., Tudu, B., Bandyopadhyay, R., \& Chatterjee, A. (2013). Identification of monofloral honey using voltammetric electronic tongue. Journal of Food Engineering 117, 205-210.

Tosun, M. (2013). Detection of adulteration in honey samples added various sugar syrups with $13 \mathrm{C} / 12 \mathrm{C}$ isotope ratio analysis method. Food Chemistry, 138, 16291632

Veloso, A. C. A., Dias, L. G., Rodrigues, N., Pereira, J. A., \& Peres, A. M. (2016). Sensory intensity assessment of olive oils using an electronic tongue. Talanta, 146, 585593.

Von Der Ohe, W., Persano-Oddo, L., Piana, M. L., Morlot, M., \& Martin, P. (2004). Harmonized methods of melissopalynology. Apidologie, 35, 18-25. 
Wang, S., Guo, Q., Wang, L., Lin, L., Shi, H., Cao, H., \& Cao, B. (2015). Detection of honey adulteration with starch syrup by high performance liquid chromatography. Food Chemistry, 172, 669-674.

Wei, Z., Wang, J., \& Liao, W. (2009). Technique potential for classification of honey by electronic tongue. Journal of Food Engineering, 94, 260-266.

Wei, Z., \& Wang, J. (2011). Classification of monofloral honeys by voltammetric electronic tongue with chemometrics method. Electrochimica Acta, 56, 49074915.

Winquist, F., Bjorklund, R., Krantz-Rülcker, C., Lundströma, I., Östergren, K., \& Skoglund, T. (2005). An electronic tongue in the dairy industry. Sensors and Actuators B, 111-112, 299-304.

Winquisk, F. (2008). Voltammetric electronic tongues-basic principles and applications. Microchim Acta, 163, 3-10.

Xue, X., Wang, Q., Li, Y., Wu, L., Chen, L., Zhao, J., \& Liu, F. (2013). 2-Acetylfuran-3Glucopyranoside as a novel marker for the detection of honey adulterated with rice syrup. Journal Agriculture and Food Chemistry, 6, 7488-7493. 

4. CONCLUSIONES 



\section{Conclusiones}

\subsection{Conclusiones del objetivo específico 1}

Aportación: Food Chemistry, 226, 61-68 (2017).

4.1.1. La caracterización de los compuestos integrantes de la fracción volátil de las mieles, mediante cromatografía de gases-espectrometría de masas (GC-MS), se puede considerar un método complementario al análisis polínico para garantizar el correcto etiquetado de las mieles monoflorales que se comercializan. Esta metodología constituye una herramienta idónea para resolver la necesidad de etiquetar correctamente las mieles monoflorales; por las implicaciones económicas que conlleva para el sector y las legales para la administración y el consumidor.

4.1.2. La información de la fracción volátil se correlaciona bien con la percepción sensorial de las mieles, por ello, esta metodología resulta especialmente útil en aquellas variedades cuyo polen está infra-representado, como es el caso de la miel de lavanda; y se aconseja especialmente cuando una miel presenta específicas características organolépticas diferenciadoras.

4.1.3. Considerando, como ejemplo, el caso de mieles comerciales etiquetadas como lavanda (tipo de monofloral cuyo polen está infra-representado) y de mieles etiquetadas como tomillo (tipo de monofloral cuyo polen no está infra-representado) se ha puesto en evidencia esta problemática. La información de la etiqueta sobre la monofloralidad de las mieles de lavanda se correspondía bastante bien con la percepción organoléptica $(81.8 \%)$, pero sobre todo con la proporcionada con la fracción volátil (90.9\%). Sin embargo, ninguna de ellas cumplía el requisito comercial habitual sobre contenido polínico (mínimo $10 \%$ de polen Lavandula spp.). Por el contrario, en la miel de tomillo la información de la etiqueta era correcta para todas las muestras considerando el contenido de polen (100\%) y para la práctica totalidad considerando sus características olfato-gustativas y perfil volátil típicas de la miel de tomillo.

\subsection{Conclusiones del objetivo específico 2}

Aportación: Journal of Science of Food and Agriculture, 100, 212-217 (2020).

4.2.1. Una lengua electrónica voltamétrica de pulsos (compuesta de electrodos metálicos de Ir, Rh, Pt, Au), con limpieza y pulido electroquímico, en combinación con un análisis estadístico de componentes principales (PCA), ha permitido discriminar mieles de diferentes países (Mozambique, Honduras y España). 
4.2.2. Con la finalidad de verificar si los datos proporcionados por la lengua electrónica podían ser útiles para predecir los niveles de determinados parámetros fisicoquímicos de las mieles, se aplicó una regresión de mínimos cuadrados parciales (PLS) demostrando que la conductividad $\left(r^{2}=0.948\right)$ y la humedad $\left(r^{2}=0.879\right)$ fueron los parámetros mejor correlacionados, mientras que los azúcares obtuvieron la menor correlación.

4.2.3. La lengua electrónica voltamétrica propuesta en este estudio se plantea como una herramienta prometedora, ya que de forma rápida y sencilla puede ayudar a la identificación del país de origen de las mieles sin la necesidad de requerir personal experto. Sin embargo, para que sea efectiva, es necesario seguir trabajando en la creación de una amplia base de datos que contemple la información de mieles de diferentes procedencias.

\subsection{Conclusiones del objetivo específico 3}

Aportación: Journal of Food Engineering, 213, 69-75 (2017).

4.3.1. Las propiedades térmicas evaluadas ( $\mathrm{Tg}$ onset, $\mathrm{Tg}$ midpoint) mediante calorimetría diferencial de barrido (DSC) en combinación con un análisis estadístico de componentes principales (PCA) ha permitido diferenciar niveles de adulteración en la miel $(5,10$ y $20 \%)$ por adición de jarabes (agave, arce, caña, cebada y diferentes tipos de arroz).

4.3.2. La adición de jarabes a la miel pura promovió cambios significativos en las propiedades térmicas de las mieles adulteradas, en proporción al nivel de adulteración y al tipo de jarabe, especialmente debido a las diferencias en su composición de azúcares.

4.3.3. Los resultados expuestos en este estudio ofrecen evidencias convincentes de que el DSC puede ser útil para identificar adulteración en la miel por adición de jarabes, aunque para ser concluyentes se debe considerar un mayor número de tipos de mieles y jarabes.

\subsection{Conclusiones del objetivo específico 4}

Aportación: Food Control, 95, 57-62 (2019).

4.4.1. La técnica de PCR (PCR convencional y PCR en tiempo real) ha permitido por primera vez identificar la adulteración por adición de melaza de arroz en miel de azahar, logrando identificar porcentajes de adulteración menores a los de otras metodologías más costosas y laboriosas. 
4.4.2. El mayor obstáculo en la aplicación de esta técnica se encontró en la etapa previa de extracción de ADN, por la dificultad en la obtención de cantidad y calidad suficiente para su posterior amplificación por PCR. Para la extracción del ADN se utilizó el kit comercial "NucleoSpin Food", por ser más efectivo que otros protocolos ensayados.

4.4.3. La técnica de PCR convencional demostró que el gen específico de arroz PLD1 fue el más efectivo, en comparación con el SPS2 y PLD2, permitiendo la visualización en gel de agarosa del adulterante hasta un $5-20 \%$.

4.4.4. La técnica de PCR en tiempo real permitió discriminar entre diferentes porcentajes de adulteración, consiguiendo dar el resultado con mayor exactitud (Ilegando hasta 2-5\%) a partir de una curva estándar realizada mediante diluciones seriadas de varias concentraciones de ADN de arroz.

4.4.5. Los resultados obtenidos mediante PCR para identificar adulteración en miel están siendo prometedores; sin embargo, es necesario seguir investigando para determinar si estos hallazgos podrían aplicarse a la detección de otros tipos de melazas y jarabes en la miel, ya que la etapa de la extracción de ADN podría ser un factor limitante.

\subsection{Conclusiones del objetivo específico 5}

Aportación: Food Control, 91, 254-260 (2018).

4.5.1. Una lengua electrónica voltamétrica de pulsos (compuesta de electrodos metálicos de Ir, Rh, Pt, $\mathrm{Au}$ ), con limpieza y pulido electroquímico, en combinación con un análisis estadístico de componentes principales (PCA), ha permitido diferenciar mieles monoflorales (girasol, azahar y brezo) y jarabes (cebada, maíz, arroz integral) e identificar hasta un $2.5 \%$ de adición de jarabe a la miel.

4.5.2. Una regresión de mínimos cuadrados parciales (PLS) verificó que los datos proporcionados por la lengua electrónica predecían mejor las adulteraciones de la miel de girasol y de brezo con jarabe de maíz $\left(r^{2}=0.997\right.$ y $\left.r^{2}=0.994\right)$ y la miel de brezo con jarabe de cebada $\left(r^{2}=0.997\right)$. Por el contrario, las peores predicciones fueron para la miel de brezo adulterada con jarabe de arroz integral $\left(r^{2}=0.763\right)$ y la miel de azahar con jarabe de maíz $\left(r^{2}=0.879\right)$.

4.5.3. La lengua electrónica voltamétrica propuesta en este estudio es una herramienta prometedora para que el sector de la apicultura resuelva la necesidad de detectar adulteraciones en miel de forma rápida y asequible. Sin embargo, se recomiendan futuros estudios con la finalidad de crear una base de datos amplia y 
completa que contemple la mayor información posible de mieles y jarabes de diferente procedencia. 


\section{Conclusión General de la Tesis}

La presente tesis doctoral ha puesto de manifiesto la idoneidad de técnicas analíticas, diferentes a las convencionales, para verificar la autenticidad de miel, uno de los alimentos con más riesgo de ser adulterados. Se trata de metodologías consolidadas en otros ámbitos científicos, pero que se plantean como emergentes en este contexto. El perfil de compuestos volátiles analizados mediante GC-MS es una de las herramientas más prometedoras, ya que informa de la presencia y abundancia de determinados compuestos que inequívocamente se pueden relacionar con el origen botánico de las plantas en las que pecorean las abejas y por lo tanto asociarlos a un determinado tipo de miel monofloral. Su principal inconveniente es que se trata de una técnica cara y requiere de personal altamente cualificado. Una lengua electrónica voltamétrica (construida con sensores metálicos en combinación con un apropiado análisis estadístico), de forma rápida y sencilla, es capaz de dar resultados fiables en la discriminación de mieles según su monofloralidad, procedencia geográfica e incluso su nivel de adulteración. Las técnicas de DSC y PCR están siendo efectivas para identificar la adulteración de la miel por adición de jarabes. Sin embargo, para que la PCR se pueda aplicar a otras melazas y jarabes distintos a los considerados en el presente estudio, es necesario resolver el principal obstáculo que implica la etapa de extracción de ADN. 